UNIVERSIDADE DE SÃO PAULO

ESCOLA DE ENFERMAGEM

PATRICIA LIMA FERREIRA SANTA ROSA

DESENVOLVIMENTO E VALIDAÇÃO DO INSTRUMENTO PERCEPÇÃO SOBRE DISCRIMINAÇÃO RACIAL INTERPESSOAL NOS SERVIÇOS DE SAÚDE (DRISS)

SÃO PAULO

2018 



\section{DESENVOLVIMENTO E VALIDAÇÃO DO INSTRUMENTO PERCEPÇÃO SOBRE DISCRIMINAÇÃO RACIAL INTERPESSOAL NOS SERVIÇOS DE SAÚDE (DRISS)}

Versão corrigida da tese apresentada ao Programa de Pós-Graduação em Enfermagem da Escola de Enfermagem da Universidade de São Paulo para obtenção do título de Doutora em Ciências

Área de concentração: Cuidados em Saúde

Orientadora: Prof. $\stackrel{\text { a }}{\text { Dr. }}+$ Ana Luiza Vilela Borges

Co-orientadora: Prof. ${ }^{\text {a }}$ Dr. ${ }^{a}$ Edna Maria de Araújo

\section{VERSÃO CORRIGIDA}

A versão original encontra-se disponível na Biblioteca da Escola de Enfermagem da Universidade de São Paulo e na Biblioteca Digital de Teses e Dissertações da Universidade de São Paulo.

\section{SÃO PAULO}


AUTORIZO A REPRODUÇÃO E DIVULGAÇÃO TOTAL OU PARCIAL DESTE TRABALHO, POR QUALQUER MEIO CONVENCIONAL OU ELETRÔNICO, PARA FINS DE ESTUDO E PESQUISA, DESDE QUE CITADA A FONTE.

Assinatura:

Data:

\section{Catalogação na Publicação (CIP) \\ Biblioteca "Wanda de Aguiar Horta" \\ Escola de Enfermagem da Universidade de São Paulo}

Santa Rosa, Patricia Lima Ferreira

Desenvolvimento e validação do instrumento Percepção sobre Discriminação Racial Interpessoal nos Serviços de Saúde (DRISS) / Patricia Lima Ferreira Santa Rosa. São Paulo, 2018.

$217 \mathrm{p}$.

Tese (Doutorado) - Escola de Enfermagem da Universidade de São Paulo.

Orientadora: Prof. ${ }^{a}$ Dr. ${ }^{a}$ Ana Luiza Vilela Borges

Co-orientadora: Prof. ${ }^{a}$ Dr. ${ }^{-}$Edna Maria de Araújo

Área de concentração: Cuidados em Saúde

1. Negros. 2. Psicometria. 3. Discriminação racial. 4. Enfermagem. I. Título.

Ficha catalográfica elaborada por Fabiana Gulin Longhi Palacio (CRB-8: 7257) 
Nome: Patricia Lima Ferreira Santa Rosa

Título: Desenvolvimento e validação do instrumento Percepção sobre Discriminação Racial Interpessoal nos Serviços de Saúde (DRISS)

Tese apresentada ao Programa de Pós-Graduação em Enfermagem da Escola de Enfermagem da Universidade de São Paulo (PPGE-EEUSP) - para obtenção do título de Doutora em Ciências

Aprovado em:

\section{Banca Examinadora}

Orientador: Prof. Dr.

Instituição:

Assinatura:

Prof. Dr. Instituição:

Julgamento: Assinatura:

Prof. Dr. Instituição:

Julgamento: Assinatura:

Prof. Dr. Instituição: Julgamento: Assinatura:

Prof. Dr. Instituição:

Julgamento: Assinatura:

Prof. Dr. Instituição: Julgamento: Assinatura: 



\section{DEDICATÓRIA}

Aos meus pais, meus genitores e meus grandes amores. 



\section{AGRADECIMENTOS}

À Deus que, com a sua luz, me conduziu nessa caminhada.

Ao meu pai, Regis Dias Santa Rosa, que me aconselhou a não desistir, quando as forças para continuar estavam quase no fim.

À minha mãe, Judir Lima Ferreira, minha preciosa, amiga para toda a vida. Ao meu irmão, Renato Ferreira Dias Santa Rosa, pelo apoio na divulgação da minha pesquisa.

Aos meus outros irmãos e sobrinhos queridos, a minha vida é melhor só por vocês existirem. Às minhas amigas do coração: Luanda Cardoso, Emiliane Santiago, Jucelir Lima Ferreira e Mônica Santana.

Às minhas orientadoras, Dras. Ana Luiza Vilela Borges e Edna Maria de Araújo, a qualidade alcançada neste trabalho é fruto da atenção e cuidado delas em cada detalhe.

Aos demais professores das disciplinas realizadas e aos membros da banca de qualificação de doutorado. Seus ensinamentos, críticas e sugestões foram fundamentais.

Aos membros do comitê de especialistas, que muito auxiliaram na construção deste trabalho. À EEVSP, docentes, funcionários e colegas de curso por todo o apoio, especialmente, aos/às que se tornaram amigos/as! 

Osmara Alves dos Santos por toda paciência e amizade.

À Ionara Magalhães de Souza pelo auxílio com a revisão de literatura. À Renata Ferreira Sena Gonçalves pela ajuda com a pesquisa. Ao Bernardo dos Santos, estatístico que me auxiliou nas análises. Ao Núcleo de Estudos e Pesquisa em Saúde Coletiva (NNEPESC). Ao $\mathcal{N} u ́ c l e o$ Interdisciplinar de Estudos sobre Desigualdades em Saúde da Universidade Estadual de Feira de Santana (NVDES-UEFS) por todo o apoio, em especial, às amizades que nasceram dessa interação.

À Organização Não-GovernamentalEducação para Afrodescendentes e Carentes (EDUCAFRO) pelo apoio na divulgação, especialmente, ao Frei Davi.

À todos os grupos do Facebook. Whatsapp que apoiaram a divulgação da pesquisa. Às pessoas que participaram da pesquisa, dando sua contribuição voluntária ao acessar o formulário e respondê-lo, via Internet.

Às minhas colegas e aos meus colegas de trabalho do Instituto Tecnológico de Barueri, do curso técnico de enfermagem, por todo o apoio e compreensão.

Aos ex-colegas de trabalho do Pronto Atendimento de Caucaia do Alto, Cotia, pelo carinho. Ao Marcello Pimentel pela formatação e ao Jorge de Lima pela correção gramatical. Ao Conselho $\mathcal{N}$ acional de Desenvolvimento Científico e Tecnológico pelo apoio financeiro. 

$O$ amor é o fundamento

Quanto mais vivo, mais entendo o significado do Amor E não adianta os poetas falarem: Camões, Vinícius, Renato...

É necessário experienciar O amor promove sentido, transcendência, continuidade Para a vida Amar e amada ser Não há poder maior do que a energia que emana do amor Ele é suave e ao mesmo tempo forte Delicado, mas tem alcance profundo Ele pode vir de várias direções Mãe, pai, outro ente querido, Amigos, animais de estimação e E também dos pássaros que cantam gratuitamente na nossa janela Você simplesmente sente A energia do amor fluindo E não há outro caminho, a não ser Devolver Amor 

Santa Rosa PLF. Desenvolvimento e validação do instrumento Percepção sobre Discriminação Racial Interpessoal nos Serviços de Saúde (DRISS) [tese]. São Paulo: Escola de Enfermagem, Universidade de São Paulo; 2018.

\section{RESUMO}

OBJETIVO: Desenvolver e validar um instrumento de medida das percepções sobre discriminação racial interpessoal no contexto dos serviços de saúde brasileiros. METODOLOGIA: Estudo do tipo metodológico conduzido com base na Teoria Clássica dos Testes para elaboração e validação psicométrica de instrumento. Para o desenvolvimento do pool de itens inicial, três fontes foram utilizadas: revisão de literatura sobre escalas já existentes; estudo qualitativo; e, sugestões de especialistas sobre racismo/desigualdades em saúde. $O$ instrumento inicialmente proposto (versão 1) constava de 50 itens. Buscou-se verificar as evidências de validade de conteúdo e constructo e, para isso, a coleta de dados foi dividida em duas etapas. A primeira etapa consistiu na avaliação do instrumento proposto junto ao comitê de especialistas e a segunda etapa consistiu no preenchimento do instrumento pela população-alvo. A análise dos dados foi realizada no R e Stata 14.2. RESULTADOS: Na validação de face e conteúdo, a versão 1 foi submetida à avaliação por comitê de especialistas composto por um metodologista, um profissional de língua portuguesa, três especialistas em relações étnico-raciais e três membros da população-alvo. Dos 50 itens elaborados originalmente, foram excluídos 28 e restaram 22 (versão 2). O CVR (razão de validade de conteúdo) médio dos itens que restaram foi 0,74 . Com relação à concordância entre os especialistas, o PABAK foi 0,30, considerado razoável. Entretanto, dos 22 itens que compuseram a versão 2, dois foram desmembrados, o que gerou a versão 3, com 24 itens. A versão 3 foi construída na plataforma digital Research Eletronic Data Capture (REDCap) e foi divulgada entre setembro e dezembro de 2017 por meio de um link (via redes sociais como Facebook e Whatsapp) que direcionou os respondentes para o instrumento. Ao todo, 480 pessoas acessaram o link, mas apenas 158 finalizaram o preenchimento do instrumento. A maior parte dos respondentes foi do sexo feminino $(87,0 \%)$, autoclassificada como de raça/cor preta ou parda $(97,5 \%)$ e pertencente ao grupo econômico A e B (61,4\%). Prosseguiu-se com a avaliação da validade de constructo por meio da análise fatorial exploratória. KMO (Kaiser-Meyer-Okin) foi 0,736; o teste de esfericidade de Bartlett foi $p<0,001$; todas as cargas fatorias estiveram entre 0,3 e 0,9; e as comunalidades abaixo de 0,4 . A avaliação do índice de confiabilidade Ômega de Mcdonald total foi 0,87, valor considerado bom. Dessa forma, produziu-se a versão 4, denominada DRISS, com 19 itens no total e seis dimensões, que são: sintomas somáticos, preparo, expressão emocional, percepção social, reação, consequências emocionais. Não foi observada diferença estatisticamente significativa nas médias dos escores em relação à idade, escolaridade, grupo econômico e outras variáveis sociodemográficas. CONCLUSÕES: Este estudo produziu uma escala que mede a 'percepção sobre discriminação racial interpessoal no contexto dos serviços de saúde', denominada DRISS, que apresenta adequadas propriedades psicométricas. O DRISS é direcionado especificamente às/aos usuárias/os dos serviços de saúde. Em nível populacional, produzirá dados relevantes para a tomada de decisões programáticas com foco na redução da discriminação racial nos serviços de saúde e consequente diminuição das iniquidades raciais em saúde.

PALAVRAS-CHAVE: Negros. Psicometria. Determinantes Sociais de Saúde.

Discriminação Racial. Enfermagem. Racismo. Raça. Cor da pele. 

Santa Rosa PLF. Development and validity of the instrument Perception on Interpersonal Racial Discrimination in Healthcare Facilities (DRISS) [thesis]. São Paulo: School of Nursing, University of São Paulo; 2018.

\section{ABSTRACT}

OBJECTIVE: To develop and validate an instrument to measure perceptions about interpersonal racial discrimination in Brazilian healthcare facilities context. METHODOLOGY: This is a methodological study based on Classical Theory of Tests. For the development of the initial items pool, three sources were used: literature review on existing scales; qualitative study; and, expert on racism health inequalities suggestions. Initially, the version 1 was composed by 50 items. In order to test content and construct validity evidence, data collection was divided into two steps. The first step consisted of the analysis of version 1 instrument to an expert committee and the second step consisted of the submission of the instrument to the target population. Data analysis was performed with R and Stata 14.2. RESULTS: Face and content validation of version 1 was performed by expert committee composed by a psychometrist, a Portuguese language expert, three experts in ethnic-racial relations and three members of the target population. From the 50 originally drafted items, 28 were excluded and 22 remained (version 2). The average CVR (content validity ratio) of the items was 0.74 . Regarding the agreement among the experts, PABAK was 0.30 , considered reasonable. Two items from version 2 were dismembered, which generated version 3, with 24 items. Version 3 was included on the Research Eletronic Data Capture (REDCap) digital platform and was released between September and December 2017 in a link (via social networks like Facebook and Whatsapp). Altogether, 480 people accessed the link, but only 158 completed the instrument. Most respondents were female $(87.0 \%)$, self-classified as black or brown $(97.5 \%)$ and were at economic group A and B (61.4\%). We proceeded with the evaluation of construct validity through exploratory factorial analysis. KMO (Kaiser-Meyer-Okin) was 0.736 ; Bartlett Sphericity Test was $p<0.001$; all factor loads were between 0.3 and 0.9 ; and commonalities below 0.4 . The McDonald's Omega Total reliability rating was 0.87 , which is considered good. In this way, version 4, named DRISS, was produced with a total of 19 items and six dimensions, that are: somatic symptoms, preparation, emotional expression, social perception, reaction, and emotional consequences. No statistically significant difference was observed in the means of the DRISS scores in relation to age, schooling, economic group and other sociodemographic variables. CONCLUSIONS: This study produced a scale that measures the 'perception about interpersonal racial discrimination in the healthcare facilities context', called DRISS, with adequate psychometric properties. DRISS is specifically targeted to the health services users. At the population level, it may produce relevant data for programmatic decisionmaking focused on reducing racial discrimination in healthcare facilities, and as a consequence, racial inequities in health.

KEYWORDS: Blacks. Psychometry. Social Determinants of Health. Racial Discrimination. Nursing. Racism. Race. Skin color. 



\section{LISTA DE TABELAS}

Tabela 1 - Frequência e proporção de respostas, para cada item, segundo o início do preenchimento do DRISS e a finalização do preenchimento. São Paulo,

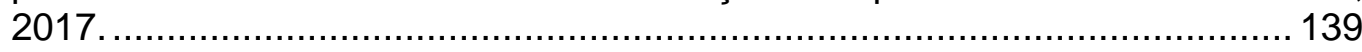

Tabela 2 - Dados sociodemográficos dos respondentes do DRISS, São Paulo, 2017 .... 142

Tabela 3 - Valores dos escores do DRISS, São Paulo, 2017. 154

Tabela 4 - Média e desvio-padrão dos escores da amostra do DRISS, segundo o sexo. São Paulo, 2017. 158

Tabela 5 - Médias e desvios-padrão dos escores do DRISS, versão 4, segundo as características sociodemográficas. São Paulo, 2017. 



\section{LISTA DE QUADROS}

Quadro 1 - Descrição de artigos de revisão de literatura que exploraram instrumentos de medida de racismo/discriminação racial de interesse para o campo da saúde.

Quadro 2 - Principais escalas utilizadas nos referidos estudos.

Quadro 3 - Pool de itens da versão 1 do DRISS, segundo a categoria de resposta e a fonte, São Paulo, 2017.

Quadro 4 - Síntese da participação de especialistas no comitê de especialistas do DRISS, segundo a área de atuação, e razão para participação/não participação. São Paulo, 2017.... 118

Quadro 5 - Versão 1 do instrumento DRISS com a síntese da avaliação dos especialistas segundo o item, CVR, avaliações qualitativas, item modificado segundo sugestões e decisão final. São Paulo, 2017

Quadro 6 - Versão 2 do DRISS, São Paulo, 2017. 130

Quadro 7 - Versão 3 do DRISS, São Paulo, 2017. 133

Quadro 8 - Matriz de correlação item-fator do DRISS, com rotação oblimim, São Paulo, 2017. 146

Quadro 9 - Matriz de correlação item-fator do DRISS, na primeira AFE, método de extração AP, com rotação oblimim e omissão das cargas fatoriais menores do que $0,3,2017 . \ldots .147$

Quadro 10 - Matriz de correlação item-fator do DRISS, na segunda AFE, método de extração AP, com rotação oblimim e omissão das cargas fatoriais menores do que 0,3 , sem os itens 14 e 23. São Paulo, 2017.

Quadro 11 - Matriz de correlação item-fator do DRISS, na segunda AFE, método de extração $\mathrm{AP}$, com rotação oblimim e omissão das cargas fatoriais menores do que 0,3 , sem os itens 14, 15, 16 e 23. São Paulo, 2017. 149

Quadro 12 - Síntese dos itens excluídos da escala DRISS a partir das quatro AFE conduzidas. São Paulo, 2017. 150

Quadro 13 - Matriz de correlação item-fator do DRISS, versão 4, na quarta AFE, método de extração AP, com rotação oblimim e omissão das cargas fatoriais menores do 0,3 , sem os itens $2,14,15,16$ e 23 , mais os itens que restaram por extenso. São Paulo, 2017. 152

Quadro 14 - Proporções de variância retida por cada fator e acumulada do DRISS, São Paulo, 2017. 153

Quadro 15 - Correlação entre os fatores da versão final da escala DRISS, São Paulo, 2017..... 153

Quadro 16 - Versão final do DRISS, contendo texto introdutório, questões e alternativas para respostas. São Paulo, 2017

Quadro 17 - Fatores rotulados, segundo os grupos de itens e os respectivos escores do DRISS, São Paulo, 2017. 



\section{LISTA DE FIGURAS}

Figura 1 - Pilares da fundamentação teórica do DRISS.

Figura 2 - Exemplo de item presente no formulário construído no REDCap para análise de face e conteúdo do DRISS por especialistas. São Paulo, 2017.

Figura 3 - Exemplo de item (texto introdutório) presente no formulário construído no REDCap para análise de face e conteúdo do DRISS por especialistas. São Paulo, 2017.

Figura 4 - A perspectiva contemporânea dos tipos de informação relevantes para a validade de um teste (modelo adaptado - tradução livre) (Furr, 2015). 104

Figura 5 - Fluxograma da análise fatorial exploratória do DRISS (adaptado do modelo de Furr (2015), São Paulo, 2017.

Figura 6 - Questões introdutórias do DRISS, versão 2. São Paulo, 2017 131

Figura 7 - Página inicial do DRISS no REDCap. São Paulo, 2017 135

Figura 8 - Chamada para responder a pesquisa no site da EDUCAFRO. São Paulo, 2017.

Figura 9 - Número de acessos e respostas ao DRISS. São Paulo, 2017. 138

Figura 10 - Gráfico contendo a matriz de correlação item-item, na versão 3 com 24 itens do DRISS, 2017.

Figura 11 - Gráfico da análise paralela da matriz de correlação do DRISS, São Paulo, 2017. 145

Figura 12 - Distribuição dos escores do DRISS. São Paulo, 2017. 158 



\section{SUMÁRIO}

1 INTRODUÇÃO

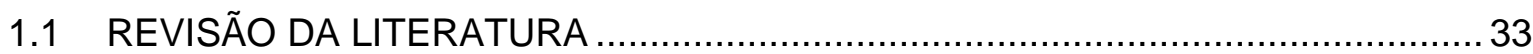

1.1.1 Breve histórico dos negros no Brasil ...................................................... 34

1.1.2 Política Nacional de Saúde Integral da População Negra ............................. 38

1.2 CONCEITOS DE RAÇA/COR DA PELE, ETNIA, DISCRIMINAÇÃO RACIAL, RACISMO E RACISMO INSTITUCIONAL...................................................... 40

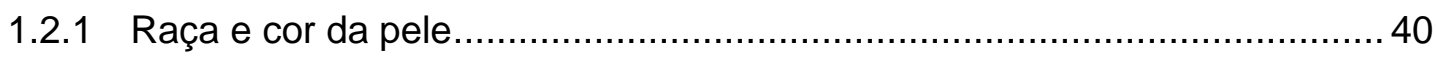

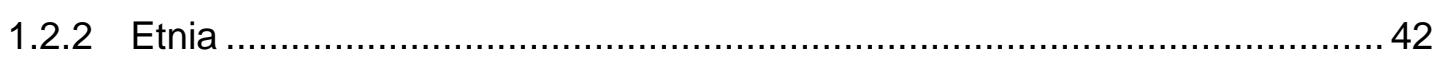

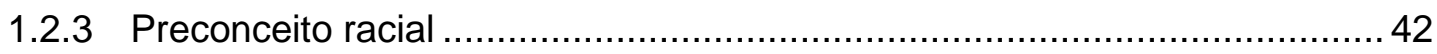

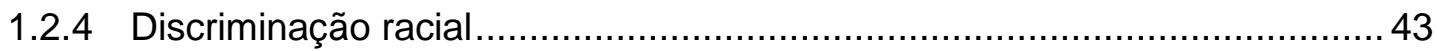

1.2 .5 Racismo

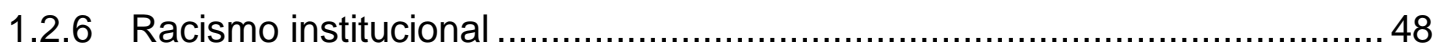

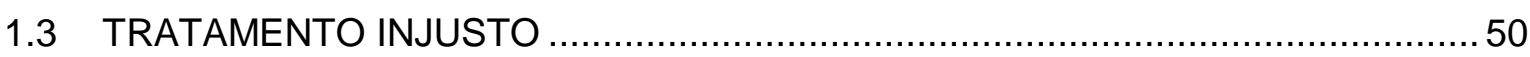

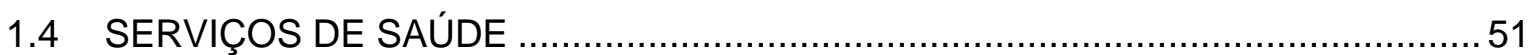

1.5 RACISMO NA DETERMINAÇÃO SOCIAL DO PROCESSO SAÚDE-DOENÇA ....52

1.6 REVISÃO DA LITERATURA SOBRE INSTRUMENTOS DE MENSURAÇÃO DE

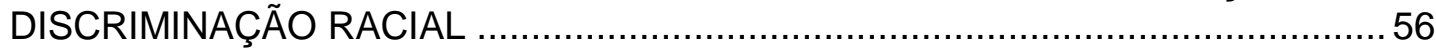

2 JUSTIFICATIVAS PARA O DESENVOLVIMENTO DO ESTUDO ……........................... 79

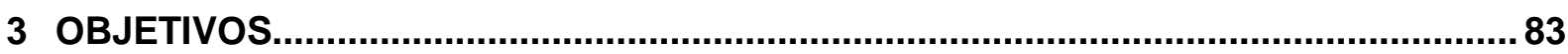

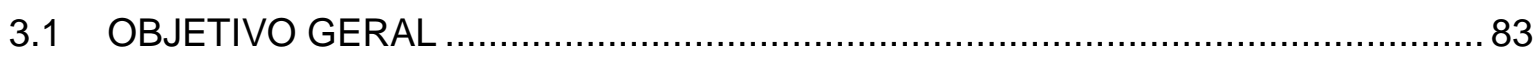

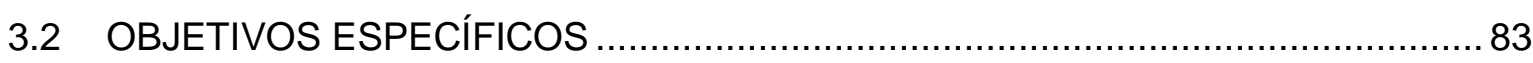

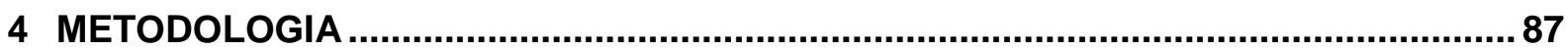

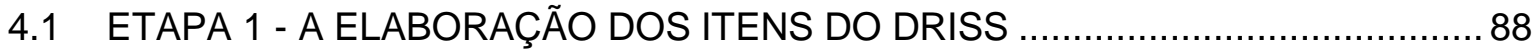

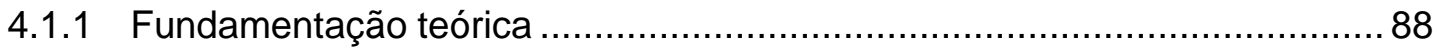

4.1.2 Versão 1 do DRISS - A elaboração do pool de itens .................................. 90

4.2 ETAPA 2 - PROCEDIMENTOS ADOTADOS PARA AS VALIDAÇÕES DE

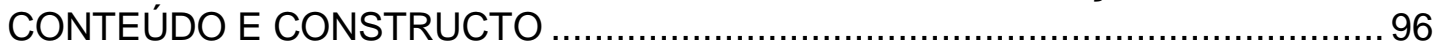

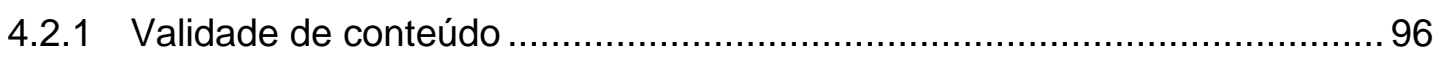

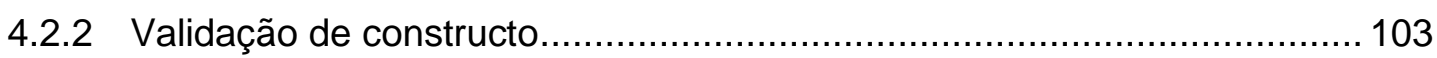

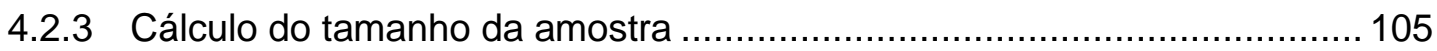

4.2.4 Preenchimento do instrumento pela população-alvo …………………....... 105

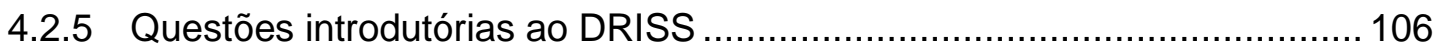

4.2.6 Instrumento para coleta de dados sociodemográficos ….......................... 107

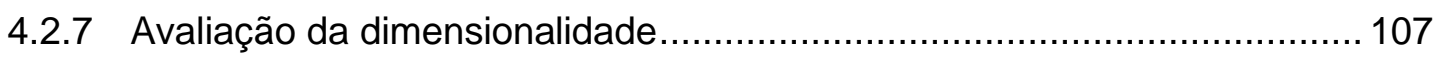

4.3 ETAPA 3 - PROCEDIMENTOS ADOTADOS PARA A VERIFICAÇÃO DA CONFIABILIDADE 

4.4 ETAPA 4 - ESCORIFICAÇÃO (CÁLCULO DE ESCORE FATORIAL) ...................113

4.5 ETAPA 5 - ANÁLISE DA DISTRIBUIÇÃO DO ESCORE SEGUNDO OS ASPECTOS SOCIODEMOGRÁFICOS DA AMOSTRA ................................................... 114

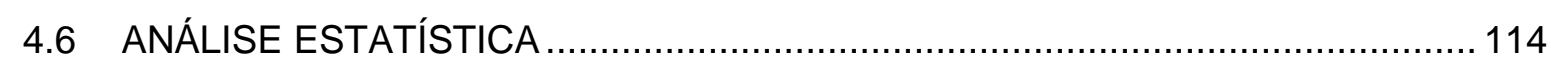

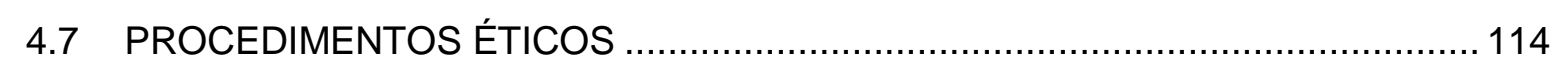

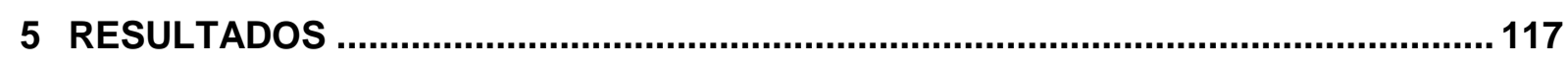

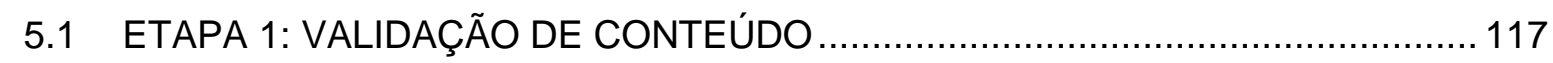

5.1.1 Composição do comitê de especialistas ............................................ 117

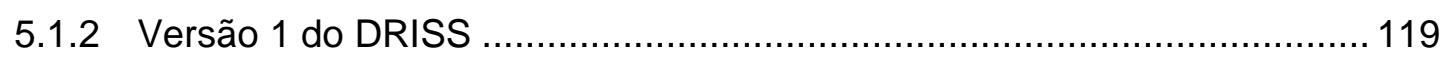

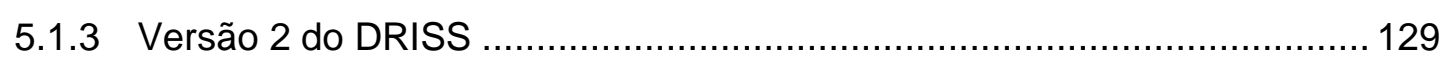

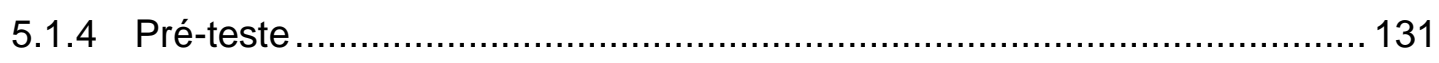

5.1.5 Versão 3 do DRISS ..................................................................... 132

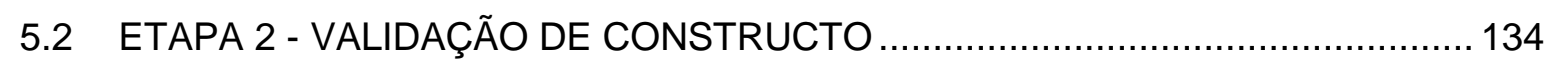

5.2.1 Divulgação do DRISS ................................................................ 134

5.2.2 Análise fatorial exploratória (AFE) ................................................ 143

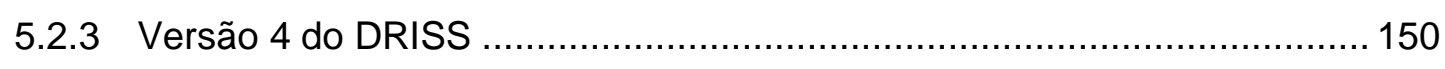

5.3 ETAPA 3 - VERIFICAÇÃO DA CONFIABILIDADE ...................................... 154

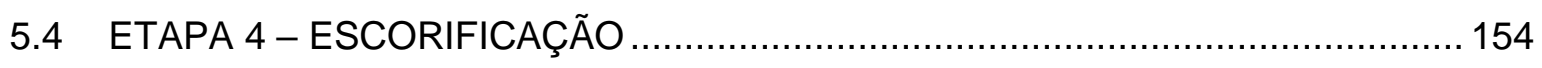

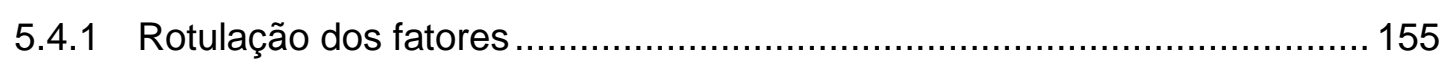

5.5 ETAPA 5 - ANÁLISE DA DISTRIBUIÇÃO DO ESCORE SEGUNDO OS ASPECTOS SOCIODEMOGRÁFICOS DA AMOSTRA ................................................... 158

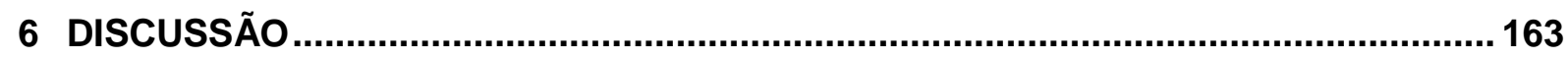

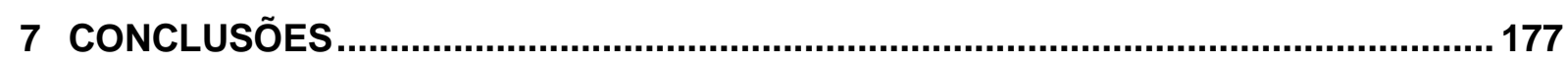

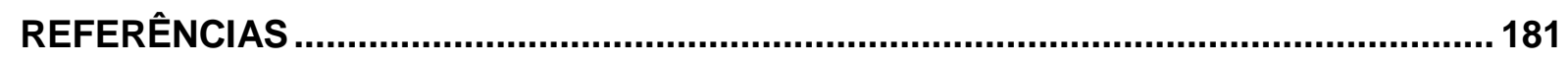

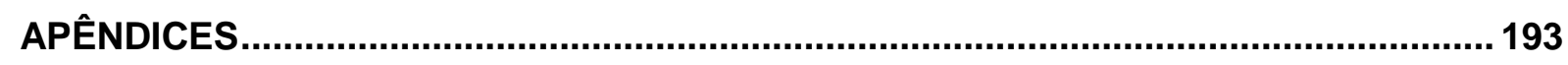

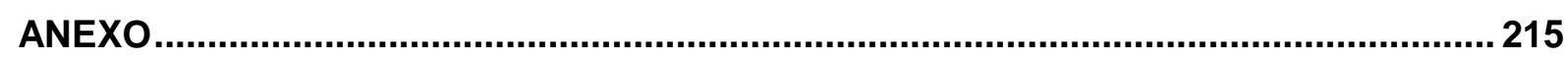



1 INTRODUCCÃO 



\section{INTRODUÇÃO}

O objetivo desta tese foi desenvolver e validar um instrumento de medida das percepções sobre discriminação racial interpessoal nos serviços de saúde (DRISS), levando em consideração os contextos histórico e racial do Brasil, país no qual o racismo atua, majoritariamente, de maneira velada e difícil de ser comprovada, persistindo o mito de que somos uma democracia racial (Fernandes, 2007). Apesar da população negra (pretos e pardos) compor mais da metade da população brasileira (IBGE, 2015) e de haver uma suposta tolerância racial e convivência pacífica entre os indivíduos, não há igualdade de direitos e oportunidades em termos sociais, econômicos e políticos (Fernandes, 2007). Frequentemente, as diferenças entre os grupos é vista apenas como um problema socioeconômico e sem fundamento racial (Guimarães, 2012).

Assim, esta tese buscou dar mais visibilidade à questão racial como elemento importante na determinação social do processo saúde-doença e, consequentemente, para o entendimento das iniquidades em saúde entre os grupos sociais no Brasil. Desse modo, partiu-se da perspectiva teórica da determinação social da saúde que assume o processo saúde-doença como um constructo de caráter social e biológico ao mesmo tempo. Assim, as condições de saúde de um grupo, quanto estudadas empiricamente, são relacionadas diretamente com as condições sociais, ou seja, trata-se de uma visão mais abrangente, que vai além do biológico nas condições de saúde (Rocha and David, 2015). Ainda,

Estabelece-se uma relação entre o processo saúde-doença do coletivo e do indivíduo, já que o processo do coletivo determina as características básicas sobre as quais se assenta a variação biológica individual (Rocha and David, 2015).

Além disso, este trabalho está alinhado com o objetivo geral da Política Nacional de Saúde Integral da População Negra (PNSIPN), que é "promover a saúde integral da população negra, priorizando a redução das desigualdades étnico-raciais, o combate ao racismo e à discriminação nas instituições e serviços do SUS" (Brasil, 2017). Em especial, este trabalho está alinhado com as diretrizes III e V, que são, respectivamente, "Incentivo à produção de conhecimento científico e tecnológico em 
saúde da população negra" e "Implementação do processo de monitoramento e avaliação das ações pertinentes ao combate ao racismo e à redução das desigualdades étnico-raciais no campo da saúde nas distintas esferas de governo".

A inspiração para o desenvolvimento desta tese foi proveniente da dissertação "Mulheres negras, o cuidado com a saúde a busca por assistência institucionalizada: estudo etnográfico em uma comunidade de baixa renda". Nesse trabalho, houve a participação de vinte mulheres negras, moradoras de um bairro periférico da cidade de São Paulo. Um dos principais resultados foi o relato das informantes de que os profissionais de saúde tratavam usuários de maneira racialmente discriminatória. Elas relataram que se tratava de uma percepção difícil de ser comprovada, pois, frequentemente, essas situações ocorriam de maneira velada, dificultando a sua observação de forma objetiva, porém, subjetivamente era percebida (Santa Rosa, 2013). No entanto, resultados de estudos qualitativos não são generalizáveis. Desse modo, surgiu a inquietação que impulsionou a busca por um instrumento que pudesse mensurar, de alguma forma, o racismo em estudos populacionais, ou seja, verificar se a percepção de discriminação racial perpetrada por profissionais de saúde é observada em outras populações além daquela amostra pequena de mulheres.

Nessa perspectiva, buscou-se um instrumento na literatura que medisse a percepção de usuários de serviços de saúde a respeito de eventuais situações discriminatórias sofridas durante $\mathrm{O}$ atendimento. Foi encontrada uma revisão sistemática da literatura sobre o racismo praticado por profissionais de saúde e as formas de mensurá-lo; os autores concluíram que, apesar do crescente número de publicações sobre racismo e saúde, pouco se sabe sobre a extensão do racismo praticado por profissionais de saúde, inclusive sobre como medi-lo (Paradies et al., 2014). Além disso, os trabalhos incluídos nessa revisão eram oriundos de inquéritos realizados a partir da perspectiva dos profissionais de saúde e não dos usuários dos serviços de saúde. Desse modo, os mesmos autores recomendaram novos estudos que buscassem captar e medir o racismo praticado por profissionais de saúde (Paradies et al., 2014).

Dessa maneira, tendo em vista que se trata de uma lacuna no campo de conhecimento da saúde da população negra, esta tese visou elaborar um instrumento capaz de medir as percepções de usuários sobre a discriminação racial interpessoal praticada no contexto dos serviços de saúde. Em outras palavras, o DRISS ora 
proposto possibilitará a mensuração do racismo institucional pela ótica dos usuários dos serviços de saúde, sendo essa uma das inovações deste trabalho. Trata-se de uma tentativa de se entender melhor a discriminação racial no nível interpessoal, na relação profissional de saúde-paciente e, assim, produzir informações relevantes que sirvam como ferramentas estratégicas no planejamento de ações programáticas, visando a redução das iniquidades raciais em saúde.

Pelo fato dos termos raça, racismo, discriminação racial e racismo institucional serem bastante utilizados, inclusive de forma intercambiável, esta tese contempla um subcapítulo que conceitua cada um desses termos separadamente e com mais detalhes. Também contempla uma revisão de literatura sobre instrumentos para aferição de discriminação existentes em níveis nacional e internacional.

Concluindo este tópico, apresentam-se aqui as motivações para o desenvolvimento desta tese: 1) não foi encontrado, nas literaturas nacional e internacional, um instrumento que medisse a discriminação racial no contexto dos serviços de saúde, em que a população-alvo fosse composta por usuários. Além disso, os instrumentos existentes, relacionados a aspectos raciais, são, em sua maioria, provenientes dos Estados Unidos, cuja construção histórica de raça/cor e a experiência de racismo são bem diversas da brasileira; 2) trabalhos qualitativos (Kalckmann et al., 2007; Santa Rosa, 2013) e quantitativos (Leal et al., 2017) mostram que há racismo nos serviços de saúde, mas esse racismo é difícil de ser identificado, porque, na maioria das vezes, não é explícito; 3) o mito da democracia racial é muito presente no Brasil; 4) as repercussões do racismo nos serviços de saúde podem ocasionar danos imediatos, crônicos e até fatais na vida das pessoas. Desse modo, entende-se que o assunto mereça um foco especial; por isso, o interesse em especificar os serviços de saúde na construção do DRISS.

\subsection{REVISÃO DA LITERATURA}

Os próximos tópicos abordam a fundamentação teórica de construção desse trabalho como um todo, destacando aspectos considerados relevantes. Primeiramente, há um breve relato da história dos negros no Brasil, buscando fundamentar as justificativas para o desenvolvimento deste trabalho. Depois, é 
abordada a Política Nacional de Saúde Integral da População Negra (PNSIPN), que é a materialização do reconhecimento, pelo Estado brasileiro, da desigualdade racial como um dos determinantes sociais do processo saúde-doença de indivíduos e coletividades. Por sua vez, são abordados os conceitos de raça, etnia, discriminação racial, racismo e racismo institucional - conceitos utilizados frequentemente ao longo desse trabalho. Em seguida, a determinação social do processo saúde-doença é discutida, com foco específico no racismo. Na sequência, é discutido o termo 'tratamento injusto' e sua relevância como indicador indireto das discriminações. Por fim, é apresentada a revisão da literatura sobre instrumentos de mensuração de discriminação racial, informando o estado da arte das escalas de discriminação existentes em níveis nacional e internacional - principalmente as de interesse para área da saúde.

\subsubsection{Breve histórico dos negros no Brasil}

Este capítulo tem como objetivo abordar brevemente a história dos negros no Brasil. A finalidade é dar destaque aos aspectos históricos mais relevantes para a compreensão do atual cenário racial brasileiro, principalmente, no que diz respeito à determinação social do processo saúde-doença.

A história dos negros no Brasil inicia-se no processo escravista, quando pessoas foram trazidas do continente africano para a execução de trabalhos forçados. Estima-se que, ao longo de três séculos, foram trazidos, pelos portugueses, aproximadamente quatro milhões de africanos para serem escravizados no território brasileiro (Azevedo, 1987; Bento, 2002). Os escravos eram tratados como mercadoria, como objetos desprovidos de alma e de vontade. Não possuíam o direito de constituir família, adquirir bens ou trabalhar em troca de qualquer remuneração (Freitas, 1984). Essa informação é relevante para compreender o processo de poder-opressão de um grupo racial em relação ao outro, desde a colonização, e que se reflete ainda na sociedade atual.

No início da colonização, no século XVI, o trabalho escravo foi utilizado, principalmente, nas lavouras de cana-de-açúcar no Nordeste. A forma de utilização da mão-de-obra escrava e a localização geográfica foram se adaptando às mudanças 
econômicas no transcorrer dos séculos. Assim, das lavouras de cana-de-açúcar no Nordeste, passou pela mineração de metais preciosos no Estado de Minas Gerais até as plantações de café nos Estados do Rio de Janeiro e São Paulo. Desse modo, observa-se a intensa utilização do trabalho escravo para a execução de serviços braçais no país ao longo dos séculos.

Para além das lavouras e da mineração, os escravos eram utilizados para muitas outras atividades como carregar água; executar funções domésticas e artesanais; prestação de serviços para seus senhores como, por exemplo, ser alugado para prestar serviços a terceiros; entre outros. Tanto os homens quanto as mulheres tinham suas atribuições, porém, as mulheres eram designadas mais para o labor doméstico como limpeza, cozinha e amas de leite dos filhos de seus senhores. Ainda, eram obrigadas a prestar serviços sexuais aos seus senhores e, se essa interação produzisse filhos, estes, por lei eram propriedade dos seus senhores também (Freitas, 1984). Por sua vez, os homens eram destinados principalmente às lavouras e mineração. Todo o sistema escravista era baseado na submissão e na força, desse modo, qualquer escravo, ou escrava, que desagradasse ao seu senhor, era punido de maneira exemplar! Portanto, os castigos físicos e a tortura eram frequentes.

Considera-se relevante enfatizar que toda essa barbárie do processo escravista no Brasil não transcorreu de maneira pacífica por parte dos escravos. Eram frequentes as fugas de escravos, a formação de quilombos, os suicídios e assassinato de senhores. Inclusive, houve uma revolta organizada, denominada Revolta dos Malês, no ano de 1835, na capital da Bahia. Tratou-se de um movimento de negros muçulmanos letrados, que tentaram tomar o poder na cidade, porém, foram punidos e massacrados por seus senhores na época (Reis, 2004).

O movimento abolicionista começou a ganhar força no Brasil e as elites começaram a temer que acontecesse aqui o mesmo que aconteceu no Haiti, país onde houve uma revolução promovida pelos escravos. Esse temor não era infundado, tendo em vista que, naquela época, a população negra era maior em número do que a população branca. Ainda, com a revolução industrial, era necessário ter mercado consumidor para os produtos da indústria nascente e em franco crescimento. Desse modo, era necessário estimular o crescimento de mão-de-obra assalariada, capaz de consumir o que era produzido. (Azevedo, 1987) 
No entanto, os ex-escravos não foram o público eleito para ocupar as vagas da indústria crescente no Brasil. De outra maneira, houve um forte incentivo à imigração, principalmente europeia e, para atrair esses imigrantes, foi oferecido trabalho remunerado e terras para o cultivo. Milhares de pessoas brancas vieram para - Brasil atraídas pela promessa de prosperidade. Sabe-se que os imigrantes encontraram duras condições de vida e de trabalho no Brasil, porém, nunca foram submetidos à situação de extrema sujeição que caracterizou a escravidão vivida pelos negros (Gonçalves, 2017)

Por fim, em 13 de maio de 1888, houve a abolição da escravatura no Brasil, mediante a Lei Áurea. No entanto, essa libertação não ocorreu por motivação humanitária, mas sim, impulsionada por um movimento internacional crescente que vinha extinguindo a escravidão aos poucos em todas as colônias. Inclusive, o tráfico de escravos já havia sido proibido há quase três décadas anteriores à abolição. $\mathrm{Na}$ verdade, o Brasil foi o último país do mundo ocidental a abolir a escravidão.

Apesar da maioria dos imigrantes europeus terem condições de fazer apenas serviços braçais e serem tão analfabetos quanto os negros libertos, que perambulavam pelas ruas após serem expulsos das fazendas, foram os europeus que tiveram oportunidade de trabalhar remuneradamente, tanto no meio rural, quanto no meio urbano, ocupando as vagas da indústria nascente. Desse modo, quando novos imigrantes europeus iam chegando ao Brasil, iam encontrando um ambiente favorável e, de certo modo, familiar, tendo em vista que encontravam apoio e identificação com os outros brancos que chegaram antes e, mesmo não sendo da mesma nacionalidade, possuíam a mesma ascendência europeia. Assim, grande parte da classe média branca de hoje, é fruto desse momento migratório intenso vivido no Brasil, no início do século passado (Gonçalves, 2017)

Lembrando que, uma outra motivação por parte da elite branca brasileira do pós-abolição para atrair imigrantes europeus era baseada na teoria de que havia um tipo ideal de civilização, e este tipo ideal tinha que ser de pele branca. Tratava-se da eugenia, uma pseudociência, cujos princípios eram disseminados na época em nível internacional. Assim, a elite branca do pós-abolição preocupou-se com a grande quantidade de negros que havia no Brasil daquela época, quase cinquenta por cento da população. Dessa forma, vislumbrou-se a possibilidade de estimular a imigração europeia branca também com o objetivo de miscigenar a população. A finalidade era 
diluir os traços da negritude até que se extinguissem ao longo das gerações e o ideal de uma sociedade branca fosse alcançado. Assim, durante três décadas de imigração, principalmente europeia, chegaram aproximadamente 3,99 milhões de imigrantes europeus, quantidade equivalente a de africanos trazidos ao Brasil no decorrer de três séculos (Azevedo, 1987; Bento, 2002).

Por sua vez, os ex-escravos, ditos libertos, não obtiveram qualquer auxílio da elite colonial branca, ficando reféns da falta de habitação, ausência de trabalho remunerado e total exclusão do processo de industrialização crescente no Brasil do século XX (Bento, 2002; Mattos, 2006). Ademais, os imigrantes recém-chegados também não esboçaram qualquer preocupação com as condições que os ex-escravos viviam no período pós-abolição (Azevedo, 1987). Também, explica o surgimento das favelas nos grandes centros urbanos e/ou a periferização do povo negro que, em cidades como São Paulo, por exemplo, se encontram, em sua maioria residindo em áreas afastadas do centro da cidade (Borelli, 2012; Carril, 2006).

Portanto, as raízes históricas das iniquidades socioeconômicas e demográficas, segundo a raça/cor da pele e observadas na população brasileira atual têm sua origem ainda no século XVII. Foram quase 400 anos de escravidão, seguidos de 130 anos da quase ausência de políticas públicas que buscassem reparar os danos sofridos pela população negra. E por mais contraditório que possa parecer, vivemos o mito de que não há segregação racial no Brasil, de que somos uma sociedade sem racismo! Isto acontece porque há uma convivência relativamente pacífica entre os indivíduos e uma suposta tolerância racial. Porém, não se observa igualdade de direitos e oportunidades. Segundo Fernandes (2007) "a democracia racial é apenas um mito no Brasil".

Estudos de base populacional recentes mostram que as iniquidades raciais no Brasil são contundentes, pois a população negra possui mais baixos níveis de renda e educação, quando comparada com a população branca (IPEA, 2014). Quanto às iniquidades em saúde, os homens negros têm duas vezes mais chance de morrer devido a qualquer causa de morte (Souza et al., 2015); as mulheres negras iniciam o pré-natal mais tardiamente, necessitam peregrinar mais pelos hospitais no momento do parto (Viellas et al., 2014), relatam menos satisfação com os cuidados de saúde recebidos e menos privacidade durante os procedimentos (d'Orsi et al., 2014). Para Guimarães (2012), enquanto as discriminações tiverem relacionadas com à raça, este 
conceito não deverá ser abandonado, auxiliando, inclusive, pesquisadores engajados na luta contra as iniquidades raciais em saúde.

\subsubsection{Política Nacional de Saúde Integral da População Negra}

A PNSIPN foi aprovada por unanimidade, no Conselho Nacional de Saúde, em 2006, mas a respectiva portaria só foi publicada em 2009, pelo Ministério da Saúde (Batista et al., 2013; Brasil, 2017). Essa política pública considera o racismo como um determinante social de saúde e reconhece a existência das iniquidades raciais em saúde. Além do reconhecimento, a PNSIPN propõe a criação de políticas específicas para o enfrentamento dessas desigualdades. São os objetivos geral e específicos da PNSIPN (Brasil, 2017):

\section{Objetivo geral}

Promover a saúde integral da população negra, priorizando a redução das desigualdades étnico-raciais, o combate ao racismo e à discriminação nas instituições e serviços do SUS.

\section{Objetivos Específicos}

I - Garantir e ampliar o acesso da população negra residente em áreas urbanas, em particular nas regiões periféricas dos grandes centros, às ações e aos serviços de saúde;

II - Garantir e ampliar o acesso da população negra do campo e da floresta, em particular as populações quilombolas, às ações e aos serviços de saúde;

III - Incluir o tema Combate às Discriminações de Gênero e Orientação Sexual, com destaque para as interseções com a saúde da população negra, nos processos de formação e educação permanente dos trabalhadores da saúde e no exercício do controle social;

IV - Identificar, combater e prevenir situações de abuso, exploração e violência, incluindo assédio moral, no ambiente de trabalho;

V - Aprimorar a qualidade dos sistemas de informação em saúde, por meio da inclusão do quesito cor em todos os instrumentos de coleta de dados adotados pelos serviços públicos, os conveniados ou contratados pelo SUS;

$\mathrm{VI}$ - Melhorar a qualidade dos sistemas de informação do SUS no que tange à coleta, processamento e análise dos dados desagregados por raça, cor e etnia;

VII - Identificar as necessidades de saúde da população negra do campo e da floresta e das áreas urbanas e utilizá-las como critério de planejamento e definição de prioridades;

VIII - Definir e pactuar, com as três esferas de governo, indicadores e metas para a promoção da equidade étnico-racial na saúde;

IX - Monitorar e avaliar os indicadores e as metas pactuados para a promoção da saúde da população negra visando reduzir as iniquidades macrorregionais, regionais, estaduais e municipais; 


\begin{abstract}
$X$ - Incluir as demandas específicas da população negra nos processos de regulação do sistema de saúde suplementar;

$\mathrm{XI}$ - Monitorar e avaliar as mudanças na cultura institucional, visando à garantia dos princípios antirracistas e não discriminatórios;

XII - Fomentar a realização de estudos e pesquisas sobre racismo e saúde da população negra (Brasil, 2017, p. 32).
\end{abstract}

Segundo Batista, Monteiro e Medeiros, (2013), o esforço em implementar a PNSIPN tem sido crescente e é de responsabilidade da Secretaria de Gestão Estratégica e Participativa do Ministério da Saúde (SGEP-MS). A SGEP-MS objetiva a disseminação da PNSIPN, a sensibilização dos profissionais, a monitoração, a avaliação e o apoio técnico aos departamentos e áreas do Ministério da Saúde (Batista et al., 2013).

Alguns estados, com destaque para São Paulo, consolidaram ações no sentido de implementar a PNSIPN por meio da difusão, sensibilização de profissionais de saúde, elaboração de projetos e propostas no nível da gestão. Contudo, sua implementação ainda é um processo em construção (Batista et al., 2013), sendo necessária a produção contínua de indicadores de monitoramento e avaliação. É somente por meio de acompanhamentos dos indicadores de saúde-doençamortalidade da população que será possível monitorar a evolução da PNSIPN no Brasil (Batista et al., 2013). Desse modo, a produção de novos conhecimentos sobre saúde da população negra pode ser útil para auxiliar na efetivação da PNSIPN, não só a partir da perspectiva dos gestores, mas também a partir da perspectiva dos usuários do Sistema Único de Saúde.

Um dos marcos da luta dos gestores para a implantação da PNSIPN é a incorporação do quesito cor nos sistemas de informação oficiais (Werneck, 2016). Entretanto, esta permanece sendo uma questão desafiadora. As proporções continentais do território nacional e a cultura de que somos uma 'democracia racial' também se constituem como barreiras para incorporar plenamente a cor da pele nos sistemas de informação em saúde.

Um estudo de abrangência nacional foi realizado, investigando a implementação da PNSIPN. Um dos principais achados foi que esta política ainda está em processo de implementação. Além disso, discute-se o atual avanço de forças políticas ancoradas no fundamentalismo conservador e ultraliberal da economia, que atacam vários direitos sociais, afetando aqueles que atendem às populações negras, 
indígenas, mulheres, comunidades gays, lésbicas, bissexuais, travestis, transexuais e transgêneros (Batista and Barros, 2017).

Assim como a PNSIPN, este estudo também considera que o racismo é estruturante na determinação do processo saúde-doença, e, assim, determina as iniquidades em saúde da população brasileira. Também está alinhado com o objetivo geral da PNSIPN, que é "promover a saúde integral da população negra, priorizando a redução das desigualdades étnico-raciais, o combate ao racismo e à discriminação nas instituições e serviços do SUS". Por isso, este estudo contribuirá para a implementação da PNSIPN, à medida que produzirá informações relevantes à tomada de decisão programática, com vistas na redução das iniquidades raciais em saúde.

\subsection{CONCEITOS DE RAÇA/COR DA PELE, ETNIA, DISCRIMINAÇÃO RACIAL, RACISMO E RACISMO INSTITUCIONAL}

É relevante tratar dos conceitos de raça e cor da pele, etnia, discriminação racial, racismo e racismo institucional, com vistas a especificar o referencial teórico utilizado para a elaboração desta tese.

\subsubsection{Raça e cor da pele}

Nesta tese, a raça não será tratada como um conceito biológico (Arteaga, 2017). Assume-se a raça como um conceito sociológico, uma ferramenta analítica, elaborada a partir da visão do observador cientista (etic) (Guimarães, 2012). Desse modo, a raça é um conceito nominalista, ou seja, visa expressar algo que não existe de fato no mundo físico, mas possui realidade social efetiva (Guimarães, 1999). O conceito de raça, aqui reivindicado, dá respaldo científico aos militantes antirracistas: 1) à medida em que reconhece o peso real e efetivo da ideia de raça na sociedade brasileira, em termos de legitimar desigualdades de tratamento e oportunidades; 2) reafirma o caráter fictício de tal construção em termos físicos e biológicos; 3) identifica o conteúdo racial das "classes sociais" brasileiras (Guimarães, 2012). 
Alguns autores manifestam perspectivas diferentes como, por exemplo, Seyferth (1986), que entende a raça como referência predominante às características fenotípicas dos indivíduos, destacando-se a cor da pele (Seyferth, 1986). Vale ressaltar que, no Brasil, a cor da pele demonstra, aparentemente, ser mais relevante do que a raça. Em geral, a população brasileira tende a se autoclassificar dentro de um continuum de cores que vai do tom pele mais claro até o mais escuro (Fry, 2005). Inclusive, há uma tendência de os brasileiros se classificarem como tendo cor de pele mais clara do que a que verdadeiramente possuem (Bastos et al., 2009; Brasil, 2011; Travassos and Williams, 2004). As exceções acontecem, notadamente, entre os indivíduos que possuem identificação racial ou por escolha política (Bastos et al., 2009; Brasil, 2011; Travassos and Williams, 2004). Guimarães (2012) observou que, a cada novo Censo, há menos pessoas se declarando como brancas e mais pessoas se declarando como pretas e pardas. O mesmo autor questiona se esse fenômeno se configura numa negação da brancura ou na atribuição de importância às características culturais e origem familiar (Guimarães, 2012).

Um estudo identificou, inclusive, que a cor da pele classificada por autodeclaração pode ser diferente da cor de pele identificada por heteroclassificação; ou seja, por meio da opinião do entrevistador (Bastos et al., 2009). No entanto, estudos mais recentes têm mostrado que a volatilidade classificatória não altera os resultados sobre a existência e a extensão das iniquidades raciais em saúde (Muniz, 2016; Muniz and Bastos, 2017). Em outros contextos, a classificação racial ocorre de forma diferenciada. Nos Estados Unidos, por exemplo, vale mais a regra do one drop (uma gota), ou seja, o indivíduo é considerado negro se possuir em sua ascendência algum negro, mesmo tendo a pele clara (Bastos and Faerstein, 2012; Travassos and Williams, 2004).

Em relação à América Latina, estudo abrangendo Brasil, Colômbia, México e Peru mostrou as disparidades na autoavaliação de saúde segundo a cor da pele, pois quanto mais escuro o tom de pele, pior foi a autoavaliação de saúde. A cor da pele mais escura também influenciou na saúde autoavaliada, conforme aumentou-se a exposição à discriminação de classe e reduziu-se o status socioeconômico (Perreira and Telles, 2014). Paletas de cores vêm sendo desenvolvidas e testadas como novas estratégias de classificar a cor da pele (Monk, 2016; Telles et al., 2015; Telles and Steele, 2012). 
Para a realização da classificação de raça/cor no Brasil, o Instituto Brasileiro de Geografia e Estatística (IBGE), por autoclassificação, disponibiliza cinco opções: preto, pardo, amarelo, branco e indígena (Brasil, 2015). Recentemente, como fruto da luta do movimento negro organizado e, a título de análise de dados, os pretos e os pardos foram incluídos na mesma categoria, chamada de 'negros' (Werneck, 2016).

Em resumo, esta tese assume a perspectiva da raça como um constructo analítico e social, reivindicado pelas ciências sociais (Guimarães, 2003) e utiliza o critério oficial do IBGE para classificar a raça/cor dos indivíduos (Brasil, 2015). Apesar de entender que o sistema de classificação brasileiro de raça/cor está sob debate ainda inacabado, assume-se, como negros, todos os pretos e os pardos (Werneck, 2016).

\subsubsection{Etnia}

Com relação ao conceito de etnia, Munanga (2004) disserta que se trata do conjunto de indivíduos que possuem uma ancestralidade comum, no sentido histórico ou mitológico. Esses indivíduos compartilham mesmo idioma, religião, cosmovisão, cultura e território geográfico. $\mathrm{O}$ autor afirma que algumas etnias acabaram por se constituir como nações inteiras, sendo chamadas de 'etnias nações', exemplificando com os casos das sociedades indígenas brasileiras, africanas, asiáticas, australianas etc.

\subsubsection{Preconceito racial}

Após os anos 2000, os cientistas sociais parecem concordar que o preconceito passa por um novo paradigma, parecendo ser visto, cada vez mais, como um constructo multidimensional, de natureza afetiva, expressando motivações humanas básicas em nível particular e intragrupo. Entende-se o preconceito como um processo motivacional e social que elabora estereótipos e vieses relativamente moderados, sendo automaticamente provocado por categorizações e identidades sociais salientes 
dentro de uma manifestação mais virulenta de preconceito e discriminação (Duckitt, 2010).

Para Nogueira (2007), o preconceito racial é:

Uma disposição (ou atitude) desfavorável, culturalmente condicionada, em relação aos membros de uma população, aos quais se têm como estigmatizados, seja devido à aparência, seja devido a toda ou parte da ascendência étnica que se lhes atribui ou reconhece (Nogueira, 2007)

Assim, Bastos e Faerstein (2012), interpretando Duckitt (2010), observam que o preconceito e o estereótipo são restritos ao campo das ideias, dos pensamentos, não se manifestando necessariamente por meio de ações, sendo, por isso também, difíceis de serem mensurados (Bastos and Faerstein, 2012; Duckitt, 2010). Trata-se, portanto, de uma manifestação individual do racismo, que é a predisposição psicológica de um indivíduo contra o outro indivíduo que não lhe seja igual em temos de cor de pele, tipos de cabelos, formas faciais e outros aspectos que denuncie alguma forma de origem familiar ou cultural (Paixão et al., 2011).

\subsubsection{Discriminação racial}

Segundo o dicionário online Dicio (2018), discriminar possui várias classificações gramaticais, porém, entre essas classificações, observa-se que as diferenças de significado são muito tênues:

Verbo transitivo direto: Excluir; tratar de forma injusta ou desigual uma pessoa ou um grupo de pessoas, por motivos relacionados com suas características pessoais específicas, como cor de pele, nível social, religião, sexualidade etc.: o Estado discriminava os deficientes;

Verbo transitivo direto: Listar; classificar tendo em conta algum motivo específico: a funcionária discriminava os produtos:

Verbo transitivo direto e bitransitivo: Discernir; aperceber-se das diferenças: o professor discriminava os alunos pelas notas; o diretor discriminou aos professores as novas regras

Verbo transitivo direto e pronominal: Construir um grupo distinto para não se misturar aos demais; distinguir-se por possuir algum tipo de preconceito étnico, religioso, sexual (Dicio, 2018).

Portanto, para a língua portuguesa, discriminar denota excluir, listar, discernir, colocar como um grupo distinto. Em se tratando de discriminação racial, esta é 
entendida como um comportamento diferenciado, baseado na raça/cor, manifesto por meio de ações que podem favorecer ou causar prejuízo de um grupo em relação ao outro, produzindo vantagens ao grupo ao qual o perpetrador pertença (Bastos and Faerstein, 2012; Dovidio, 2010). Segundo os mesmos autores, a discriminação é observável por meio de tratamentos desiguais de pessoas (ou grupos) devido às suas origens, ao pertencimento, à aparência e às opiniões, sendo a diferença entre discriminação e o preconceito, a possibilidade de mensurar (Bastos and Faerstein, 2012; Taguieff, 1997). Vale lembrar que a discriminação também caracteriza-se pelo tratamento desigual atribuído não por mérito ou reciprocidade, mas sim, pelo puro pertencimento do indivíduo a um grupo socialmente definido (Allport, 1979; Bastos and Faerstein, 2012).

Na presente pesquisa, o termo discriminação racial foi adotado para compor o nome do instrumento que se pretende construir, o DRISS. Isto porque há 0 entendimento de que a discriminação racial é observável, sendo assim, possível de ser medida. Já o termo racismo é muito utilizado na literatura internacional, inclusive de maneira intercambiável. Para Bastos e Faerstain (2012), racismo e discriminação não são termos intercambiáveis, porque o racismo refere-se a uma ideologia, enquanto, para esses autores, a discriminação racial é a manifestação externalizada do racismo - sendo o preconceito, por sua vez, a manifestação internalizada do racismo.

A discriminação racial pode ser perpetrada nos níveis interpessoal e institucional. Quanto ao nível institucional, haverá um tópico mais adiante abordando o tema. Em relação à discriminação interpessoal, esta se refere ao ato racialmente discriminatório praticado no nível individual, de uma pessoa para a outra. Segundo Paradies, Truong e Priest (2014), o racismo interpessoal se refere às interações racistas entre indivíduos. Lembrando que os autores utilizam o termo "racismo interpessoal" (tradução livre) com o significado de "discriminação racial interpessoal".

\subsubsection{Racismo}

Uma revisão sistemática da literatura traz uma definição sucinta e pertinente sobre racismo que pode ser entendido como um dos diversos tipos de opressão com 
vistas a garantir o privilégio histórico de um grupo racial em relação ao outro. O conceito interligado de privilégio/opressão pode ser definido como um sistema societal em que os atores são divididos ao longo de dimensões socialmente construídas e com poder distribuído (ou produzido) de maneira desigual (Paradies, 2006a). O racismo constituise como fenômeno que resulta em iniquidades evitáveis e injustas de poder, recursos e oportunidades por meio dos grupos étnico/raciais. Ele pode se expressar por meio de crenças, estereótipos, preconceitos ou discriminação e pode estar profundamente arraigado nos sistemas e nas estruturas sociais (Berman and Paradies, 2010).

Assim, o grupo dos privilegiados é beneficiado por um sistema de atitudes, crenças, comportamentos, leis, normas, práticas, padrões estéticos, bens, serviços, educação, emprego, entre outros. Do outro lado, as pessoas das raças oprimidas sofrem experiências opostas (Jones, 2002, 2000; Werneck, 2016). Além disso, existe um racismo encoberto, o que significa que a atitude racista não é explicitamente feita com insultos verbais ou físicos, mas percebida por indivíduo ou grupo oprimido (Krieger, 2001). Geralmente, o racismo encoberto (covert, no inglês) que também pode ser entendido como velado, é percebido comparando o tratamento injusto recebido quando a raça/cor é a única diferença entre as pessoas presentes no mesmo local.

O racismo pode ocorrer em múltiplos níveis: internalizado, interpessoal ou institucionalizado. O racismo internalizado é definido como a "aceitação", por membros das raças estigmatizadas, de mensagens negativas sobre suas próprias habilidades e valor intrínseco. Destrói a autoestima do indivíduo e o faz não acreditar nem em si mesmo, nem nos que se parecem com ele. Manifesta-se por meio da incorporação de "atitudes/comportamentos da branquitude" como utilizar cremes para alisar e clarear os cabelos; preferência por consumir produtos vendidos e fabricados por pessoas brancas; autodesvalorização (utilizando insultos como apelido, rejeição da cultura ancestral e fratericidade); resignação, desesperança, desamparo (abandono escolar, abstenção do direito ao voto e envolvimento em práticas arriscadas de saúde); dentre outros (Jones, 2000).

Já o racismo interpessoal é definido como o preconceito e a discriminação, em que o preconceito manifesta-se ao se assumir um diferencial relacionado às habilidades, motivos, intenções dos outros de acordo com a raça. A discriminação refere-se às ações diferenciais direcionadas a outras pessoas de acordo com a raça. 
O racismo interpessoal pode ser intencional ou não intencional, comandado por alguém ou omisso. Manifesta-se por meio de falta de respeito (prestação de serviço de menor qualidade ou a não prestação do serviço, falha ao comunicar opções), suspeita (vigilância dos lojistas, pessoas evitando a convivência diária, incluindo travessia de rua, apertar a bolsa e se manter em lugares vazios nos transportes públicos), desvalorização (surpresa com a competência) e desumanização (brutalidade policial, esterilização abusiva de mulheres e crimes de ódio) (Jones, 2000).

Por fim, o racismo institucionalizado é definido como ações diferenciais para acessar bens, serviços e oportunidades que a sociedade dispõe, segundo a raça/cor da pele. O racismo institucionalizado é normativo, às vezes legalizado e, frequentemente, manifesta-se como desvantagem herdada. Também é estrutural e codificado em nossas instituições, práticas, leis e, portanto, o perpetrador não é necessariamente identificável (Jones, 2000).

O racismo é considerado eixo estruturante da determinação social do processo saúde-doença (Braveman et al., 2011), pois afeta as condições de saúde por meio de inúmeros caminhos: limitação do acesso de indivíduos de determinado grupo racial a recursos sociais, como emprego, habitação e educação; exposição aumentada a situações de risco (como o contato desnecessário com o sistema de justiça criminal); desencadeia processos afetivos/cognitivos e outros processos psicopatológicos; pode contribuir para a carga alostática ou outro processo fisiopatológico; induz a menor engajamento a comportamentos saudáveis (por exemplo: exercícios físicos), induz a maior adoção a comportamentos não saudáveis (por ex.: uso abusivo de substâncias) que são, muitas vezes, utilizados diretamente como estratégia de coping para o estresse ou indiretamente reduzindo a autorregulação; além de danos físicos diretos causados pela violência motivada por racismo (Brandolo et al., 2011; Gee et al., 2009; Harrell et al., 2011; Paradies, 2006a; Pascoe and Smart Richman, 2009; Priest et al., 2013). Seguindo esse raciocínio, pessoas que sofrem racismo têm mais risco de desenvolver problemas relacionados à saúde física e mental (Paradies et al., 2015). 


\subsubsection{Dificuldades para medir discriminação}

Bastos e Faerstein (2012) problematizam os desafios metodológicos para a mensuração da discriminação interpessoal no Brasil, enfatizando a necessidade de se considerar as especificidades sociais e culturais de cada contexto. O principal desafio é o de garantir que os instrumentos captem experiências discriminatórias oriundas de diversas motivações como cor da pele, idade, obesidade, pobreza, entre outros. Os autores lançam mão de ferramentas da psicologia transcultural para discutir o assunto e apontam três dificuldades consideradas principais quando se objetiva aferir discriminação: 1) o fato da maioria dos instrumentos de aferição disponíveis serem norte-americanos; 2) o Brasil ser um país com proporções continentais e com muitas diferenças regionais em relação à classe, raça, gênero entre outros, sendo todos esses aspectos relevantes para a forma como a discriminação se manifesta $e$ como é popularmente interpretada; 3) a intersecção dos diferentes tipos de discriminação.

Adiciona-se a isso o fato de que, para que um indivíduo assuma ter sofrido discriminação, é necessária a identificação como pertencente a um grupo. No caso da discriminação racial, o indivíduo necessita se identificar como pertencente a algum grupo racial. Assim, ao se deparar com um ato discriminatório, haverá uma percepção mais nítida de que ocorreu por motivação racial. Pois bem, esse é um dos principais desafios para estudiosos que pretendem investigar discriminação racial no Brasil, tendo em vista que nem todo brasileiro se identifica com algum grupo racial específico (Brasil, 2011). Boa parte desse fenômeno ocorre devido à grande mistura de raças que se tem no Brasil, originada, no início, pela mistura dos portugueses com as índias brasileiras, depois dos mesmos portugueses com as mulheres escravizadas. Porém, tal mistura ocorreu com maior expressividade com os imigrantes europeus que chegaram no início do século passado.

Ademais, quando o indivíduo identifica-se como pertencente a um grupo, pode acontecer também de não querer admitir ou enfrentar um assunto doloroso, como é o caso da discriminação. Para Mattos (2006), a identificação com um grupo de pertença racial é um processo e, sua construção pode ser fortemente subsidiada pela apresentação de fatos históricos e políticos. A autora disserta que é necessário reivindicar a cor, pois trata-se de uma bandeira de luta em busca de reparações. 
Reivindicar ou não reivindicar "são frutos diferentes da presença difusa do racismo na sociedade brasileira em suas complexas relações com a memória do cativeiro" (Mattos, 2006).

\subsubsection{Racismo institucional}

Há meio século, o termo "racismo institucional" (RI) foi criado por Charles Hamilton e Stokely Carmichael, membros do movimento Black Power estadunidense. Esse termo pode ser intercambiado por racismo institucionalizado ou racismo sistêmico e se refere "a falha coletiva de uma organização em prover um serviço apropriado e profissional às pessoas por causa de sua cor, cultura ou origem étnica" (Ture and Hamilton, 1967). O RI é um tipo de racismo perpetrado por instituições, organizações, políticas e normas que resultam em tratamento desigual a determinados grupos (Jones, 2002, 2000; Paradies, 2006a; Werneck, 2016). O RI provoca fortes consequências, incluindo uma série de restrições a determinados grupos raciais; em contrapartida, privilegia outros grupos raciais (Feagin and Bennefield, 2014).

Discute-se que, no Brasil, o racismo não é e nem foi institucionalizado como nos Estados Unidos. Isso porque, no país norte-americano, o racismo era praticado por meio da discriminação racial mediada por todo um aparato legal, onde pessoas não brancas eram segregadas nos espaços públicos e havia a proibição do casamento inter-racial. Trata-se do conjunto de leis chamadas de Jim Crow, promulgadas principalmente em estados sulinos daquele país entre os anos de 1881 e 1964 (Tischauser, 2012). No entanto, apesar de não ter havido no Brasil um aparato segregacionista legalizado, considera-se que o racismo aqui foi e ainda é institucionalizado, uma vez que os ex-escravos foram excluídos do mercado de trabalho no início do século passado, a mão-de-obra remunerada de pessoas brancas foi importada (em detrimento da mão de obra das pessoas negras que já estavam aqui) e políticas de reparação foram praticamente inexistentes por cem anos pósabolição (López, 2012).

Nesse sentido, somente após cem anos de abolição da escravidão no Brasil, ou seja, em 1988, foi promulgada a Constituição Brasileira, garantindo a 
universalização do atendimento à saúde com a criação do SUS, por exemplo. Além de outras conquistas importantes como os benefícios da assistência social, a gratuidade e obrigatoriedade do Ensino Fundamental, entre outros (López, 2012). Vale lembrar que ações afirmativas referem-se a políticas públicas que se destinam a corrigir desigualdades e desvantagens históricas sofridas por um grupo étnico-racial frente ao Estado nacional que o discriminou negativamente (López, 2012). Assim, outras ações afirmativas podem ser listadas como:

\begin{abstract}
Políticas de acesso e permanência de estudantes negros nas universidades; a aplicação de conteúdos de história e cultura afro-brasileira e africana, assim como práticas de educação antirracista nas instituições de Ensino Fundamental e Médio (Lei Federal 10639/03); a reserva de vagas para negros no mercado de trabalho; o reconhecimento étnico e a regularização fundiária de comunidades negras rurais e urbanas (chamadas na Constituição Federal de "remanescentes de quilombos"), e a própria Política Nacional de Saúde Integral da População Negra, já mencionada. Estas políticas destinam-se a reverter a desigualdade racial em vários campos sociais (López, 2012, p. 124).
\end{abstract}

Há que se lembrar, no entanto, que essas ações não foram iniciativas espontâneas do governo e sim, ocorreram devido à forte pressão do movimento social organizado, em especial, o movimento negro. A organização não-governamental Geledés (2013), em parceria com membros da Organização das Nações Unidas e do Instituto de Pesquisa Econômica e Aplicada (IPEA), entre outros, desenvolveu, por exemplo, o Guia de Enfrentamento ao RI. Trata-se de um documento importante, que teve como um dos produtos um quadro com indicadores do RI. Essa iniciativa configura-se como um documento estratégico para auxiliar gestores na direção do combate ao RI. Os principais eixos desse documento são: Visibilização do compromisso institucional; Instância de Governança; Ações Afirmativas e outras políticas de enfrentamento do Racismo Institucional; Produção de dados e informações cadastrais sobre o público; Competência cultural; Avaliação das políticas e serviços (Geledés, 2013).

Dialogando com o Guia de Enfrentamento ao RI, o DRISS foi elaborado para medir a percepção de usuários sobre discriminação racial interpessoal praticada por profissionais de saúde. Apesar de o DRISS não medir diretamente o RI, porque essa medida deve ser efetuada no nível institucional e não no nível interpessoal, o DRISS 
produz dados relevantes sobre a interação profissional de saúde-usuário, pois esse profissional de saúde é o reflexo da instituição e de suas práticas - o mesmo profissional de saúde que se configura como um dos principais desafios para a equidade no SUS (Kalckmann et al., 2007)

Isso posto, o RI, numa visualização mais aprofundada, pode ser entendido como racismo estrutural. Para Feagin e Bennefield (2014), a maioria das instituições existentes (hospitais, escolas, universidades, entre outros) foi fundada por pessoas de pele branca; consequentemente, essas instituições possuem concepções e práticas baseadas em seu pertencimento racial (Feagin and Bennefield, 2014). Nesse sentido, entende-se que os profissionais compartilham a sistemática branca aprendida em sociedade (Feagin, 2010). Apesar de se tratarem de estudos que tomaram como base $o$ contexto estadunidense, os achados mostraram-se pertinentes à realidade brasileira (Santos, 2015).

\subsection{TRATAMENTO INJUSTO}

Com relação ao termo 'tratamento injusto', usado nos enunciados dos dois primeiros grupos de itens do DRISS, observa-se, na literatura sobre discriminação em saúde, o uso, muitas vezes intercambiado, dos conceitos de "tratamento diferencial/injusto" e "tratamento discriminatório" - apesar de não haver, necessariamente, equivalência direta entre ambos os construtos.

Para melhor compreender a distinção dos conceitos, faz-se necessário abordar 'discriminação'. Para Major e Dover (2016), a 'discriminação atribuída' necessita de dois componentes primários: 1 . O julgamento de que o tratamento foi baseado na identidade social e no pertencimento a um determinado grupo; 2 . O julgamento de que o tratamento foi injusto ou não merecido. Assim, do ponto de vista fenomenológico, o indivíduo atribui o tratamento recebido à discriminação por ter sentido que foi tratado injustamente devido ao seu pertencimento à uma categoria social ou a um grupo (Major and Dover, 2016). O mesmo estudo aponta a necessidade de estudos futuros que busquem desatrelar os efeitos da discriminação percebida (tratamento injusto atribuído à identidade social) dos efeitos do tratamento injusto percebido em geral (isto é, não rotulado como discriminação) (Major and Dover, 2016). 
Nesse sentido, o DRISS buscou isolar a experiência do tratamento injusto relacionado ao pertencimento racial dos respondentes, perguntando explicitamente se esse respondente atribuía o eventual tratamento injusto percebido, em serviço de saúde, à sua raça/cor da pele. Assim, o termo 'tratado injustamente' - o mais usado nos estudos incluídos na revisão de literatura realizada para esta tese - foi utilizado (Bastos et al., 2010; Krieger, 1990), acrescendo-se, ao enunciado da questão, o trecho: "devido à sua raça/cor da pele". Adicionalmente, antes de iniciar o preenchimento do DRISS, o respondente deveria indicar a sua raça/cor (o que indica identificação racial). Portanto, do indivíduo que não considerasse que a motivação do tratamento injusto tenha sido racial, esperava-se que não continuasse a responder ao formulário.

Quanto ao termo 'tratamento diferencial', também com base em uma identidade social ou pertencimento a um determinado grupo, optou-se por não utilizá-lo, porque pareceu mais provável que o indivíduo atribua o termo 'tratamento injusto' à discriminação do que o 'tratamento diferencial' à discriminação. O 'tratamento diferencial' esteve mais associado a variáveis que teoricamente podem ser controladas pelas pessoas que a possuem, por exemplo, peso corporal - o que não é o caso da raça/cor (Major and Dover, 2016).

\subsection{SERVIÇOS DE SAÚDE}

Considerou-se relevante explicitar o que é entendido como serviço de saúde, tendo em vista que se trata de um termo frequentemente utilizado nesta tese, inclusive no título. Segundo a Agência Nacional de Vigilância Sanitária, serviços de saúde são:

estabelecimentos destinados a promover a saúde do indivíduo, protegê-lo de doenças e agravos, prevenir e limitar os danos a ele causados e reabilitá-lo quando sua capacidade física, psíquica ou social for afetada. Serviços de Interesse à Saúde são estabelecimentos que exercem atividades que, direta ou indiretamente, podem provocar benefícios, danos ou agravos à saúde (ANVISA, 2003, p. 01).

Este estudo utiliza alguns exemplos de serviços de saúde brasileiros, comumente acessados pela população, tais como hospitais, prontos-socorros, maternidades, entre outros (Apêndice III). 


\subsection{RACISMO NA DETERMINAÇÃO SOCIAL DO PROCESSO SAÚDE- DOENÇA}

Revisões sistemáticas recentes da literatura têm reunido evidências que relacionam o racismo com os piores resultados na saúde de grupos étnicos considerados desfavorecidos (Paradies, 2006a; Priest et al., 2013). Nessas pesquisas, diversos grupos étnicos foram contemplados; todavia, predominaram pesquisas com negros (Bastos et al., 2010; Kressin et al., 2008; Paradies, 2006a; Paradies et al., 2014).

As evidências do cenário internacional são provenientes, majoritariamente, de estudos conduzidos nos Estados Unidos e na Europa (Paradies, 2006a). Duas revisões sistemáticas recentes encontraram associações estatisticamente significativas entre a experiência de ter sofrido racismo e os piores resultados em saúde mental (Goto et al., 2013; Paradies, 2006a). A primeira revisão, feita por Goto, Couto e Bastos (2013), incluiu 34 artigos, sendo todos americanos. Os autores relataram não ter sido possível realizar uma metanálise devido à falta de homogeneidade entre os estudos com relação à autoclassificação ou à heteroclassificação de raça/cor dos participantes, por conta dos critérios distintos de seleção de participantes e pelo fato de os estudos terem diferentes planos amostrais, muitas vezes com amostra por conveniência.

$\mathrm{Na}$ segunda revisão de literatura consultada, Paradies (2006) incluiu 138 estudos quantitativos de base populacional e chegou a conclusões similares ao primeiro. A novidade do estudo está na constatação de que o pertencimento a grupos, ou seja, a socialização, atenua os efeitos do racismo sobre a saúde mental. Além disso, também encontrou efeito positivo das estratégias de coping desenvolvidas pelos entrevistados (Paradies, 2006a).

As duas revisões sistemáticas mencionadas observaram que os efeitos do racismo na saúde física são menos expressivos do que na saúde mental, sugerindo que investigações mais refinadas devem ser realizadas por meio de estudos longitudinais por possibilitarem a avaliação dos efeitos da exposição (racismo) nos desfechos (saúde física e mental). Além disso, sugerem também que sejam realizados estudos com 
amostras mais amplas e com uso de medidas objetivas do racismo, ao invés do simples autorrelato (Bastos and Faerstein, 2012; Goto et al., 2013; Paradies, 2006b).

Corroborando esse quadro, recente revisão sistemática investigou a associação entre discriminação racial e hipertensão arterial sistêmica (HAS). Porém, os resultados não permitiram identificar essa associação entre os 22 estudos incluídos na revisão (Couto et al., 2012), justamente por conta dos mesmos motivos já expostos. Chama a atenção também o fato de que todos os estudos eram estadunidenses, impossibilitando-nos o entendimento de como os efeitos do racismo afetam a saúde de populações negras residentes em outras localidades, como o Brasil.

Dessa forma, independentemente de os resultados sumarizados nas revisões de literatura mostrarem que não há evidências suficientes que associem a discriminação racial aos efeitos na saúde física dos indivíduos, estudos primários encontraram, entre negros estadunidenses, maior incidência de doenças cardíacas, câncer, diabetes, hipertensão arterial sistêmica, entre outras, em comparação com os brancos (Kung, 2008). Williams e Mohammed (2009) observaram que há certos aspectos, para além da questão racial, que contribuem adversamente para os efeitos na saúde de determinados grupos raciais nos Estados Unidos, como a inserção socioeconômica. Em comparação com a população branca estadunidense, negros com educação superior têm maior probabilidade de viverem a experiência do desemprego. Além disso, negros estadunidenses empregados têm maior probabilidade de exposição a riscos ocupacionais e cancerígenos, mesmo após ajustes por experiência de trabalho e educação. Os negros estadunidenses possuem status socioeconômico menor em todos os níveis de renda e têm menor poder de compra devido aos custos de uma ampla gama de produtos e serviços - que são mais caros nas comunidades negras (Williams and Mohammed, 2009).

As diferenças de status socioeconômico na infância e a adversidade psicossocial e econômica entre os diferentes grupos raciais também contribuem de maneira importante nas disparidades raciais em saúde na vida adulta (Williams and Mohammed, 2009). Os mesmos pesquisadores chamam a atenção para a necessidade de se explorar os múltiplos caminhos pelos quais o racismo pode afetar adversamente a saúde das pessoas (Williams and Mohammed, 2009).

Um estudo norte-americano avaliou o índice de massa corporal (IMC) e a medida da circunferência da cintura (CC) de mulheres, fazendo a intersecção entre essas 
medidas, a discriminação racial, o gênero e a vigilância, e observou que mulheres negras tinham médias maiores de IMC e CC do que qualquer outro grupo racial, assim como também maior nível de vigilância. Entre mulheres negras, foi encontrada uma associação entre vigilância e CC (Hicken et al., 2017). O estudo discute o comportamento de vigilância que está diretamente relacionado ao estresse crônico, consequentemente, aumentando os riscos para a saúde (Hicken et al., 2017, 2013).

No Brasil, da mesma forma que nos Estados Unidos (Williams and Mohammed, 2009), há forte iniquidade socioeconômica entre os grupos raciais. A população negra está muito mais exposta à pobreza, ao analfabetismo, ao desemprego e possui menos acesso aos serviços de saúde, segundo dados do IPEA (Paixão et al., 2011). Consequentemente, a população negra brasileira também tem os piores indicadores de saúde (IPEA, 2014).

Uma revisão de literatura, publicada em 2011 (Morse et al., 2011), reuniu a produção científica sobre mortalidade materna no Brasil nos últimos 30 anos e concluiu que as mulheres pretas têm risco maior de mortalidade materna em vários estados brasileiros. Quando comparadas com as mulheres brancas, as mulheres pretas apresentam risco de mortalidade materna 3,7 vezes maior na Bahia e 8,2 vezes maior no Paraná. O mesmo estudo discute que os prováveis motivos são a maior severidade da hipertensão arterial em mulheres pretas e acesso mais limitado aos serviços e práticas de saúde, como pré-natal, por exemplo. Todos esses motivos podem ser evitados com a ampliação do acesso e da qualidade dos serviços de saúde (Morse et al., 2011).

Inquéritos recentes de base populacional realizados no país, como o Nascer no Brasil, apresentaram dados contundentes relativos à saúde de mulheres pretas e pardas. Viellas et al. (2014) relataram que as mulheres pretas iniciam o pré-natal mais tardiamente e são as que mais peregrinam no momento da internação para o parto, principalmente nos estados pertencentes ao Norte e ao Nordeste do país (Viellas et al., 2014). Outro estudo derivado do mesmo inquérito apresenta percentuais maiores de relatos de violência verbal, física ou psicológica entre as mulheres pretas e pardas, com menor escolaridade, idade entre 20 e 34 anos, moradoras da região Nordeste, que tiveram parto vaginal, sem acompanhante, atendidas no setor público e que passaram por trabalho de parto (d'Orsi et al., 2014). O mesmo estudo mostra que, entre as mulheres pretas, há menor satisfação geral com o atendimento, menos privacidade 
durante o atendimento, menor satisfação com o tempo de espera (d'Orsi et al., 2014) e menos aplicação de anestesia quando essa é necessária (Leal et al., 2017).

Em relação à saúde de homens negros, Batista (2005), por meio de dados extraídos do Sistema de Informação em Mortalidade, no ano de 1999, concluiu que os homens negros morrem mais do que os homens brancos. Dentre as principais causas de morte entre os homens negros, estavam os transtornos mentais devido ao uso de álcool e outras drogas; doenças infecciosas e parasitárias, predominando tuberculose e HIV/Aids; e causas externas, com destaque para os homicídios (Batista, 2005).

No mesmo sentido, estudo descritivo realizado no município de Salvador, Bahia, com 9.626 registros de óbitos por causas externas, entre 1998 e 2003, revelou que há desigualdade entre os óbitos de homens por causas externas segundo a raça/cor da pele. Os resultados mostraram que os homens negros tiveram maior perda de anos potenciais de vida, maior número médio de anos não vividos e morreram em idades mais precoces por homicídios, acidentes de trânsito e demais causas externas (Araújo et al., 2009). Pesquisa realizada também em Salvador, no mesmo período, diferenciando-se quanto à abordagem de distribuição espacial, mostrou que a taxa predita de mortalidade por homicídio aumenta quando há aumento na proporção de população masculina negra com idade entre 15 e 49 anos (Araújo et al., 2010).

Outro estudo mais recente sobre a mortalidade de homens negros, publicado em 2015, comparou os dados de mortalidade entre o Sudeste e o Nordeste brasileiros e revelou que houve crescimento total de mortes de homens negros, quando consideradas praticamente todas as causas de morte, sendo que, nos estados do Nordeste, o crescimento foi mais expressivo, apresentando significância estatística para o estado da Paraíba (Souza et al., 2015).

Embora muitos indicadores de saúde sofram influência direta da pobreza e das iniquidades no acesso aos serviços de saúde de qualidade, nosso pressuposto é que o racismo exerce efeito nas condições de saúde da população negra brasileira.

Com o objetivo de conhecer o que já foi publicado sobre a temática em discussão, é apresentada uma revisão de literatura sobre escalas de medida de racismo e discriminação racial existentes - nos contextos nacional e internacional. Trata-se de uma revisão que busca apresentar o escopo do que já foi produzido sobre essa temática. Inicialmente, três revisões sistemáticas sobre instrumentos de medida 
são apresentadas e sua relevância para este projeto de pesquisa é discutida no Quadro 1. Em seguida, é apresentado o Quadro 2, com as escalas mais relevantes encontradas, revelando as fontes de inspiração para a criação de alguns itens (questões) que compuseram o DRISS.

\subsection{REVISÃo DA LITERATURA SOBRE INSTRUMENTOS DE MENSURAÇÃO DE DISCRIMINAÇÃO RACIAL}

Apesar de as revisões apresentadas terem incluído predominantemente estudos que exploravam a perspectiva do profissional de saúde sobre racismo e/ou discriminação racial, elas são abordadas por conta da proximidade temática e relevância. O Quadro 1 apresenta um resumo do conteúdo de cada artigo, traduzido de maneira literal pela autora. Na última coluna, é apresentada discussão sobre o conteúdo de cada estudo e a relevância para esta tese. 
Quadro 1 - Descrição de artigos de revisão de literatura que exploraram instrumentos de medida de racismo/discriminação racial de interesse para o campo da saúde.

\begin{tabular}{|c|c|c|c|c|c|c|c|c|}
\hline $\begin{array}{l}\begin{array}{l}\text { Autores/Ano/ } \\
\text { Periódico }\end{array} \\
\\
\text { (Kressin et al., } \\
2008)\end{array}$ & Título & $\begin{array}{l}\text { Tipo de } \\
\text { estudo }\end{array}$ & $\begin{array}{c}\mathrm{N} . \mathrm{o} \\
\text { trabalhos } \\
\text { inclúídos }\end{array}$ & \multicolumn{2}{|c|}{$\begin{array}{c}\text { Principais resultados } \\
\text { (tradução literal do artigo) }\end{array}$} & \multicolumn{2}{|c|}{$\begin{array}{c}\text { Conclusões (tradução literal do } \\
\text { artigo) }\end{array}$} & Discussão (feita pela autora) \\
\hline $\begin{array}{l} \\
\\
\text { (Kressin et al., } \\
\text { 2008) } \\
\text { J Health Care } \\
\text { Poor } \\
\text { Underserved. } \\
\text { 19(3):697-730 }\end{array}$ & $\begin{array}{l}\text { Perceptions of } \\
\text { race/ethnicity- } \\
\text { based } \\
\text { discrimination: } \\
\text { a review of } \\
\text { measures and } \\
\text { evaluation of } \\
\text { their } \\
\text { usefulness for } \\
\text { the health care } \\
\text { setting }\end{array}$ & $\begin{array}{l}\text { Revisão } \\
\text { (não- } \\
\text { sistemática) }\end{array}$ & 17 & b) & $\begin{array}{l}\text { Foco na experiência da } \\
\text { população negra } \\
\text { estadunidense. } \\
\text { Só a metade dos } \\
\text { instrumentos incluídos } \\
\text { na revisão possuía } \\
\text { propriedades } \\
\text { psicométricas } \\
\text { aceitáveis. }\end{array}$ & $\begin{array}{l}\text { 2) } \\
\text { 3) }\end{array}$ & $\begin{array}{l}\text { São necessários novos } \\
\text { instrumentos que realizem } \\
\text { mensuração mais } \\
\text { detalhada sobre } \\
\text { discriminação racial } \\
\text { percebida em serviços de } \\
\text { saúde. } \\
\text { Esses novos instrumentos } \\
\text { devem ser possíveis de se } \\
\text { aplicar em uma variedade } \\
\text { de grupos étnicos. } \\
\text { Além disso, eles devem } \\
\text { avaliar como o } \\
\text { racismo/discriminação afeta } \\
\text { o processo de decisão no } \\
\text { cuidado à saúde e nos } \\
\text { tratamentos oferecidos. }\end{array}$ & $\begin{array}{l}\text { Kressin, Raymond e Manze (2008) avaliaram a utilidade } \\
\text { de diversas escalas na medida do racismo no contexto } \\
\text { dos serviços de saúde. Dentre os } 37 \text { estudos incluídos, } \\
16 \text { tipos diferentes de escalas de mensuração de } \\
\text { racismo foram identificados. No entanto, muitas dessas } \\
\text { escalas não eram totalmente voltadas para a } \\
\text { mensuração do racismo em serviços de saúde. Ao } \\
\text { invés disso, algumas escalas possuíam perguntas } \\
\text { sobre a experiência do racismo em diversos lugares } \\
\text { (busca por emprego, repartições públicas, etc.), com } \\
\text { alguma pergunta adicional sobre serviço de saúde. As } \\
\text { autoras enfatizaram a falta de propriedades } \\
\text { psicométricas aceitáveis dentre os estudos incluídos. } \\
\text { A principal propriedade psicométrica avaliada foi o } \\
\text { coeficiente Alpha de Cronbach, que mede a } \\
\text { confiabilidade de um instrumento. Aparentemente, este } \\
\text { coeficiente era usado indiscriminadamente, mesmo em } \\
\text { situações que demandavam outros tipos de análises. } \\
\text { Outras propriedades psicométricas também avaliadas } \\
\text { foram as validades de conteúdo, construto e } \\
\text { convergente, a confiabilidade do teste reteste. No } \\
\text { entanto, muitos dos estudos incluídos na revisão } \\
\text { sequer informaram se houve algum tipo de } \\
\text { procedimento psicométrico. Além disso, observou-se } \\
\text { que não houve padronização na forma de apresentar os } \\
\text { resultados referentes à avaliação psicométrica dos } \\
\text { artigos. Na tabela descritiva dos estudos contida no } \\
\text { artigo, as autoras detalham mais alguns estudos em } \\
\text { detrimento de outros. }\end{array}$ \\
\hline $\begin{array}{l}\text { (Bastos et al., } \\
\text { 2010) } \\
\text { Soc Sci Med } \\
70(7): 1091-9\end{array}$ & $\begin{array}{l}\text { Racial } \\
\text { discrimination } \\
\text { and health: A } \\
\text { systematic } \\
\text { review of } \\
\text { scales with a }\end{array}$ & $\begin{array}{l}\text { Revisão } \\
\text { sistemática }\end{array}$ & 24 & & $\begin{array}{l}96 \% \text { das escalas são } \\
\text { dos EUA. } \\
\text { A maioria dos estudos } \\
\text { foi publicada nos } \\
\text { últimos } 12 \text { anos } \\
\text { (contados a partir da }\end{array}$ & 1) & $\begin{array}{l}\text { O uso de terminologia } \\
\text { racial e como ela pode } \\
\text { influenciar experiências de } \\
\text { discriminação autorrelatada } \\
\text { ainda não foi } \\
\text { exaustivamente analisado. }\end{array}$ & $\begin{array}{l}\text { Esta revisão enfocou especificamente as propriedades } \\
\text { psicométricas das escalas envolvidas no estudo e } \\
\text { considerou as seguintes propriedades como } \\
\text { 'aceitáveis': } \\
\text { - Fundamentação teórica explícita }\end{array}$ \\
\hline
\end{tabular}




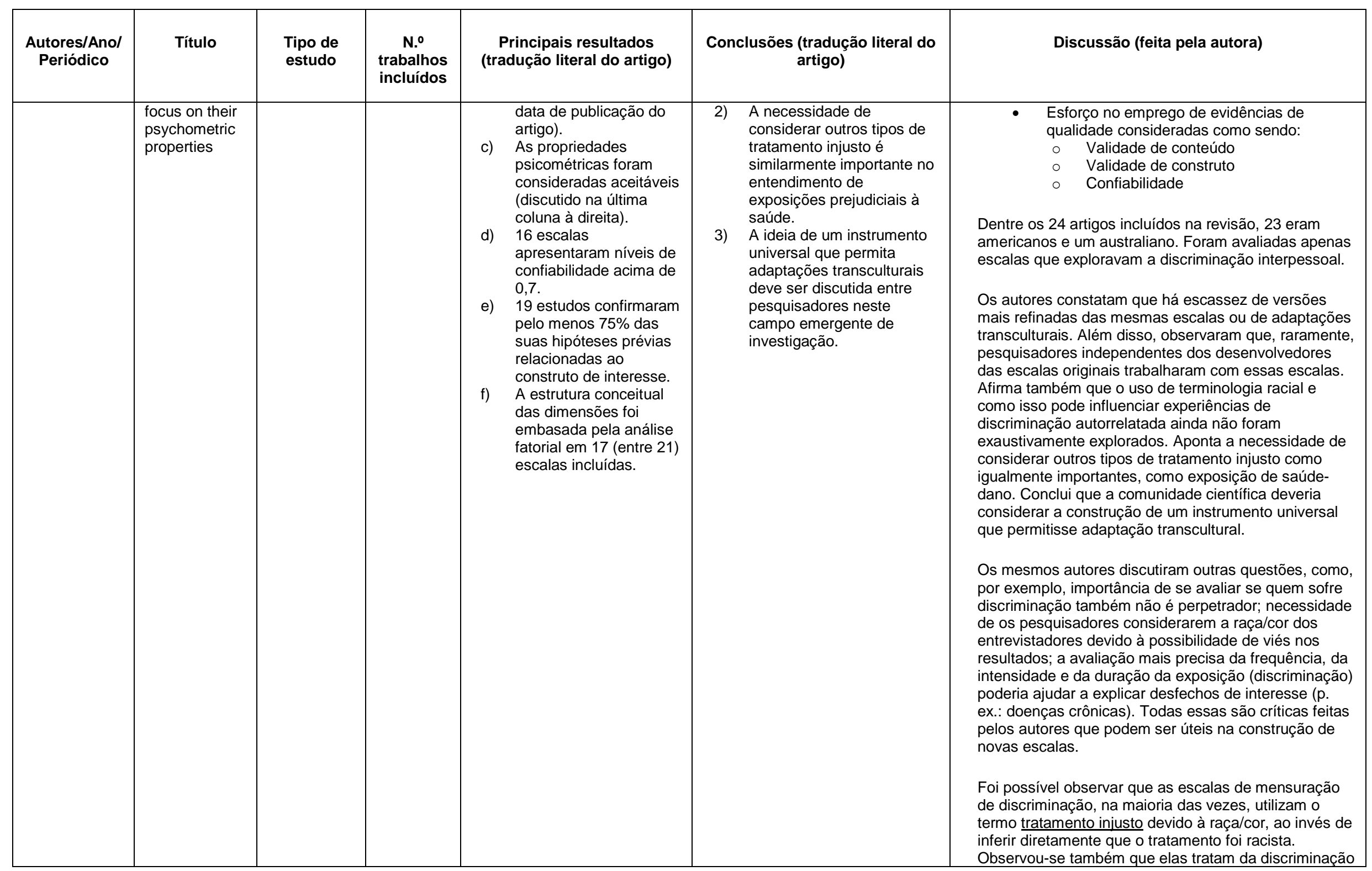




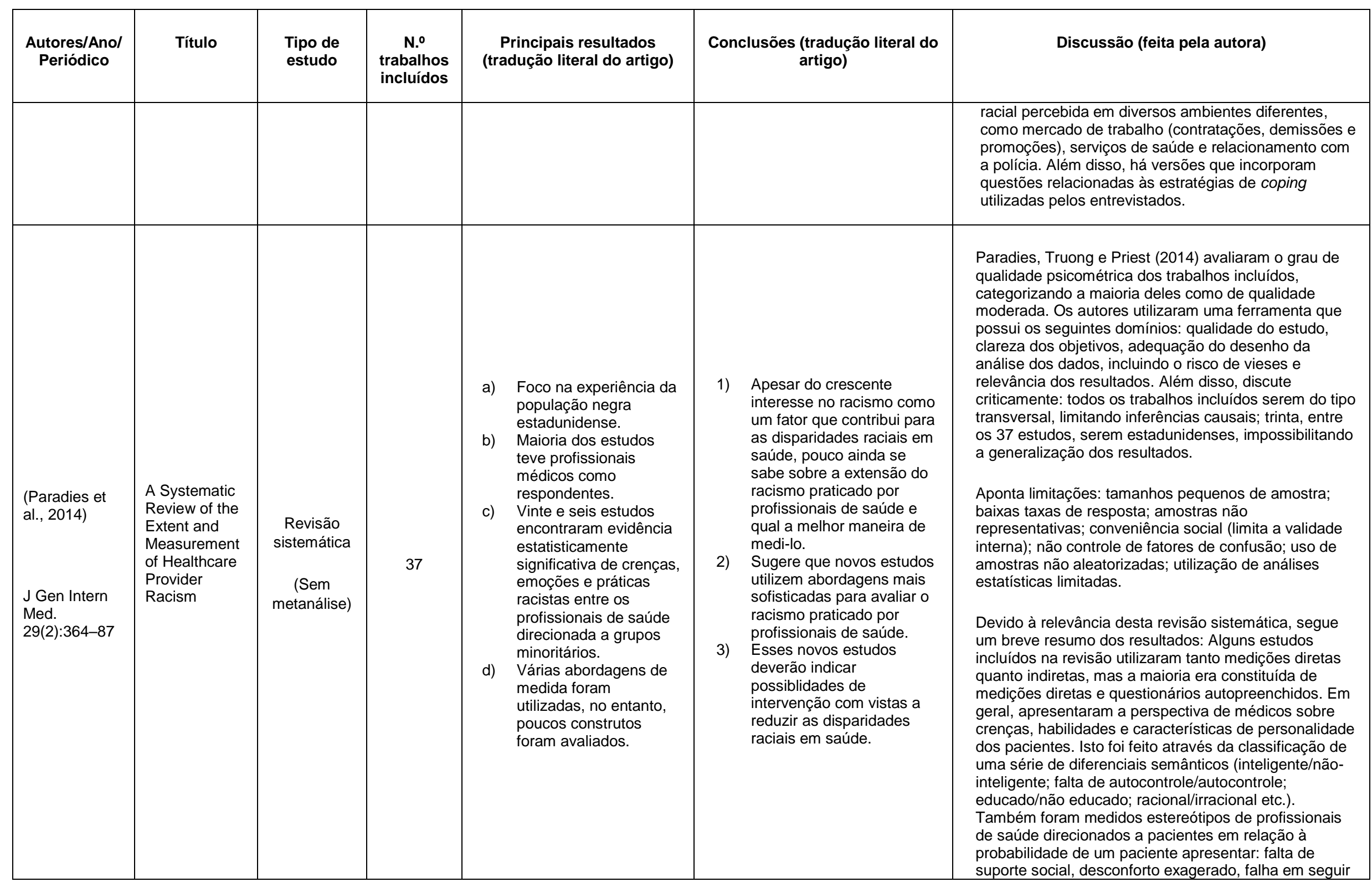




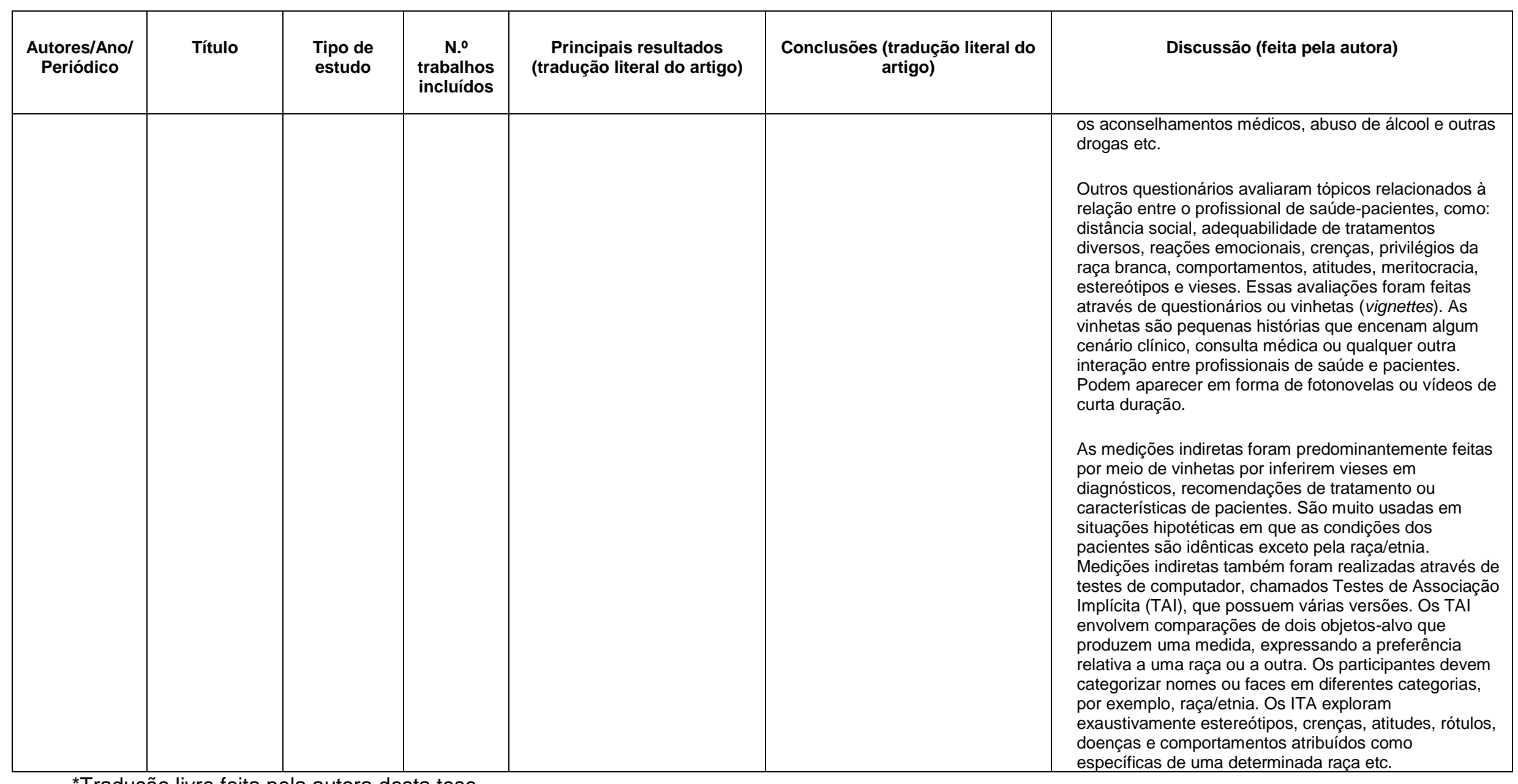

${ }^{*}$ Tradução livre feita pela autora desta tese. 
Os três estudos apresentados no Quadro 1 facilitaram a revisão de literatura para construção do DRISS, pois trouxeram informações já selecionadas da literatura a respeito das escalas sobre racismo e discriminação racial publicadas nas últimas décadas. Esses estudos permitiram também uma visualização geral dos instrumentos de aferição de discriminação existentes, apontaram vantagens, desvantagens, fraquezas e fortalezas dos instrumentos do ponto de vista psicométrico, principalmente. Assim, foi possível selecionar os instrumentos que se alinhavam mais aos objetivos desta tese.

No Quadro 2, são apresentadas as principais escalas incluídas nas revisões de literatura e destacadas as questões que foram extraídas para compor os itens do DRISS. Algumas escalas não foram apresentadas por um ou mais dos seguintes motivos: não possuíam nenhuma questão relevante para o contexto dos serviços de saúde; não estavam presentes nos respectivos artigos; foram solicitadas aos autores, que, por sua vez, não responderam. 
Quadro 2 - Principais escalas utilizadas nos referidos estudos.

\begin{tabular}{|c|c|c|c|}
\hline N.. & $\begin{array}{c}\text { Nome da escala/país de } \\
\text { origem/referência/outras } \\
\text { versões da mesma quando } \\
\text { existentes }\end{array}$ & $\begin{array}{c}\text { Conteúdo da escala (ou questão/questões relevantes para o contexto dos } \\
\text { serviços de saúde) }\end{array}$ & Comentários da autora \\
\hline 1 & $\begin{array}{l}\text { Experiences of } \\
\text { discrimination } \\
\text { EUA } \\
\text { (Krieger, 1990) } \\
\text { Krieger N. Racial and gender } \\
\text { discrimination: Risk factors for } \\
\text { high blood pressure? Soc Sci } \\
\text { Med 1990;30:1273-81. } \\
\text { doi:10.1016/0277- } \\
\text { 9536(90)90307-E. }\end{array}$ & $\begin{array}{l}\text { If you feel you've been treated unfairly, how do you usually respond, do you: } \\
\text {-Accept it as a fact of life? } \\
\text {-Try to do something about it? } \\
\text { And if you've been treated unfairly, do you: } \\
\text {-Talk to other people about it? } \\
\text {-Keep it to yourself? } \\
\text { Have you ever experienced discrimination, been prevented from doing something, } \\
\text { or been hassled or made to feel inferior in any of the following five situations } \\
\text { because you're a woman? (Yes or No) } \\
\text {-At school } \\
\text {-Getting a job } \\
\text {-At work } \\
\text {-At home } \\
\text {-Getting medical care } \\
\text { Have you ever experienced discrimination, been prevented from doing something, } \\
\text { or been hassled or made to feel inferior, in any of the following six situations } \\
\text { because of your race or color? (Yes or No) } \\
\text {-At school } \\
\text {-Getting a job } \\
\text {-At work } \\
\text {-Getting housing } \\
\text {-Getting medical care } \\
\text {-From the police or in the courts }\end{array}$ & $\begin{array}{l}\text { - Destaques em negrito para o uso do } \\
\text { termo 'tratamento injusto'; } \\
\text { - Questionário genérico que pergunta } \\
\text { sobre experiências em diversos } \\
\text { lugares, com itens específicos sobre } \\
\text { locais que ofereçam cuidados à saúde; } \\
\text { - Uso do termo 'por causa da sua raça } \\
\text { ou cor'. }\end{array}$ \\
\hline 2 & $\begin{array}{l}\text { Minority Status Stress Scales } \\
\text { EUA } \\
\text { (Smedley et al., 1993) }\end{array}$ & & \\
\hline
\end{tabular}




\begin{tabular}{|c|c|c|c|}
\hline 4 & $\begin{array}{l}\text { Everyday discrimination } \\
\text { scale } \\
\text { EUA } \\
\text { (Williams et al., 1997) } \\
\text { Williams DR, Yan Yu, Jackson } \\
\text { JS, Anderson NB. Racial } \\
\text { Differences in Physical and } \\
\text { Mental Health: Socio-economic }\end{array}$ & $\begin{array}{l}\text { - Everyday Discrimination Scale com coping } \\
\text { How did you respond to this experience? Please tell me if you did each of the } \\
\text { following things A LOT, SOME, or NOT AT ALL: } \\
\text { 1. Tried to do something about it. } \\
\text { 2. Accepted it as a fact of life. } \\
\text { 3. Worked harder to prove them wrong. } \\
\text { 4. Talked to someone about what to do about the situation. } \\
\text { 5. Didn't let it get to you; refused to think about it too much. } \\
\text { 6. Felt that you brought it on yourself. } \\
\text { 7. Talked to someone about how you were feeling. } \\
\text { 8. Tried to keep your feelings to yourself. }\end{array}$ & $\begin{array}{l}\text { - Algumas respostas foram utilizadas } \\
\text { para compor os itens desta pesquisa } \\
\text { versando sobre os modos de } \\
\text { responder às situações discriminatórias } \\
\text { e as estratégias de coping. }\end{array}$ \\
\hline
\end{tabular}




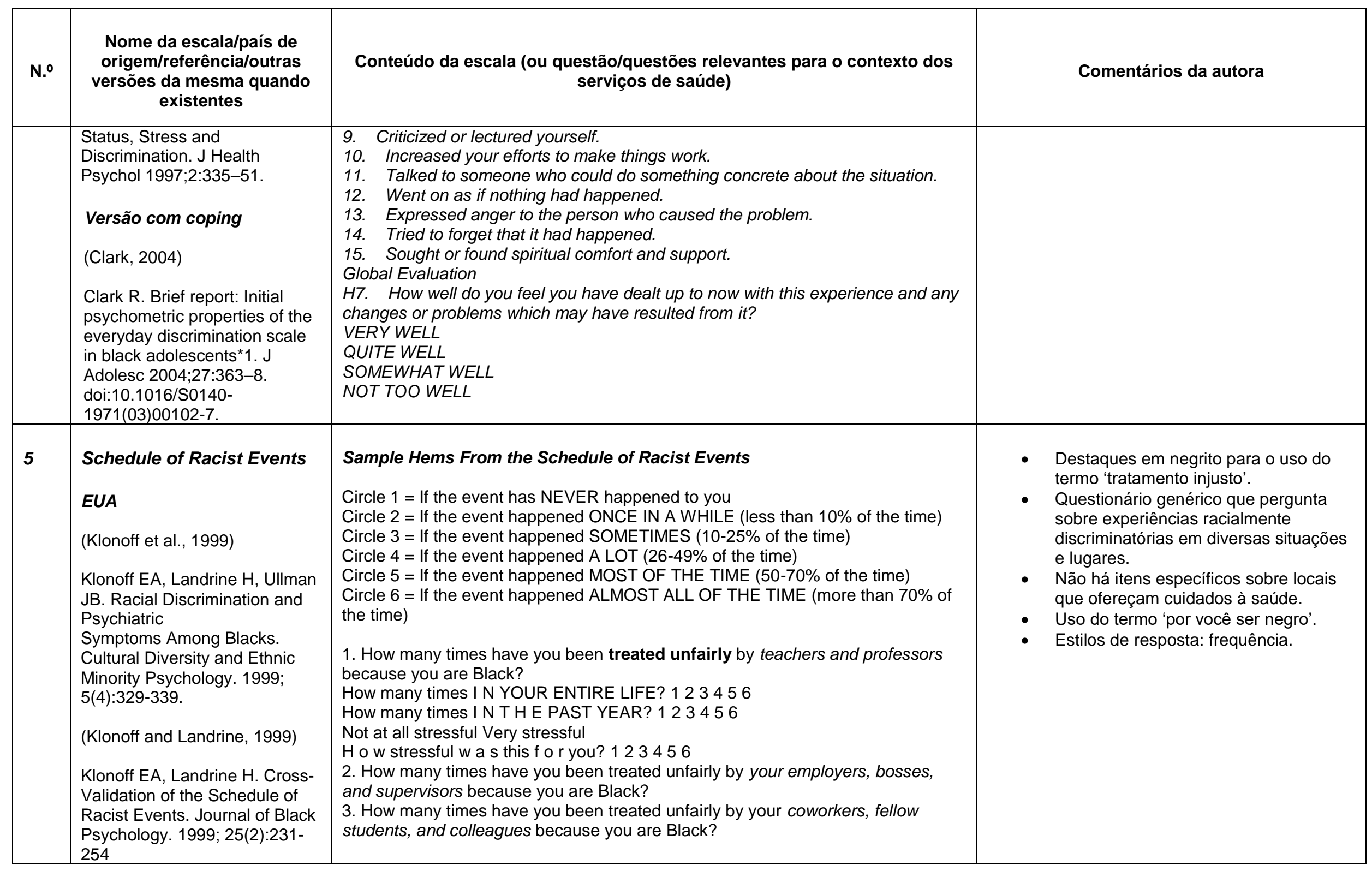




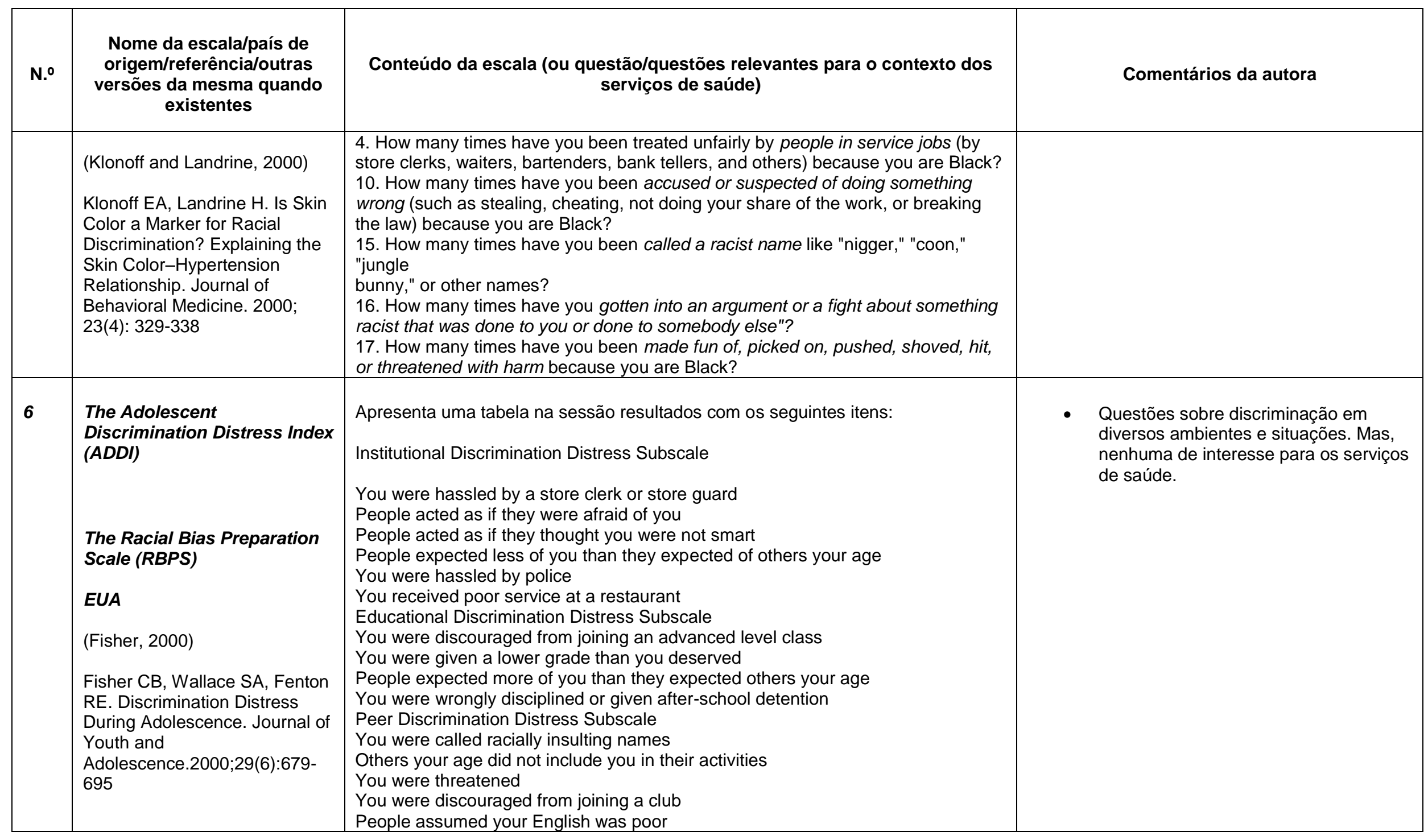




\begin{tabular}{|c|c|c|c|}
\hline N.․ & $\begin{array}{c}\text { Nome da escala/país de } \\
\text { origem/referência/outras } \\
\text { versões da mesma quando } \\
\text { existentes }\end{array}$ & $\begin{array}{c}\text { Conteúdo da escala (ou questão/questões relevantes para o contexto dos } \\
\text { serviços de saúde) }\end{array}$ & Comentários da autora \\
\hline 7 & $\begin{array}{l}\text { Telephone-Administered } \\
\text { Perceived Racism Scale } \\
\text { (TPRS) } \\
\text { EUA } \\
\text { (Vines et al., 2001) } \\
\text { Vines et al. Development and } \\
\text { Reliability of a Telephone- } \\
\text { Administered } \\
\text { Perceived Racism Scale } \\
\text { (TPRS): A Tool for } \\
\text { Epidemiological Use. Ethn Dis. } \\
\text { 2001; 11(2): 251-262. }\end{array}$ & $\begin{array}{l}\text { Apresenta apenas os componentes: } \\
\text { Components of the telephone administered perceived racism scale } \\
\text { Scales Subscales [\# of items] ltems } \\
\text { Experience of racism Personal [15] Respondent assigned menial jobs } \\
\text { Respondent not asked opinions } \\
\text { Respondent watched closely } \\
\text { Respondent assumed promoted because Black } \\
\text { Respondent paid less } \\
\text { Respondent has lower status jobs } \\
\text { Respondent pressured to fit in } \\
\text { Respondent's suggestions worth less } \\
\text { Respondent called insulting names } \\
\text { Respondent followed when shopping } \\
\text { Discriminated against when getting loan } \\
\text { Discriminated against when seeking housing } \\
\text { Discriminated against when needing medical care } \\
\text { Discriminated against in public place(s) } \\
\text { Discriminated against by police } \\
\text { Group Blacks assigned menial jobs } \\
\text { Blacks not asked opinions } \\
\text { Blacks watched closely } \\
\text { Assumed promoted because Black } \\
\text { Blacks are paid less } \\
\text { Blacks have lower status jobs } \\
\text { Blacks pressured to fit in } \\
\text { Blacks' suggestions worth less } \\
\text { Blacks called insulting names } \\
\text { Blacks followed when shopping } \\
\text { Emotional responses } \\
\text { Passive emotions } \\
\text { Hopeless } \\
\text { Powerless } \\
\text { Active emotions }\end{array}$ & $\begin{array}{l}\text { - } \quad \text { Questionário genérico sobre } \\
\text { - } \quad \text { Incluiu perguntas sobre sentimentos } \\
\text { experimentados quando a experiência } \\
\text { discriminatória foi sofrida. } \\
\text { - } \quad \text { Incluiu perguntas sobre estratégias de } \\
\text { enfrentamento quando a experiência } \\
\text { discriminatória foi sofrida. } \\
\text { - Não há itens específicos sobre locais } \\
\text { - } \quad \text { que ofereçam cuidados à saúde. } \\
\text { Estilos de resposta: concordância. }\end{array}$ \\
\hline
\end{tabular}




\begin{tabular}{|c|c|c|c|}
\hline 8 & $\begin{array}{l}\text { Perceived Ethnic } \\
\text { Discrimination } \\
\text { Questionnaire (PEDQ) } \\
\text { EUA } \\
\text { (Contrada et al., 2001) } \\
\text { Contrada et al. Measures of } \\
\text { Ethnicity-Related Stress: } \\
\text { Psychometric Properties, } \\
\text { Ethnic Group Differences, and }\end{array}$ & Não apresenta a escala. & \\
\hline
\end{tabular}




\begin{tabular}{|c|c|c|c|}
\hline 9 & $\begin{array}{l}\text { Race-Related Stressor Scale } \\
\text { for Asian American Veterans } \\
\text { EUA } \\
\text { (Loo et al., 2001) } \\
\text { Loo CM et al. Measuring } \\
\text { Exposure to Racism: } \\
\text { Development and Validation } \\
\text { of a Race-Related Stressor } \\
\text { Scale (RRSS) for Asian } \\
\text { American Vietnam Veterans. } \\
\text { Psychological Assessment. } \\
2001 ; 13(4): 503-520\end{array}$ & & $\begin{array}{l}\text { - Questionário genérico que pergunta } \\
\text { sobre experiências racialmente } \\
\text { discriminatórias em diversas situações } \\
\text { e lugares. } \\
\text { - } \quad \text { Não há itens específicos sobre locais } \\
\text { que ofereçam cuidados à saúde. } \\
\text { - Uso do termo 'por você ser Asian } \\
\text { - American Veterans. } \\
\text { - Estilos de resposta: frequência. }\end{array}$ \\
\hline 10 & $\begin{array}{l}\text { Asian American Racism- } \\
\text { Related Stress Inventory } \\
\text { (AARRSI)- (No livro) } \\
\text { EUA }\end{array}$ & & $\begin{array}{l}\text { Questões sobre discriminação em } \\
\text { diversos ambientes e situações. Mas, } \\
\text { nenhuma de interesse para os serviços } \\
\text { de saúde. }\end{array}$ \\
\hline
\end{tabular}




\begin{tabular}{|c|c|c|c|}
\hline 11 & $\begin{array}{l}\text { Experiences of } \\
\text { Discrimination } \\
\text { EUA } \\
\text { (Krieger et al., 2005) } \\
\text { Krieger et al. Experiences of } \\
\text { discrimination: Validity and } \\
\text { reliability of a self-report } \\
\text { measure for population health } \\
\text { research on racism and health } \\
\text { Social. Science \& } \\
\text { Medicine.2005;61:1576-1596 }\end{array}$ & $\begin{array}{l}\text { Experience of Discrimination (EOD) } \\
\text { Introduction: "This next section is going to ask about how you and others like you } \\
\text { are treated, and how you typically respond" } \\
\text { Response to unfair treatment } \\
\text { If you feel you have been treated unfairly, do you } \\
\text { usually: (please select the best response) } \\
\text { If you have been treated unfairly, do you usually: } \\
\text { (please select the best response) } \\
\text { Discrimination } \\
\text { Have you ever experienced discrimination, been } \\
\text { prevented from doing something, or been hassled } \\
\text { or made to feel inferior in any of the following } \\
\text { situations because of your race, ethnicity, or } \\
\text { color? } \\
\text { (1) At school? } \\
\text { (2) Getting hired or getting a job? } \\
\text { (3) At work? } \\
\text { (4) Getting housing? } \\
\text { (5) Getting medical care? } \\
\text { (6) Getting service in a store or restaurant? } \\
\text { (7) Getting credit, bank loans, or a mortgage? } \\
\text { (8) On the street or in a public setting? } \\
\text { (9) From the police or in the courts? }\end{array}$ & $\begin{array}{l}\text { - Destaques em negrito para o uso do } \\
\text { termo 'tratamento injusto'. } \\
\text { - Questionário genérico que pergunta } \\
\text { sobre experiências em diversos } \\
\text { lugares, com itens específicos sobre } \\
\text { locais que ofereçam cuidados à saúde. }\end{array}$ \\
\hline
\end{tabular}




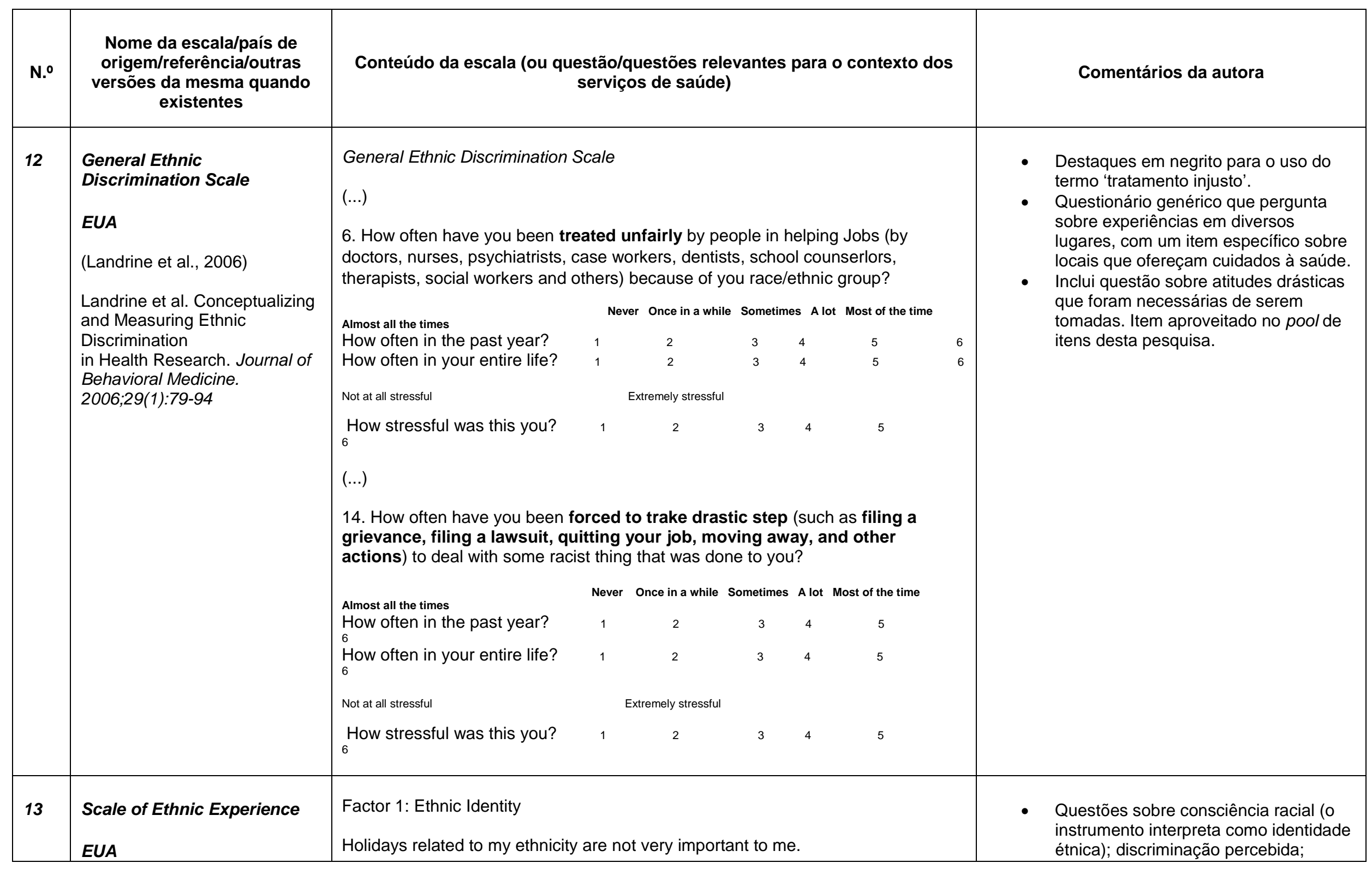




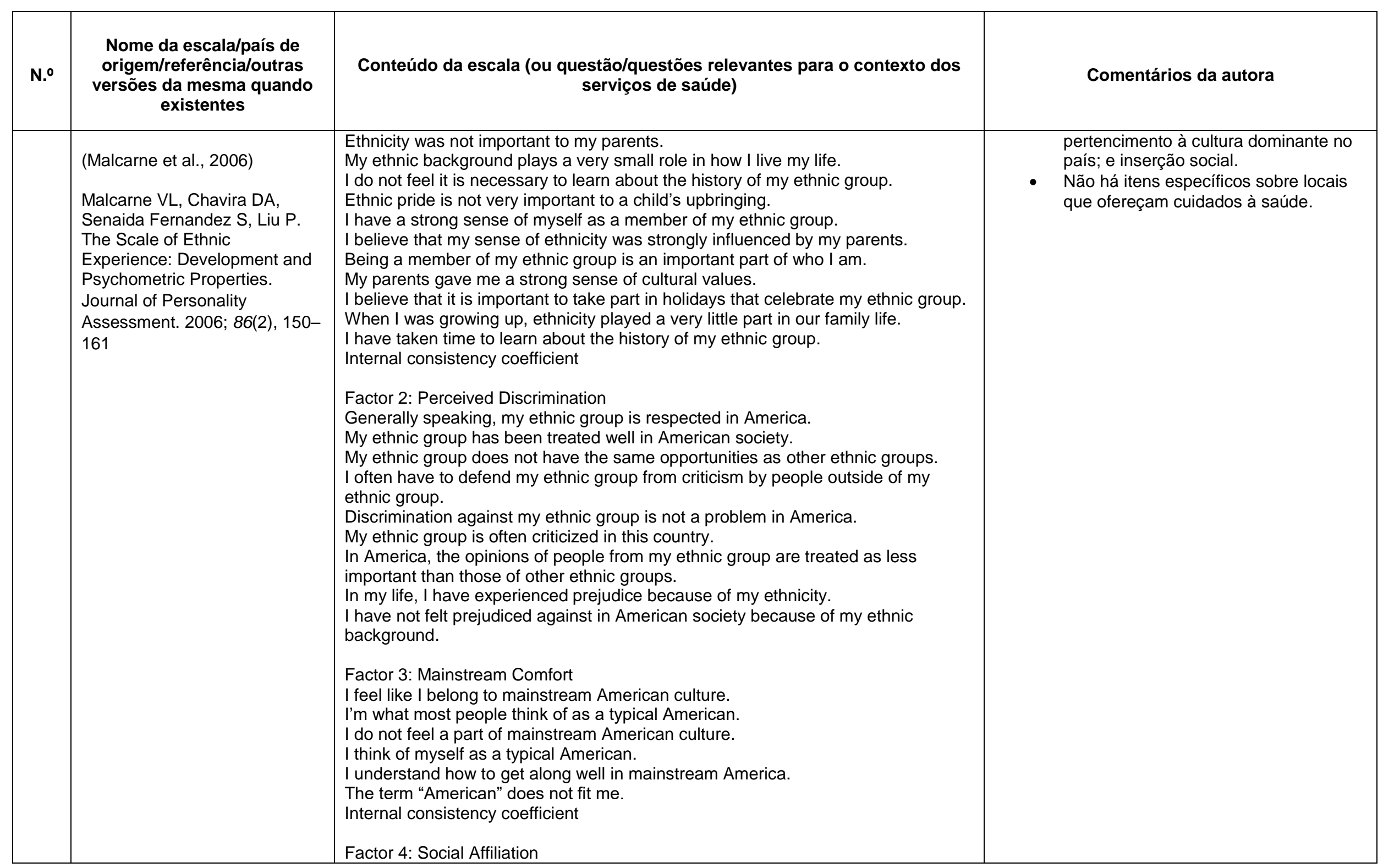




\begin{tabular}{|c|c|c|c|}
\hline 14 & $\begin{array}{l}\text { Escala de Racismo Moderno } \\
\text { EUA (Adaptada para o } \\
\text { português falado no Brasil) } \\
\text { (Santos et al., 2006) } \\
\text { Santos et al. Escala de racismo } \\
\text { moderno: adaptacão ao } \\
\text { contexto brasileiro. Psicologia } \\
\text { em Estudo, Maringá. 2006; } \\
\text { 11(3): 637-645. }\end{array}$ & $\begin{array}{l}\text { Discordo totalmente } 1234567 \text { Concordo totalmente } \\
\text { Eles têm conseguido mais do que merecem } \\
\text { Eles recebem muito respeito e consideração } \\
\text { Eles são muito exigentes em relação aos seus direitos } \\
\text { A discriminação nãa é um problema do Brasil } \\
\text { Eles têm muita influência política } \\
\text { Eles não necessitam de ajuda, apenas devem se esforçar } \\
\text { Eles devem superar o preconceito sem apoio como aconteceu com outros grupos } \\
\text { Eles são mais habilidosos em trabalhos manuais } \\
\text { Possuem maior habilidade culinária } \\
\text { Estão em moda suas danças pela sensualidade que expressam } \\
\text { Tem-se dada demasiada importância aos seus movimentos de protesto } \\
\text { Parece pouco prudente dar importância as suas queixas } \\
\text { Apresentam melhor desempenho em modalidades esportivas } \\
\text { Possuem uma beleza diferente }\end{array}$ & $\begin{array}{l}\text { - Questionário genérico sobre } \\
\text { percepções preconceituosas. } \\
\text { - Não há itens específicos sobre locais } \\
\text { - } \quad \text { Eue ofereçam cuidados à saúde. } \\
\text { - Estilos de resposta: concordância. }\end{array}$ \\
\hline 15 & $\begin{array}{l}\text { Measure of Indigenous } \\
\text { Racism } \\
\text { Experiences (MIRE) } \\
\text { Austrália } \\
\text { (Paradies and Cunningham, } \\
\text { 2008) } \\
\text { Paradies YC, Cunningham J. } \\
\text { International Journal for Equity }\end{array}$ & $\begin{array}{l}\text { Question } 1 \text { (Q1) How often are you treated unfairly because you are Indigenous } \\
\text { in each of the following situations? (If the situation doesn't apply to you, please } \\
\text { tell me) } \\
\text { (a) At work or on the job? } \\
\text { (b) At home, by neighbours or at somebody else's house? } \\
\text { (c) At school, university or other academic setting? } \\
\text { (d)While doing sporting, recreational or leisure activities? } \\
\text { (e) By the police, security personnel, lawyers or in a court of law? } \\
\text { (f) By doctors, nurses or other staff at hospitals or doctors' surgeries? } \\
\text { (g) By staff of government agencies like Centrelink, ATSIC, etc.? }\end{array}$ & $\begin{array}{l}\text { - Destaques em negrito para o uso do } \\
\text { termo 'tratamento injusto'. } \\
\text { - Questionário genérico que pergunta } \\
\text { sobre experiências em diversos } \\
\text { lugares, com itens específicos sobre } \\
\text { locais que ofereçam cuidados à saúde. } \\
\text { - Uso do termo 'por você ser indígena'. } \\
\text { - Uso de vários estilos de resposta } \\
\text { diferentes (frequência, } \\
\text { presença/ausência, concordância). }\end{array}$ \\
\hline
\end{tabular}




\begin{tabular}{|c|c|c|c|}
\hline 16 & $\begin{array}{l}\text { Explicit Discrimination Scale } \\
\text { (EDE) } \\
\text { (Bastos et al., 2012) } \\
\text { Bastos JL et al. Explicit } \\
\text { discrimination and health: } \\
\text { development and psychometric } \\
\text { properties of an assessment } \\
\text { instrument. Rev Saúde Pública } \\
\text { 2012;46(2):269-78 }\end{array}$ & $\begin{array}{l}\text { Questão } 18 \\
\text { Ao frequentar postos de saúde, hospitais, prontos-socorros ou outros serviços de } \\
\text { saúde, você já foi tratado de maneira inferior em relação às outras pessoas lá } \\
\text { presentes? }\end{array}$ & $\begin{array}{l}\text { - Destaque em negrito para o uso do } \\
\text { termo 'tratado de maneira inferior'. } \\
\text { Questionário genérico que pergunta } \\
\text { sobre experiências em diversos } \\
\text { lugares, com um item específico sobre } \\
\text { locais que ofereçam cuidados à saúde. } \\
\text { Estilo de resposta - Primeiro questiona } \\
\text { presença/ausência, depois motivação, } \\
\text { em seguida se o respondente se sentiu } \\
\text { incomodado e por fim se se sentiu } \\
\text { discriminado. }\end{array}$ \\
\hline
\end{tabular}




\begin{tabular}{|c|c|c|c|}
\hline & & 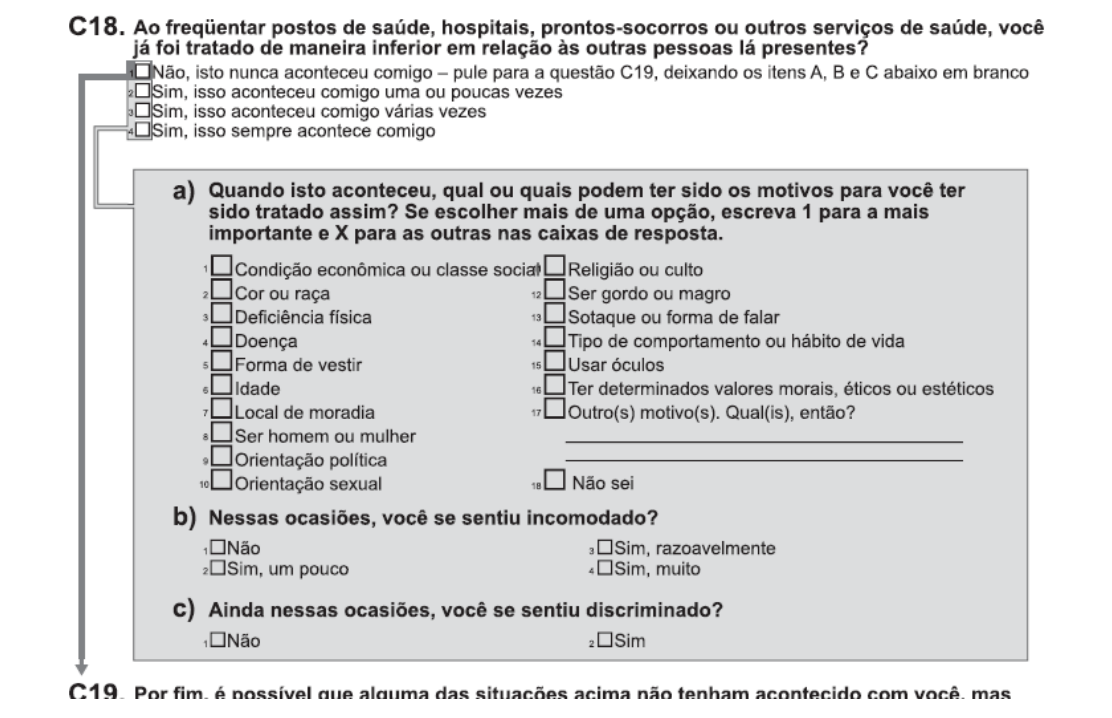 & \\
\hline
\end{tabular}


A partir da revisão de literatura apresentada, observou-se que, dentre os 16 instrumentos considerados, nenhum contempla integralmente o construto "percepção de discriminação racial interpessoal em serviços de saúde, cuja população-alvo fosse os usuários". Desse modo, reitera-se a justificativa para se desenvolver um novo instrumento ao invés de realizar uma adaptação transcultural de uma escala existente, elaborada em outro contexto.

Embora especialistas recomendem o uso de instrumentos já validados em outros contextos, sob o argumento de que o uso de uma mesma escala de maneira padronizada produz resultados comparáveis, o desenvolvimento de novas escalas é justificável quando o construto de interesse ainda não foi contemplado por nenhuma escala existente em determinado contexto ou se as escalas existentes possuírem limitações psicométricas graves (Bastos et al., 2014; DeVellis, 2012; Reichenheim and Moraes, 2007).

Ademais, conforme já explorado em tópicos anteriores, o Brasil possui muitas especificidades culturais, raciais e históricas que lhe imprimem um padrão diverso de outros países nos quais os instrumentos já existentes foram desenvolvidos.

Por fim, o número de ajustes necessários para a adaptação transcultural de uma escala seria tão expressivo que poderia inviabilizar o processo. Assim, considerou-se necessário desenvolver uma nova escala, com base em itens de escalas já existentes e incorporando outros provenientes do estudo qualitativo e da contribuição de especialistas, cuja sistematização do processo será detalhada na metodologia. 



\section{JUSTIFICATIVAS PARA O DESENVOLVIMENTO DO ESTUDO}





\section{JUSTIFICATIVAS PARA O DESENVOLVIMENTO DO ESTUDO}

As justificativas para o desenvolvimento desta tese foram:

a) Não foi encontrado na literatura nenhum instrumento que mensurasse as percepções sobre discriminação racial interpessoal, no contexto específico dos serviços de saúde, e no qual a população-alvo fosse composta por usuários desses serviços.

b) O Brasil possui contextos histórico e racial específicos e complexos, o que, por si só, já demandaria cautela para a execução de uma adaptação transcultural.

c) A maioria dos estudos sobre a relação entre racismo e saúde, publicados em bases de dados internacionais, é de origem estadunidense. É preciso considerar que a construção histórica de raça/cor e a experiência de racismo nos Estados Unidos operam por meio de mecanismos completamente diferentes do Brasil.

d) No Brasil, o mito da democracia racial contribui para invisibilizar o racismo como um aspecto determinante das iniquidades em saúde da população, dificultando sua mensuração e demandando novas estratégias de identificação.

e) O desenvolvimento do instrumento de medida DRISS poderá contribuir com a produção de indicadores importantes para o aprimoramento, o monitoramento e a implementação da PNSIPN.

f) As repercussões do racismo nos serviços de saúde podem ocasionar danos imediatos, crônicos e até fatais na vida das pessoas. Assim, considerou-se relevante enfocar os serviços de saúde na construção do DRISS. 

3 OBJETIVOS 



\section{OBJETIVOS}

\subsection{OBJETIVO GERAL}

Desenvolver e validar um instrumento para mensurar a percepção dos usuários sobre discriminação racial interpessoal no contexto dos serviços de saúde brasileiros.

\subsection{OBJETIVOS ESPECÍFICOS}

1) Verificar as evidências de validade de face, conteúdo e constructo.

2) Verificar evidências de confiabilidade.

3) Identificar fatores socioeconômicos e demográficos associados ao escore final da escala. 

4 METODOLOGIA 



\section{METODOLOGIA}

Trata-se de um estudo do tipo metodológico que visou a construção e a validação psicométrica do instrumento 'Percepção sobre Discriminação Racial Interpessoal no Contexto dos Serviços de Saúde' (DRISS).

Segundo o Dicionário Online Aurélio, psicometria é a "medida dos fenômenos psíquicos" (Aurélio, 2017). Trata-se uma ciência originária da psicologia, embora não seja atribuição exclusiva dos profissionais dessa área. Visa transformar pensamentos, crenças, emoções, sentimentos e fenômenos em valor numérico, possibilitando, assim, proceder com análises estatísticas. Para Pasquali (2009), "psicometria representa a teoria e a técnica de medida dos processos mentais, especialmente aplicada nas áreas da psicologia e da educação" (Pasquali, 2009).

Os procedimentos metodológicos deste estudo estão ancorados na Teoria Clássica dos Testes (TCT) (Sartes, Souza-Formigoni, 2013) Segundo DeVellis (2012), o ato de medir é característica fundamental da ciência, sendo que o processo de medir deve ser realizado com qualidade, que, por sua vez, é alcançada por meio de rigor metodológico (DeVellis, 2012).

A TCT é uma das teorias que fundamentam a psicometria. Refere-se a um conjunto de procedimentos que fundamentam o desenvolvimento de instrumentos de medida (DeVellis, 2006; Sartes, Souza-Formigoni, 2013). Destacam-se dois postulados importantes relacionados à TCT: o primeiro refere-se ao resultado do teste feito pelo indivíduo $(\mathrm{X})$, que é resultante da soma do valor verdadeiro (V: valor real ou escore verdadeiro), mais o erro de medida associado a esse resultado (E: erro aleatório, ou seja: $X=V+E$ ); o segundo postulado indica que o resultado esperado é o resultado verdadeiro, o que significa que a precisão do eventual resultado aumenta conforme aumenta o número de observações. Assim, na TCT, os erros aleatórios devem ser independentes em qualquer circunstância (DeVellis, 2006; Sartes, SouzaFormigoni, 2013). Na TCT, também é necessário analisar um conjunto de itens, visando selecionar os que representarão melhor o fenômeno sob investigação. Em suma, trata-se de um processo que pode ser realizado por meio das validações conteúdo e constructo - que serão descritos com mais detalhes posteriormente. 
Isto posto, os procedimentos metodológicos são apresentados em cinco etapas: 1) elaboração dos itens do DRISS; 2) procedimentos adotados para as validações, conteúdo e constructo; 3) procedimentos adotados para a verificação da confiabilidade; 4) escorificação (cálculo do escore fatorial); 5) análise da distribuição do escore segundo os aspectos sociodemográficos da amostra.

\subsection{ETAPA 1 - A ELABORAÇÃO DOS ITENS DO DRISS}

Para o desenvolvimento de um instrumento de medida, foram seguidos os seguintes passos (DeVellis, 2012; Furr, 2015): 1) fundamentação teórica; 2) Versão 1 do DRISS - a elaboração do pool de itens; e 3) escolha do estilo de respostas.

\subsubsection{Fundamentação teórica}

A fundamentação teórica é o passo inicial para a construção de um novo instrumento. Deve ser baseada, primordialmente, em dois pilares: revisão de literatura e estudo qualitativo. Neste trabalho, foi adicionado mais um pilar: opinião de especialistas (DeVellis, 2012) (Figura 1).

Figura 1 - Pilares da fundamentação teórica do DRISS.

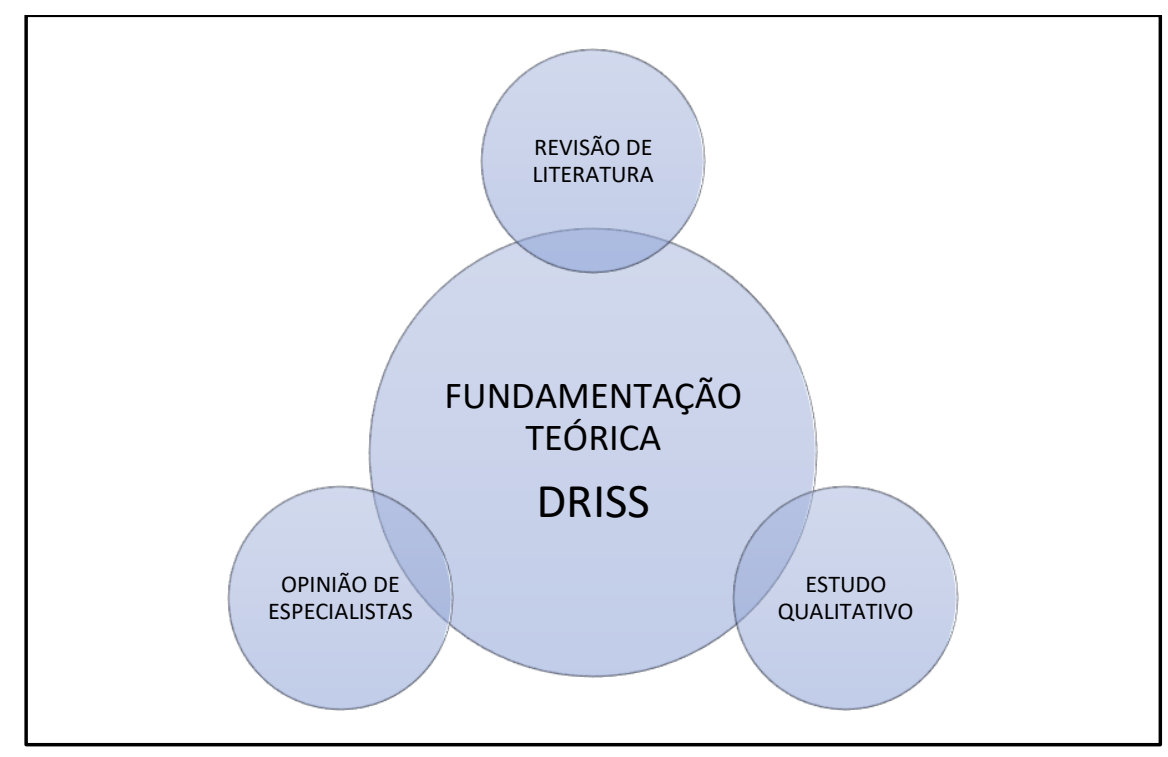


Como primeiro passo, procedeu-se à revisão de literatura para identificar se há escalas elaboradas para medir o fenômeno de interesse. Em seguida, verificou-se se o fenômeno é passível de ser observado indiretamente (Reichenheim, Moraes, 2007; DeVellis, 2012; Bastos et al., 2014). Todas essas etapas foram realizadas adequadamente e a revisão de literatura das escalas encontra-se no subcapítulo "Revisão da literatura sobre instrumentos de mensuração de discriminação racial".

Vale lembrar que os itens (questões) que compõem o instrumento devem indicar o caminho para o entendimento da variável latente, porém, sem fazer menção direta a ela (DeVellis, 2012). Exemplificando: o DRISS visa medir 'percepção sobre discriminação racial no contexto de serviços de saúde'. No entanto, em nenhum item, o termo 'discriminação racial' foi utilizado, pois se trata da variável latente que se deseja mensurar.

Quanto ao segundo pilar, para a fundamentação teórica da construção de um novo instrumento, um estudo qualitativo deve ser utilizado (Reichenheim, Moraes, 2007; DeVellis, 2012). Estudos qualitativos com o propósito de fundamentar a construção de instrumentos devem ser provenientes de dados coletados de grupo focais ou de entrevistas em profundidade. Isto porque, entende-se que o fenômeno é melhor observado por quem está diretamente relacionado a ele; ou seja, a população-alvo.

A partir dessa premissa, o estudo qualitativo utilizado nesta tese foi a dissertação de mestrado: 'Mulheres negras, o cuidado com a saúde e a busca por assistência: estudo etnográfico em uma comunidade de baixa renda' (Santa Rosa, 2013). Trata-se de uma etnografia realizada em um bairro de baixa renda, com grande proporção de residentes autodeclarados como negros, na periferia da cidade de São Paulo. O estudo foi baseado nos discursos de vinte mulheres, autodeclaradas negras. Os discursos revelaram que as experiências das mulheres sobre discriminação racial interpessoal em serviços de saúde eram, majoritariamente, relacionadas à interação usuária-profissional de saúde. Essas vivências variavam entre experiências pessoais ou testemunhadas. As informantes do estudo, em face ao ato racialmente discriminatório perpetrado por profissionais de saúde, relataram vivenciar sentimentos diversos que podiam variar de 'guardar para si mesmas' até desenvolver sintomas físicos. Tais sentimentos culminavam em reações que podiam se manifestar por meio de silêncio, estratégias de coping ou outras atitudes, tais como fazer um escândalo ou denunciar às autoridades. 
Dessa forma, os achados da dissertação coincidiram com outros trabalhos encontrados na literatura - inclusive, pareciam estar sintetizados em alguns itens de instrumentos já existentes e validados em outros contextos (Krieger, 1990; Paradies, Cunningham, 2008). Os achados inéditos foram usados para elaborar outros itens não vislumbrados nas escalas existentes, como a adoção de cuidados adicionais com a aparência antes de ir a um serviço de saúde (por exemplo: depilação e escolha cuidadosa das roupas), pré-disposição para não reclamar do atendimento recebido por medo de ser negligenciada, maltratada ou abandonada, entre outros. Essas informações compuseram a elaboração de alguns itens do DRISS.

Em relação ao terceiro pilar da fundamentação teórica, a elaboração do DRISS contou com a sugestão dos membros do Grupo de Pesquisa Núcleo Interdisciplinar de Estudos sobre Desigualdades em Saúde (NUDES) da Universidade Estadual de Feira de Santana (UEFS), na Bahia, sob coordenação da Profa. Dra. Edna Maria de Araújo - co-orientadora deste trabalho. Esse grupo desenvolve pesquisas na área de desigualdades étnico-raciais em saúde. Assim, estabeleceu-se uma parceria de pesquisa, em que o projeto que originou esta tese compõe o 'subprojeto 3' de um projeto maior apoiado pelo Conselho Nacional de Desenvolvimento Científico e Tecnológico. Em 2015, o pool de itens inicial foi apresentado ao NUDES, contendo os itens provenientes da revisão de literatura e do estudo qualitativo. Naquele momento, professores mestres, doutores e alunos de pós-graduação fizeram importantes contribuições para a elaboração do instrumento.

\subsubsection{Versão 1 do DRISS - A elaboração do pool de itens}

Para DeVellis (2012), o pool de itens é um conjunto de itens que deve ser construído, considerando a maior abrangência teórica possível sobre um determinado fenômeno a ser investigado. A criatividade do pesquisador para compor esse pool de itens é permitida e recomendada. Preferencialmente, o pool de itens deve atingir a quantidade de quatro vezes mais a quantidade de itens que se pretende manter ao final do processo de desenvolvimento do instrumento. Para o mesmo autor, se o objeto de estudo for de difícil exploração, há que se ter um pool de itens de, pelo menos, 
$50 \%$ a mais do que a quantidade total que permanecerá na versão final. A redundância é desejável nessa fase e pode se manifestar por meio de diferentes maneiras de expressar a mesma ideia - como, por exemplo, com estruturas gramaticais diferentes (DeVellis, 2012).

O pool de itens deve refletir o modelo teórico estabelecido e o constructo de interesse. Na construção dos itens, sugere-se que se inicie com um trecho que parafraseie o construto (DeVellis, 2012). Assim, para a construção do texto introdutório do DRISS, utilizou-se como modelo o texto introdutório de um instrumento já existente, o Measure of Indigenous Racism Experiences (MIRE) (Paradies, Cunningham, 2008).

Há várias outras recomendações consideradas fundamentais para a construção do pool de itens. Por exemplo, os itens não devem ser ambíguos, não podem gerar dilemas nos respondentes, não podem ser longos demais, deve-se evitar palavras desnecessárias, utilizar grau de dificuldade mediana de redação, evitar a inclusão de duas ou mais ideias no mesmo item, evitar múltiplas negativas no mesmo item, evitar "sujeitos genéricos" ou ambíguos e preferir formas substantivas às adjetivas (DeVellis, 2012).

Partindo desses pressupostos, foi necessário, por exemplo, dividir um item, extraído do MIRE (Paradies, Cunningham, 2008): "Eu ignoro, esqueço ou aceito o que aconteceu como um fato que faz parte da vida", pois contém três ações na mesma sentença. Esse item inspirou a elaboração de três itens separadamente: a. Eu ignoro (1); b. Eu esqueço (2); c. Encaro como um acontecimento que faz parte da vida (4) (Quadro 1).

\subsubsection{Dimensionalidade do DRISS}

Antecipadamente, esperava-se que o DRISS fosse um instrumento multidimensional, devido à natureza multitemática apresentada pela teoria que versou sobre reações, experiências, sentimentos, entre outros, em face ao tratamento injusto devido à raça/cor da pele. Assim, foi solicitado aos membros do comitê de especialistas, sobre o qual será tratado mais adiante, que opinassem qualitativamente sobre a dimensionalidade que eles atribuiriam para cada item. Contudo, sabia-se que 
essa dimensionalidade também poderia ser avaliada durante análises estatísticas posteriores (análise fatorial exploratória).

\subsubsection{Escolha do estilo de resposta}

Outra questão relevante é a escolha do estilo de respostas do instrumento (DeVellis, 2012). Para isso, foi necessário decidir se o instrumento iria mensurar presença/ausência, concordância/discordância ou frequência do fenômeno sob investigação. Assim, partiu-se do entendimento de que a discriminação racial ocorre no contexto dos serviços de saúde, ou seja, que o fenômeno já existe. Portanto, buscou-se mensurar a 'frequência' das experiências, dos sentimentos, das reações e das atitudes. Desse modo, optou-se pelo seguinte grupo de respostas: 1 = raramente; 2 = algumas vezes; 3 = muitas vezes; 4 = quase sempre; 5 = sempre. Isso posto, 0 pool de itens foi elaborado (versão 1 do DRISS - Quadro 3), inicialmente com vistas a refletir, de maneira mais abrangente possível, o fenômeno DRISS. 
Quadro 3 - Pool de itens da versão 1 do DRISS, segundo a categoria de resposta e a fonte, São Paulo, 2017.

\begin{tabular}{|c|c|c|c|c|c|c|}
\hline $\begin{array}{l}\text { Quando eu sou tratada/o } \\
\text { de maneira injusta devido } \\
\text { a minha raça/cor da pele, } \\
\text { eu: }\end{array}$ & $\begin{array}{l}\text { Rara- } \\
\text { mente }\end{array}$ & $\begin{array}{l}\text { Algumas } \\
\text { vezes }\end{array}$ & $\begin{array}{l}\text { Muitas } \\
\text { vezes }\end{array}$ & $\begin{array}{l}\text { Quase } \\
\text { sempre }\end{array}$ & Sempre & Fonte \\
\hline 1. Ignoro & & & & & & \multirow{7}{*}{$\begin{array}{l}\text { Experiences of } \\
\text { Discrimination } \\
\text { e } \\
\text { Measure of Indigenous } \\
\text { Racism Experiences } \\
\text { (Krieger, 1990; Paradies, } \\
\text { Cunningham, 2008) }\end{array}$} \\
\hline $\begin{array}{l}\text { 2. Encaro como um } \\
\text { acontecimento que faz } \\
\text { parte da vida }\end{array}$ & & & & & & \\
\hline $\begin{array}{l}\text { 3. Converso com alguma } \\
\text { pessoa, como um } \\
\text { familiar, ou amigo, } \\
\text { sobre o que } \\
\text { aconteceu }\end{array}$ & & & & & & \\
\hline $\begin{array}{l}\text { 4. Esqueço o que } \\
\text { aconteceu }\end{array}$ & & & & & & \\
\hline $\begin{array}{ll}\text { 5. Escrevo sobre o que } \\
\text { aconteceu }\end{array}$ & & & & & & \\
\hline $\begin{array}{l}\text { 6. Desenho sobre o que } \\
\text { aconteceu }\end{array}$ & & & & & & \\
\hline $\begin{array}{l}\text { 7. Canto sobre o que } \\
\text { aconteceu }\end{array}$ & & & & & & \\
\hline $\begin{array}{l}\text { 8. Pinto sobre o que } \\
\text { aconteceu }\end{array}$ & & & & & & \\
\hline $\begin{array}{l}\text { 9. Faço uma oração (ou } \\
\text { rezo) pela situação. }\end{array}$ & & & & & & \\
\hline $\begin{array}{l}\text { 10. Guardo isso para mim } \\
\text { mesma/o }\end{array}$ & & & & & & \\
\hline $\begin{array}{l}\text { 11. Reclamo em voz baixa } \\
\text { com as pessoas que } \\
\text { estão próximas a mim }\end{array}$ & & & & & & $\begin{array}{l}\text { Dissertação (Santa Rosa, } \\
\text { 2013) }\end{array}$ \\
\hline 12. Reclamo em voz alta & & & & & & \\
\hline $\begin{array}{l}\text { 13. Faço um "barraco" } \\
\text { (escândalo) }\end{array}$ & & & & & & \\
\hline $\begin{array}{l}\text { 14. Denuncio para as } \\
\text { autoridades (por } \\
\text { exemplo: polícia, abro } \\
\text { um processo na } \\
\text { justiça) }\end{array}$ & & & & & & \\
\hline 15. Me sinto humilhada/o & & & & & & Especialistas NUDES \\
\hline 16. Me sinto impotente & & & & & & \\
\hline 17. Sinto raiva & & & & & & \\
\hline $\begin{array}{l}\text { 18. Sinto algum sintoma } \\
\text { físico, como: dores de } \\
\text { cabeça, de estômago, } \\
\text { tensão nos músculos, } \\
\text { ou palpitação no } \\
\text { coração }\end{array}$ & & & & & & $\begin{array}{l}\text { MIRE } \\
\text { (Paradies, Cunningham, } \\
\text { 2008) }\end{array}$ \\
\hline $\begin{array}{l}\text { 19. Sinto medo de ter que } \\
\text { esperar mais do que o } \\
\text { normal para ser } \\
\text { atendida/o }\end{array}$ & & & & & & $\begin{array}{l}\text { Dissertação (Santa Rosa, } \\
\text { 2013) }\end{array}$ \\
\hline
\end{tabular}




\begin{tabular}{|c|c|c|c|c|c|c|}
\hline $\begin{array}{l}\text { Quando eu sou tratada/o } \\
\text { de maneira injusta devido } \\
\text { a minha raça/cor da pele, } \\
\text { eu: }\end{array}$ & $\begin{array}{l}\text { Rara- } \\
\text { mente }\end{array}$ & $\begin{array}{l}\text { Algumas } \\
\text { vezes }\end{array}$ & $\begin{array}{l}\text { Muitas } \\
\text { vezes }\end{array}$ & $\begin{array}{l}\text { Quase } \\
\text { sempre }\end{array}$ & Sempre & Fonte \\
\hline \multicolumn{7}{|l|}{$\begin{array}{l}\text { 20. Sinto medo de ser } \\
\text { humilhada/o }\end{array}$} \\
\hline \multicolumn{7}{|l|}{$\begin{array}{l}\text { 21. Sinto medo de ser } \\
\text { maltratada/o }\end{array}$} \\
\hline $\begin{array}{l}\text { 22. Sinto medo de não ser } \\
\text { atendida/o }\end{array}$ & & & & & & Especialistas NUDES \\
\hline $\begin{array}{l}\text { 23. Sinto medo de receber } \\
\text { medicamento errado }\end{array}$ & & & & & & \multirow[t]{2}{*}{$\begin{array}{l}\text { Dissertação (Santa Rosa, } \\
\text { 2013) }\end{array}$} \\
\hline $\begin{array}{l}\text { 24. Sinto medo de receber } \\
\text { tratamento errado }\end{array}$ & & & & & & \\
\hline \multicolumn{7}{|c|}{ Com o objetivo de evitar ser tratada/o injustamente devido à minha raça/cor de pele, eu: } \\
\hline $\begin{array}{l}\text { 25. Tomo cuidados } \\
\text { adicionais com a } \\
\text { aparência (higiene, } \\
\text { depilação...) }\end{array}$ & 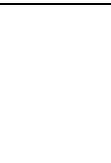 & 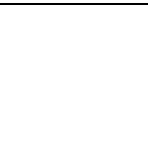 & 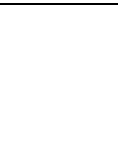 & 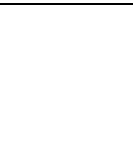 & +2 & \multirow[t]{2}{*}{$\begin{array}{l}\text { Dissertação (Santa Rosa, } \\
\text { 2013) }\end{array}$} \\
\hline $\begin{array}{l}\text { 26. Vou predisposta/o a } \\
\text { não reclamar do } \\
\text { atendimento, mesmo } \\
\text { se eu estiver sofrendo } \\
\text { ou com dor }\end{array}$ & & & & & & \\
\hline $\begin{array}{l}\text { 27. Mudo o local de } \\
\text { atendimento }\end{array}$ & & & & & & \multirow[t]{2}{*}{ Especialistas NUDES } \\
\hline $\begin{array}{l}\text { 28. Não busco mais } \\
\text { atendimento }\end{array}$ & & & & & & \\
\hline \multicolumn{7}{|l|}{ Na minha opinião: } \\
\hline $\begin{array}{l}\text { 29. Os homens brancos } \\
\text { são os que mais } \\
\text { recebem tratamento } \\
\text { injusto nos serviços de } \\
\text { saúde }\end{array}$ & & & & & & \multirow[t]{6}{*}{$\begin{array}{l}\text { Dissertação (Santa Rosa, } \\
\text { 2013) }\end{array}$} \\
\hline \multicolumn{6}{|l|}{$\begin{array}{l}\text { 30. As mulheres brancas } \\
\text { são as que mais } \\
\text { recebem tratamento } \\
\text { injusto nos serviços de } \\
\text { saúde }\end{array}$} & \\
\hline \multicolumn{6}{|l|}{$\begin{array}{l}\text { 31. Os homens asiáticos } \\
\text { são os que mais } \\
\text { recebem tratamento } \\
\text { injusto nos serviços de } \\
\text { saúde }\end{array}$} & \\
\hline \multicolumn{6}{|l|}{$\begin{array}{l}\text { 32. As mulheres asiáticas } \\
\text { são as que mais } \\
\text { recebem tratamento } \\
\text { injusto nos serviços de } \\
\text { saúde }\end{array}$} & \\
\hline \multicolumn{6}{|l|}{$\begin{array}{l}\text { 33. Os homens pardos } \\
\text { são os que mais } \\
\text { recebem tratamento } \\
\text { injusto nos serviços de } \\
\text { saúde }\end{array}$} & \\
\hline $\begin{array}{l}\text { 34. As mulheres pardas } \\
\text { são as que mais }\end{array}$ & & & & & & \\
\hline
\end{tabular}




\begin{tabular}{|c|c|c|c|c|c|c|}
\hline $\begin{array}{l}\text { Quando eu sou tratada/o } \\
\text { de maneira injusta devido } \\
\text { a minha raça/cor da pele, } \\
\text { eu: }\end{array}$ & $\begin{array}{l}\text { Rara- } \\
\text { mente }\end{array}$ & $\begin{array}{l}\text { Algumas } \\
\text { vezes }\end{array}$ & $\begin{array}{l}\text { Muitas } \\
\text { vezes }\end{array}$ & $\begin{array}{l}\text { Quase } \\
\text { sempre }\end{array}$ & Sempre & Fonte \\
\hline $\begin{array}{l}\text { recebem tratamento } \\
\text { injusto nos serviços de } \\
\text { saúde }\end{array}$ & & & & & & \\
\hline $\begin{array}{l}\text { 35. Os homens pretos são } \\
\text { os que mais recebem } \\
\text { tratamento injusto nos } \\
\text { serviços de saúde }\end{array}$ & & & & & & \\
\hline $\begin{array}{l}\text { 36. As mulheres pretas } \\
\text { são as que mais } \\
\text { recebem tratamento } \\
\text { injusto nos serviços de } \\
\text { saúde }\end{array}$ & & & & & & \\
\hline $\begin{array}{l}\text { 37. Os homens indígenas } \\
\text { são os que mais } \\
\text { recebem tratamento } \\
\text { injusto nos serviços de } \\
\text { saúde }\end{array}$ & & & & & & \\
\hline $\begin{array}{l}\text { 38. As mulheres } \\
\text { indígenas são as que } \\
\text { mais recebem } \\
\text { tratamento injusto nos } \\
\text { serviços de saúde }\end{array}$ & & & & & & \\
\hline \multicolumn{7}{|c|}{$\begin{array}{l}\text { Eu costumo me sentir tratada/o injustamente devido à minha raça/cor da pele quando, entre os } \\
\text { profissionais de saúde (médicos, enfermeiras, atendentes etc.) }\end{array}$} \\
\hline $\begin{array}{l}\text { 39. Há só pessoas de } \\
\text { raça/cor da pele } \\
\text { brancas }\end{array}$ & & & & & & \multirow[t]{6}{*}{$\begin{array}{l}\text { Recomendação da } \\
\text { literatura (Beard, Volcy, } \\
\text { 2013) }\end{array}$} \\
\hline $\begin{array}{l}\text { 40. Há só pessoas de } \\
\text { raça/cor da pele } \\
\text { pretos e pardos }\end{array}$ & & & & & & \\
\hline $\begin{array}{l}\text { 41. Há só pessoas de } \\
\text { raça/cor da pele } \\
\text { brancas e asiáticas }\end{array}$ & & & & & & \\
\hline $\begin{array}{l}\text { 42. Há só pessoas de } \\
\text { raça/cor da pele } \\
\text { brancas, asiáticas e } \\
\text { pardas }\end{array}$ & & & & & & \\
\hline $\begin{array}{l}\text { 43. Há só pessoas de } \\
\text { raça/cor da pele } \\
\text { brancas, asiáticas, } \\
\text { pardas e pretas }\end{array}$ & & & & & & \\
\hline $\begin{array}{l}\text { 44. Há pessoas de todas } \\
\text { as raças e cores }\end{array}$ & & & & & & \\
\hline $\begin{array}{l}\text { 45. Eu já presenciei um/a } \\
\text { familiar, parente ou } \\
\text { amiga/o ser tratada/o } \\
\text { injustamente devido à } \\
\text { raça/cor da pele em } \\
\text { serviços de saúde? }\end{array}$ & & & & & & \multirow[t]{2}{*}{$\begin{array}{l}\text { Dissertação (Santa Rosa, } \\
\text { 2013) }\end{array}$} \\
\hline $\begin{array}{l}\text { 46. Eu já presenciei } \\
\text { outras pessoas serem } \\
\text { tratadas injustamente }\end{array}$ & & & & & & \\
\hline
\end{tabular}




\begin{tabular}{|l|l|l|l|l|l|l|}
\hline $\begin{array}{l}\text { Quando eu sou tratada/o } \\
\text { de maneira injusta devido } \\
\text { a minha raça/cor da pele, } \\
\text { eu: }\end{array}$ & $\begin{array}{l}\text { Rara- } \\
\text { mente }\end{array}$ & $\begin{array}{l}\text { Algumas } \\
\text { vezes }\end{array}$ & $\begin{array}{l}\text { Muitas } \\
\text { vezes }\end{array}$ & $\begin{array}{l}\text { Quase } \\
\text { sempre }\end{array}$ & Sempre & Fonte \\
\hline $\begin{array}{l}\text { devido à raça/cor da } \\
\text { pele em serviços de } \\
\text { saúde? }\end{array}$ & & & & & & \\
\hline $\begin{array}{l}\text { 47. Eu já me senti } \\
\text { tratada/o com } \\
\text { privilégios devido à } \\
\text { minha raça/cor da } \\
\text { pele em serviços de } \\
\text { saúde }\end{array}$ & & & & & & $\begin{array}{l}\text { Recomendação da } \\
\text { literatura (Paradies, } \\
\text { Truong, Priest, 2014) }\end{array}$ \\
\hline $\begin{array}{l}\text { 48. Eu já vi um/a familiar, } \\
\text { parente ou amigo/a } \\
\text { ser tratada/o com } \\
\text { privilégios devido à } \\
\text { raça/cor da pele em } \\
\text { serviços de saúde }\end{array}$ & & & & & & \\
\hline $\begin{array}{l}\text { 49. Eu já vi um/a } \\
\text { desconhecido/a ser } \\
\text { tratada/o com } \\
\text { privilégios devido à } \\
\text { raça/cor da pele em } \\
\text { serviços de saúde }\end{array}$ & & & & & & \\
\hline
\end{tabular}

\subsection{ETAPA 2 - PROCEDIMENTOS ADOTADOS PARA AS VALIDAÇÕES DE CONTEÚDO E CONSTRUCTO}

Para conduzir o processo de validação do instrumento DRISS, foram contempladas estratégias de validação de conteúdo e de construto, conforme proposto por Furr (2015).

\subsubsection{Validade de conteúdo}

A validade de conteúdo refere-se a um conjunto de itens que refletem adequadamente um determinado fenômeno (DeVellis, 2012). Ou seja, dentro de um universo de itens possíveis, devem permanecer no instrumento final apenas os itens que reflitam o constructo sob estudo (Polit, Beck, Hungler, 2004). Para se verificar a validade de conteúdo, podem ser considerados critérios qualitativos e quantitativos (Alexandre, Coluci, 2011). Os critérios qualitativos foram apontados por escrito pelo 
comitê de especialistas e os critérios quantitativos foram análises feitas pelo pesquisador, a partir dos dados coletados do comitê de especialistas e do consenso entre juízes/concordância.

Para a validação de conteúdo, considerou-se relevante, antes de mais nada, avaliar a clareza, a relevância, a adequação da amostra e a qualidade do instrumento (Fitzpatrick,1983; Wilson, Pan, Schumsky, 2012). Para tanto, cada um desses critérios foi avaliado pelos especialistas em todos os itens.

\subsubsection{O comitê de especialistas}

Para avaliar a validade de conteúdo, foi formado um comitê de especialistas que avaliou a versão 1 do DRISS. Não existe um consenso na literatura sobre a quantidade e a formação dos especialistas que devem compor um comitê. No entanto, parece ser consenso que, ao escolher o comitê de especialistas, é necessário considerar as características do instrumento, além da formação, da qualificação e da disponibilidade dos especialistas. Há que se escolher, também, indivíduos que tenham experiência para trabalhar na temática de estudo, indivíduos com conhecimentos relativos à construção de escalas, bem como que sejam membros da população-alvo, ou seja, leigos (Alexandre, Coluci, 2011). Decidiu-se que, para a compor o comitê de especialistas do DRISS, deveria haver, no mínimo, um metodologista, três especialistas em relações étnico-raciais, um linguista e membros da população-alvo. Considerou-se relevante também buscar indivíduos com os quais não houvesse conflito de interesse. Assim, os metodologistas e especialistas em relações étnicoraciais foram escolhidos por busca na Plataforma Lattes, com as palavras-chave psicometria, instrumentos e relações-étnico-raciais.

Os convites para os especialistas comporem o comitê de especialistas do DRISS foram enviados por e-mail em fevereiro de 2017. Conforme houvesse demora na resposta (esperavam-se 20 dias) ou quando a resposta era negativa, buscava-se outro especialista com a mesma experiência na mesma área.

Nessa fase, quando a versão 1 do DRISS (pool de itens inicial) estava pronta, o Formulário de Avaliação dos Especialistas foi criado e inserido no Research 


\section{Eletronic Data Capture (REDCap) ${ }^{1}$ (Harris et al., 2009). No e-mail-convite enviado aos} especialistas, constava a seguinte mensagem:

Meu nome é Patricia Lima Ferreira Santa Rosa, doutoranda do Programa de Pós-Graduação em Enfermagem da Escola de Enfermagem da Universidade de São Paulo (EEUSP), sob orientação das Profas. Dras. Ana Luíza Vilela Borges e Edna Maria de Araújo.

Você foi convidado/a por ser um/a especialista em uma das seguintes áreas: psicometria, relações étnico-raciais, epidemiologia, linguística ou outra.

Obrigada por participar desta fase da minha pesquisa, intitulada 'Desenvolvimento e validação do instrumento de medida das percepções sobre discriminação racial interpessoal e institucional nos serviços de saúde brasileiros"!

A sua participação consistirá, primeiramente, em preencher o formulário com questões introdutórias gerais (nome, afiliação, especialidade). Em seguida, deverá preencher o formulário de avaliação do instrumento por especialistas.

Você deverá analisar o texto introdutório e os 49 itens propostos. Trata-se de uma escala do tipo Likert em que, excetuando o texto introdutório, todas as questões terão o seguinte estilo de resposta: raramente, algumas vezes, muitas vezes, quase sempre e sempre.

A avaliação será quanto à relevância; à clareza; se deve ser mantido sem alterações, mantido com alterações, ou excluído. Caso decida por manter o item com alterações, uma caixa de texto será automaticamente aberta, onde você deverá fazer suas sugestões. Caso você escolha a opção excluir, uma caixa de texto também será automaticamente aberta, onde você precisará justificar a razão pela qual sugeriu a exclusão. Além disso, há uma caixa de texto adicional, caso deseje sugerir ou comentar algo a mais.

Após a análise do conjunto de respostas de todos os especialistas, vislumbra-se atingir uma versão pronta para ser aplicada à população. Assim, terá fim a etapa de desenvolvimento do instrumento, tornando possível a etapa de validação, ou seja, a aplicação do instrumento à população-alvo.

A população-alvo será composta por pessoas adultas, em gozo de suas faculdades mentais, dispostas a participar do estudo.

O tempo a ser gasto no preenchimento será de 20 a 30 minutos.

Este projeto foi aprovado pelo Comitê de Ética em Pesquisa da EEUSP em 05/07/2016.

Estou muito satisfeita em poder contar com a sua colaboração e coloco-me à disposição em caso de dúvidas, por e-mail patriciasantarosa@usp.br ou telefone celular: (11) XXXXXXXXXX.

Muito obrigada!

No momento em que o especialista aceitava participar do estudo para compor o comitê de especialistas, o link com o Formulário de Avaliação do Instrumento por Especialistas era enviado por e-mail para ser preenchido no REDCap (exemplo na Figura 2). Adicionalmente, foram enviados o projeto de pesquisa e o comprovante de aceitação do Comitê de Ética.

\footnotetext{
1 "REDCap é um sistema eletrônico baseado na web, consolidado internacionalmente e altamente seguro para coleta e gerenciamento de dados em pesquisas científicas. Esse sistema foi desenvolvido por pesquisadores da Vanderbilt University (Tennessee, Estados Unidos) e é disponibilizado para centros de pesquisas do mundo inteiro, por intermédio do estabelecimento de um contrato de afiliação com o REDCap Consortium (Harris et al., 2009).

- https://projectredcap.org/
} 
Aos especialistas foi solicitado avaliar cada item segundo a relevância, a dimensão e a clareza do seguinte modo:

- Relevância

○ não relevante

- relevante, porém, necessita de grande revisão

- relevante, porém, necessita de pequena revisão

$\circ$ item relevante

- Clareza

○ não claro

- pouco claro

- muito claro

- Dimensão

○ reação

○ experiência

○ sentimento

o outra

- Manutenção

- mantido inalterado

○ modificado

○ excluído

Em relação à avaliação sobre a 'dimensão' do instrumento, foram sugeridos temas aos especialistas com base na revisão de literatura, embora já se soubesse que tais dimensões seriam definidas após a análise fatorial. $\mathrm{Na}$ ocasião da participação do especialista, se fosse escolhida a opção 'outra', em seguida, uma caixa de texto era aberta para a inclusão da crítica sugerida.

Quanto à pergunta sobre a manutenção do item, se o especialista escolhesse a opção 'manter modificado', uma caixa de texto se abria para que ele incluísse sua sugestão de modificação; se a opção escolhida fosse 'excluído', se abriria a caixa de diálogo solicitando uma justificativa. 
Além disso, para todos os itens, havia uma caixa de diálogo no final para sugestões relacionadas ao item como um todo. Portanto, essas caixas de diálogo permitiram que os especialistas pudessem ter espaço para realizar críticas e sugestões sobre cada um dos itens.

Figura 2 - Exemplo de item presente no formulário construído no REDCap para análise de face e conteúdo do DRISS por especialistas. São Paulo, 2017.

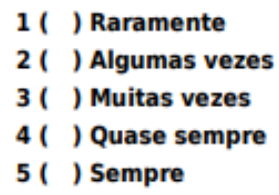

O texto introdutório também foi submetido ao julgamento dos especialistas, conforme mostra a Figura 3. 
Figura 3 - Exemplo de item (texto introdutório) presente no formulário construído no REDCap para análise de face e conteúdo do DRISS por especialistas. São Paulo, 2017.

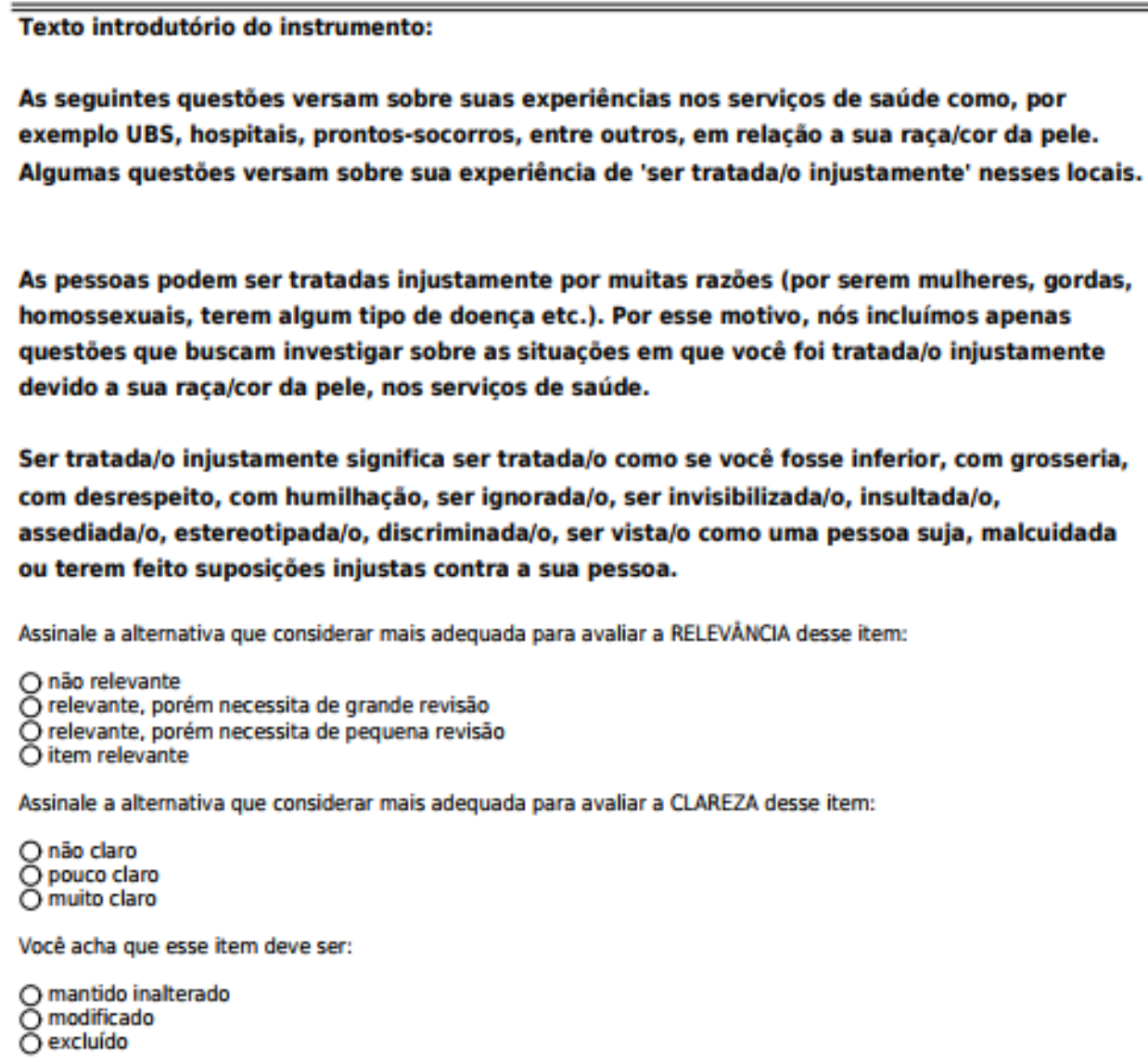

Para a realização da análise quantitativa da validade de conteúdo, foi utilizado como parâmetro a pergunta a respeito da manutenção do item (mantido inalterado modificado - excluído). Quando o especialista escolhesse 'mantido inalterado' ou 'mantido modificado', o item era contabilizado como um voto para manter (recebendo o código 1); quando a opção do especialista era 'excluído', o item era contabilizado com um voto para excluir (recebendo o código 0 ).

O índice utilizado para realizar a análise quantitativa concernente à validade de conteúdo foi a Razão de Validade de Conteúdo (CVR) (Alexandre, Coluci, 2011), considerado metodologicamente mais acurado (Wilson, Pan, Schumsky, 2012). 
A CVR, também conhecida como Razão de Validade de Conteúdo de Lawshe (Wilson, Pan, Schumsky, 2012), consiste na seguinte fórmula:

$$
\mathrm{CVR}=\frac{\mathrm{n}_{\mathrm{e}}-(\mathrm{N} / 2)}{\mathrm{N} / 2}
$$

ne = número de especialistas que consideraram o item como essencial, ou seja, que decidiram pela manutenção do item

$\mathrm{N}=$ total de especialistas do comitê

Portanto, se todos os especialistas concordarem com a manutenção do item, o índice será igual a 1; se o número de especialistas que concordaram com a manutenção do item for maior do que a metade do número total de especialistas, o CVR será ficará entre zero e um; se menos da metade dos especialistas concordarem com a manutenção do item, o CVR ficará com o valor negativo. Trata-se de uma estatística linear da proporção de especialistas que concordam com a manutenção do item (Wilson, Pan, Schumsky, 2012). O ponto de corte utilizado foi de 0,75 (Wilson, Pan, Schumsky, 2012), ou seja, foram mantidos todos os itens com CVR maior ou igual a 0,75 e excluídos todos os itens com CVR menor do que esse valor.

Após a aplicação do CVR, realizou-se o teste de concordância entre os especialistas, chamado Kappa ajustado pela prevalência (PABAK) (Byrt , Bishop, Carlin, 1993; Brito, Portela, Vasconcellos, 2005; Lobão et al., 2005; Cunningham, 2009), dado pela seguinte fórmula:

$$
\begin{gathered}
\text { pi }=(\mathrm{a}-\mathrm{d}) / \mathrm{N} \\
\mathrm{bi}=(\mathrm{b}-\mathrm{c}) / \mathrm{N} \\
\mathrm{PABAK}=2 \mathrm{P}_{\mathrm{o}}-1
\end{gathered}
$$

$\mathrm{p}_{i}$ - índice de prevalência

$b_{i}-$ índice de erro

Po - proporção de concordância 
O resultado do PABAK serve para observar o nível de concordância entre os especialistas. A interpretação dos valores de PABAK é: $<0$, sem concordância (caso seja menos do que zero, indica que não há concordância); 0-0,19, concordância pobre; 0,20-0,39, há concordância razoável; 0,40-0,59, concordância moderada; 0,600,79, concordância substancial; e 0,80-1,00, concordância quase perfeita.

\subsubsection{Pré-teste}

Inicialmente, o pré-teste foi realizado com entrevistas face-a-face, utilizando o formulário impresso. Posteriormente, as participações foram feitas diretamente no REDCap, por intermédio de um link enviado via e-mail, Whatsapp ou Facebook. Buscou-se observar se as questões estavam sendo bem entendidas pelos respondentes e se o formulário no REDCap estava funcionando adequadamente.

\subsubsection{Validação de constructo}

Segundo o Dicionário Online de Português, a palavra constructo é substantiva, de gênero masculino. A origem da palavra é latina (constructos) e é sinônimo de construto. Trata-se de um modelo criado mentalmente que estabelece um paralelo entre uma observação idealizada e uma teoria; ideia ou teoria construída a partir de elementos conceituais ou subjetivos, não baseados em evidências empíricas; [Psicologia] Ideia ou conceito que é resultado da sintetização de ideias mais simples (Dicio, 2017).

Para DeVellis (2012), a validade de constructo refere-se a uma relação teórica direta de uma variável (por exemplo: escore de uma escala) com outras variáveis. Segundo Pasquali (2009), a validade de constructo

é considerada a forma mais fundamental de validade dos instrumentos psicológicos e com toda a razão, dado que ela constitui a maneira direta de verificar a hipótese da legitimidade da representação comportamental dos traços latentes e, portanto, se coaduna exatamente com a teoria psicométrica aqui defendida (Pasquali, 2009). 
Segundo Furr (2015), a validade de constructo pode ser entendida a partir de um modelo pentagonal, ou seja, deve ser baseada em 5 pilares: no conteúdo do teste, na estrutura interna, na associação com outras variáveis, nas consequências do uso e no processo de resposta (Figura 4).

Figura 4 - A perspectiva contemporânea dos tipos de informação relevantes para a validade de um teste (modelo adaptado - tradução livre) (Furr, 2015).

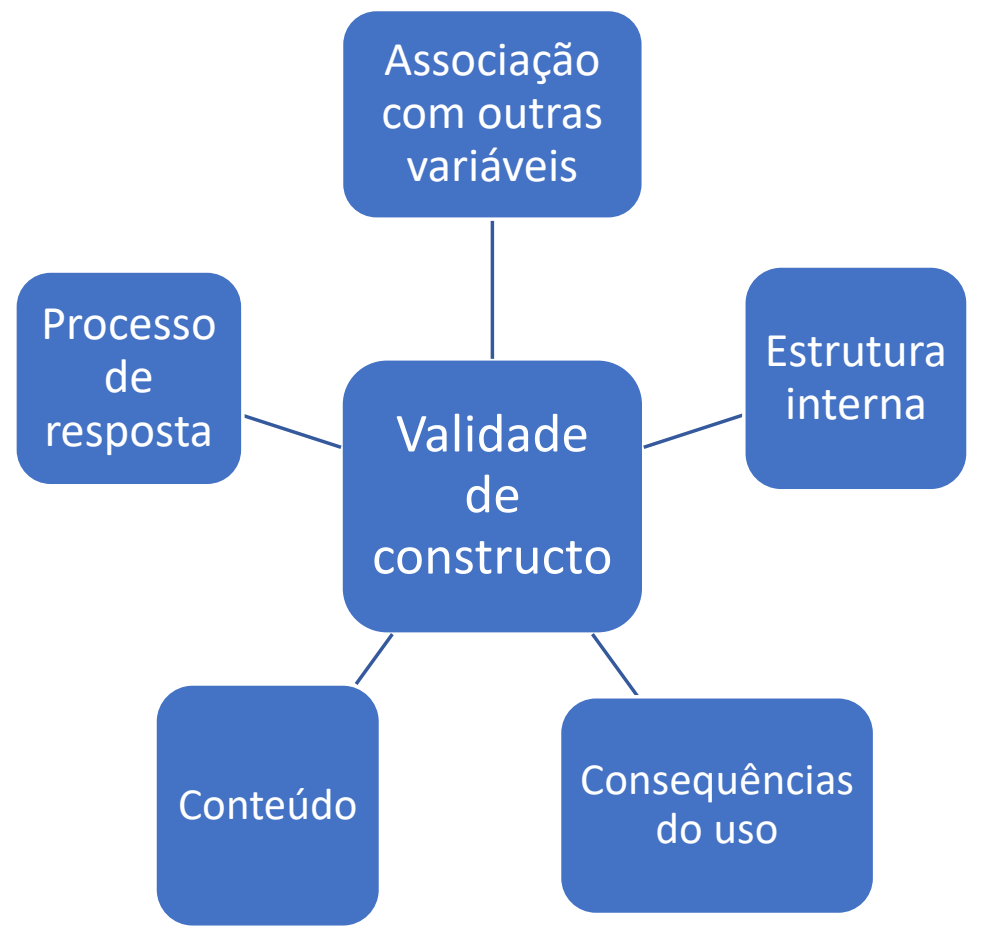

Quanto ao conteúdo do teste, o autor refere-se a uma validação de conteúdo bem-feita, realizada por um comitê de especialistas. $O$ autor alerta também que a validade de conteúdo não pode ser confundida ou omitida por meio da validade de face (Furr, 2015). Em relação à estrutura interna, o autor refere-se à dimensionalidade do teste, apresentada pela análise fatorial, devendo refletir o conteúdo teórico do constructo. Concernente ao processo de resposta, o conceito diz respeito ao processo mental utilizado pelos respondentes. Finalmente, em relação às consequências do uso da escala, o autor alerta para uma reflexão necessária em termos de responsabilidade, por parte do desenvolvedor da escala, sobre o papel social e político do seu uso. Já, a associação com outras variáveis, se refere à validade de critério (Furr, 2015) - que não será possível verificar, porque não há um instrumento padrãoouro para efetuar a comparação entre ela o DRISS. 
Partindo do princípio que a validação de construto é um processo que depende dos cinco vértices apontados por Furr (2015), aqui são apresentados os procedimentos realizados antes da avaliação da dimensionalidade propriamente dita (um dos cinco vértices). Esses procedimentos são: cálculo do tamanho da amostra, preenchimento do instrumento pela população-alvo e, finalmente, avaliação da dimensionalidade (análise fatorial exploratória).

\subsubsection{Cálculo do tamanho da amostra}

Neste estudo, adotou-se a perspectiva de Hair, Black e Babin (2014), que propuseram um mínimo aceitável de cinco observações para cada item proposto. Por exemplo, para uma escala com 24 itens, a amostra deve ser composta por, no mínimo, 120 sujeitos.

\subsubsection{Preenchimento do instrumento pela população-alvo}

Considerou-se população-alvo qualquer indivíduos com idade acima de 18 anos, que tivesse interesse em participar da pesquisa. A população-alvo respondeu o instrumento no REDCap após as alterações sugeridas pelo comitê de especialistas e os ajustes no número de itens, considerando o CVR. O link para o instrumento foi enviado por e-mail e redes sociais, como Whatsapp e Facebook.

\subsubsection{Envio do instrumento}

O instrumento foi administrado por meio de um formulário autoadministrado, via computador [do inglês: Computerized self-administered questionnaires (CSAQ)], no REDCap. A escolha do CSAQ deveu-se ao fato de ser uma forma de coleta de dados que reúne várias potencialidades (Fielding, Lee, Blank, 2008). Desse modo, um link foi enviado para os potenciais respondentes. O DRISS foi inserido no REDCap e um 
link foi enviado por e-mail ou grupo de contatos em redes sociais, como Facebook e Whatsapp, contendo a seguinte mensagem:

\section{Olá!}

Sou doutoranda e pesquiso discriminação racial nos serviços de saúde.

Se devido à sua raça ou cor de pele, você sentiu que foi tratado de maneira injusta em um posto de saúde, pronto socorro, maternidade ou qualquer outro serviço de saúde, público ou privado, por favor, responda a esta pesquisa, que é do meu doutorado, clicando no link http://j.mp/2tge2Ro.

Vai levar apenas 10 minutos e você ajudará no reconhecimento e combate à discriminação racial dentro dos serviços de saúde brasileiros.

\section{Obrigada!}

Patricia Santa Rosa

Esta mensagem, contendo o link, direcionava os respondentes ao formulário no REDcap. A mensagem foi enviada para listas de e-mails de diferentes grupos da sociedade, como, por exemplo: universitários, membros de movimentos sociais, entre outros.

Segundo estudiosos sobre métodos de pesquisa pela internet, todas as formas de comunicação são válidas (Fragoso, Recuero, Amaral, 2015). Pesquisas realizadas na internet possibilitam, por exemplo, a realização de entrevistas sem a presença de entrevistadores, oferecendo vantagens tanto para o entrevistado quanto para o entrevistador (Fielding, Lee, Blank, 2008). Dentre as vantagens para o entrevistado, destaca-se a possibilidade de preenchimento em qualquer momento ou lugar e a elevada sensação de privacidade. Dentre as vantagens para o entrevistador, estão a alimentação automática do banco de dados, a redução de tempo, custos e erros provenientes das transcrições e, por fim, a ausência do viés do entrevistador. Dentre as desvantagens, destaca-se a dificuldade de atingir pessoas que não tenham acesso à internet ou que não saibam utilizar o computador (Fielding, Lee, Blank, 2008) - a despeito de o Brasil ser o quarto país do mundo em número de usuários de internet, segundo dados da Organização das Nações Unidas (ONU, 2017).

\subsubsection{Questões introdutórias ao DRISS}

Adicionalmente, mais três perguntas introdutórias foram incluídas. Elas versam sobre a existência ou não de experiência com tratamento injusto, devido à raça/cor de 
pele, em serviços de saúde, devendo ser respondidas antes do DRISS propriamente dito (Apêndice III). Além disso, essas perguntas possibilitaram identificar e quantificar os cenários, o momento (tempo) e qual categoria profissional que perpetrou a discriminação racial interpessoal.

\subsubsection{Instrumento para coleta de dados sociodemográficos}

Um questionário socioeconômico-demográfico foi elaborado para ser respondido antes do DRISS. As variáveis coletadas neste questionário foram: sexo, idade, estado de residência, região (rural ou urbana), religião, escolaridade, raça/cor, profissão, trabalho remunerado, plano de saúde (ou convênio), união estável e informações para a classificação do grupo econômico (quantidade de automóveis, empregados domésticos, eletroeletrônicos, benefícios sociais - ou previdenciários recebidos, pavimentação, água encanada) (ABEP, 2016) (Apêndice IV).

Os três instrumentos foram disponibilizados na seguinte sequência: 1) socioeconômico-demográfico, 2) questões introdutórias ao DRISS, 3) DRISS (Apêndice I).

\subsubsection{Avaliação da dimensionalidade}

A análise fatorial exploratória (AFE) foi o método utilizado para a avaliação da dimensionalidade do DRISS. A AFE avaliou a correlação item-item, agrupando-os segundo a força da correlação, em uma matriz do tipo policórica (Hair, Black, Babin, 2014). O grupo de itens fortemente correlacionados é denominado fator. Quando todos os itens de uma escala estiverem fortemente correlacionados, diz-se que a escala é unidimensional e, quando a correlação é forte, porém em grupos (fatores) separados, diz-se que a escala é multidimensional.

Os itens de um fator também podem estar correlacionados com itens de outro fator. A AFE permite estimar os fatores que devem refletir o que a teoria representa, porém, é necessário o julgamento constante do pesquisador. Trata-se, pois, de um processo interativo constante em que o pesquisador deve interpretar o que a AFE 
apresenta e tomar as decisões necessárias sobre a exclusão ou a permanência de um item na escala, baseado nos parâmetros pré-estabelecidos - como carga fatorial, comunalidade, entre outros (Furr, 2015). A figura 5 representa, de forma simplificada, os passos seguidos para a realização da AFE deste trabalho.

Figura 5 - Fluxograma da análise fatorial exploratória do DRISS (adaptado do modelo de Furr (2015), São Paulo, 2017.

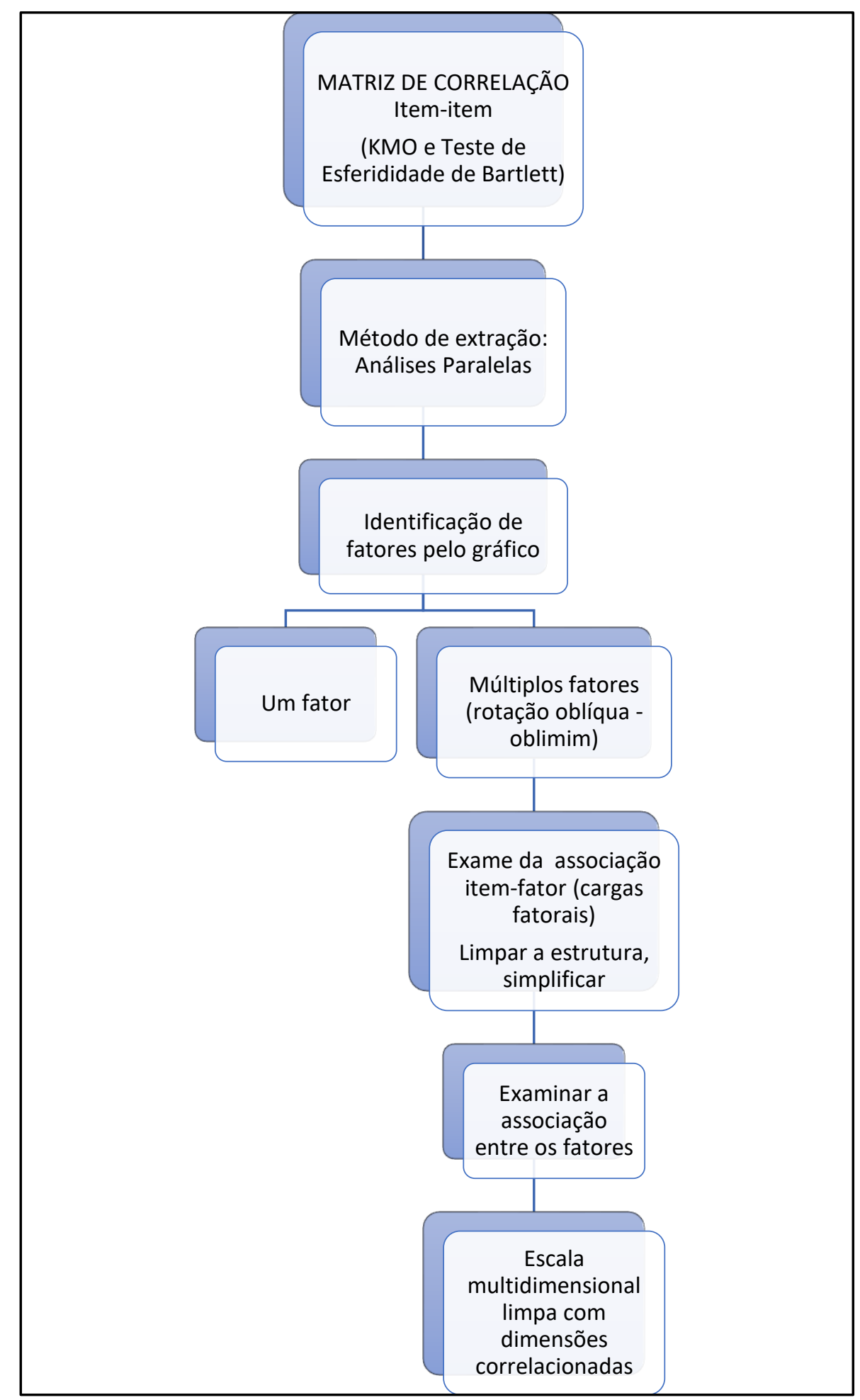


O primeiro produto da AFE foi a matriz de correlação entre os itens que foi submetida testes para verificar se ela era passível ou não de fatoração (Pasquali, 1999; Damásio, 2012). Os testes utilizados foram o Critério de Kaiser-Meyer-Okin (KMO), conhecido também como índice de adequação da amostra, e o Teste de Esfericidade de Bartlett. O KMO é um "teste estatístico que sugere a proporção de variância dos itens que pode estar sendo explicada por uma variável latente" (LorenzoSeva, Ferrando, 2006; Damásio, 2012). Esse índice diz o quão adequado é aplicar a AFE - para um determinado conjunto de dados (Hair, Black, Babin, 2014).

$$
\begin{aligned}
& \mathrm{KMO}=\text { quadrado das correlações totais } \\
& \text { quadrado das correlações parciais }
\end{aligned}
$$

$\mathrm{O}$ valor do $\mathrm{KMO}$ pode variar entre zero e um: valores próximos a zero indicam que é inapropriado proceder com a análise fatorial. A interpretação dos valores do KMO é a seguinte: até 0,5 , inaceitável; 0,5-0,7, medíocre; 0,7-,08, bom e 0,8-0,9, excelente.

Por sua vez, o Teste de Esfericidade de Bartlett avalia "em que medida a matriz de (co)variância é similar a uma matriz-identidade". Assim, os valores da diagonal da matriz serão iguais a um - isto porque é o item se correlacionando com ele mesmo. Esse teste avalia a significância geral de todas as correlações da matriz de dados (Hair, Black, Babin, 2014). Portanto, o valor de significância da matriz $p<0,05$ indica que a matriz é fatorável (Tabachinick, Fidell, 2012), pois rejeita a hipótese nula de que a matriz seja similar a uma matriz-identidade.

Após a indicação de fatorabilidade da matriz, o próximo passo foi usar como método de extração de fatores as Análises Paralelas (AP). O método das AP tem acurácia adequada, pois é baseado na amostra e não na população (Damásio, 2012). Trata-se de um procedimento estatístico de simulação de Monte-Carlo, que constrói aleatoriamente um conjunto hipotético de matrizes de correlação de variáveis, utilizando como base a mesma dimensionalidade do conjunto de dados reais (Laros, 2004; Damásio, 2012). A matriz hipotética é fatorada, segundo a quantidade de vezes que o pesquisador determinar, podendo ser centenas ou milhares de vezes. Assim, obtém-se a média dos autovalores (do termo, em inglês, eigenvalue) oriundos dessa 
simulação. Autovalor, ou raiz latente, se refere à ideia de que "qualquer fator individual deve explicar a variância de, pelo menos, uma variável se o mesmo há de ser mantido para interpretação; cada variável contribui com o valor 1 do autovalor total (Hair, Black, Babin, 2014). Por fim, os autovalores reais são pareados com os autovalores aleatórios, visíveis nitidamente em um gráfico de autovalor. Portanto, a leitura é feita do seguinte modo: os fatores com autovalores $>1$, mas com autovalores menores do que os obtidos na AP, são excluídos.

O passo seguinte, após a indicação do número de fatores, foi a rotação dos fatores. As rotações de fatores são técnicas que visam facilitar a interpretação dos mesmos. Trata-se de um processo de manipulação dos dados, porém, sem melhorar os resultados. Em outras palavras, não se trata de soluções estatísticas para disfarçar resultados ruins e nem apresentar soluções ótimas (Costello, Osborne, 2005; Damásio, 2012). Também é fundamental que se escolha a rotação adequada, segundo a natureza dos dados. Desse modo, as rotações oblíquas são mais adequadas para pesquisas em ciências humanas e saúde, pois avaliam comportamentos, sintomas, entre outros. As rotações oblíquas assumem a priori que os fatores são correlacionados, ou seja, possuem interdependência. Portanto, a rotação escolhida para esta análise foi a do tipo oblimim.

\subsubsection{Interpretação e reespecificação de fatores}

Após a etapa de extração de fatores (AP) e rotação, a associação entre os itens e os fatores foi examinada por meio das cargas fatoriais apresentadas. As cargas fatoriais consideradas aceitáveis foram as que estiveram entre 0,3 e 0,9. Os valores $<0,3$ foram descartados, pois indicaram baixa (ou nenhuma) colineraridade, significando que a variável não mede o constructo de interesse; e os valores $>0,9$ podem ser indicadores de multicolinearidade, indicando que é possível que existam duas variáveis medindo constructos similares; neste caso, foram excluídos (Tabachinick, Fidell, 2012).

Logo após a exclusão de itens que não possuíam cargas fatorais entre 0,3 e 0,9 , uma nova AFE (análise paralela com rotação oblimim) foi realizada, possibilitando a avaliação das novas cargas fatoriais. Trata-se de um processo de limpeza e 
simplificação que foi repetido até que o modelo mais parcimonioso possível fora atingido (Hair, Black, Babin, 2014).

Após a avaliação das cargas fatoriais, observava-se a comunalidade - que é a soma das cargas fatoriais ao quadrado, estimados para cada item. A interpretação das comunalidade é: entre 0,40 e 0,70, considera-se o valor de baixo a moderado (comum e aceitável em pesquisas da área das ciências sociais); $\geq 0,8$ (alta); $<0,40$, pode indicar duas coisas: a) não estar relacionado aos outros itens ou b) sugerir um fator adicional que deve ser explorado. Itens com comunalidade $<0,40$ foram excluídos (Costello, Osborne, 2005).

A variância acumulada é a variância explicada que é somada a cada fator e, posteriormente, acumulada. Variância explicada "refere-se à porção de variância comum que um fator, ou um conjunto de fatores, consegue extrair de um determinado conjunto de dados" (Damásio, 2012). A variância acumulada não foi utilizada como método para extrair itens ou fatores, mas sim como um parâmetro de consulta a cada nova AFE realizada, tendo em vista a recomendação de se atingir pelo menos $60 \%$ de variância acumulada (Figueiredo Filho, Silva Júnior, 2010).

A matriz de correlação entre os fatores revela quaisquer correlações existentes entre os fatores (Costello, Osborne, 2005). É esperado que os fatores estejam correlacionados, porém não podem ser muito correlacionados, pois indicariam que estavam tratando do mesmo fenômeno.

Três índices de ajuste foram utilizados: o Standardized Root Mean Square Residual (SRMR), o Índice de Tucker Lewis e o Root Mean Square Error of Aproximation (RMSEA). Quanto ao SRMR, trata-se de um indicador da média padronizada dos resíduos (discrepâncias entre a matriz observada e modelada), sendo que índices menores do que 0,10 são indicativos de bom ajuste (Hair, Black, Babin, 2014; Noronha, Pinto, Ottati, 2016). O Índice de Tucker Lewis calcula o ajuste relativo do modelo observado ao compará-lo com um modelo base, cujos valores acima de 0,95 indicam ótimo ajuste e os superiores a 0,90 indicam ajuste adequado (Bentler, 1990; Noronha, Pinto, Ottati, 2016). Por fim, o RMSEA é uma medida de discrepância. Seu valor varia entre 0 e 1, sendo esperados resultados menores do que 0,05 (Hooper, Coughlan, Mullen, 2008). 
Após a avaliação dos índices de ajuste, chegou-se a um modelo final e os fatores foram rotulados, considerando a teoria (Hair, Black, Babin, 2014). Nesta etapa, foi obtida a versão final do DRISS.

\subsection{ETAPA 3 - PROCEDIMENTOS ADOTADOS PARA A VERIFICAÇÃO DA CONFIABILIDADE}

A confiabilidade, como o próprio nome diz, denota o quão confiável é um instrumento. Assim, uma escala perfeitamente confiável produzirá um escore verdadeiro (true score), ou seja, o reflexo exato do constructo (DeVellis, 2012). Há vários métodos para se computar a confiabilidade, o que dependerá do tipo de dado que se deseja avaliar (por exemplo: variáveis contínuas, dicotômicas, entre outras). No entanto, todos os métodos de avaliação da confiabilidade possuem um ponto em comum: que a confiabilidade é a proporção de variância em um escore observado que pode ser atribuído ao verdadeiro escore da variável que está sendo avaliada (DeVellis, 2012).

Para DeVellis (2012), a consistência interna refere-se à homogeneidade de uma escala, ou seja, os itens devem estar conectados logicamente com o constructo. Uma escala é considerada internamente consistente à medida em que seus itens forem altamente intercorrelacionados. Isso pode significar duas coisas: ou os itens afetam uns aos outros (p. ex.: item A "causa" item B) ou os itens dividem uma causa comum. Assim, elevadas correlações inter-item sugerem que os itens estão todos medindo (ou são manifestações de) um mesmo fenômeno. No entanto, essa multicolinearidade é desejável somente em certa medida, pois pode indicar redundância (Hair, Black, Babin, 2014).

A medida de confiabilidade utilizada neste estudo, foi a consistência interna. Ao se avaliar a consistência interna, objetiva-se que os itens indicadores individuais da escala meçam o mesmo constructo e, assim, acabem sendo altamente correlacionados (Hair, Black, Babin, 2014). A medida mais amplamente utilizada é o Alpha de Cronbach, sendo a sua aplicação mais adequada em escalas unidimensionais (Revelle, Zinbarg, 2009; Widhiarso, Ravand, 2014). No caso de escalas multidimensionais, o Alpha de Cronbach faz sentido quando aplicado separadamente, segundo os fatores. 
Portanto, neste trabalho utilizou-se o Ômega de McDonald, que vem sendo recomendado pela literatura recente como sendo mais preciso, no caso de escalas multidimensionais (Zinbarg et al., 2005, 2006; Zinbarg, Revelle, Yovel, 2007; Revelle, Zinbarg, 2009; Widhiarso, Ravand, 2014). A fórmula é a seguinte:

$$
\omega=\frac{\sum_{j=1}^{k}\left(\sum_{i=1}^{p} \lambda_{i j}\right)^{2}}{\sum_{j=1}^{k}\left(\sum_{i=1}^{p} \lambda_{i j}\right)^{2}+\sum_{i=1}^{p} e_{i}},
$$

Onde:

$\lambda i j=$ carga fatorial de $i$-indicators on $j$-factor

$e i=$ variância de cada indicador

O denominador da equação é a variância da soma dos escores de todos os itens

Os resultados de ambos os testes são interpretados da seguinte forma, em relação à confiabilidade: $<0,30$, muito baixa; $0,30-0,60$, baixa; $0,60-0,75$, moderada; 0,75 - 0,90, alta; > 0,90, muito alta.

\subsection{ETAPA 4 - ESCORIFICAÇÃO (CÁLCULO DE ESCORE FATORIAL)}

Após a elaboração da versão final do DRISS, considerando as etapas de validade e confiabilidade alcançadas, o escore foi construído com base na porcentagem de contribuição de cada fator ao fenômeno DRISS como um todo. Em outras palavras, o escore foi calculado, segundo a proporção de variância explicada. Assim sendo, ocorreu dos escores ficarem com números não inteiros e diferentes entre um item e outro. 


\subsection{ETAPA 5 - ANÁLISE DA DISTRIBUIÇÃO DO ESCORE SEGUNDO OS ASPECTOS SOCIODEMOGRÁFICOS DA AMOSTRA}

Verificou-se se a distribuição dos escores da amostra obedecia a uma distribuição normal, por meio do teste de Shapiro-Wilk, ao nível de significância de $5 \%$. Buscou-se verificar se havia diferença estatisticamente significativa entre as médias, em comparação com as características sociodemográficas.

\subsection{ANÁLISE ESTATÍSTICA}

O banco de dados foi extraído do REDCap e trabalhado no Stata 14.2 (exclusão de recusas, perdas e duplicidades, além da análise do perfil sociodemográfico) e no Excel (cálculo do CVR). Todas as demais análises foram realizadas no $\mathrm{R}$ (KMO, Teste de Esfericidade de Bartlett, Análises Paralelas com rotação oblimim, gráfico de autovalores, comunalidade, proporção de variância acumulada e explicada, correlação entre fatores, RMSR, Tucker Lewis Index, RMSEA, Ômega de McDonald, Alpha de Cronbach) (R Core Team, 2017).

\subsection{PROCEDIMENTOS ÉTICOS}

Este projeto de pesquisa foi aprovado pelo Comitê de Ética em Pesquisa da Escola de Enfermagem da USP, sob o número 1.622.586 (Anexo VI). O Termo de Consentimento Livre e Esclarecido (TCLE) se encontrava na primeira página do instrumento online. A participação do respondente estava condicionada à aceitação do TCLE (Anexo I). Foram tomadas providências quanto ao sigilo das informações. 



\section{RESULTADOS}

Os resultados do processo de validação da escala DRISS são apresentados em cinco etapas: a primeira é a validação de conteúdo, em que são apresentadas as etapas de análise do instrumento por comitê de especialistas, a Razão de Validade de Conteúdo (CVR) e as versões sucessivas a partir desses testes. A segunda, que é a validação de constructo, em que são apresentadas, na análise fatorial exploratória (AFE), as versões elaboradas do instrumento. A terceira é a verificação da confiabilidade. A quarta é a escorificação. A quinta é a análise da distribuição do escore segundo os aspectos sociodemográficos da amostra.

\subsection{ETAPA 1: VALIDAÇÃO DE CONTEÚDO}

\subsubsection{Composição do comitê de especialistas}

Ao todo, foram convidadas 18 pessoas para compor o comitê de especialistas. Os convites aos especialistas foram enviados a partir de fevereiro de 2017, de acordo com a possibilidade e em momentos diferentes. Os profissionais convidados constituíram-se em dois metodologistas, dois profissionais de língua portuguesa, sete especialistas em relações étnico-raciais e seis membros da população-alvo. Seis pessoas não responderam, uma recusou-se a participar e dois membros da população-alvo não conseguiram compreender as instruções para o preenchimento do formulário (Quadro 4). No total, oito pessoas aceitaram participar, dos quais uma era metodologista, uma profissional de língua portuguesa (foi contratado para tal), três especialistas em relações étnico-raciais e três membros da população-alvo. 
Quadro 4 - Síntese da participação de especialistas no comitê de especialistas do DRISS, segundo a área de atuação, e razão para participação/não participação. São Paulo, 2017.

\begin{tabular}{|c|c|c|c|}
\hline Área de atuação & Convidado/a & Motivo da não participação & Aceitou \\
\hline Psicometria & 2 & 1 não respondeu & 1 aceitou \\
\hline $\begin{array}{c}\text { Profissionais língua } \\
\text { portuguesa }\end{array}$ & 3 & 2 não responderam & $\begin{array}{c}1 \text { aceitou mediante } \\
\text { pagamento }\end{array}$ \\
\hline $\begin{array}{c}\text { Especialistas em relações } \\
\text { étnico-raciais }\end{array}$ & 7 & $\begin{array}{c}3 \text { não responderam } \\
1 \text { recusou }\end{array}$ & 3 aceitaram \\
\hline Membros da população-alvo & 6 & $\begin{array}{c}1 \text { não respondeu } \\
2 \text { tiveram dificuldade para } \\
\text { entender as instruções }\end{array}$ & 3 aceitaram \\
\hline Total & 18 & 10 & 8 \\
\hline
\end{tabular}

O metodologista era pós-doutor em psicometria, com vasta experiência e inúmeras publicações na área. O profissional de língua portuguesa possuía experiência prévia em analisar instrumentos de medida e corrigir outros tipos de trabalhos acadêmicos. Os três especialistas em relações étnico-raciais eram professores doutores de universidades públicas das regiões nordeste e sudeste brasileiros.

Com relação aos membros da população-alvo, dois eram advogados e uma era enfermeira - e foram escolhidos por serem envolvidos com liderança de movimentos sociais; eles demonstraram compreensão plena do que era solicitado para avaliação do instrumento, ou seja, entendimento das instruções escritas e do conteúdo social do trabalho.

É preciso ressaltar que a escolha dos membros da população-alvo não foi simples. Inicialmente, foram incluídas duas pessoas da população geral, uma com ensino médio completo a outra com graduação completa. No entanto, observou-se que tiveram dificuldade para interpretar o que era solicitado, pois não compreenderam que sua função era avaliar o instrumento, ao invés de respondê-lo. Ou seja, que elas deveriam avaliar os itens e não os responder como sujeitos de pesquisa. Mesmo após instruções realizadas verbalmente, o conjunto de respostas foi confuso e ambíguo. Portanto, decidiu-se excluir essas contribuições. 


\subsubsection{Versão 1 do DRISS}

A versão 1 do DRISS, justamente a que foi enviada para análise do comitê de especialistas, está no Quadro 5. Neste quadro, é apresentada a versão 1 do instrumento segundo os itens: Razão de Validade de Conteúdo (CVR), avaliações qualitativas dos especialistas e decisão final sobre a manutenção, modificação ou exclusão do item, de acordo com cada item proposto. Todas as linhas do Quadro 5 sem sombreamento indicam que 0 item foi mantido, ao passo que as linhas sombreadas indicam que o item foi excluído após essa etapa.

Quadro 5 - Versão 1 do instrumento DRISS com a síntese da avaliação dos especialistas segundo o item, CVR, avaliações qualitativas, item modificado segundo sugestões e decisão final. São Paulo, 2017.

\begin{tabular}{|c|c|c|c|c|c|}
\hline Item & Descrição & CVR & $\begin{array}{l}\text { Resumo das } \\
\text { avaliações qualitativas }\end{array}$ & $\begin{array}{l}\text { Item modificado } \\
\text { segundo as } \\
\text { sugestões }\end{array}$ & $\begin{array}{l}\text { Decisão } \\
\text { final }\end{array}$ \\
\hline $\begin{array}{l}\text { Texto } \\
\text { introdutório }\end{array}$ & $\begin{array}{l}\text { As seguintes } \\
\text { questões versam } \\
\text { sobre suas } \\
\text { experiências nos } \\
\text { serviços de } \\
\text { saúde como, por } \\
\text { exemplo UBS, } \\
\text { hospitais, } \\
\text { prontos-socorros, } \\
\text { entre outros, em } \\
\text { relação à sua } \\
\text { raça/cor da pele. } \\
\text { Algumas } \\
\text { questões versam } \\
\text { sobre sua } \\
\text { experiência de } \\
\text { 'ser tratada/o } \\
\text { injustamente' } \\
\text { nesses locais. As } \\
\text { pessoas podem } \\
\text { ser tratadas } \\
\text { injustamente por } \\
\text { muitas razões } \\
\text { (por serem } \\
\text { mulheres, gordas, } \\
\text { homossexuais, } \\
\text { terem algum tipo } \\
\text { de doença etc.). } \\
\text { Por esse motivo, } \\
\text { nós incluímos } \\
\text { apenas questões } \\
\text { que buscam } \\
\text { investigar sobre } \\
\text { as situações em } \\
\text { que você foi } \\
\text { tratada/o } \\
\text { injustamente } \\
\text { devido à sua } \\
\text { raça/cor da pele, }\end{array}$ & 1 & $\begin{array}{l}\text { Reduzir; } \\
\text { Modificar; } \\
\text { Evitar explicação de } \\
\text { conceitos devido ao } \\
\text { risco de interferir nas } \\
\text { respostas }\end{array}$ & $\begin{array}{l}\text { Nesse estudo, } \\
\text { nós incluímos } \\
\text { apenas questões } \\
\text { que buscam } \\
\text { investigar as } \\
\text { situações em que } \\
\text { você foi tratada/o } \\
\text { injustamente } \\
\text { devido à sua } \\
\text { raça/cor da pele, } \\
\text { nos serviços de } \\
\text { saúde. }\end{array}$ & $\begin{array}{c}\text { Mantido } \\
\text { (modificado) }\end{array}$ \\
\hline
\end{tabular}




\begin{tabular}{|c|c|c|c|c|c|}
\hline Item & Descrição & CVR & $\begin{array}{c}\text { Resumo das } \\
\text { avaliações qualitativas }\end{array}$ & $\begin{array}{l}\text { Item modificado } \\
\text { segundo as } \\
\text { sugestões }\end{array}$ & $\begin{array}{c}\text { Decisão } \\
\text { final }\end{array}$ \\
\hline & $\begin{array}{l}\text { nos serviços de } \\
\text { saúde. Ser } \\
\text { tratada/o } \\
\text { injustamente } \\
\text { significa ser } \\
\text { tratada/o como se } \\
\text { você fosse } \\
\text { inferior, com } \\
\text { grosseria, com } \\
\text { desrespeito, com } \\
\text { humilhação, ser } \\
\text { ignorada/o, ser } \\
\text { invisibilizada/o, } \\
\text { insultada/o, } \\
\text { assediada/o, } \\
\text { estereotipada/o, } \\
\text { discriminada/o, } \\
\text { ser vista/o como } \\
\text { uma pessoa suja, } \\
\text { malcuidada ou } \\
\text { terem feito } \\
\text { suposições } \\
\text { injustas contra a } \\
\text { sua pessoa. }\end{array}$ & & & & \\
\hline
\end{tabular}

Quando eu sou tratada/o de maneira injusta devido a minha raça/cor da pele, em serviços de saúde, eu: (Sugeriu-se trocar 'maneira injusta' por 'injustamente' e incluir 'serviços de saúde'), então, ficará assim: Quanto eu sou tratada/o injustamente devido à minha raça/cor da pele, em serviços de saúde, eu:

\begin{tabular}{|c|c|c|c|c|c|}
\hline 1 & Ignoro & 1 & $\begin{array}{l}\text { O termo "ignoro" pode } \\
\text { ser de difícil } \\
\text { compreensão para } \\
\text { alguns seguimentos da } \\
\text { população; } \\
\text { Pensar em um termo } \\
\text { alternativo; }\end{array}$ & $\begin{array}{l}\text { Item não } \\
\text { modificado }\end{array}$ & Mantido \\
\hline 2 & $\begin{array}{l}\text { Encaro como um } \\
\text { acontecimento } \\
\text { que faz parte da } \\
\text { vida }\end{array}$ & 1 & $\begin{array}{l}\text { O termo “acontecimento" } \\
\text { pode ser de difícil } \\
\text { compreensão para } \\
\text { alguns seguimentos da } \\
\text { população; } \\
\text { ‘Encarar', termo } \\
\text { questionado. Sugestões: } \\
\text { aceitar, entender ou } \\
\text { resignar-se; } \\
\text { Outra sugestão: 'Encaro } \\
\text { como um acontecimento } \\
\text { cotidiano'. }\end{array}$ & $\begin{array}{l}\text { Encaro como um } \\
\text { acontecimento } \\
\text { cotidiano }\end{array}$ & $\begin{array}{c}\text { Mantido } \\
\text { (modificado) }\end{array}$ \\
\hline 3 & $\begin{array}{l}\text { Converso com } \\
\text { alguma pessoa, } \\
\text { como um familiar, } \\
\text { ou amigo, sobre o } \\
\text { que aconteceu }\end{array}$ & 0,75 & $\begin{array}{l}\text { Se ele não falar? Se não } \\
\text { for característica dele? } \\
\text { Especialista, sugerindo } \\
\text { que algumas pessoas } \\
\text { não têm hábito de se } \\
\text { expressar verbalmente } \\
\text { com outras pessoas. }\end{array}$ & $\begin{array}{l}\text { Item não } \\
\text { modificado }\end{array}$ & Mantido \\
\hline 4 & $\begin{array}{c}\text { Esqueço o que } \\
\text { aconteceu }\end{array}$ & 1 & $\begin{array}{l}\text { Sugestão de substituir } \\
\text { "eu esqueço o que } \\
\text { aconteceu" por eu } \\
\text { "procuro esquecer o que } \\
\text { aconteceu", tendo em } \\
\text { vista que o item abarca } \\
\text { uma das possíveis }\end{array}$ & $\begin{array}{l}\text { Procuro esquecer } \\
\text { o que aconteceu. }\end{array}$ & $\begin{array}{c}\text { Mantido } \\
\text { (modificado) }\end{array}$ \\
\hline
\end{tabular}




\begin{tabular}{|c|c|c|c|c|c|}
\hline Item & Descrição & CVR & $\begin{array}{c}\text { Resumo das } \\
\text { avaliações qualitativas }\end{array}$ & $\begin{array}{l}\text { Item modificado } \\
\text { segundo as } \\
\text { sugestões }\end{array}$ & $\begin{array}{l}\text { Decisão } \\
\text { final }\end{array}$ \\
\hline & & & $\begin{array}{l}\text { reações à experiência de } \\
\text { discriminação racial. }\end{array}$ & & \\
\hline 5 & $\begin{array}{l}\text { Escrevo sobre o } \\
\text { que aconteceu }\end{array}$ & 0,25 & $\begin{array}{l}\text { Essa pergunta terá } \\
\text { interferência do sexo e } \\
\text { da faixa etária. Os } \\
\text { homens tendem a } \\
\text { escrever muito menos. } \\
\text { A expressão "eu escrevo } \\
\text { sobre o que aconteceu" } \\
\text { pressupõe que o } \\
\text { respondente sabe } \\
\text { ler/escrever. A depender } \\
\text { do domínio populacional } \\
\text { em que se deseja aplicar } \\
\text { o instrumento, esse item } \\
\text { deverá ser revisto; } \\
\text { Reação inverossímil ou } \\
\text { pouco usual. }\end{array}$ & - & Excluído \\
\hline 6 & $\begin{array}{l}\text { Desenho sobre o } \\
\text { que aconteceu }\end{array}$ & 0 & $\begin{array}{l}\text { Considerações } \\
\text { semelhantes às do item } \\
\text { anterior }\end{array}$ & - & Excluído \\
\hline 7 & $\begin{array}{l}\text { Canto sobre o } \\
\text { que aconteceu }\end{array}$ & 0 & $\begin{array}{l}\text { Considerações } \\
\text { semelhantes às do item } \\
\text { anterior }\end{array}$ & - & Excluído \\
\hline 8 & $\begin{array}{l}\text { Pinto sobre o que } \\
\text { aconteceu }\end{array}$ & 0 & $\begin{array}{l}\text { Considerações } \\
\text { semelhantes às do item } \\
\text { anterior }\end{array}$ & - & Excluído \\
\hline 9 & $\begin{array}{l}\text { Faço uma oração } \\
\text { (ou rezo) pela } \\
\text { situação. }\end{array}$ & 0,75 & $\begin{array}{l}\text { Trata-se de uma reação } \\
\text { e não percepção; } \\
\text { Sugestão: adicionar } \\
\text { 'meditação/reflexão'. }\end{array}$ & $\begin{array}{l}\text { Item não } \\
\text { modificado }\end{array}$ & Mantido \\
\hline 10 & $\begin{array}{c}\text { Guardo isso para } \\
\text { mim mesma/o }\end{array}$ & 0,75 & $\begin{array}{l}\text { Trata-se de uma reação } \\
\text { e não percepção; }\end{array}$ & $\begin{array}{l}\text { Item não } \\
\text { modificado }\end{array}$ & Mantido \\
\hline 11 & $\begin{array}{c}\text { Reclamo em voz } \\
\text { baixa com as } \\
\text { pessoas que } \\
\text { estão próximas a } \\
\text { mim }\end{array}$ & 0,50 & $\begin{array}{l}\text { Trata-se de uma reação } \\
\text { e não percepção; } \\
\text { Sugestão: incluir nos } \\
\text { enunciados 'serviços de } \\
\text { saúde'. Apesar de já } \\
\text { estar escrito no texto } \\
\text { introdutório, isso fica } \\
\text { perdido ao longo do } \\
\text { instrumento; } \\
\text { Sugestão: '(...) reclamo, } \\
\text { calmamente, com outras } \\
\text { pessoas que estão } \\
\text { próximas a mim'; } \\
\text { Não faz sentido reclamar } \\
\text { em voz baixa. }\end{array}$ & 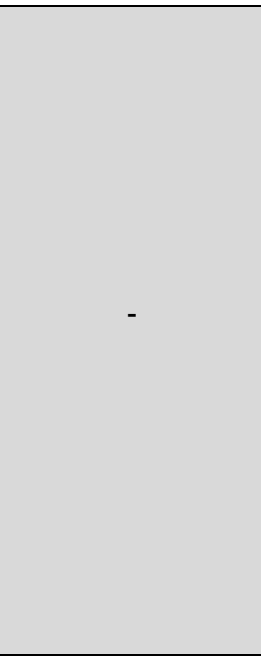 & Excluído \\
\hline 12 & $\begin{array}{l}\text { Reclamo em voz } \\
\text { alta } \\
\end{array}$ & 0,75 & $\begin{array}{l}\text { Trata-se de uma reação } \\
\text { e não percepção }\end{array}$ & $\begin{array}{l}\text { Item não } \\
\text { modificado }\end{array}$ & Mantido \\
\hline 13 & $\begin{array}{l}\text { Faço um } \\
\text { "barraco" } \\
\text { (escândalo) }\end{array}$ & 0,50 & $\begin{array}{l}\text { Trata-se de uma reação } \\
\text { e não percepção; } \\
\text { O item anterior já } \\
\text { responde a isso. }\end{array}$ & - & Excluído \\
\hline
\end{tabular}




\begin{tabular}{|c|c|c|c|c|c|}
\hline Item & Descrição & CVR & $\begin{array}{c}\text { Resumo das } \\
\text { avaliações qualitativas }\end{array}$ & $\begin{array}{l}\text { Item modificado } \\
\text { segundo as } \\
\text { sugestões } \\
\end{array}$ & $\begin{array}{l}\text { Decisão } \\
\text { final }\end{array}$ \\
\hline 14 & $\begin{array}{l}\text { Denuncio para as } \\
\text { autoridades (por } \\
\text { exemplo: polícia, } \\
\text { abro um processo } \\
\text { na justiça) }\end{array}$ & 0,75 & $\begin{array}{l}\text { Trata-se de uma reação } \\
\text { e não percepção; } \\
\text { Sugestão de nova } \\
\text { redação: (...) 'Denuncio } \\
\text { para as autoridades (por } \\
\text { exemplo: registro uma } \\
\text { ocorrência na polícia ou } \\
\text { abro um processo na } \\
\text { justiça)'. }\end{array}$ & $\begin{array}{l}\text { Denuncio para as } \\
\text { autoridades (por } \\
\text { exemplo: registro } \\
\text { uma ocorrência } \\
\text { na polícia ou } \\
\text { abro um } \\
\text { processo na } \\
\text { justiça). }\end{array}$ & $\begin{array}{c}\text { Mantido } \\
\text { (modificado) }\end{array}$ \\
\hline 15 & $\begin{array}{c}\text { Me sinto } \\
\text { humilhada/o }\end{array}$ & 0,75 & $\begin{array}{l}\text { Não é percepção do } \\
\text { fenômeno }\end{array}$ & $\begin{array}{l}\text { Item não } \\
\text { modificado }\end{array}$ & Mantido \\
\hline 16 & $\begin{array}{l}\text { Me sinto } \\
\text { impotente }\end{array}$ & 0,75 & $\begin{array}{l}\text { Não faz parte do objetivo } \\
\text { do trabalho; } \\
\text { Revisar com cuidado, } \\
\text { pode haver amplo } \\
\text { entendimento do que é } \\
\text { "impotente". }\end{array}$ & $\begin{array}{l}\text { Item não } \\
\text { modificado }\end{array}$ & Mantido \\
\hline 17 & Sinto raiva & 0,75 & $\begin{array}{l}\text { Não faz parte do objetivo } \\
\text { do trabalho; }\end{array}$ & $\begin{array}{l}\text { Item não } \\
\text { modificado }\end{array}$ & Mantido \\
\hline 18 & $\begin{array}{c}\text { Sinto algum } \\
\text { sintoma físico } \\
\text { como: dores de } \\
\text { cabeça, de } \\
\text { estômago, tensão } \\
\text { nos músculos, ou } \\
\text { palpitação no } \\
\text { coração }\end{array}$ & 0,75 & $\begin{array}{l}\text { Não faz parte do objetivo } \\
\text { do trabalho; } \\
\text { Não se colocam } \\
\text { múltiplos fatores juntos, } \\
\text { mesmo que sejam } \\
\text { exemplos; } \\
\text { Desmembrar; } \\
\text { Sugestão de nova } \\
\text { redação: (...) } \\
\text { 'Desenvolvo/tenho } \\
\text { algum sintoma físico } \\
\text { como: dor de cabeça, de } \\
\text { estômago, tensão nos } \\
\text { músculos ou palpitação } \\
\text { no coração'. }\end{array}$ & $\begin{array}{l}\text { Desmembrado } \\
\text { em questões } \\
\text { diferentes: } \\
\text { - Tenho dores de } \\
\text { cabeça; } \\
\text { - Tenho dores de } \\
\text { estômago; } \\
\text { - Tenho tensão } \\
\text { nos músculos; } \\
\text { - Tenho palpitação } \\
\text { no coração. }\end{array}$ & $\begin{array}{c}\text { Mantido } \\
\text { (modificado) }\end{array}$ \\
\hline 19 & $\begin{array}{l}\text { Sinto medo de ter } \\
\text { que esperar mais } \\
\text { do que o normal } \\
\text { para ser } \\
\text { atendida/o }\end{array}$ & 0,75 & $\begin{array}{l}\text { Sugestão de mudar a } \\
\text { pergunta para } \\
\text { percepção: "Eu percebo } \\
\text { que espero mais do que } \\
\text { o normal para ser } \\
\text { atendida/o" } \\
\text { Sugestão de outro } \\
\text { especialista: (...) 'eu } \\
\text { tenho receio de ter que } \\
\text { esperar mais... }\end{array}$ & $\begin{array}{l}\text { Eu tenho receio } \\
\text { de ter que } \\
\text { esperar mais do } \\
\text { que o normal } \\
\text { para ser } \\
\text { atendida/o. }\end{array}$ & $\begin{array}{c}\text { Mantido } \\
\text { (modificado) }\end{array}$ \\
\hline 20 & $\begin{array}{l}\text { Sinto medo de } \\
\text { ser humilhada/o }\end{array}$ & 0 & $\begin{array}{l}\text { Não faz parte do objetivo } \\
\text { do trabalho; } \\
\text { Muito parecida com a } \\
\text { Q15. }\end{array}$ & - & Excluído \\
\hline 21 & $\begin{array}{l}\text { Sinto medo de } \\
\text { ser maltratada/o }\end{array}$ & 0 & $\begin{array}{l}\text { Não faz parte do objetivo } \\
\text { do trabalho; } \\
\text { Confusão com os termos } \\
\text { 'maltratado' e 'tratado } \\
\text { injustamente'; } \\
\text { Parecido com outras } \\
\text { questões. }\end{array}$ & - & Excluído \\
\hline 22 & $\begin{array}{l}\text { Sinto medo de } \\
\text { não ser } \\
\text { atendida/o }\end{array}$ & 0 & $\begin{array}{l}\text { Não faz parte do objetivo } \\
\text { do trabalho; } \\
\text { Confusão com os termos } \\
\text { 'maltratado' e 'tratado } \\
\text { injustamente'; }\end{array}$ & - & Excluído \\
\hline
\end{tabular}




\begin{tabular}{|c|c|c|c|c|c|}
\hline Item & Descrição & CVR & $\begin{array}{c}\text { Resumo das } \\
\text { avaliações qualitativas }\end{array}$ & $\begin{array}{c}\text { Item modificado } \\
\text { segundo as } \\
\text { sugestões }\end{array}$ & $\begin{array}{l}\text { Decisão } \\
\text { final }\end{array}$ \\
\hline & & & $\begin{array}{l}\text { Parecido com outras } \\
\text { questões; } \\
\text { Pode causar dúvida no } \\
\text { respondente }\end{array}$ & & \\
\hline 23 & $\begin{array}{l}\text { Sinto medo de } \\
\text { receber } \\
\text { medicamento } \\
\text { errado }\end{array}$ & 0,50 & $\begin{array}{l}\text { Não faz parte do objetivo } \\
\text { do trabalho; } \\
\text { Confusão com os termos } \\
\text { 'maltratado' e 'tratado } \\
\text { injustamente'; } \\
\text { Parecido com outras } \\
\text { questões; } \\
\text { - Causa dilema no } \\
\text { respondente }\end{array}$ & - & Excluído \\
\hline 24 & $\begin{array}{l}\text { Sinto medo de } \\
\text { receber } \\
\text { tratamento errado }\end{array}$ & 0 & $\begin{array}{l}\text { Não faz parte do objetivo } \\
\text { do trabalho; } \\
\text { Confusão com os termos } \\
\text { 'maltratado' e 'tratado } \\
\text { injustamente'; } \\
\text { Parecido com outras } \\
\text { questões; } \\
\text { Pode causar dúvida no } \\
\text { respondente }\end{array}$ & - & Excluído \\
\hline
\end{tabular}

Com o objetivo de evitar ser tratada/o injustamente devido à minha raça/cor de pele, eu: Sugestão: retirar 'Para evitar' e incluir 'serviços de saúde', então, ficará: Para evitar ser tratada/o injustamente, em serviços de saúde, devido à minha raça/cor de pele, eu:

\begin{tabular}{|c|c|c|c|c|c|}
\hline 25 & $\begin{array}{l}\text { Tomo cuidados } \\
\text { adicionais com a } \\
\text { aparência } \\
\text { (higiene, } \\
\text { depilação...) }\end{array}$ & 0,75 & $\begin{array}{l}\text { Antecipação do evento } \\
\text { discriminatório ou de } \\
\text { injustiça; } \\
\text { Qual a relação de } \\
\text { higiene com racismo?; } \\
\text { Sugestão: incluir } \\
\text { 'roupas'; } \\
\text { Desmembrar. }\end{array}$ & $\begin{array}{l}\text { Desmembrado } \\
\text { em questões } \\
\text { diferentes: } \\
\text { - Tomo cuidados } \\
\text { adicionais com } \\
\text { a higiene. } \\
\text { - Tomo cuidados } \\
\text { adicionais com } \\
\text { a } \\
\text { depilação/barba. } \\
\text { - Tomo cuidados } \\
\text { adicionais com } \\
\text { as minhas } \\
\text { roupas. }\end{array}$ & $\begin{array}{c}\text { Mantido } \\
\text { (modificado) }\end{array}$ \\
\hline 26 & $\begin{array}{c}\text { Vou } \\
\text { predisposta/o a } \\
\text { não reclamar do } \\
\text { atendimento, } \\
\text { mesmo se eu } \\
\text { estiver sofrendo } \\
\text { ou com dor }\end{array}$ & 1 & $\begin{array}{l}\text { Sugestão: retirar } \\
\text { "mesmo"; } \\
\text { Antecipação do evento } \\
\text { discriminatório ou de } \\
\text { injustiça. Sugere revisar } \\
\text { bibliografia sobre } \\
\text { "antecipatory threat"/HIV } \\
\text { e AIDS; } \\
\text { Sugestão de nova } \\
\text { redação: 'Eu me } \\
\text { programo/preparo para } \\
\text { não reclamar do } \\
\text { atendimento'. }\end{array}$ & $\begin{array}{l}\text { Me preparo para } \\
\text { não reclamar do } \\
\text { atendimento. }\end{array}$ & $\begin{array}{c}\text { Mantido } \\
\text { (modificado) }\end{array}$ \\
\hline 27 & $\begin{array}{l}\text { Mudo o local de } \\
\text { atendimento }\end{array}$ & 0,50 & $\begin{array}{l}\text { Trata-se de uma reação } \\
\text { e não percepção } \\
\text { Antecipação do evento } \\
\text { discriminatório ou de } \\
\text { injustiça; }\end{array}$ & - & Excluído \\
\hline 28 & $\begin{array}{l}\text { Não busco mais } \\
\text { atendimento }\end{array}$ & 0,25 & $\begin{array}{l}\text { Trata-se de uma reação } \\
\text { e não percepção; } \\
\text { Muito semelhante à } \\
\text { anterior. }\end{array}$ & - & Excluído \\
\hline
\end{tabular}




\begin{tabular}{|c|c|c|c|c|c|}
\hline Item & Descrição & CVR & $\begin{array}{l}\text { Resumo das } \\
\text { avaliações qualitativas }\end{array}$ & $\begin{array}{l}\text { Item modificado } \\
\text { segundo as } \\
\text { sugestões }\end{array}$ & $\begin{array}{l}\text { Decisão } \\
\text { final }\end{array}$ \\
\hline \multicolumn{6}{|c|}{$\begin{array}{l}\text { Na minha opinião: Sugestão: incluir 'serviços de saúde', então, ficou: Na minha opinião, em serviços de } \\
\text { saúde: }\end{array}$} \\
\hline 29 & $\begin{array}{l}\text { Os homens } \\
\text { brancos são os } \\
\text { que mais } \\
\text { recebem } \\
\text { tratamento injusto } \\
\text { nos serviços de } \\
\text { saúde }\end{array}$ & 0,25 & $\begin{array}{l}\text { A estrutura da pergunta } \\
\text { é indutiva. É necessário } \\
\text { excluir a palavra "mais". } \\
\text { Esse "mais" ou "menos" } \\
\text { será obtido na } \\
\text { quantificação dos dados. } \\
\text { As questões de } 29 \text { a } 38 \\
\text { tratam de sujeitos } \\
\text { (homens, mulheres } \\
\text { brancas, negros, etc). } \\
\text { Como isso pontuaria na } \\
\text { escala? Em que } \\
\text { dimensão? Eu estou } \\
\text { colocando da dimensão } \\
\text { experiência, mas... Você } \\
\text { está avaliando o } \\
\text { sistema, se você coletar } \\
\text { dados em que as } \\
\text { pessoas já têm pré- } \\
\text { disposição a estrutura } \\
\text { das questões vão gerar } \\
\text { tendências de respostas } \\
\text { sem que o sistema de } \\
\text { saúde seja avaliado; } \\
\text { Não tenho sugestão } \\
\text { para esse item, mas } \\
\text { entendo que o mesmo } \\
\text { foge do objetivo do } \\
\text { instrumento, que aborda } \\
\text { experiências de } \\
\text { discriminação racial em } \\
\text { nível interpessoal ou } \\
\text { institucional. Uma } \\
\text { pergunta genérica como } \\
\text { essa não abrange } \\
\text { claramente, em minha } \\
\text { opinião, essas } \\
\text { dimensões de } \\
\text { manifestação da } \\
\text { discriminação; } \\
\text { Não reflete o construto } \\
\text { de interesse do } \\
\text { instrumento em suas } \\
\text { dimensões pretendidas. }\end{array}$ & - & Excluído \\
\hline 30 & $\begin{array}{c}\text { As mulheres } \\
\text { brancas são os } \\
\text { que mais } \\
\text { recebem } \\
\text { tratamento injusto } \\
\text { nos serviços de } \\
\text { saúde }\end{array}$ & 0,25 & Idem ao anterior & - & Excluído \\
\hline 31 & $\begin{array}{l}\text { Os homens } \\
\text { asiáticos são os } \\
\text { que mais } \\
\text { recebem } \\
\text { tratamento } \\
\text { injusto nos } \\
\text { serviços de } \\
\text { saúde }\end{array}$ & 0,50 & $\begin{array}{l}\text { Idem ao anterior; } \\
\text { Uniformizar para } \\
\text { 'amarelo'; } \\
\text { Os russos e hindus } \\
\text { também são asiático; } \\
\text { Sugestão de redação: } \\
\text { (...) 'os homens } \\
\text { amarelos ("orientais", } \\
\text { japoneses, chineses } \\
\text { etc.)' }\end{array}$ & - & Excluído \\
\hline
\end{tabular}




\begin{tabular}{|c|c|c|c|c|c|}
\hline Item & Descrição & CVR & $\begin{array}{c}\text { Resumo das } \\
\text { avaliações qualitativas }\end{array}$ & $\begin{array}{c}\text { Item modificado } \\
\text { segundo as } \\
\text { sugestões }\end{array}$ & $\begin{array}{l}\text { Decisão } \\
\text { final }\end{array}$ \\
\hline 32 & $\begin{array}{c}\text { As mulheres } \\
\text { asiáticas são os } \\
\text { que mais } \\
\text { recebem } \\
\text { tratamento } \\
\text { injusto nos } \\
\text { serviços de } \\
\text { saúde }\end{array}$ & 0,25 & Idem & - & Excluído \\
\hline 33 & $\begin{array}{l}\text { Os homens } \\
\text { pardos são os } \\
\text { que mais } \\
\text { recebem } \\
\text { tratamento } \\
\text { injusto nos } \\
\text { serviços de } \\
\text { saúde }\end{array}$ & 0,25 & Idem & - & Excluído \\
\hline 34 & $\begin{array}{l}\text { As mulheres } \\
\text { pardas são os } \\
\text { que mais } \\
\text { recebem } \\
\text { tratamento } \\
\text { injusto nos } \\
\text { serviços de } \\
\text { saúde }\end{array}$ & 0,25 & Idem & - & Excluído \\
\hline 35 & $\begin{array}{l}\text { Os homens } \\
\text { pretos são os } \\
\text { que mais } \\
\text { recebem } \\
\text { tratamento } \\
\text { injusto nos } \\
\text { serviços de } \\
\text { saúde }\end{array}$ & 0,25 & Idem & - & Excluído \\
\hline 36 & $\begin{array}{l}\text { As mulheres } \\
\text { pretas são os } \\
\text { que mais } \\
\text { recebem } \\
\text { tratamento } \\
\text { injusto nos } \\
\text { serviços de } \\
\text { saúde }\end{array}$ & 0,25 & $\begin{array}{l}\text { Idem } \\
\text { Se só negros } \\
\text { responderão o } \\
\text { questionário, isso vai } \\
\text { gerar um enviesamento } \\
\text { das respostas }\end{array}$ & - & Excluído \\
\hline 37 & $\begin{array}{l}\text { Os homens } \\
\text { indígenas são os } \\
\text { que mais } \\
\text { recebem } \\
\text { tratamento } \\
\text { injusto nos } \\
\text { serviços de } \\
\text { saúde }\end{array}$ & 0,75 & $\begin{array}{l}\text { Idem } \\
\text { Se só negros } \\
\text { responderão o } \\
\text { questionário, isso vai } \\
\text { gerar um enviesamento } \\
\text { das respostas; } \\
\text { Apesar do valor de CVR } \\
\text { justificar a permanência } \\
\text { do item, este só faz } \\
\text { sentido no conjunto de } \\
\text { itens do mesmo bloco. } \\
\text { Portanto, foi excluído. }\end{array}$ & - & Excluído \\
\hline 38 & $\begin{array}{l}\text { As mulheres } \\
\text { indígenas são os } \\
\text { que mais } \\
\text { recebem } \\
\text { tratamento } \\
\text { injusto nos } \\
\text { serviços de } \\
\text { saúde }\end{array}$ & 0,75 & $\begin{array}{l}\text { Idem; } \\
\text { Se só negros } \\
\text { responderão o } \\
\text { questionário, isso vai } \\
\text { gerar um enviesamento } \\
\text { das respostas } \\
\text { Apesar do valor de CVR } \\
\text { justificar a permanência } \\
\text { do item, este só faz } \\
\text { sentido no conjunto. } \\
\text { Portanto, será excluído. }\end{array}$ & - & Excluído \\
\hline
\end{tabular}




\begin{tabular}{|c|c|c|c|c|c|}
\hline Item & Descrição & CVR & $\begin{array}{c}\text { Resumo das } \\
\text { avaliações qualitativas }\end{array}$ & $\begin{array}{l}\text { Item modificado } \\
\text { segundo as } \\
\text { sugestões }\end{array}$ & $\begin{array}{l}\text { Decisão } \\
\text { final }\end{array}$ \\
\hline \multicolumn{6}{|c|}{$\begin{array}{l}\text { Eu costumo me sentir tratada/o injustamente devido à minha raça/cor da pele quando entre os } \\
\text { profissionais de saúde (médicos, enfermeiras, atendentes etc.) Sugestão: incluir 'serviços de saúde', } \\
\text { então, ficou: Eu costumo me sentir tratada/o injustamente, em serviços de saúde, devido à minha } \\
\text { raça/cor da pele quando, entre os profissionais de saúde (médicos, enfermeiras, atendentes etc.): }\end{array}$} \\
\hline 39 & $\begin{array}{l}\text { Há só pessoas } \\
\text { de raça/cor da } \\
\text { pele brancas }\end{array}$ & 0,75 & $\begin{array}{l}\text { Dos itens } 39 \text { a 44: Os } \\
\text { respondentes serão } \\
\text { apenas negros? Se for } \\
\text { há um enviesamento do } \\
\text { estudo. Se for não } \\
\text { estará avaliando a } \\
\text { injustiça do sistema. Os } \\
\text { problemas apontados } \\
\text { pelos negros podem } \\
\text { também ser apontados } \\
\text { pelos brancos, o que } \\
\text { retiraria do pano primário } \\
\text { o racismo e focaria } \\
\text { sobre a inabilidade do } \\
\text { sistema para o } \\
\text { atendimento como um } \\
\text { todo. Outra forma de } \\
\text { olhar é que há um } \\
\text { racismo/preconceito por } \\
\text { parte do paciente, já que } \\
\text { ele considera a cor/raça } \\
\text { do corpo técnico que irá } \\
\text { atendê-lo e isto já } \\
\text { levaria-o a se sentir } \\
\text { injustiçado??!!!! } \\
\text { (metodologista) } \\
\text { Resposta: Pessoas de } \\
\text { todas as raças/cor } \\
\text { deverão responder ao } \\
\text { instrumento; } \\
\text { Sugestão de nova } \\
\text { redação: (...) 'Só há } \\
\text { pessoas de raça/cor da } \\
\text { pele branca'. } \\
\end{array}$ & $\begin{array}{l}\text { Só há pessoas } \\
\text { de raça/cor da } \\
\text { pele branca }\end{array}$ & $\begin{array}{c}\text { Mantido } \\
\text { (modificado) }\end{array}$ \\
\hline 40 & $\begin{array}{l}\text { Há só pessoas } \\
\text { de raça/cor da } \\
\text { pele pretos e } \\
\text { pardos }\end{array}$ & 0,75 & $\begin{array}{l}\text { Isso antecede a } \\
\text { qualquer ato de } \\
\text { injustiça/discriminação; } \\
\text { O item não evoca } \\
\text { injustiça; } \\
\text { Sugestão de nova } \\
\text { redação: (...) 'Só há } \\
\text { pessoas de raça/cor da } \\
\text { pele preta ou parda'. } \\
\text { Sugestão de outro } \\
\text { especialista: (...) Só há } \\
\text { pessoas negras'. }\end{array}$ & $\begin{array}{l}\text { Só há pessoas } \\
\text { de raça/cor da } \\
\text { pele negra }\end{array}$ & $\begin{array}{c}\text { Mantido } \\
\text { (modificado) }\end{array}$ \\
\hline 41 & $\begin{array}{c}\text { Há só pessoas } \\
\text { de raça/cor da } \\
\text { pele brancas e } \\
\text { asiáticas }\end{array}$ & 0,50 & $\begin{array}{l}\text { Isso antecede a } \\
\text { qualquer ato de } \\
\text { injustiça/discriminação; } \\
\text { O item não evoca } \\
\text { injustiça. } \\
\text { Item potencialmente } \\
\text { redundante com ou } \\
\text { anterior, que abordava } \\
\text { apenas profissionais } \\
\text { brancos; } \\
\text { Sugestão: 'amarelas'. }\end{array}$ & - & Excluído \\
\hline 42 & $\begin{array}{l}\text { Há só pessoas } \\
\text { de raça/cor da } \\
\text { pele brancas, }\end{array}$ & 0 & Idem ao anterior & - & Excluído \\
\hline
\end{tabular}




\begin{tabular}{|c|c|c|c|c|c|}
\hline Item & Descrição & CVR & $\begin{array}{c}\text { Resumo das } \\
\text { avaliações qualitativas }\end{array}$ & $\begin{array}{l}\text { Item modificado } \\
\text { segundo as } \\
\text { sugestões }\end{array}$ & $\begin{array}{l}\text { Decisão } \\
\text { final }\end{array}$ \\
\hline & $\begin{array}{l}\text { asiáticas e } \\
\text { pardas }\end{array}$ & & & & \\
\hline 43 & $\begin{array}{c}\text { Há só pessoas } \\
\text { de raça/cor da } \\
\text { pele brancas, } \\
\text { asiáticas, pardas } \\
\text { e pretas }\end{array}$ & 0 & $\begin{array}{l}\text { Item provoca dúvida no } \\
\text { respondente; } \\
\text { Isso antecede a } \\
\text { qualquer ato de } \\
\text { injustiça/discriminação; } \\
\text { O item não evoca } \\
\text { injustiça. } \\
\text { Item potencialmente } \\
\text { redundante com ou } \\
\text { anterior, que abordava } \\
\text { apenas profissionais } \\
\text { brancos }\end{array}$ & - & Excluído \\
\hline 44 & $\begin{array}{c}\text { Há pessoas de } \\
\text { todas as raças e } \\
\text { cores }\end{array}$ & 0,50 & $\begin{array}{l}\text { Idem ao anterior; + } \\
\text { Esse conjunto de } \\
\text { perguntas ( } 39 \text { a 44) em } \\
\text { nenhum momento avalia } \\
\text { a injustiça do sistema. } \\
\text { Veja se o corpo técnico } \\
\text { não tiver a cor/raça que } \\
\text { agrade o paciente, } \\
\text { significa injustiça do } \\
\text { sistema? (metodologista) } \\
\text { Resposta: uma leitura } \\
\text { possível: racismo } \\
\text { estrutural. }\end{array}$ & - & Excluído \\
\hline 45 & $\begin{array}{l}\text { Eu já presenciei } \\
\text { um/a familiar, } \\
\text { parente ou } \\
\text { amiga/o ser } \\
\text { tratada/o } \\
\text { injustamente } \\
\text { devido à } \\
\text { raça/cor da pele } \\
\text { em serviços de } \\
\text { saúde }\end{array}$ & 1 & - & $\begin{array}{l}\text { Item não } \\
\text { modificado }\end{array}$ & Mantido \\
\hline 46 & $\begin{array}{c}\text { Eu já presenciei } \\
\text { outras pessoas } \\
\text { serem tratadas } \\
\text { injustamente } \\
\text { devido à } \\
\text { raça/cor da pele } \\
\text { em serviços de } \\
\text { saúde }\end{array}$ & 1 & - & $\begin{array}{l}\text { Item não } \\
\text { modificado }\end{array}$ & Mantido \\
\hline 47 & $\begin{array}{c}\text { Eu já me senti } \\
\text { tratada/o com } \\
\text { privilégios } \\
\text { devido à minha } \\
\text { raça/cor da pele } \\
\text { em serviços de } \\
\text { saúde }\end{array}$ & 0,75 & $\begin{array}{l}\text { Se ele se sentir } \\
\text { privilegiado, a escala } \\
\text { segue a mesma } \\
\text { normatização de quando } \\
\text { ele sente que } \\
\text { parente/amigos foram } \\
\text { tratados injustamente? } \\
\text { Eles tendem a ter } \\
\text { sentido de resposta } \\
\text { inversas na escala, o } \\
\text { que geraria correlações } \\
\text { negativas na validação } \\
\text { de construto, } \\
\text { considerando que estas } \\
\text { perguntas pressupõem- } \\
\text { se tratarem de injustiça } \\
\text { e, portanto, do mesmo } \\
\text { fenômeno. Elas não }\end{array}$ & & Mantido \\
\hline
\end{tabular}




\begin{tabular}{|c|c|c|c|c|c|}
\hline Item & Descrição & CVR & $\begin{array}{c}\text { Resumo das } \\
\text { avaliações qualitativas }\end{array}$ & $\begin{array}{l}\text { Item modificado } \\
\text { segundo as } \\
\text { sugestões }\end{array}$ & $\begin{array}{l}\text { Decisão } \\
\text { final }\end{array}$ \\
\hline & & & $\begin{array}{l}\text { poderiam gerar } \\
\text { correlações negativas; } \\
\text { O instrumento aborda } \\
\text { discriminação ou } \\
\text { tratamento injusto e, } \\
\text { portanto, não deve } \\
\text { incluir itens que captem } \\
\text { a situação oposta, de } \\
\text { privilégio. }\end{array}$ & & \\
\hline 48 & $\begin{array}{c}\text { Eu já vi um } \\
\text { familiar, parente } \\
\text { ou amigo ser } \\
\text { tratada/o com } \\
\text { privilégios } \\
\text { devido à } \\
\text { raça/cor da pele } \\
\text { em serviços de } \\
\text { saúde. } \\
\end{array}$ & 0,50 & $\begin{array}{l}\text { O instrumento aborda } \\
\text { discriminação ou } \\
\text { tratamento injusto e, } \\
\text { portanto, não deve } \\
\text { incluir itens que captem } \\
\text { a situação oposta, de } \\
\text { privilégio. }\end{array}$ & - & Excluído \\
\hline 49 & $\begin{array}{c}\text { Eu já vi um/a } \\
\text { desconhecido/a } \\
\text { ser tratada/o } \\
\text { com privilégios } \\
\text { devido à } \\
\text { raça/cor da pele } \\
\text { em serviços de } \\
\text { saúde. }\end{array}$ & 0,75 & $\begin{array}{l}\text { O instrumento aborda } \\
\text { discriminação ou } \\
\text { tratamento injusto e, } \\
\text { portanto, não deve } \\
\text { incluir itens que captem } \\
\text { a situação oposta, de } \\
\text { privilégio; } \\
\text { Sugestão de nova } \\
\text { redação: 'Eu já vi um/a } \\
\text { desconhecida/o ser } \\
\text { tratada/o com privilégios } \\
\text { devido à raça/cor da } \\
\text { pele. }\end{array}$ & $\begin{array}{c}\text { Eu já vi uma/m } \\
\text { desconhecida/o } \\
\text { ser tratada/o com } \\
\text { privilégios devido } \\
\text { à raça/cor da } \\
\text { pele }\end{array}$ & Mantido \\
\hline
\end{tabular}

Nesta etapa, dois critérios foram utilizados para avaliar o DRISS, o critério qualitativo e o critério quantitativo. O critério qualitativo se referiu à contribuição por escrito dada por cada especialista do comitê, contendo críticas e sugestões. Essas contribuições eram feitas por meio caixas de texto digitáveis disponibilizadas para cada item a ser avaliado. Além disso, também foram feitas contribuições qualitativas por e-mail, falando do instrumento no geral. Assim, foi possível verificar a parte qualitativa da validade de conteúdo, ou seja, se os itens estavam refletindo, de fato o melhor conjunto de itens possíveis para medir o DRISS. Desse modo, por meio das avaliações qualitativas, 9 itens foram modificados, além do texto introdutório; os itens foram: 2, 4, 14, 18, 19, 25, 26, 39 e 40 (Quadro 6).

Quanto ao critério quantitativo, os itens que apresentaram CVR $\geq 0,75$ foram mantidos, enquanto os itens que não atingiram esse valor foram excluídos; são eles os itens: $5,6,7,8,11,13,20,21,22,23,24,27,28,29,30,31,32,33,34,35,36,37,38,41$, 42, 43, 44 e 48. Portanto, dos 50 itens elaborados originalmente, restaram apenas 22.0 CVR médio dos itens que restaram foi 0,74 . 
Com relação à concordância entre os especialistas, o PABAK foi 0,30 - valor considerado razoável.

\subsubsection{Versão 2 do DRISS}

Após as avaliações do comitê de especialistas, foi elaborada a versão 2 do DRISS, que pode ser observada no Quadro 6. A versão 2 foi submetida a pré-teste junto aos membros população-alvo. 
Quadro 6 - Versão 2 do DRISS, São Paulo, 2017.

\begin{tabular}{|c|c|c|c|c|c|}
\hline \multirow{2}{*}{$\begin{array}{l}\text { Item } \\
\text { Texto introdutório: } \\
\text { Nesse estudo, nós incluímos apenas questões que buscam } \\
\text { investigar as situações em que você foi tratada/o } \\
\text { injustamente devido à sua raça/cor da pele, nos serviços } \\
\text { de saúde. }\end{array}$} & \multicolumn{5}{|c|}{ Opções de resposta } \\
\hline & 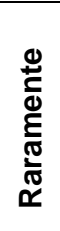 & 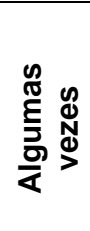 & 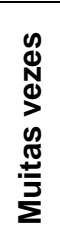 & 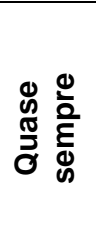 & 흘 \\
\hline \multicolumn{6}{|l|}{$\begin{array}{l}\text { Quando eu sou tratada/o injustamente devido à } \\
\text { minha raça/cor da pele, em serviços de saúde, eu: }\end{array}$} \\
\hline \multicolumn{6}{|l|}{ 1. Ignoro } \\
\hline \multicolumn{6}{|l|}{ 2. Encaro como um acontecimento cotidiano } \\
\hline \multicolumn{6}{|l|}{$\begin{array}{l}\text { 3. Converso com alguma pessoa, como um familiar, } \\
\text { ou amigo, sobre o que aconteceu }\end{array}$} \\
\hline 4. Procuro esquecer o que aconteceu & & & & & \\
\hline 5. Faço uma oração (ou rezo) pela situação. & & & & & \\
\hline 6. Guardo isso para mim mesma/o & & & & & \\
\hline 7. Me sinto humilhada/o & & & & & \\
\hline 8. Me sinto impotente & & & & & \\
\hline \multicolumn{6}{|l|}{ 9. Sinto raiva } \\
\hline \multicolumn{6}{|l|}{ 10. Tenho dores de cabeça } \\
\hline \multicolumn{6}{|l|}{ 11. Tenho dores de estômago } \\
\hline \multicolumn{6}{|l|}{ 12. Tenho tensão nos músculos } \\
\hline \multicolumn{6}{|l|}{ 13. Tenho palpitação no coração } \\
\hline \multicolumn{6}{|l|}{$\begin{array}{l}\text { 14. Tenho receio de ter que esperar mais do que o } \\
\text { normal para ser atendida/o }\end{array}$} \\
\hline \multicolumn{6}{|l|}{ 15. Reclamo em voz alta } \\
\hline \multicolumn{6}{|l|}{$\begin{array}{l}\text { 16. Denuncio para as autoridades (por exemplo: } \\
\text { registro uma ocorrência na polícia ou abro um } \\
\text { processo na justiça) }\end{array}$} \\
\hline \multicolumn{6}{|l|}{$\begin{array}{l}\text { Para evitar ser tratada/o injustamente, em serviços } \\
\text { de saúde, devido à minha raça/cor de pele, eu: }\end{array}$} \\
\hline \multicolumn{6}{|l|}{ 17. Tomo cuidados adicionais com a higiene } \\
\hline \multicolumn{6}{|l|}{ 18. Tomo cuidados adicionais com a depilação/barba } \\
\hline \multicolumn{6}{|l|}{ 19. Tomo cuidados adicionais com as minhas roupas } \\
\hline \multicolumn{6}{|l|}{ 20. Me preparo para não reclamar do atendimento } \\
\hline \multicolumn{6}{|l|}{$\begin{array}{l}\text { Responda as próximas perguntas pensando em } \\
\text { situações que ocorreram com outras pessoas }\end{array}$} \\
\hline \multicolumn{6}{|l|}{$\begin{array}{l}\text { 21. Eu já presenciei um/a familiar, parente ou amiga/o } \\
\text { ser tratada/o injustamente devido à raça/cor da } \\
\text { pele em serviços de saúde? }\end{array}$} \\
\hline \multicolumn{6}{|l|}{$\begin{array}{l}\text { 22. Eu já presenciei outras pessoas serem tratadas } \\
\text { injustamente devido à raça/cor da pele em } \\
\text { serviços de saúde? }\end{array}$} \\
\hline \multicolumn{6}{|l|}{$\begin{array}{l}\text { Responda as próximas perguntas pensando em } \\
\text { situações em que você observou privilégio }\end{array}$} \\
\hline \multicolumn{6}{|l|}{$\begin{array}{l}\text { 23. Eu já me senti tratada/o com privilégios devido à } \\
\text { minha raça/cor da pele em serviços de saúde }\end{array}$} \\
\hline $\begin{array}{l}\text { 24. Eu já vi um/a desconhecido/a ser tratada/o com } \\
\text { privilégios devido à raça/cor da pele em serviços } \\
\text { de saúde. }\end{array}$ & & & & & \\
\hline
\end{tabular}




\subsubsection{Pré-teste}

O pré-teste ocorreu entre os meses de agosto e setembro de 2017. No primeiro momento, foram realizadas três entrevistas com registro em papel junto aos membros da população-alvo. Estas entrevistas possibilitaram compreender a necessidade de incluir mais perguntas introdutórias que estimulassem as pessoas a focarem nos objetivos da pesquisa e na especificidade dos serviços de saúde. Assim, foram inseridas, entre as perguntas introdutórias, exemplos de tipos de serviços de saúde e nove exemplos de tratamento injusto, com possibilidade de incluir por escrito alguma 'outra' situação (Figura 6).

Figura 6 - Questões introdutórias do DRISS, versão 2. São Paulo, 2017.

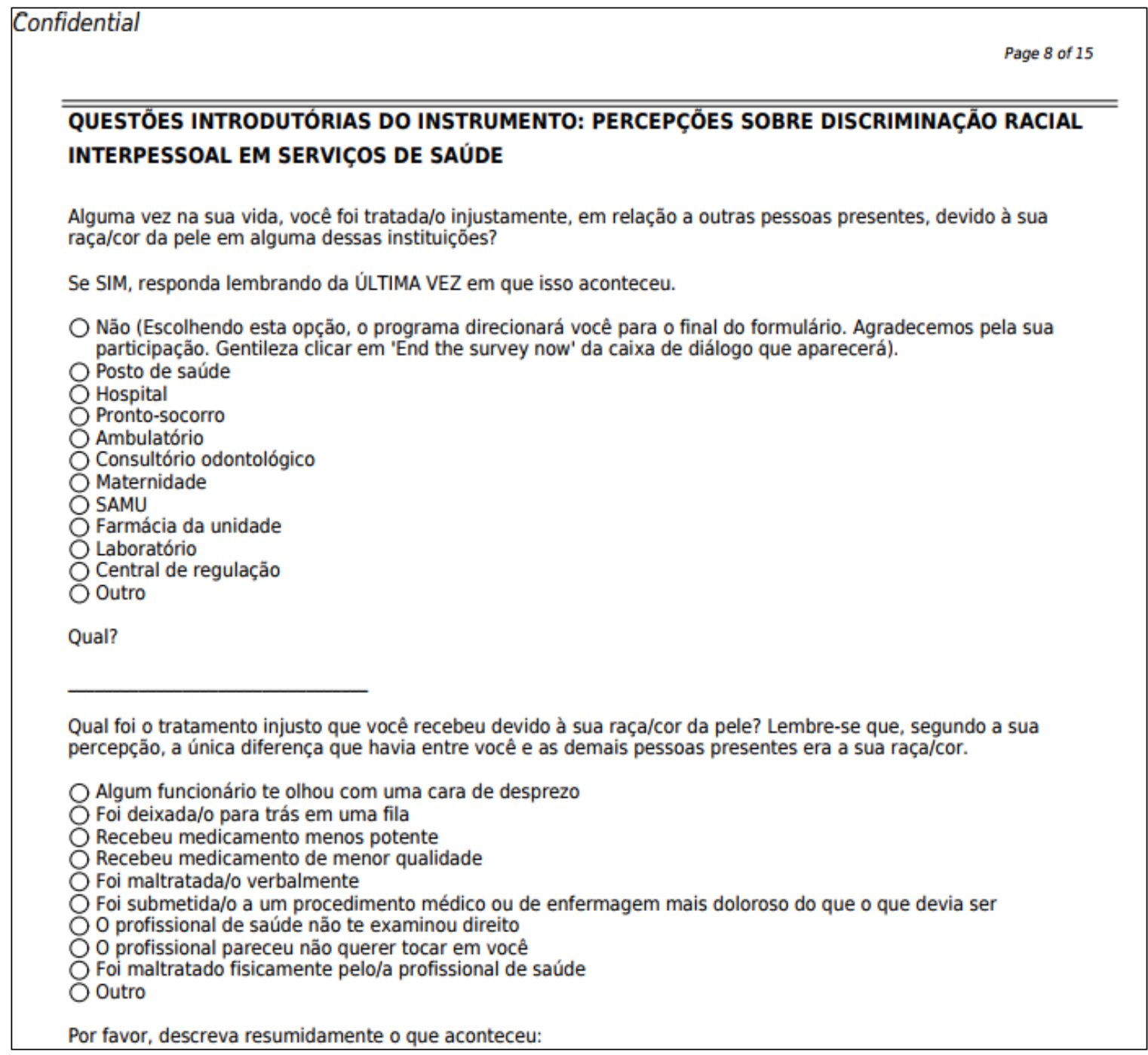


Além disso, observou-se que os respondentes estavam tendo dificuldade de compreender $\mathrm{o}$ item 24, pois se tratava de um item que questionava sobre terceiros: "Eu já vi um/a desconhecido/a ser tratada/o com privilégios devido à raça/cor da pele em serviços de saúde". Assim, decidiu-se incluir o termo "DA PESSOA", com letra maiúscula, para facilitar a compreensão do respondente (Quadro 7).

No segundo momento, esses três formulários preenchidos em papel foram digitados no REDCap. A partir daí, solicitou-se auxílio de colegas de curso, das orientadoras deste trabalho e de membros da população-alvo para que respondessem ao instrumento diretamente no REDCap, por meio do link disponibilizado. Foram apontados pequenos problemas nos saltos entre um item e outro, que foram resolvidos. No total, o pré-teste recebeu 40 acessos, tendo 21 instrumentos preenchidos por completo.

Após essas modificações e a inserção de mais duas questões introdutórias, foi elaborada a versão 3 do DRISS, que foi disponibilizado para que a população-alvo respondesse.

Portanto, o pré-teste mostrou que o DRISS que era viável para ser respondido online via REDCap e que estava pronto para ser disponibilizado para a populaçãoalvo.

\subsubsection{Versão 3 do DRISS}

A versão 3 do DRISS encontra-se no Quadro 7. Essa versão foi disponibilizada no REDCap e constitui a versão utilizada para analisar a validade de constructo. 
Quadro 7 - Versão 3 do DRISS, São Paulo, 2017.

\begin{tabular}{|c|c|c|c|c|c|}
\hline \multirow{2}{*}{$\begin{array}{l}\text { Item } \\
\text { Texto introdutório: } \\
\text { Nesse estudo, nós incluímos apenas questões que buscam } \\
\text { investigar as situações em que você foi tratada/o } \\
\text { injustamente devido à sua raça/cor da pele, nos serviços } \\
\text { de saúde. }\end{array}$} & \multicolumn{5}{|c|}{ Opções de resposta } \\
\hline & 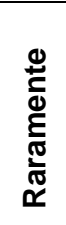 & 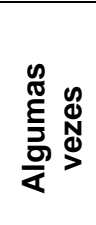 & 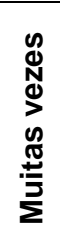 & 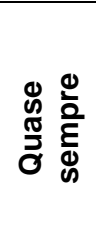 & 을 \\
\hline \multicolumn{6}{|l|}{$\begin{array}{l}\text { Quando eu sou tratada/o injustamente devido à minha } \\
\text { raça/cor da pele, em serviços de saúde, eu: }\end{array}$} \\
\hline \multicolumn{6}{|l|}{ 1. Ignoro } \\
\hline \multicolumn{6}{|l|}{ 2. Encaro como um acontecimento cotidiano } \\
\hline \multicolumn{6}{|l|}{$\begin{array}{l}\text { 3. Converso com alguma pessoa, como um familiar, ou } \\
\text { amigo, sobre o que aconteceu }\end{array}$} \\
\hline \multicolumn{6}{|l|}{ 4. Procuro esquecer o que aconteceu } \\
\hline \multicolumn{6}{|l|}{ 5. Faço uma oração (ou rezo) pela situação. } \\
\hline \multicolumn{6}{|l|}{ 6. Guardo isso para mim mesma/o } \\
\hline \multicolumn{6}{|l|}{ 7. Me sinto humilhada/o. } \\
\hline \multicolumn{6}{|l|}{ 8. Me sinto impotente. } \\
\hline \multicolumn{6}{|l|}{ 9. Sinto raiva } \\
\hline \multicolumn{6}{|l|}{ 10. Tenho dores de cabeça; } \\
\hline \multicolumn{6}{|l|}{ 11. Tenho dores de estômago; } \\
\hline \multicolumn{6}{|l|}{ 12. Tenho tensão nos músculos; } \\
\hline \multicolumn{6}{|l|}{ 13. Tenho palpitação no coração } \\
\hline \multicolumn{6}{|l|}{$\begin{array}{l}\text { 14. Tenho receio de ter que esperar mais do que o normal } \\
\text { para ser atendida/o. }\end{array}$} \\
\hline \multicolumn{6}{|l|}{ 15. Reclamo em voz alta } \\
\hline \multicolumn{6}{|l|}{$\begin{array}{l}\text { 16. Denuncio para as autoridades (por exemplo: registro } \\
\text { uma ocorrência na polícia ou abro um processo na } \\
\text { justiça). }\end{array}$} \\
\hline \multicolumn{6}{|l|}{$\begin{array}{l}\text { Para evitar ser tratada/o injustamente, em serviços de } \\
\text { saúde, devido à minha raça/cor de pele, eu: }\end{array}$} \\
\hline \multicolumn{6}{|l|}{ 17. Tomo cuidados adicionais com a higiene. } \\
\hline \multicolumn{6}{|l|}{ 18. Tomo cuidados adicionais com a depilação/barba. } \\
\hline \multicolumn{6}{|l|}{ 19. Tomo cuidados adicionais com as minhas roupas. } \\
\hline \multicolumn{6}{|l|}{ 20. Me preparo para não reclamar do atendimento } \\
\hline \multicolumn{6}{|l|}{$\begin{array}{l}\text { Responda as próximas perguntas pensando em } \\
\text { situações que ocorreram com outras pessoas }\end{array}$} \\
\hline \multicolumn{6}{|l|}{$\begin{array}{l}\text { 21. Eu já presenciei um/a familiar, parente ou amiga/o ser } \\
\text { tratada/o injustamente devido à raça/cor da pele em } \\
\text { serviços de saúde? }\end{array}$} \\
\hline \multicolumn{6}{|l|}{$\begin{array}{l}\text { 22. Eu já presenciei outras pessoas serem tratadas } \\
\text { injustamente devido à raça/cor da pele em serviços de } \\
\text { saúde? }\end{array}$} \\
\hline \multicolumn{6}{|l|}{$\begin{array}{l}\text { Responda as próximas perguntas pensando em } \\
\text { situações em que você observou privilégio }\end{array}$} \\
\hline \multicolumn{6}{|l|}{$\begin{array}{l}\text { 23. Eu já me senti tratada/o com privilégios devido à minha } \\
\text { raça/cor da pele em serviços de saúde }\end{array}$} \\
\hline $\begin{array}{l}\text { 24. Eu já vi um/a desconhecido/a ser tratado/a com } \\
\text { privilégios devido à raça/cor da pele DA PESSOA, em } \\
\text { serviços de saúde }\end{array}$ & & & & & \\
\hline
\end{tabular}


Com a finalização da versão 3 , observou-se que a verificação da validade de conteúdo foi concluída, utilizando critérios qualitativos e quantitativos que mostraram resultados adequados.

\subsection{ETAPA 2 - VALIDAÇÃO DE CONSTRUCTO}

Este capítulo apresenta resultados da validação de constructo do DRISS em sua versão 3 (Apêndice I), que foi disponibilizada online para a população-alvo no REDCap. Os resultados oriundos das respostas da população-alvo ao DRISS possibilitaram conduzir a análise estatística para proceder a validação de constructo. Portanto, este capítulo contém informações sobre: divulgação do DRISS, fluxo de respondentes, dados sociodemográficos da amostra, análise fatorial, rotulação de fatores, escores e associações entre escores e variáveis sociodemográficas.

\subsubsection{Divulgação do DRISS}

O DRISS foi divulgado por e-mail e em redes sociais a partir de 16/09/2017, tendo permanecido até 05/12/2017, totalizando 80 dias ativo, por meio do link: http://j.mp/2tge2Ro. Ao clicar no link, o respondente era direcionado para a primeira página do DRISS, que continha o TCLE (Figura 7). No caso de aceitar participar da pesquisa, o respondente clicava em "aceito" e era direcionado para as páginas subsequentes, que continham o questionário sociodemográfico, as questões introdutórias ao DRISS e o DRISS, propriamente dito. 
Figura 7 - Página inicial do DRISS no REDCap. São Paulo, 2017.

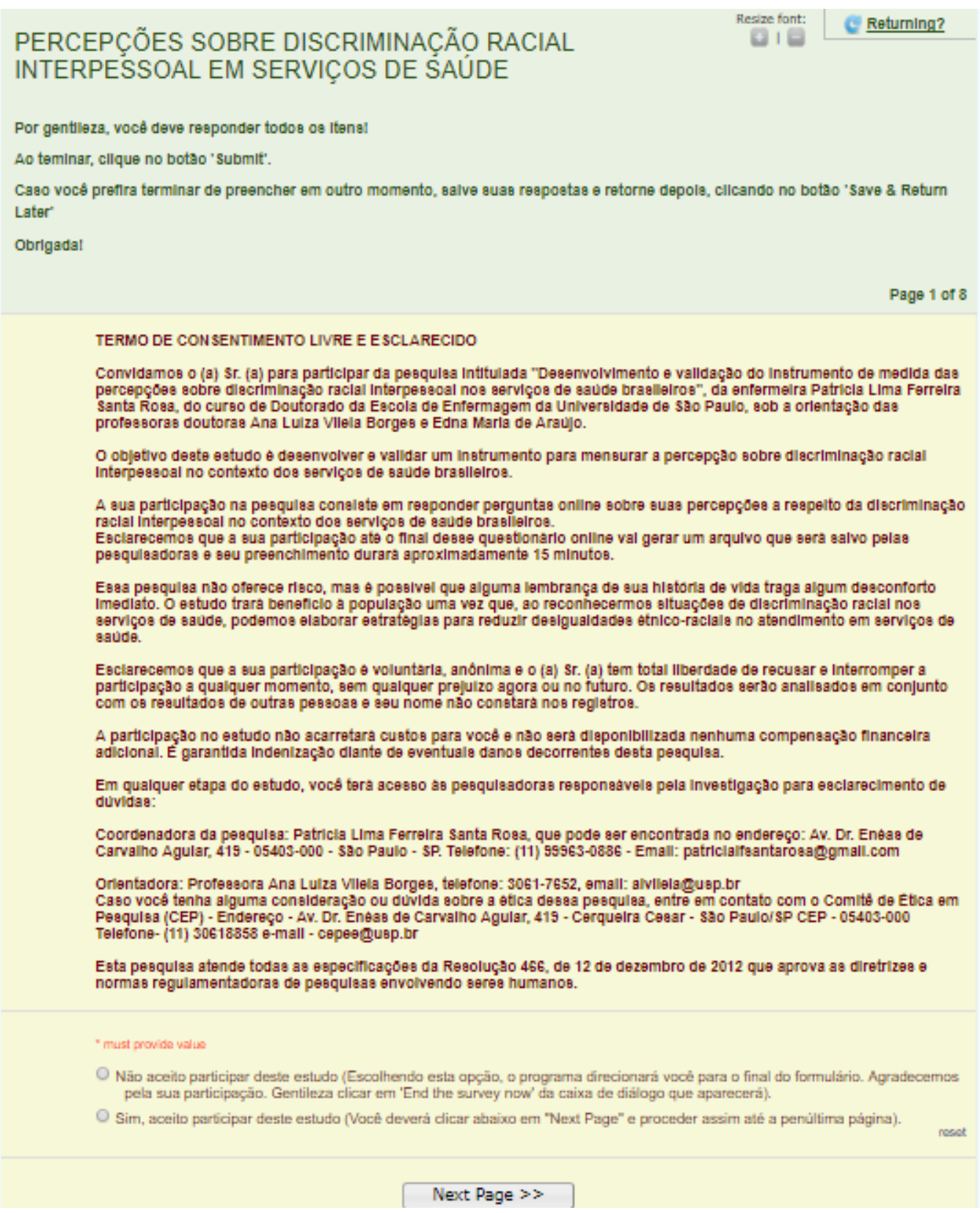

No primeiro mês, entre os dias 17 de setembro e 16 de outubro, houve pouca adesão à pesquisa, a despeito da divulgação realizada, inclusive com chamada para a pesquisa publicada no site da Organização Não-Governamental Educação para Afrodescendentes e Carentes (EDUCAFRO) (Figura 8), uma entidade que trata de assuntos voltados para interesses educacionais de pessoas negras e carentes. Por essa razão, a divulgação foi intensificada nos mesmos meios, mas com outras três estratégias. 
Figura 8 - Chamada para responder a pesquisa no site da EDUCAFRO. São Paulo, 2017.

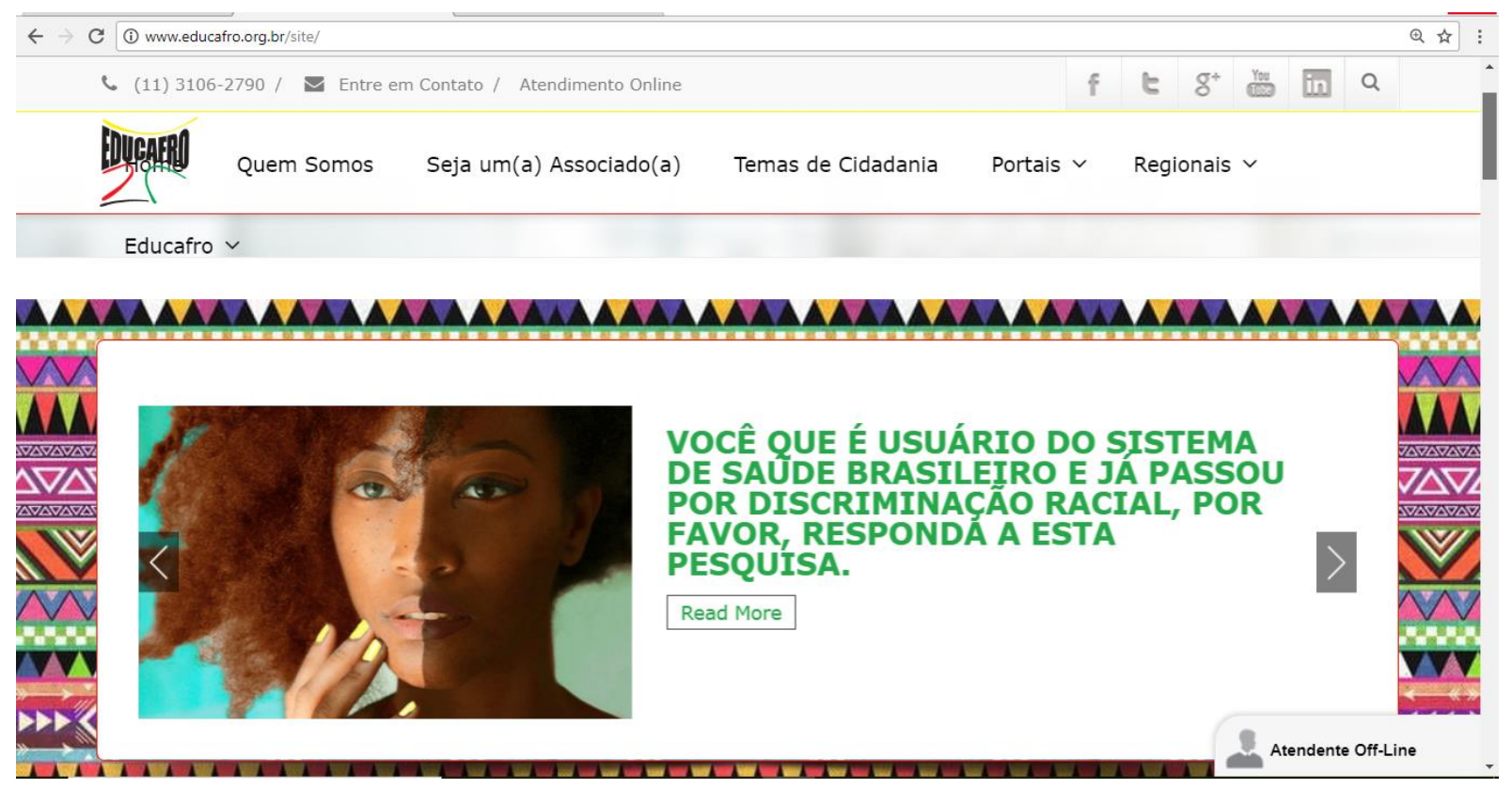

A primeira estratégia foi a divulgação de um vídeo caseiro de 34 segundos, convidando o público para responder a pesquisa, cujo link foi https://www.youtube.com/watch?v=gpUa5EFHOkw (Apêndice II). O vídeo abordava resumidamente os objetivos da pesquisa e quais pessoas eram elegíveis para participar do estudo, tendo sido divulgado por Whatsapp, Facebook e e-mail. O vídeo continha a seguinte mensagem, que foi disponibilizada no dia 22 de outubro de 2017:

Olá!

Se devido à sua raça ou cor de pele, você sentiu que foi tratado de maneira injusta em um posto de saúde, pronto socorro, maternidade ou em qualquer outro serviço de saúde público ou privado, por favor, responda a esta pesquisa clicando no link abaixo. Vai demorar de 10 a 15 minutos e você ajudará no reconhecimento e combate à discriminação racial dentro dos serviços de saúde brasileiros. Obrigada!

Após esta iniciativa, observou-se aumento considerável de respostas, sendo 87 acessos e 54 formulários respondidos completamente, no segundo mês, ou seja, o dobro do primeiro mês.

A segunda estratégia foi uma divulgação ainda mais intensa do vídeo nas redes sociais, principalmente, Whatsapp e Facebook (Grupos: Fala Guerreira, Negras, UNEGRO, Preta \& Acadêmica), buscando grupos ligados a movimentos sociais que pudessem auxiliar na divulgação, listas de e-mails da Escola de Enfermagem e da Faculdade de Saúde Pública da USP. E-mails foram enviados para algumas ONG, 
que, no entanto, não responderam. As ONG eram de movimentos sociais ligados ao feminismo, ativismo de atores asiáticos, feminismo negro, entre outros. Não é possível estimar a quantidade de pessoas que tiveram acesso à divulgação da pesquisa. Coincidentemente, a divulgação da pesquisa no mês de novembro foi importante para aumentar o número de acessos e respostas, possivelmente por conta de a população estar mais sensibilizada às questões relacionadas ao racismo, justamente por ser o mês da consciência negra no Brasil.

A terceira estratégia foi divulgar o DRISS em reuniões, manifestações e atos culturais ligados às atividades do mês da consciência negra. Quando estive nesses espaços, solicitava permissão para falar e divulgava rapidamente a pesquisa. Uma estratégia fundamental foi permanecer no recinto, mesmo que ao fim das atividades ou reuniões, permitindo assim realizar troca de contatos com as pessoas. Esses contatos eram consolidados depois por telefone, e-mail, mensagens de texto do tipo SMS, Whatsapp e Facebook. As pessoas aproveitavam a oportunidade para tirar dúvidas, elogiar, criticar, fazer sugestões.

Ao fim do mês de novembro, 480 pessoas tinham acessado o link e visualizado a primeira página do DRISS. Destas, seis recusaram a participação por meio da resposta 'não' ao TCLE; 423 pessoas responderam 'sim' e 51 pessoas não responderam nada - e acabaram abandonando a pesquisa.

A primeira pergunta após a aceitação do TCLE versava sobre o sexo dos respondentes. Já neste item, 73 pessoas desistiram de responder ao instrumento, restando 350 respostas.

Ao final do questionário sociodemográfico, que constava de 33 perguntas, estavam as questões introdutórias do DRISS, em que a primeira pergunta era se a pessoa havia ou não sofrido tratamento injusto devido à raça/cor dentro de um serviço de saúde. Nessa etapa momento, 108 pessoas responderam 'não' e 71 pessoas desistiram de responder. Assim, 171 pessoas iniciaram o preenchimento do DRISS, mas somente 158 responderam todos os itens, ou seja, 13 pessoas desistiram. Nitidamente, essas desistências ocorreram a partir do item 17, que é "Tomo cuidados adicionais com a higiene". O número de acessos e respostas ao DRISS pode ser observado na Figura 9. 
Figura 9 - Número de acessos e respostas ao DRISS. São Paulo, 2017

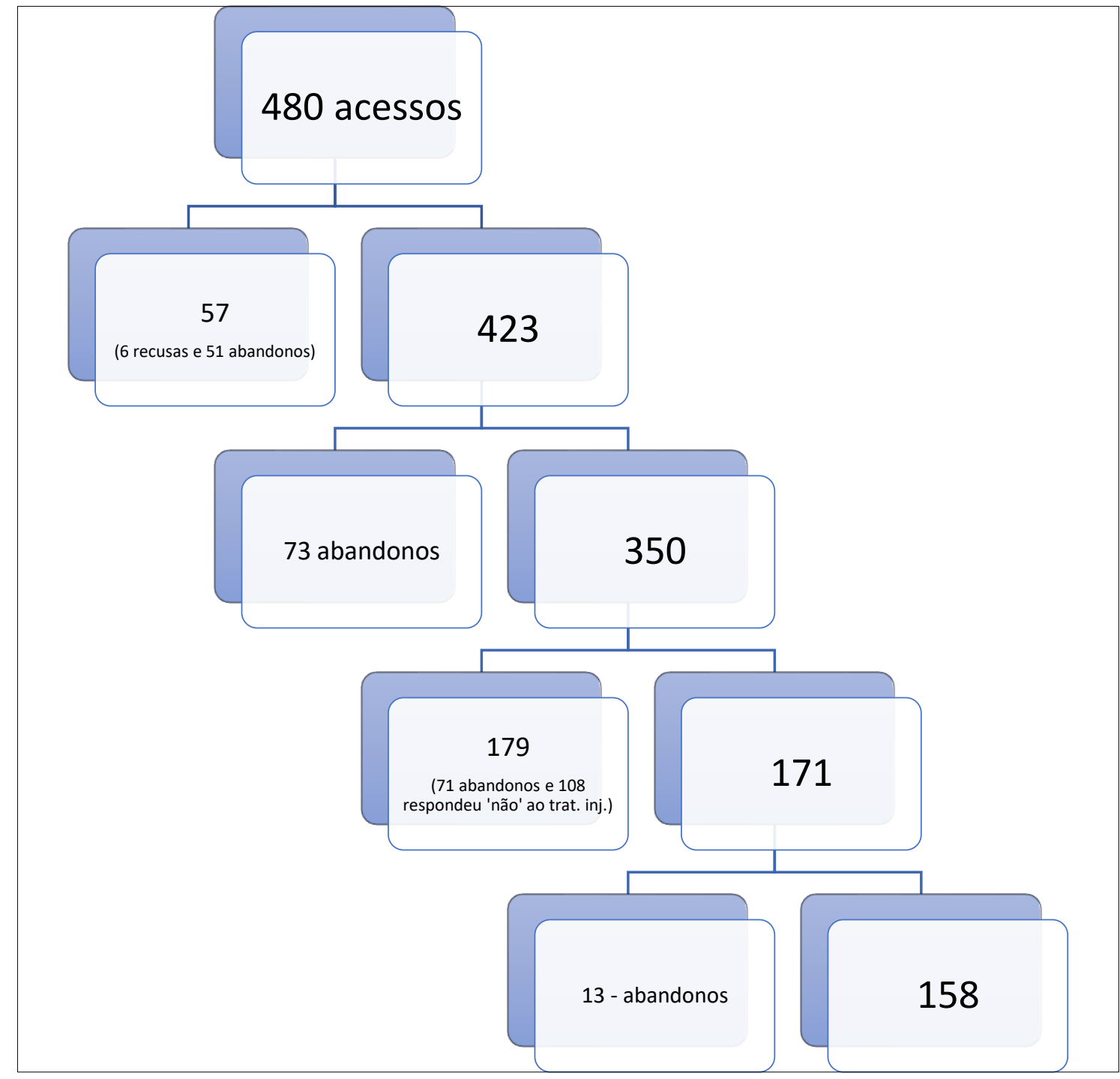

Verificou-se se havia duplicidade de respostas e, dentre os respondentes, foram observados dois com as mesmas datas de nascimento. Porém, todas as demais informações preenchidas eram diferentes. Portanto, descartou-se a possibilidade de respostas duplicadas e eles foram mantidos na amostra final de 158 respondentes.

$\mathrm{Na}$ Tabela 1, são apresentadas as frequências absolutas e proporções de respostas, segundo o item, comparando todos os respondentes que iniciaram (171) com os respondentes que, de fato, foram até o fim e preencheram todo o instrumento (158). Observa-se que, no caso do item 16, este teve número de resposta 'muitas vezes' e 'quase sempre' muito pequeno, enquanto, no item 23 , as alternativas 'quase sempre' e 'sempre' não tiveram nenhuma resposta. Porém, no geral, houve frequência de respostas para todas as alternativas em todos os demais itens. 
Tabela 1 - Frequência e proporção de respostas, para cada item, segundo o início do preenchimento do DRISS e a finalização do preenchimento. São Paulo, 2017.

\begin{tabular}{|c|c|c|c|c|}
\hline \multirow[b]{2}{*}{$\begin{array}{l}\text { Quando eu sou tratada/o injustamente devido à } \\
\text { minha raça/cor da pele, em serviços de saúde, } \\
\text { eu: }\end{array}$} & \multicolumn{2}{|c|}{$\begin{array}{l}\text { Indivíduos que iniciaram o } \\
\text { preenchimento do DRISS }\end{array}$} & \multicolumn{2}{|c|}{$\begin{array}{c}\text { Indivíduos que finalizaram } \\
\text { o preenchimento do } \\
\text { DRISS }\end{array}$} \\
\hline & $\mathbf{n}$ & $\%$ & $\mathbf{n}$ & $\%$ \\
\hline 1. Ignoro $(n=171)$ & & & & \\
\hline Raramente & 60 & 35,1 & 57 & 36,1 \\
\hline Algumas vezes & 54 & 31,6 & 49 & 31,0 \\
\hline Muitas vezes & 15 & 8,8 & 15 & 9,5 \\
\hline Quase sempre & 22 & 12,9 & 20 & 12,7 \\
\hline Sempre & 20 & 11,7 & 17 & 10,8 \\
\hline \multicolumn{5}{|l|}{$\begin{array}{l}\text { 2. Encaro como um acontecimento } \\
\text { cotidiano }\end{array}$} \\
\hline Raramente & 77 & 45,0 & 73 & 46,2 \\
\hline Algumas vezes & 45 & 26,3 & 40 & 25,3 \\
\hline Muitas vezes & 18 & 10,5 & 18 & 11,4 \\
\hline Quase sempre & 18 & 10,5 & 16 & 10,1 \\
\hline Sempre & 13 & 7,6 & 11 & 7,0 \\
\hline \multicolumn{5}{|l|}{$\begin{array}{l}\text { 3. Converso com alguma pessoa, como um } \\
\text { familiar, ou amigo, sobre o que aconteceu }\end{array}$} \\
\hline Raramente & 32 & 18,7 & 29 & 18,4 \\
\hline Algumas vezes & 23 & 13,5 & 20 & 12,7 \\
\hline Muitas vezes & 21 & 12,3 & 19 & 12,0 \\
\hline Quase sempre & 18 & 10,5 & 18 & 11,4 \\
\hline Sempre & 77 & 45,0 & 72 & 45,6 \\
\hline \multicolumn{5}{|l|}{ 4. Procuro esquecer o que aconteceu } \\
\hline Raramente & 72 & 42,1 & 68 & 43,0 \\
\hline Algumas vezes & 38 & 22,2 & 33 & 20,9 \\
\hline Muitas vezes & 16 & 9,4 & 16 & 10,1 \\
\hline Quase sempre & 24 & 14,0 & 22 & 13,9 \\
\hline Sempre & 21 & 12,3 & 19 & 12,0 \\
\hline \multicolumn{5}{|l|}{ 5. Faço uma oração (ou rezo) pela situação } \\
\hline Raramente & 107 & 62,9 & 101 & 63,9 \\
\hline Algumas vezes & 25 & 14,7 & 23 & 14,6 \\
\hline Muitas vezes & 12 & 7,1 & 9 & 5,7 \\
\hline Quase sempre & 7 & 4,1 & 6 & 3,8 \\
\hline Sempre & 19 & 11,2 & 13 & 12,0 \\
\hline \multicolumn{5}{|l|}{ 6. Guardo isso para mim mesma/o } \\
\hline Raramente & 95 & 55,6 & 90 & 57,0 \\
\hline Algumas vezes & 38 & 22,2 & 36 & 22,8 \\
\hline Muitas vezes & 13 & 7,6 & 10 & 6,3 \\
\hline Quase sempre & 12 & 7,0 & 12 & 7,6 \\
\hline Sempre & 13 & 7,6 & 10 & 6,3 \\
\hline \multicolumn{5}{|l|}{ 7. Me sinto humilhada/o } \\
\hline Raramente & 28 & 16,4 & 24 & 15,2 \\
\hline Algumas vezes & 35 & 20,5 & 33 & 20,9 \\
\hline Muitas vezes & 24 & 14,0 & 23 & 14,6 \\
\hline Quase sempre & 19 & 11,1 & 17 & 10,8 \\
\hline Sempre & 65 & 38,0 & 61 & 38,6 \\
\hline \multicolumn{5}{|l|}{ 8. Me sinto impotente } \\
\hline Raramente & 30 & 17,7 & 27 & 17,1 \\
\hline Algumas vezes & 36 & 21,2 & 34 & 21,5 \\
\hline Muitas vezes & 23 & 13,5 & 23 & 14,6 \\
\hline Quase sempre & 23 & 13,5 & 23 & 14,6 \\
\hline Sempre & 58 & 34,1 & 51 & 32,3 \\
\hline \multicolumn{5}{|l|}{ 9. Sinto raiva } \\
\hline Raramente & 15 & 8,8 & 11 & 7,0 \\
\hline Algumas vezes & 20 & 11,7 & 19 & 12,0 \\
\hline Muitas vezes & 24 & 14,0 & 23 & 14,6 \\
\hline Quase sempre & 19 & 11,1 & 18 & 11,4 \\
\hline Sempre & 93 & 54,4 & 87 & 55,1 \\
\hline
\end{tabular}




\begin{tabular}{lcc}
\hline \multicolumn{1}{c}{ Item } & $\begin{array}{c}\text { Indivíduos que iniciaram o } \\
\text { preenchimento do DRISS }\end{array}$ & $\begin{array}{c}\text { Indivíduos que finalizaram } \\
\text { o preenchimento do } \\
\text { DRISS }\end{array}$ \\
\hline $\begin{array}{l}\text { Quando eu sou tratada/o injustamente devido à } \\
\text { minha raça/cor da pele, em serviços de saúde, } \\
\text { eu: }\end{array}$ & $\mathbf{n}$ & $\%$ \\
\hline
\end{tabular}

10. Tenho dores de cabeça $(n=171)$

Raramente

Algumas vezes

Muitas vezes

Quase sempre

Sempre

$\begin{array}{rrr}42,7 & 67 & 42,4 \\ 22,8 & 37 & 23,4 \\ 11,1 & 19 & 12,0 \\ 4,1 & 6 & 3,8 \\ 19,3 & 29 & 18,4\end{array}$

11. Tenho dores de estômago

Raramente

Algumas vezes

Muitas vezes

Quase sempre

Sempre

39

19

33

12. Tenho tensão nos músculos

Raramente

Algumas vezes

Muitas vezes

Quase sempre

Sempre

13. Tenho palpitação no coração $(n=171)$

Raramente

Algumas vezes

Muitas vezes

Quase sempre

Sempre

14. Tenho receio de ter que esperar mais do que o normal para ser atendida/o

Raramente

Algumas vezes

Muitas vezes

Quase sempre

Sempre

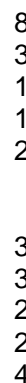

15. Reclamo em voz alta

Raramente

Algumas vezes

Muitas vezes

Quase sempre

Sempre

$\begin{array}{lll}21,6 & 33 & 20,9 \\ 22,2 & 36 & 22,8 \\ 16,4 & 27 & 17,1 \\ 11,7 & 20 & 12,7 \\ 28,1 & 42 & 26,6\end{array}$

48,7

16. Denuncio para as autoridades (por exemplo: registro uma ocorrência na polícia ou abro um processo na justiça) Raramente

Algumas vezes

Muitas vezes

Quase sempre

Sempre

Para evitar ser tratada/o injustamente, em serviços de saúde, devido à minha raça/cor de pele, eu:

17. Tomo cuidados adicionais com a higiene $(n=168)$

Raramente

Algumas vezes

Muitas vezes

Quase sempre

Sempre

18. Tomo cuidados adicionais com a depilação/barba

Raramente

Algumas vezes

Muitas vezes 


\begin{tabular}{|c|c|c|c|c|}
\hline \multirow[b]{2}{*}{$\begin{array}{l}\text { Quando eu sou tratada/o injustamente devido à } \\
\text { minha raça/cor da pele, em serviços de saúde, } \\
\text { eu: }\end{array}$} & \multicolumn{2}{|c|}{$\begin{array}{l}\text { Indivíduos que iniciaram o } \\
\text { preenchimento do DRISS }\end{array}$} & \multicolumn{2}{|c|}{$\begin{array}{c}\text { Indivíduos que finalizaram } \\
\text { o preenchimento do } \\
\text { DRISS } \\
\end{array}$} \\
\hline & $\mathbf{n}$ & $\%$ & $\mathbf{n}$ & $\%$ \\
\hline Quase sempre & 21 & 12,5 & 21 & 13,3 \\
\hline Sempre & 81 & 48,2 & 73 & 46,2 \\
\hline \multicolumn{5}{|l|}{$\begin{array}{l}\text { 19. Tomo cuidados adicionais com as } \\
\text { minhas roupas }\end{array}$} \\
\hline Raramente & 17 & 10,1 & 16 & 10,1 \\
\hline Algumas vezes & 23 & 13,7 & 23 & 14,6 \\
\hline Muitas vezes & 22 & 13,1 & 22 & 13,9 \\
\hline Quase sempre & 19 & 11,3 & 19 & 12,0 \\
\hline Sempre & 87 & 51,8 & 78 & 49,4 \\
\hline \multicolumn{5}{|l|}{$\begin{array}{l}\text { 20. Me preparo para não reclamar do } \\
\text { atendimento }\end{array}$} \\
\hline Raramente & 66 & 39,3 & 63 & 39,9 \\
\hline Algumas vezes & 40 & 23,8 & 38 & 24,1 \\
\hline Muitas vezes & 20 & 11,9 & 19 & 12,0 \\
\hline Quase sempre & 15 & 8,9 & 15 & 9,5 \\
\hline Sempre & 27 & 16,1 & 23 & 14,6 \\
\hline \multicolumn{5}{|l|}{$\begin{array}{l}\text { Responda as próximas perguntas pensando em } \\
\text { situações que ocorreram com outras pessoas. } \\
21 \text {. Eu já presenciei um/a familiar, parente } \\
\text { ou amiga/o ser tratada/o injustamente } \\
\text { devido à raça/cor da pele em serviços de } \\
\text { saúde? }(n=164)\end{array}$} \\
\hline Raramente & 36 & 22,0 & 35 & 22,2 \\
\hline Algumas vezes & 65 & 39,6 & 62 & 39,2 \\
\hline Muitas vezes & 33 & 20,1 & 33 & 20,9 \\
\hline Quase sempre & 20 & 12,2 & 18 & 11,4 \\
\hline Sempre & 10 & 6,1 & 10 & 6,3 \\
\hline \multicolumn{5}{|l|}{$\begin{array}{l}\text { 22. Eu já presenciei outras pessoas serem } \\
\text { tratadas injustamente devido à raça/cor } \\
\text { da pele em serviços de saúde? ( } n=163)\end{array}$} \\
\hline Raramente & 16 & 9,8 & 16 & 10,1 \\
\hline Algumas vezes & 41 & 25,2 & 39 & 24,7 \\
\hline Muitas vezes & 56 & 34,4 & 55 & 34,8 \\
\hline Quase sempre & 28 & 17,2 & 28 & 17,7 \\
\hline Sempre & 22 & 13,5 & 20 & 12,7 \\
\hline \multicolumn{5}{|l|}{$\begin{array}{l}\text { Responda as próximas perguntas pensando em } \\
\text { situações em que você observou privilégio. } \\
\text { 23. Eu já me senti tratada/o com privilégios } \\
\text { devido à minha raça/cor da pele em } \\
\text { serviços de saúde }(n=158)\end{array}$} \\
\hline Raramente & 144 & 91,1 & 144 & 91,1 \\
\hline Algumas vezes & 8 & 5,1 & 8 & 5,1 \\
\hline Muitas vezes & 6 & 3,8 & 6 & 3,8 \\
\hline Quase sempre & - & - & - & - \\
\hline Sempre & - & - & - & - \\
\hline \multicolumn{5}{|l|}{$\begin{array}{l}\text { 24. Eu já vi um desconhecido ser tratada/o } \\
\text { com privilégios devido à raça/cor da pele } \\
\text { em serviços de saúde. }\end{array}$} \\
\hline Raramente & 29 & 18,4 & 29 & 18,4 \\
\hline Algumas vezes & 27 & 17,1 & 27 & 17,1 \\
\hline Muitas vezes & 37 & 23,4 & 37 & 23,4 \\
\hline Quase sempre & 28 & 17,7 & 28 & 17,7 \\
\hline Sempre & 37 & 23,4 & 37 & 23,4 \\
\hline Total & 171 & 100,0 & 158 & 100,0 \\
\hline
\end{tabular}




\subsubsection{Perfil sociodemográfico dos respondentes}

Dentre os 158 respondentes que finalizaram o preenchimento do DRISS, a maior parte era do sexo feminino (87,0\%), entre 18 e 30 anos de idade $(38,6 \%)$ e residente em São Paulo (42,4\%). A idade média foi 35,9 anos ( $d p=12,65)$. Quanto ao local de residência, 98,1\% viviam em meio urbano. Quanto ao grupo econômico de pertencimento, $61,4 \%$ eram dos grupos $\mathrm{A}$ e $\mathrm{B}$. Todos os respondentes possuíam pelo menos o ensino fundamental completo e mais do que a metade possuía curso superior completo. Quanto à raça/cor autodeclarada, a maioria declarou-se preta $(81,6 \%)$. No que concerne ao emprego, 63,9\% exerciam atividade remunerada. Quase a metade possuía convênio médico. Em relação ao status marital, 56,3\% das pessoas não eram casadas nem estavam em uma união estável (Tabela 2).

Tabela 2 - Dados sociodemográficos dos respondentes do DRISS, São Paulo, 2017.

\begin{tabular}{|c|c|c|}
\hline Dados sociodemográficos & $\mathbf{N}$ & $\%$ \\
\hline \multicolumn{3}{|l|}{ Sexo } \\
\hline Masculino & 21 & 13,0 \\
\hline Feminino & 137 & 87,0 \\
\hline \multicolumn{3}{|l|}{ Idade } \\
\hline $18-30$ & 61 & 38,6 \\
\hline $31-40$ & 43 & 27,2 \\
\hline $41-50$ & 33 & 20,9 \\
\hline 51 e mais & 21 & 13,3 \\
\hline \multicolumn{3}{|l|}{ Estado } \\
\hline São Paulo & 67 & 42,4 \\
\hline Outros & 26 & 16,5 \\
\hline Bahia & 25 & 15,8 \\
\hline Rio de Janeiro & 24 & 15,2 \\
\hline Rio Grande do Sul & 16 & 10,1 \\
\hline \multicolumn{3}{|l|}{ Local de residência } \\
\hline Urbano & 153 & 98,1 \\
\hline Rural & 3 & 1,9 \\
\hline \multicolumn{3}{|l|}{ Religião } \\
\hline Afro-brasileira (candomblé e umbanda) & 35 & 22,2 \\
\hline Evangélica & 28 & 17,7 \\
\hline Católica & 25 & 15,8 \\
\hline Espírita & 16 & 10,1 \\
\hline Nenhuma & 45 & 8,5 \\
\hline Outras & 9 & 5,7 \\
\hline \multicolumn{3}{|l|}{ Escolaridade } \\
\hline Superior completo & 87 & 55,1 \\
\hline Médio completo/superior incompleto & 63 & 39,9 \\
\hline Fundamental completo & 8 & 5,1 \\
\hline
\end{tabular}




\begin{tabular}{lrr}
\hline \multicolumn{1}{c}{ Dados sociodemográficos } & $\mathbf{N}$ & \% \\
\hline Raça/cor & & \\
Preto & 129 & 81,7 \\
Pardo & 25 & 15,8 \\
Branco & 3 & 1,9 \\
Indígena & 1 & 0,6 \\
Trabalho remunerado & & \\
Sim & 101 & 63,9 \\
Não & 57 & 36,1 \\
Possui convênio médico & & \\
Não & 84 & 53,2 \\
Sim & 74 & 46,8 \\
União estável & & \\
Sim & 89 & 56,3 \\
Não & 69 & 43,7 \\
Grupo econômico & & \\
3 (AB) & 97 & 61,4 \\
2 (C) & 57 & 36,1 \\
1 (DE) & 7 & 2,5 \\
\hline Total & $\mathbf{1 5 8}$ & $\mathbf{1 0 0 , 0}$ \\
\hline
\end{tabular}

\subsubsection{Análise fatorial exploratória (AFE)}

Para conduzir a AFE, foram realizados os seguintes procedimentos: elaboração de uma matriz de correlação item-item; verificação da fatorabilidade dessa matriz (cálculo dos testes Kaiser-Meyer-Okin e Teste de Esfericidade de Bartlett); método de extração de fatores (Análises Paralelas - AP); identificação do número de fatores por meio do gráfico de scree plot; rotação de fatores (oblimim); exame de cargas fatorais (limpeza e simplificação da estrutura); análise da associação entre fatores; obtenção da estrutura final da escala multidimensional com seis fatores; rotulação qualitativa dos fatores; e, por fim, criação dos escores, segundo a carga fatorial.

A matriz de correlação (correlações policóricas) entre os itens é apresentada na Figura 10. Quanto mais próximo da cor azul, maior a correlação positiva entre os itens. Quanto mais próximo da cor vermelha, maior a correlação inversa entre os itens. Por exemplo, é possível observar que entre os itens 7 e 14 do eixo $Y$ e os itens 7 e 13 do eixo X, a cor azul é mais forte, indicando maior correlação; o que é observado, também, entre os itens 17 e 20 dos dois eixos. Em contrapartida, observam-se dois quadradinhos, em especial, que estão com a cor vermelha forte: são as correlações entre o item 6, no eixo Y, e 4, no eixo X, e vice-e-versa, indicando correlação negativa ou, em outras palavras, o que um diz, o outro contradiz. 
Figura 10 - Gráfico contendo a matriz de correlação item-item, na versão 3 com 24 itens do DRISS, 2017.

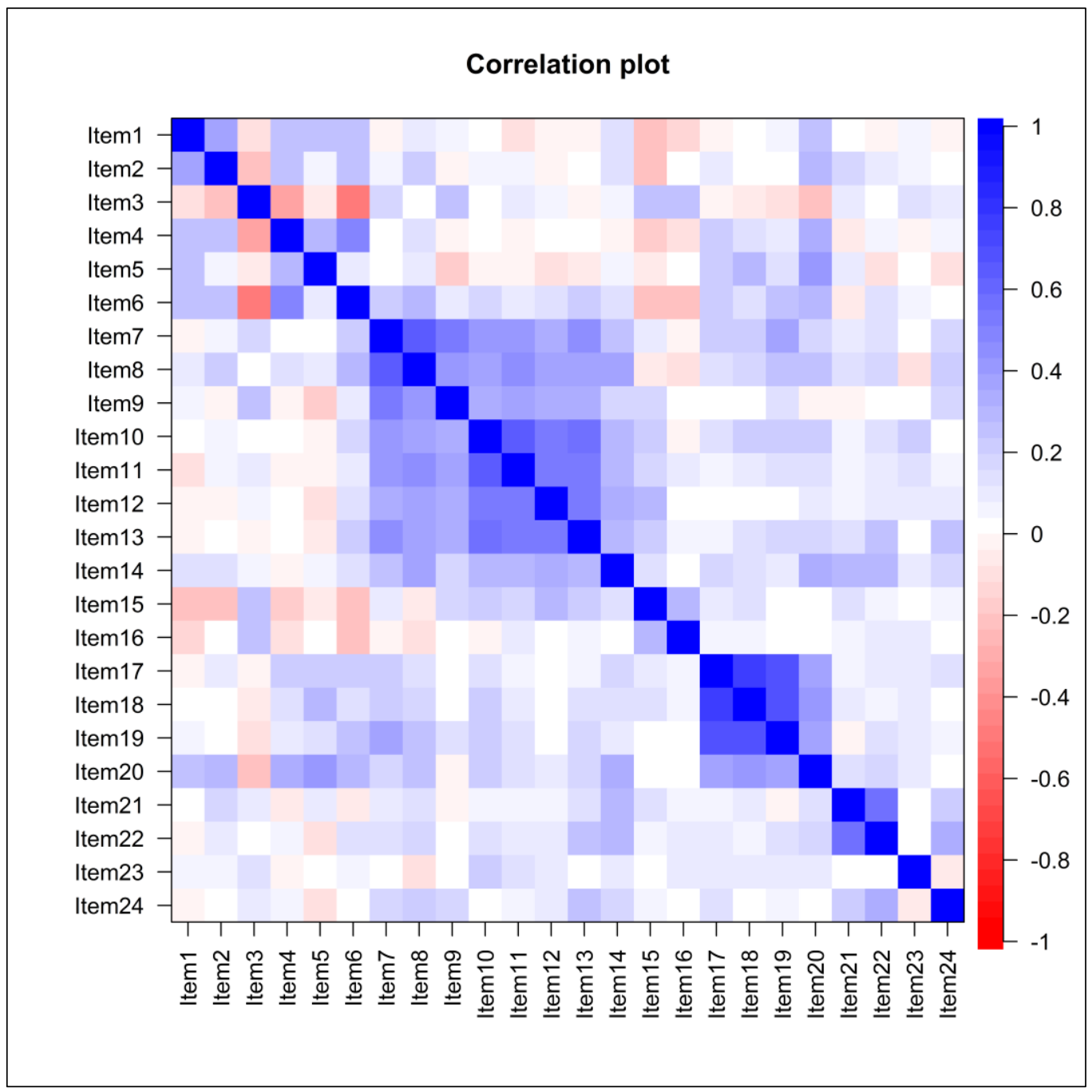

O KMO foi 0,736, indicando que é adequado proceder a AFE com esse conjunto de dados. Por sua vez, o Teste de Esfericidade de Bartlett foi significativo $(p<0,001)$, indicando também que a matriz é fatorável.

A AP mostrou que a escala possui seis fatores (Figura 11). Para interpretar o gráfico, deve-se considerar que a linha azul mostra os autovalores e a linha vermelha mostra os autovalores da AP. Assim, consideraram-se os seis fatores que ficaram acima da linha vermelha da AP. 
Figura 11 - Gráfico da análise paralela da matriz de correlação do DRISS, São Paulo, 2017.

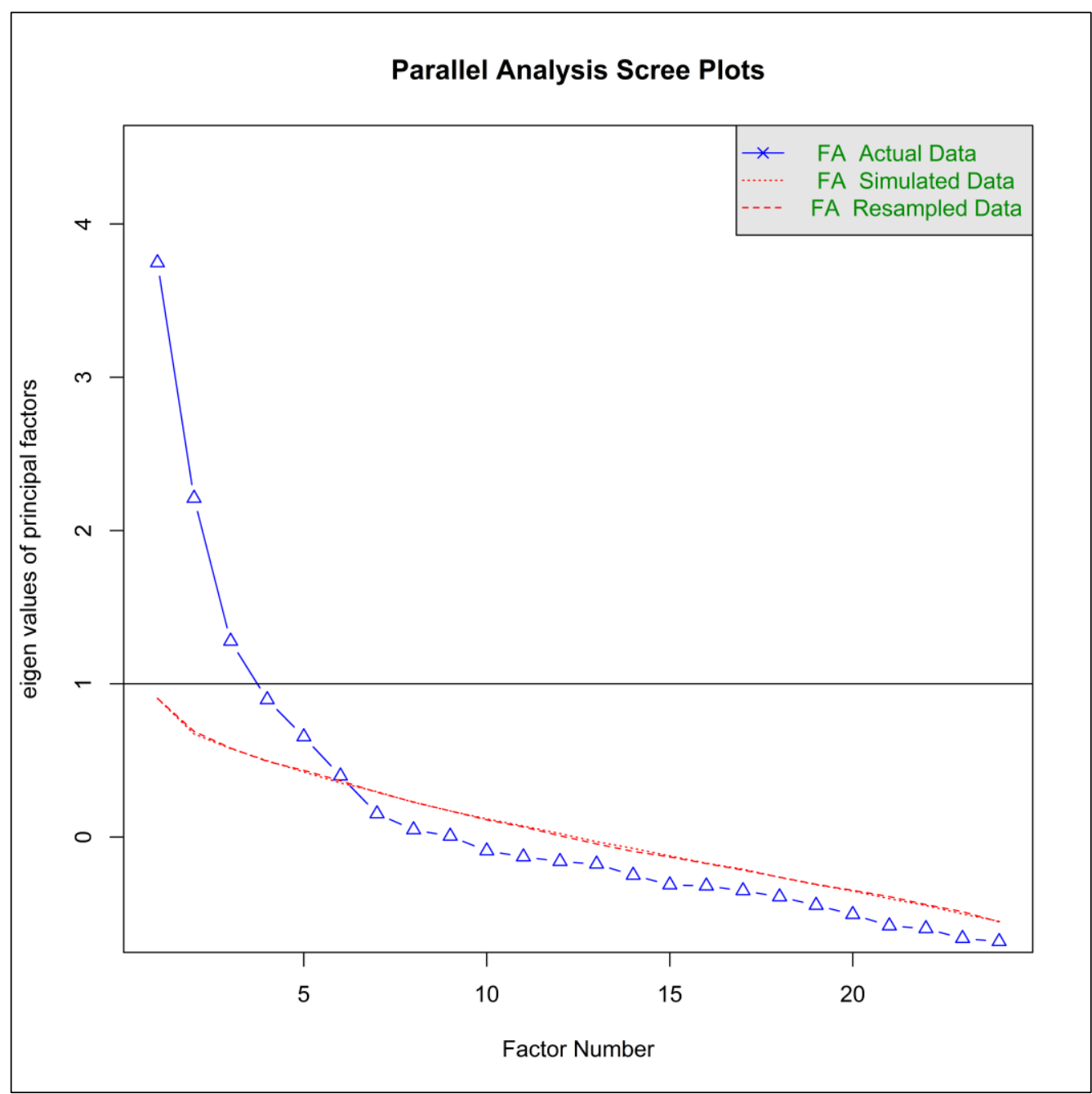

\subsubsection{Primeira AFE}

A matriz de correlação dos itens-fatores, conduzida com a rotação do tipo oblimim, encontra-se no Quadro 8. Observa-se que as correlações abaixo de 0,3 indicaram carga fatorial muito baixa (em negrito). Também, são apresentadas as comunalidades. 
Quadro 8 - Matriz de correlação item-fator do DRISS, com rotação oblimim, São Paulo, 2017.

\begin{tabular}{|c|c|c|c|c|c|c|c|c|}
\hline & item & Fator 1 & Fator 3 & Fator 2 & Fator 5 & Fator 4 & Fator 6 & Comunalidade \\
\hline Item10 & 10 & 0,779 & 0,051 & 0,043 & 0,015 & $-0,054$ & 0,063 & 0,631 \\
\hline Item11 & 11 & 0,708 & $-0,034$ & $-0,026$ & 0,112 & $-0,036$ & 0,019 & 0,569 \\
\hline Item12 & 12 & 0,695 & $-0,119$ & 0,025 & 0,059 & $-0,006$ & $-0,024$ & 0,510 \\
\hline Item13 & 13 & 0,596 & 0,002 & 0,133 & 0,126 & 0,166 & $-0,117$ & 0,534 \\
\hline Item15 & 15 & 0,391 & 0,140 & $-0,339$ & $-0,220$ & 0,071 & $-0,111$ & 0,303 \\
\hline Item23 & 23 & 0,203 & 0,085 & $-0,072$ & $-0,159$ & $-0,035$ & 0,093 & 0,058 \\
\hline Item18 & 18 & 0,040 & 0,854 & $-0,040$ & $-0,056$ & $-0,021$ & 0,082 & 0,752 \\
\hline Item17 & 17 & $-0,058$ & 0,839 & 0,005 & 0,014 & 0,038 & 0,022 & 0,712 \\
\hline Item19 & 19 & $-0,037$ & 0,761 & 0,113 & 0,159 & $-0,021$ & $-0,089$ & 0,636 \\
\hline Item6 & 6 & 0,071 & 0,069 & 0,758 & 0,121 & 0,016 & 0,005 & 0,650 \\
\hline Item3 & 3 & $-0,046$ & $-0,017$ & $-0,727$ & 0,245 & $-0,004$ & $-0,017$ & 0,554 \\
\hline Item4 & 4 & $-0,065$ & 0,054 & 0,450 & 0,041 & $-0,045$ & 0,234 & 0,333 \\
\hline Item16 & 16 & 0,123 & 0,109 & $-0,307$ & $-0,179$ & 0,080 & $-0,001$ & 0,140 \\
\hline Item7 & 7 & 0,122 & 0,187 & $-0,076$ & 0,716 & 0,004 & $-0,051$ & 0,679 \\
\hline Item8 & 8 & 0,104 & $-0,017$ & 0,087 & 0,699 & 0,085 & 0,155 & 0,648 \\
\hline Item9 & 9 & 0,195 & $-0,036$ & $-0,114$ & 0,545 & $-0,091$ & $-0,124$ & 0,435 \\
\hline Item22 & 22 & $-0,005$ & 0,013 & 0,070 & $-0,010$ & 0,847 & $-0,078$ & 0,716 \\
\hline Item21 & 21 & $-0,022$ & $-0,035$ & $-0,169$ & $-0,007$ & 0,642 & 0,190 & 0,464 \\
\hline Item24 & 24 & $-0,107$ & 0,026 & $-0,012$ & 0,255 & 0,367 & $-0,160$ & 0,214 \\
\hline Item14 & 14 & 0,273 & 0,000 & $-0,097$ & 0,143 & 0,280 & 0,265 & 0,321 \\
\hline Item20 & 20 & 0,167 & 0,269 & 0,127 & $-0,041$ & 0,109 & 0,550 & 0,563 \\
\hline Item5 & 5 & $-0,062$ & 0,170 & $-0,064$ & $-0,049$ & $-0,108$ & 0,529 & 0,336 \\
\hline Item1 & 1 & $-0,135$ & $-0,154$ & 0,151 & 0,178 & $-0,074$ & 0,478 & 0,317 \\
\hline Item2 & 2 & $-0,073$ & $-0,105$ & 0,221 & 0,113 & 0,112 & 0,379 & 0,261 \\
\hline
\end{tabular}

O Quadro 9 mostra a mesma matriz de correlação do Quadro 6, no entanto, com a omissão de cargas fatoriais menores do que 0,3 . Ressalta-se que todos os itens mantiveram carga fatorial menor do que 0,9, sugerindo ausência de multicolinearidade. Ressalta-se também que os itens 14 e 23 não carregaram em nenhum fator, portanto, também foram excluídos. 
Quadro 9 - Matriz de correlação item-fator do DRISS, na primeira AFE, método de extração AP, com rotação oblimim e omissão das cargas fatoriais menores do que 0,3, 2017.

\begin{tabular}{|c|c|c|c|c|c|c|c|c|}
\hline & item & Fator 1 & Fator 3 & Fator 2 & Fator 5 & Fator 4 & Fator 6 & Comunalidade \\
\hline Item10 & 10 & 0,779 & & & & & & 0,6305 \\
\hline Item11 & 11 & 0,708 & & & & & & 0,5686 \\
\hline Item12 & 12 & 0,695 & & & & & & 0,5095 \\
\hline Item13 & 13 & 0,596 & & & & & & 0,5335 \\
\hline Item15 & 15 & 0,391 & & $-0,339$ & & & & 0,3034 \\
\hline Item23 & 23 & & & & & & & 0,0582 \\
\hline Item18 & 18 & & 0,854 & & & & & 0,7521 \\
\hline Item17 & 17 & & 0,839 & & & & & 0,7121 \\
\hline Item19 & 19 & & 0,761 & & & & & 0,6361 \\
\hline Item6 & 6 & & & 0,758 & & & & 0,6495 \\
\hline Item3 & 3 & & & $-0,727$ & & & & 0,5539 \\
\hline Item4 & 4 & & & 0,450 & & & & 0,3334 \\
\hline Item16 & 16 & & & $-0,307$ & & & & 0,1399 \\
\hline Item7 & 7 & & & & 0,716 & & & 0,6791 \\
\hline Item8 & 8 & & & & 0,699 & & & 0,6478 \\
\hline Item9 & 9 & & & & 0,545 & & & 0,435 \\
\hline Item22 & 22 & & & & & 0,847 & & 0,7159 \\
\hline Item21 & 21 & & & & & 0,642 & & 0,4644 \\
\hline Item24 & 24 & & & & & 0,367 & & 0,2135 \\
\hline Item14 & 14 & & & & & & & 0,3211 \\
\hline Item20 & 20 & & & & & & 0,550 & 0,5633 \\
\hline Item5 & 5 & & & & & & 0,529 & 0,3361 \\
\hline Item1 & 1 & & & & & & 0,478 & 0,3165 \\
\hline Item2 & 2 & & & & & & 0,379 & 0,2614 \\
\hline
\end{tabular}

Para a primeira AP, a variância acumulada foi $47,2 \%$.

\subsubsection{Segunda AFE}

A segunda AFE foi conduzida sem os itens 23 e 14. Os dados mostram que 0 item 16 apresentou comunalidade muito baixa e que o item 15 apresentou comunalidade baixa, passando a carregar em dois fatores (1 e 2) - porém, com cargas fatoriais muito similares, impedindo, a distinção de qual fator pertencia. Por esses 
motivos, os dois itens foram excluídos. Os demais itens se demonstraram estáveis (Quadro 10).

Quadro 10 - Matriz de correlação item-fator do DRISS, na segunda AFE, método de extração $\mathrm{AP}$, com rotação oblimim e omissão das cargas fatoriais menores do que 0,3 , sem os itens 14 e 23. São Paulo, 2017.

\begin{tabular}{|c|c|c|c|c|c|c|c|c|}
\hline & Item & Fator 1 & Fator 3 & Fator 2 & Fator 5 & Fator 4 & Fator 6 & Comunalidade \\
\hline Item10 & 10 & 0,751 & & & & & & 0,602 \\
\hline Item 11 & 11 & 0,710 & & & & & & 0,571 \\
\hline Item12 & 12 & 0,698 & & & & & & 0,506 \\
\hline Item13 & 13 & 0,620 & & & & & & 0,542 \\
\hline Item15 & 15 & 0,407 & & $-0,348$ & & & & 0,320 \\
\hline Item18 & 18 & & 0,848 & & & & & 0,756 \\
\hline Item17 & 17 & & 0,842 & & & & & 0,713 \\
\hline Item19 & 19 & & 0,762 & & & & & 0,638 \\
\hline Item6 & 6 & & & 0,769 & & & & 0,660 \\
\hline Item3 & 3 & & & $-0,720$ & & & & 0,558 \\
\hline Item4 & 4 & & & 0,429 & & & & 0,335 \\
\hline Item16 & 16 & & & $-0,320$ & & & & 0,145 \\
\hline Item7 & 7 & & & & 0,708 & & & 0,688 \\
\hline Item8 & 8 & & & & 0,641 & & & 0,598 \\
\hline Item9 & 9 & & & & 0,544 & & & 0,443 \\
\hline Item22 & 22 & & & & & 0,875 & & 0,770 \\
\hline Item21 & 21 & & & & & 0,631 & & 0,446 \\
\hline Item24 & 24 & & & & & 0,356 & & 0,199 \\
\hline Item5 & 5 & & & & & & 0,594 & 0,394 \\
\hline Item20 & 20 & & & & & & 0,547 & 0,546 \\
\hline Item1 & 1 & & & & & & 0,442 & 0,305 \\
\hline Item2 & 2 & & & & & & 0,358 & 0,258 \\
\hline
\end{tabular}

Para a segunda AP, a variância acumulada foi $50 \%$.

\subsubsection{Terceira AFE}

A terceira AFE foi conduzida sem os itens 15 e 16. Os dados mostraram que o item 2 apresentou comunalidade baixa, o que ocasionou sua exclusão. Na verdade, esse item foi fortemente criticado, desde a análise de conteúdo, pelos especialistas (Quadro 11). 
Quadro 11 - Matriz de correlação item-fator do DRISS, na segunda AFE, método de extração $\mathrm{AP}$, com rotação oblimim e omissão das cargas fatoriais menores do que 0,3 , sem os itens 14, 15, 16 e 23. São Paulo, 2017.

\begin{tabular}{|c|c|c|c|c|c|c|c|c|}
\hline & item & Fator 2 & Fator 1 & Fator 3 & Fator 5 & Fator 4 & Fator 6 & Comunalidade \\
\hline Item18 & 15 & 0,867 & & & & & & 0,776 \\
\hline Item17 & 14 & 0,831 & & & & & & 0,701 \\
\hline Item19 & 16 & 0,758 & & & & & & 0,634 \\
\hline Item10 & 10 & & 0,801 & & & & & 0,642 \\
\hline Item11 & 11 & & 0,753 & & & & & 0,607 \\
\hline Item12 & 12 & & 0,651 & & & & & 0,470 \\
\hline Item13 & 13 & & 0,600 & & & & & 0,533 \\
\hline Item6 & 6 & & & 0,824 & & & & 0,721 \\
\hline Item3 & 3 & & & $-0,669$ & 0,312 & & & 0,518 \\
\hline Item4 & 4 & & & 0,470 & & & & 0,362 \\
\hline Item7 & 7 & & & & 0,729 & & & 0,690 \\
\hline Item9 & 9 & & & & 0,614 & & & 0,475 \\
\hline Item8 & 8 & & & & 0,592 & & & 0,558 \\
\hline Item22 & 19 & & & & & 0,856 & & 0,742 \\
\hline Item21 & 18 & & & & & 0,656 & & 0,480 \\
\hline Item24 & 20 & & & & & 0,352 & & 0,209 \\
\hline Item5 & 5 & & & & & & 0,582 & 0,389 \\
\hline Item20 & 17 & & & & & & 0,522 & 0,534 \\
\hline Item1 & 1 & & & & & & 0,457 & 0,291 \\
\hline Item2 & 2 & & & & & & 0,360 & 0,252 \\
\hline
\end{tabular}

Para a terceira AP, a variância acumulada foi $52,9 \%$

\subsubsection{Quarta AFE}

A quarta AFE foi conduzida sem os itens 2, 14, 15, 16 e 23. O resultado pode ser visto no Quadro 12. A síntese de todas as AFE realizadas está no quadro 10. Com as decisões tomadas a partir delas, foi possível construir a versão 4 do DRISS. 
Quadro 12 - Síntese dos itens excluídos da escala DRISS a partir das quatro AFE conduzidas. São Paulo, 2017.

\begin{tabular}{|c|c|c|c|}
\hline AFE & $\begin{array}{l}\text { Número do item na } \\
\text { versão } 1 \text { do DRISS }\end{array}$ & Item excluído & Motivo \\
\hline \multirow{2}{*}{$2^{\mathrm{a}}$} & 14 & $\begin{array}{l}\text { Tenho receio de ter que } \\
\text { esperar mais do que o } \\
\text { normal para ser } \\
\text { atendida/o }\end{array}$ & $\begin{array}{l}\text { Não carregou em } \\
\text { nenhum fator }\end{array}$ \\
\hline & 23 & $\begin{array}{l}\text { Eu já me senti tratada/o } \\
\text { com privilégios devido à } \\
\text { minha raça/cor da pele } \\
\text { em serviços de saúde }\end{array}$ & $\begin{array}{l}\text { Não carregou em } \\
\text { nenhum fator }\end{array}$ \\
\hline \multirow[t]{2}{*}{$3^{a}$} & 16 & $\begin{array}{l}\text { Denuncio para as } \\
\text { autoridades (por } \\
\text { exemplo: registro uma } \\
\text { ocorrência na polícia ou } \\
\text { abro um processo na } \\
\text { justiça). }\end{array}$ & $\begin{array}{l}\text { Comunalidade baixa } \\
(<0,4)\end{array}$ \\
\hline & 15 & Reclamo em voz alta & $\begin{array}{l}\text { Comunalidade baixa } \\
(<0,4) ; \\
\text { Carregou em dois } \\
\text { fatores com cargas } \\
\text { similares. }\end{array}$ \\
\hline $4^{\underline{a}}$ & 2 & $\begin{array}{l}\text { Encaro como um } \\
\text { acontecimento cotidiano }\end{array}$ & $\begin{array}{l}\text { Comunalidade baixa } \\
(<0,4) ;\end{array}$ \\
\hline
\end{tabular}

\subsubsection{Versão 4 do DRISS}

No Quadro 13, é apresentada a AFE realizada com os itens 1, 3, 4, 5, 6, 7, 8, $9,10,11,12,13,17,18,19,20,21,22$ e 24 - que gerou a versão 4 do DRISS. Observa-se que o item 3 apresentou carga fatorial negativa em dois fatores (3 e 6), porém, foi mantido. A decisão foi tomada com base no fato de que, aparentemente, espera-se que o respondente que pontue mais neste item, coerentemente, pontue menos nos demais itens pertencentes ao mesmo fator. Isto porque ele possui carga fatorial negativa. Em outras palavras, nossa hipótese é que a pessoa que sofreu tratamento injusto em um serviço de saúde e costuma conversar com algum familiar sobre o fato ocorrido (item 3), não é uma pessoa que guarda para si (item 6) ou que procura esquecer (item 4). Outra razão para manter o item 3 é que, apesar de ter 
carregado em dois fatores, ele pertence nitidamente ao fator 3, pois a carga fatorial apresentada é mais que o dobro do valor da carga fatorial apresentada pelo fator 6 .

Apesar de os itens 1 e 24 terem ficado com comunalidade abaixo de 0,4, observou-se que, ao retirá-los, a escala se desestabilizava; ou seja, comprometia as cargas fatoriais e a comunalidade de outros itens - o que podia gerar uma escala que não atendia mais aos objetivos da pesquisa.

A partir dessa análise, considerou-se que a escala estava satisfatória do ponto de vista da validade de constructo e a versão 4 é a versão proposta para a mensuração das percepções sobre discriminação racial interpessoal nos serviços de saúde. 
Quadro 13 - Matriz de correlação item-fator do DRISS, versão 4, na quarta AFE, método de extração AP, com rotação oblimim e omissão das cargas fatoriais menores do 0,3, sem os itens 2, 14, 15, 16 e 23, mais os itens que restaram por extenso. São Paulo, 2017.

\begin{tabular}{|c|c|c|c|c|c|c|c|c|}
\hline & $\begin{array}{l}\text { Fator } \\
2\end{array}$ & $\begin{array}{c}\text { Fator } \\
1\end{array}$ & $\begin{array}{c}\text { Fator } \\
3\end{array}$ & $\begin{array}{l}\text { Fator } \\
6\end{array}$ & $\begin{array}{c}\text { Fator } \\
4\end{array}$ & $\begin{array}{l}\text { Fator } \\
5\end{array}$ & $\begin{array}{l}\text { Comuna- } \\
\text { lidade }\end{array}$ & Item por escrito \\
\hline Item18 & 0,855 & & & & & & 0,768 & 18. Tomo cuidados adicionais com a depilação/barba \\
\hline Item17 & 0,846 & & & & & & 0,715 & 17. Tomo cuidados adicionais com a higiene \\
\hline Item19 & 0,768 & & & & & & 0,641 & 19. Tomo cuidados adicionais com as minhas roupas \\
\hline Item10 & & 0,814 & & & & & 0,652 & 10. Sinto dores de cabeça \\
\hline Item11 & & 0,757 & & & & & 0,611 & 11. Sinto dores de estômago \\
\hline Item12 & & 0,644 & & & & & 0,466 & 12. Sinto tensão nos músculos \\
\hline Item13 & & 0,593 & & & & & 0,525 & 13. Sinto palpitação no coração \\
\hline Item6 & & & 0,849 & & & & 0,752 & 6. Guardo isso para mim mesma/o \\
\hline Item3 & & & $-0,651$ & 0,319 & & & 0,492 & $\begin{array}{l}\text { 3. Converso com alguma pessoa sobre o que aconteceu (familiar ou } \\
\text { amiga/o) }\end{array}$ \\
\hline Item4 & & & 0,513 & & & & 0,382 & 4. Procuro esquecer o que aconteceu \\
\hline Item7 & & & & 0,758 & & & 0,707 & 7. Me sinto humilhada/o. \\
\hline Item8 & & & & 0,606 & & & 0,555 & 8. Me sinto impotente. \\
\hline Item9 & & & & 0,605 & & & 0,468 & 9. Sinto raiva \\
\hline Item22 & & & & & 0,902 & & 0,823 & $\begin{array}{l}\text { 22. Eu presenciei outras pessoas desconhecidas serem tratadas } \\
\text { injustamente devido à raça/cor da pele em serviços de saúde }\end{array}$ \\
\hline Item21 & & & & & 0,625 & & 0,422 & $\begin{array}{l}\text { 21. Eu presenciei um/a familiar, parente ou amiga/o ser tratada/o } \\
\text { injustamente devido à raça/cor da pele em serviços de saúde }\end{array}$ \\
\hline Item24 & & & & & 0,341 & & 0,202 & $\begin{array}{l}\text { 24. Eu já vi um/a desconhecido/a ser tratado/a com privilégios devido à } \\
\text { raça/cor da pele DA PESSOA, em serviços de saúde }\end{array}$ \\
\hline Item5 & & & & & & 0,756 & 0,586 & 5. Faço uma oração (ou rezo) pela situação. \\
\hline Item20 & & & & & & 0,475 & 0,493 & 20. Me preparo para não reclamar do atendimento \\
\hline Item 1 & & & & & & 0,336 & 0,192 & 1. Ignoro \\
\hline
\end{tabular}


O Quadro 14 refere-se às proporções de variância retida por cada fator e acumulada da escala DRISS, em sua versão 4, ou seja, a versão final. Os fatores apresentaram cargas na seguinte ordem decrescente: Fator $1=12 \%$, Fator $2=11,6 \%$, Fator $6=9,1 \%$, Fator $3=8,7 \%$, Fator $4=7,4 \%$ e Fator $5=6,2 \%$. Todos os fatores juntos somam uma proporção de variância acumulada de $55 \%$, o que significa que os seis fatores representam $55,0 \%$ do fenômeno DRISS.

Quadro 14 - Proporções de variância retida por cada fator e acumulada do DRISS, São Paulo, 2017.

\begin{tabular}{|l|r|r|r|r|r|r|}
\hline & Fator 2 & Fator 1 & Fator 3 & Fator 6 & Fator 4 & Fator 5 \\
\hline Carga fatorial & 2,206 & 2,278 & 1,648 & 1,733 & 1,408 & 1,177 \\
\hline Proporção de variância & $11,6 \%$ & $12,0 \%$ & $8,7 \%$ & $9,1 \%$ & $7,4 \%$ & $6,2 \%$ \\
\hline Variância acumulada & $11,6 \%$ & $23,6 \%$ & $32,3 \%$ & $41,4 \%$ & $48,8 \%$ & $55,0 \%$ \\
\hline Proporção explicada & $21,1 \%$ & $21,8 \%$ & $15,8 \%$ & $16,6 \%$ & $13,5 \%$ & $11,3 \%$ \\
\hline Proporção cumulativa & $21,1 \%$ & $42,9 \%$ & $58,7 \%$ & $75,3 \%$ & $88,7 \%$ & $100,0 \%$ \\
\hline
\end{tabular}

O Quadro 15 mostra a correlação entre os fatores, composta pelos itens de acordo com a AFE 4. Observou-se que a correlação entre os fatores foi baixa, o que é considerado adequado, tendo em vista que, quando alta (próxima de 1), os diferentes fatores podem estar medindo o mesmo fenômeno.

Quadro 15 - Correlação entre os fatores da versão final da escala DRISS, São Paulo, 2017.

\begin{tabular}{|l|c|c|c|c|c|c|}
\hline & Fator 2 & Fator 1 & Fator 3 & Fator 6 & Fator 4 & Fator 5 \\
\hline Fator 2 & 1 & 0,146 & 0,189 & 0,183 & 0,092 & 0,278 \\
\hline Fator 1 & 0,146 & 1 & 0,124 & 0,504 & 0,149 & $-0,022$ \\
\hline Fator 3 & 0,189 & 0,124 & 1 & 0,084 & 0,074 & 0,188 \\
\hline Fator 6 & 0,183 & 0,504 & 0,084 & 1 & 0,129 & $-0,046$ \\
\hline Fator 4 & 0,092 & 0,149 & 0,074 & 0,129 & 1 & $-0,002$ \\
\hline Fator 5 & 0,278 & $-0,022$ & 0,188 & $-0,046$ & $-0,002$ & 1 \\
\hline
\end{tabular}

As medidas de adequação da amostra e os indicadores de resíduos foram todos considerados aceitáveis: O root mean square of the residuals (RMSR) foi 0,025; o índice de confiabilidade da fatoração de Tucker Lewis foi 1,0067 e o root mean square error of approximation (RMSEA) foi 0,0161 , com intervalo de confiança de $90 \%$. 


\subsection{ETAPA 3 - VERIFICAÇÃO DA CONFIABILIDADE}

Quanto às análises de confiabilidade, o Ômega de McDonald total foi 0,87 _ valor considerado bom.

\subsection{ETAPA 4 - ESCORIFICAÇÃO}

A Tabela 3 apresenta a porcentagem de contribuição de cada fator ao fenômeno DRISS como um todo. Os valores dos escores foram extraídos obedecendo a essas proporções. Assim, obtiveram-se os valores máximo e mínimo de cada escore. Os escores intermediários foram construídos a partir da soma do próprio número na casela seguinte. O menor escore possível de se atingir do DRISS é 20 pontos, enquanto o maior é 100 pontos.

Tabela 3 - Valores dos escores do DRISS, São Paulo, 2017.

\begin{tabular}{ccccccc}
\hline $\begin{array}{c}\text { Proporção } \\
\text { de } \\
\text { variância } \\
\text { explicada } \\
(\%)\end{array}$ & Fator & $\begin{array}{c}\text { Núm. de itens } \\
\text { no fator }\end{array}$ & $\begin{array}{c}\text { Valor } \\
\text { máximo } \\
\text { atribuído } \\
\text { a cada } \\
\text { item }\end{array}$ & $\begin{array}{c}\text { Valor } \\
\text { mínimo } \\
\text { atribuído a } \\
\text { cada item }\end{array}$ & $\begin{array}{c}\text { Pontuação } \\
\text { mínima }\end{array}$ & $\begin{array}{c}\text { Pontuação } \\
\text { máxima }\end{array}$ \\
\hline 21,8 & 1 & 4 & 5 & 1,1 & 4 & 22 \\
21,1 & 2 & 3 & 7 & 1,4 & 4 & 21 \\
16,6 & 6 & 3 & 6 & 1,1 & 3 & 17 \\
15,8 & 3 & 3 & 5 & 1,1 & 3 & 16 \\
13,5 & 4 & 3 & 5 & 0,9 & 3 & 14 \\
11,3 & 5 & 3 & 4 & 0,8 & 2 & 11 \\
\hline 100,0 & & 19 & & & 20 & 100 \\
\hline
\end{tabular}

O quadro 17 apresenta valores dos escores para todas as possibilidades de resposta. O Quadro 16 apresenta a versão final do DRISS após a conclusão das verificações das validades de face, conteúdo e confiabilidade e a escorificação. 
Quadro 16 - Versão final do DRISS, contendo texto introdutório, questões e alternativas para respostas. São Paulo, 2017.

\section{DRISS}

\section{Texto introdutório:}

Nesse estudo, nós incluímos apenas questões que buscam investigar as situações em que você foi tratada/o injustamente devido à sua raça/cor da pele, nos serviços de saúde.

\begin{tabular}{|c|c|c|c|c|c|}
\hline Item & $\begin{array}{l}\text { Rara- } \\
\text { Mente }\end{array}$ & $\begin{array}{c}\text { Algumas } \\
\text { vezes }\end{array}$ & $\begin{array}{l}\text { Muitas } \\
\text { vezes }\end{array}$ & $\begin{array}{l}\text { Quase } \\
\text { sempre }\end{array}$ & Sempre \\
\hline \multicolumn{6}{|l|}{$\begin{array}{l}\text { Quando eu sou tratada/o injustamente devido à minha } \\
\text { raça/cor da pele, em serviços de saúde, eu: }\end{array}$} \\
\hline 1. Ignoro & & & & & \\
\hline $\begin{array}{l}\text { 2. Converso com alguma pessoa sobre o que } \\
\text { aconteceu (familiar ou amiga/o) }\end{array}$ & & & & & \\
\hline 3. Procuro esquecer o que aconteceu & & & & & \\
\hline 4. Faço uma oração (ou rezo) pelo que aconteceu & & & & & \\
\hline 5. Guardo isso para mim mesma/o & & & & & \\
\hline 6. Me sinto humilhada/o & & & & & \\
\hline 7. Me sinto impotente & & & & & \\
\hline 8. Sinto raiva & & & & & \\
\hline 9. Sinto dores de cabeça & & & & & \\
\hline \multicolumn{6}{|l|}{ 10. Sinto dores no estômago } \\
\hline \multicolumn{6}{|l|}{ 11. Sinto tensão nos músculos } \\
\hline \multicolumn{6}{|l|}{ 12. Sinto palpitação no coração } \\
\hline \multicolumn{6}{|l|}{$\begin{array}{l}\text { Para evitar ser tratada/o injustamente, em serviços de } \\
\text { saúde, devido à minha raça/cor da pele, eu: }\end{array}$} \\
\hline \multicolumn{6}{|l|}{ 13. Tomo cuidados adicionais com a higiene } \\
\hline \multicolumn{6}{|l|}{ 14. Tomo cuidados adicionais com a depilação/barba } \\
\hline \multicolumn{6}{|l|}{ 15. Tomo cuidados adicionais com as minhas roupas } \\
\hline \multicolumn{6}{|l|}{ 16. Me preparo para não reclamar do atendimento } \\
\hline \multicolumn{6}{|l|}{$\begin{array}{l}\text { Responda as próximas perguntas pensando em } \\
\text { situações que ocorreram com outras pessoas }\end{array}$} \\
\hline \multicolumn{6}{|l|}{$\begin{array}{l}\text { 17. Eu presenciei um/a familiar, parente ou amiga/o ser } \\
\text { tratada/o injustamente devido à raça/cor da pele em } \\
\text { serviços de saúde }\end{array}$} \\
\hline \multicolumn{6}{|l|}{$\begin{array}{l}\text { 18. Eu presenciei outras pessoas desconhecidas serem } \\
\text { tratadas injustamente devido à raça/cor da pele em } \\
\text { serviços de saúde }\end{array}$} \\
\hline \multicolumn{6}{|l|}{$\begin{array}{l}\text { Responda à próxima pergunta pensando em situações } \\
\text { em que você observou privilégio. }\end{array}$} \\
\hline $\begin{array}{l}\text { 19. Eu já vi um/a desconhecido/a ser tratado/a com } \\
\text { privilégios, devido à raça/cor da pele DA PESSOA, } \\
\text { em serviços de saúde }\end{array}$ & & & & & \\
\hline
\end{tabular}

\subsubsection{Rotulação dos fatores}

Após a escorificação, procedeu-se uma avaliação qualitativa sobre os fatores apontados na AFE, com vistas a rotular cada fator. Ao observar os agrupamentos de 
itens (fatores) apresentados pela AFE, buscaram-se termos que sintetizassem qualitativamente o que cada fator representava. Assim, chegou-se aos seguintes rótulos, na ordem em que são apresentados no quadro 15: Fator 1 - Sintoma somático; Fator 2 - Preparo; Fator 6 - Consequências emocionais; Fator 3 Expressão emocional; Fator 4 - Percepção social; Fator 5 - reação. 
Quadro 17 - Fatores rotulados, segundo os grupos de itens e os respectivos escores do DRISS, São Paulo, 2017.

\begin{tabular}{|c|c|c|c|c|c|c|}
\hline Fatores & Item & Raramente & $\begin{array}{l}\text { Algumas } \\
\text { vezes }\end{array}$ & $\begin{array}{l}\text { Muitas } \\
\text { vezes }\end{array}$ & $\begin{array}{l}\text { Quase } \\
\text { sempre }\end{array}$ & Sempre \\
\hline \multirow{4}{*}{$\begin{array}{l}\text { Fator } 1 \\
\text { Sintoma somático }\end{array}$} & 10. Sinto dores de cabeça & 1 & 2 & 3 & 4 & 5 \\
\hline & 11. Sinto dores de estômago & 1 & 2 & 3 & 4 & 5 \\
\hline & 12. Sinto tensão nos músculos & 1 & 2 & 3 & 4 & 5 \\
\hline & 13. Sinto palpitação no coração & 1 & 2 & 3 & 4 & 5 \\
\hline \multirow{3}{*}{$\begin{array}{l}\text { Fator } 2 \\
\text { Preparo }\end{array}$} & 18. Tomo cuidados adicionais com a depilação/barba & 1,4 & 2,8 & 4,2 & 5,6 & 7 \\
\hline & 17. Tomo cuidados adicionais com a higiene & 1,4 & 2,8 & 4,2 & 5,6 & 7 \\
\hline & 19. Tomo cuidados adicionais com as minhas roupas & 1,4 & 2,8 & 4,2 & 5,6 & 7 \\
\hline \multirow{3}{*}{$\begin{array}{l}\text { Fator } 6 \\
\text { Consequências } \\
\text { emocionais }\end{array}$} & 7. Me sinto humilhada/o & 1,2 & 2,4 & 3,6 & 4,8 & 6 \\
\hline & 8. Me sinto impotente & 1,2 & 2,4 & 3,6 & 4,8 & 6 \\
\hline & 9. Sinto raiva & 1,2 & 2,4 & 3,6 & 4,8 & 6 \\
\hline \multirow{3}{*}{$\begin{array}{l}\text { Fator } 3 \\
\text { Expressão } \\
\text { emocional }\end{array}$} & 6. Guardo isso para mim mesma/o & 1 & 2 & 3 & 4 & 5 \\
\hline & $\begin{array}{l}\text { 3. Converso com alguma pessoa sobre o que aconteceu (familiar ou } \\
\text { amiga/o) }\end{array}$ & 1 & 2 & 3 & 4 & 5 \\
\hline & 4. Procuro esquecer o que aconteceu & 1 & 2 & 3 & 4 & 5 \\
\hline \multirow{3}{*}{$\begin{array}{l}\text { Fator } 4 \\
\text { Percepção social }\end{array}$} & $\begin{array}{l}\text { 22. Eu presenciei outras pessoas desconhecidas serem tratadas } \\
\text { injustamente devido à raça/cor da pele em serviços de saúde }\end{array}$ & 1 & 2 & 3 & 4 & 5 \\
\hline & $\begin{array}{l}\text { 21. Eu presenciei um/a familiar, parente ou amiga/o ser tratada/o } \\
\text { injustamente devido à raça/cor da pele em serviços de saúde }\end{array}$ & 1 & 2 & 3 & 4 & 5 \\
\hline & $\begin{array}{l}\text { 24. Eu já vi um/a desconhecido/a ser tratado/a com privilégios } \\
\text { devido à raça/cor da pele DA PESSOA, em serviços de saúde }\end{array}$ & 1 & 2 & 3 & 4 & 5 \\
\hline \multirow{3}{*}{$\begin{array}{l}\text { Fator } 5 \\
\text { Reação }\end{array}$} & 5. Faço uma oração (ou rezo) pela situação. & 0,8 & 1,6 & 2,4 & 3,2 & 4 \\
\hline & 20. Me preparo para não reclamar do atendimento & 0,8 & 1,6 & 2,4 & 3,2 & 4 \\
\hline & 1. Ignoro & 0,8 & 1,6 & 2,4 & 3,2 & 4 \\
\hline Total & & 20,2 & 40,4 & 60,6 & 80,8 & 101 \\
\hline
\end{tabular}




\subsection{ETAPA 5 - ANÁLISE DA DISTRIBUIÇÃO DO ESCORE SEGUNDO OS ASPECTOS SOCIODEMOGRÁFICOS DA AMOSTRA}

A somatória dos escores da versão 4 do DRISS revelou que a pontuação mínima foi 23,8 e a máxima foi 90,6 , com média igual a 59,6 pontos $(\mathrm{dp}=12,9)$ e mediana igual a 60,1. A distribuição dos escores pode ser observada na Figura 12.

Figura 12 - Distribuição dos escores do DRISS. São Paulo, 2017.

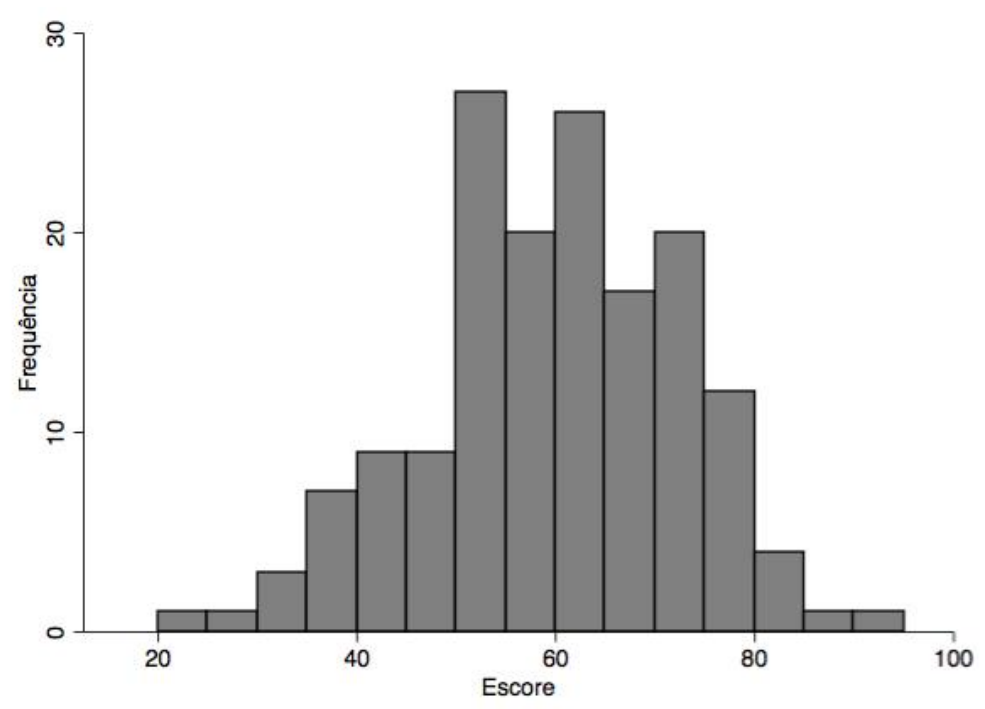

A partir do gráfico, pode-se perceber que a distribuição da pontuação do DRISS lembra uma distribuição normal. O teste de Shapiro-Wilk indicou um valor de $p=0,379$, ou seja, ao nível de significância de 5\%, pode-se afirmar que a amostra de pontuação do DRISS teve uma distribuição normal.

Foi realizada a comparação das médias pela análise de variância das mesmas. Comparando as médias dos escores entre os grupos, por exemplo, em relação ao sexo, os homens alcançaram a média de 55,5 pontos no DRISS, ao passo que a média das mulheres foi um pouco maior, 60,2 (Tabela 4). No entanto, essa diferença não foi estatisticamente significativa $(p=0,126)$.

Tabela 4 - Média e desvio-padrão dos escores da amostra do DRISS, segundo o sexo. São Paulo, 2017.

\begin{tabular}{cccc}
\hline Sexo & Média & Desvio padrão & Frequência \\
\hline Homens & 55,50 & 13,9 & 21 \\
Mulheres & 60,10 & 12,7 & 137 \\
\hline Total & 59,57 & 12,9 & 158 \\
\hline
\end{tabular}


Não foi observada diferença estatisticamente significativa em nenhuma média quando comparadas as características sociodemográficas, conforme Tabela 5.

Tabela 5 - Médias e desvios-padrão dos escores do DRISS, versão 4, segundo as características sociodemográficas. São Paulo, 2017.

\begin{tabular}{|c|c|c|c|}
\hline Dados sociodemográficos & Média & $\begin{array}{l}\text { Desvio- } \\
\text { padrão }\end{array}$ & p \\
\hline \multicolumn{4}{|l|}{ Sexo } \\
\hline Masculino & 55,5 & 13,9 & \multirow{2}{*}{0,125} \\
\hline Feminino & 50,2 & 12,7 & \\
\hline \multicolumn{4}{|l|}{ Idade } \\
\hline $18-30$ & 60,7 & 12,6 & \multirow[t]{4}{*}{0,714} \\
\hline $31-40$ & 59,9 & 12,2 & \\
\hline $41-50$ & 58,2 & 13,8 & \\
\hline 51 e mais & 57,5 & 14,3 & \\
\hline \multicolumn{4}{|l|}{ Estado } \\
\hline São Paulo & 61,9 & 13,0 & \multirow[t]{5}{*}{0,217} \\
\hline Outros & 60,0 & 10,6 & \\
\hline Bahia & 57,3 & 14,0 & \\
\hline Rio de Janeiro & 54,6 & 13,2 & \\
\hline Rio Grande do Sul & 58,2 & 13,2 & \\
\hline \multicolumn{4}{|l|}{ Local de residência } \\
\hline Urbano & 59,3 & 12,9 & \multirow[t]{2}{*}{0,077} \\
\hline Rural & 72,7 & 15,8 & \\
\hline \multicolumn{4}{|l|}{ Religião } \\
\hline Afro-brasileira (candomblé e umbanda) & 59,7 & 10,3 & \multirow[t]{6}{*}{0,099} \\
\hline Evangélica & 65,0 & 13,6 & \\
\hline Católica & 56,0 & 12,2 & \\
\hline Espírita & 58,1 & 13,1 & \\
\hline Nenhuma & 57,6 & 13,5 & \\
\hline Outras & 67,2 & 15,4 & \\
\hline \multicolumn{4}{|l|}{ Escolaridade } \\
\hline Superior completo & 59,2 & 12,5 & \multirow[t]{3}{*}{0,873} \\
\hline Médio completo/superior incompleto & 59,9 & 12,8 & \\
\hline Fundamental completo & 61,3 & 18,9 & \\
\hline \multicolumn{4}{|l|}{ Raça/cor } \\
\hline Preto & 59,7 & 12,3 & \multirow[t]{4}{*}{0,833} \\
\hline Pardo & 59,8 & 14,4 & \\
\hline Branco & 57,7 & 13,5 & \\
\hline Indígena & 48,0 & 0,0 & \\
\hline \multicolumn{4}{|l|}{ Trabalho remunerado } \\
\hline $\operatorname{Sim}$ & 58,8 & 12,37 & \multirow[t]{2}{*}{0,333} \\
\hline Não & 60,9 & 13,9 & \\
\hline \multicolumn{4}{|l|}{ Possui convênio médico } \\
\hline Não & 61,0 & 12,4 & \multirow[t]{2}{*}{0,125} \\
\hline Sim & 57,9 & 13,4 & \\
\hline \multicolumn{4}{|l|}{ União estável } \\
\hline Sim & 59,2 & 11,8 & \multirow[t]{2}{*}{0,722} \\
\hline Não & 60,0 & 14,4 & \\
\hline \multicolumn{4}{|l|}{ Grupo econômico } \\
\hline DeE & 70,6 & 13,2 & \multirow[t]{3}{*}{0,219} \\
\hline C & 59,7 & 13,0 & \\
\hline$A$ e $B$ & 59,0 & 12,8 & \\
\hline Total & 158,0 & 100,0 & \\
\hline
\end{tabular}


O DRISS pareceu não discriminar a percepção de discriminação racial nos serviços de saúde entre pessoas que diferem entre si quanto a sexo, idade, raça/cor, escolaridade e demais dados sociodemográficos. 
6 DISCUSSÃO 



\section{DISCUSSÃO}

Este estudo teve como objetivo desenvolver e validar uma escala para mensurar a percepção sobre discriminação racial interpessoal no contexto dos serviços de saúde. Após o seguimento de todas as estratégias metodológicas ancoradas na Teoria Clássica dos Testes, é apresentado o DRISS. Trata-se do primeiro instrumento construído e que validado - tendo como constructo a percepção sobre discriminação racial nos serviços de saúde - em que os contextos histórico e racial, específicos do Brasil, foram considerados.

Ao contrário do que ocorre nos países onde a maior parte dos instrumentos sobre racismo foi desenvolvida, em que os indivíduos possuem identificação racial muito determinada e, por isso, são mais atentos em situações racialmente discriminatórias, no Brasil, ainda prevalece o mito da democracia racial (Fernandes, 2007). Esta, que é desmascarada ao se explicitarem dados estatísticos revelando iniquidades raciais na área da saúde da população brasileira (Paixão et al., 2011) cuja maioria é negra (IBGE, 2015). Onde, por exemplo: homens negros têm duas vezes mais chances de morrer por qualquer causa de morte; enquanto as mulheres pretas iniciam o pré-natal mais tardiamente, têm que peregrinar mais na hora do parto (Viellas et al., 2014) e reportam menos satisfação com o atendimento e menos privacidade na hora dos procedimentos médico-hospitalares (d'Orsi et al., 2014).

O DRISS busca captar a percepção sobre discriminação racial das pessoas que possuem identificação racial definida e têm a percepção de que a raça/cor influencia na forma em que o profissional de saúde exerce seu trabalho. Essa percepção pode ter sido motivada por uma experiência racialmente discriminatória vivida, porém, difícil de ser comprovada, devido ao fato de ser velada.

Desse modo, o indivíduo que já se percebeu vítima de discriminação racial nos serviços de saúde informa, ao longo do instrumento, quais os sentimentos vivenciados durante ou após o ato discriminatório (expressos em sintomas somáticos e psíquicos), sua percepção social (a forma como terceiros são tratados), as estratégias de enfrentamento, tanto subjetivas quanto objetivas, adotadas frente ao episódio, bem como suas reações posteriores ao evento. 
É justamente esse conjunto de sentimentos, reações e estratégias que compõe a percepção de discriminação racial nos serviços de saúde, segundo os achados destes estudo, o que está em consonância com o estudo qualitativo tomado como base da elaboração do DRISS (Santa Rosa, 2013), assim como com demais estudos internacionais (Paradies, 2006a; Kressin, Raymond, Manze, 2008; Bastos et al., 2010).

O DRISS avança em relação aos demais instrumentos já disponíveis em âmbito internacional (Paradies, Cunningham, 2008) à medida em que identifica e distingue os sintomas ocasionados na experiência da discriminação racial interpessoal em itens diferentes, que, contudo, permanecem compondo um mesmo fator, no caso, o Fator 1 Sintoma Somático. Por exemplo, no instrumento MIRE (Paradies, Cunningham, 2008), que contém o item: "Quando eu sou tratada/o de maneira injusta devido a minha raça/cor da pele, eu sinto algum sintoma físico como: dores de cabeça, de estômago, tensão nos músculos, ou palpitação no coração". O DRISS também é inovador, pois inclui itens que versam sobre o preparo (Fator 2), que se constitui nas medidas que os indivíduos tomam para se antecipar ao ato discriminatório - o que pode se configurar em preocupação ou estresse por antecipação. Por fim, também estão incluídas informações sobre o que os respondentes já observaram no que concerne à discriminação observada em relação a terceiros (Fator 4) - o que parece significar que a percepção pode ser incrementada com a experiência de ver outros serem discriminados.

Ao apresentar uma escala válida e confiável para mensurar a percepção sobre discriminação racial interpessoal no contexto dos serviços de saúde, que é o DRISS, é necessário enfatizar que ela poderá ser utilizada em estudos populacionais ou epidemiológicos que pretendam medir a percepção de usuários de serviços de saúde, públicos ou privados, sobre a discriminação racial perpetrada por profissionais de saúde. Isso é importante, porque possibilitará a mensuração do racismo institucional por um ângulo diferente do institucional, que é o dos usuários dos serviços de saúde.

Em geral, os instrumentos relacionados ao racismo, construídos e validados em outros contextos, além de não terem foco específico em serviços de saúde, consideram, em sua maior parte, o ponto de vista dos profissionais de saúde, e não dos usuários que sofrem com a discriminação racial e, consequentemente, com o tratamento injusto. A injustiça no atendimento pode ser preterir, negligenciar, executar 
procedimentos mais dolorosos do que o usual (Santa Rosa, 2013), não utilizar anestesia, quando essa é necessária (Burgess et al., 2008; Kreling, Pimenta, Garanhani, 2014; Dickason et al., 2015; Leal et al., 2017), entre outros. O tratamento injusto motivado, aparentemente, pela raça/cor da pele, leva usuários e usuárias a buscarem assistência em outras unidades de atendimento à saúde, quando disponíveis. Porém, para algumas pessoas, isso pode acarretar em desistência do tratamento e, em casos mais extremos, pode até ser fatal (Batista, Escuder, Pereira, 2004; Martins, 2006a; Leal et al., 2017).

O DRISS é uma escala multidimensional (seis fatores), com 19 itens ao todo, cujas categorias de resposta são raramente, algumas vezes, muitas vezes, quase sempre e sempre. Seu escore varia entre 20 e 100 pontos, sendo que 20 pontos significam a menor percepção possível de DRISS e 100 pontos a maior percepção possível de DRISS. A validação foi executada com a participação de homens e mulheres, maiores de 18 anos. Apesar de o nome da escala conter o termo "serviços de saúde", a coleta de dados não deve ser realizada dentro dos serviços de saúde, para se evitarem eventuais vieses ocasionados pela proximidade com os profissionais de saúde.

Partindo de uma pesquisa qualitativa - conduzida com mulheres negras residentes em áreas periféricas da cidade de São Paulo que relataram ter vivenciado situações de discriminação racial em serviços de saúde e a forma como reagiram a essas situações e para evitar a vivência de outras situações semelhantes no futuro (Santa Rosa, 2013); de vasta busca bibliográfica, que mostrou a existência de poucos instrumentos construídos para mensurar a discriminação racial nos serviços de saúde, sendo todos eles validados em contextos diferentes do Brasil (Paradies, 2006a; Kressin, Raymond, Manze, 2008; Bastos et al., 2010); e, por fim, de sugestões e recomendações de um grupo de pesquisa com experiência na condução de estudos sobre saúde da população negra, a primeira versão do instrumento ora apresentado foi elaborada, inicialmente com 50 itens.

$\mathrm{Na}$ etapa de validação de conteúdo, houve a exclusão de 28 itens, enquanto diversos outros sofreram modificações. Isso já era esperado, tendo em vista a quantidade de itens similares que, se mantidos, poderiam confundir e/ou cansar os respondentes, mas que faziam parte do processo de elaboração de novos instrumentos, cabendo aos especialistas decidirem pela manutenção ou exclusão 
(Alexandre, Coluci, 2011; DeVellis, 2012). Desse modo, modificou-se o texto introdutório para uma versão menor, simples e objetiva, especificando que os respondentes deveriam levar em consideração apenas percepções sobre discriminação racial vivenciadas em serviços de saúde e não em outros lugares/contextos.

Os itens que se referiam a escrever, desenhar, cantar e pintar, como possíveis reações ao ato discriminatório, foram excluídos sob o argumento principal de que não se tratavam de ações comuns aos brasileiros. Da mesma forma, os itens reclamar em voz baixa e fazer escândalo foram excluídos em meio a diversas críticas do comitê de especialistas, o que causou surpresa, pois o estudo qualitativo que fundamentou esses itens vislumbrou esse aspecto de maneira contundente (Santa Rosa, 2013). O conjunto de itens sobre se sentir humilhado, maltratado, medo de não ser atendido, de receber medicamento errado e tratamento errado foram avaliados como sendo itens muito parecidos uns com os outros, tendo recebido vários votos para serem excluídos. Mudar o local de atendimento e não buscar mais atendimento, curiosamente, eram itens que o grupo de pesquisa consultado entendeu como sendo assuntos importantes a serem abordados, porém, foram itens que receberam votos suficientes para serem excluídos também. Todos os itens sobre diversidade étnica entre os profissionais de saúde foram excluídos, provavelmente porque a maioria dos especialistas julgou como irrelevantes para o instrumento. Eu já vi um familiar ser tratado com privilégio foi um item em que os juízes entenderam não fazer parte dos objetivos da pesquisa, embora fosse um item que tenha tentado captar o testemunho em relação ao que aconteceu com terceiros, assunto recomendado pela literatura (Paradies, Truong, Priest, 2014).

A etapa de pré-teste conduzida com 40 indivíduos mostrou que era necessário incluir mais questões introdutórias, pois os respondentes consideraram situações que perceberam discriminação racial em outros ambientes diferentes dos serviços de saúde, como em busca por emprego, presença em lojas, repartições públicas, entre outros. Essas questões exemplificam possíveis situações de tratamento injusto ocorridas no contexto dos serviços de saúde, de acordo com dados provenientes de estudos anteriores (Santa Rosa, 2013; d'Orsi et al., 2014; Viellas et al., 2014; Hall et al., 2015; Dehon et al., 2017; Leal et al., 2017). A inclusão dessas questões 
introdutórias adicionais surtiu o efeito desejado, não sendo mais observada dúvida em relação ao foco específico nos serviços de saúde.

A partir das modificações e das exclusões descritas acima, a validação de face e conteúdo do instrumento foi alcançada e permitiu prosseguir com a validação de construto - a partir de uma versão com 24 itens. Essa versão foi disponibilizada para o público-alvo por meio de um link no REDCap.

O uso do REDCap para o gerenciamento dos dados foi estratégico e apresentou inúmeras vantagens. A primeira é que se trata de um software com elevada credibilidade nos meios acadêmicos, em nível internacional, cuja utilização é gratuita, desde que o usuário tenha vínculo institucional com alguma das instituições colaboradoras (Harris et al., 2009). A segunda é que possibilitou a participação tanto dos membros do comitê de especialistas quanto da população-alvo de várias partes do país, sem que houvesse dispêndio financeiro e em tempo rápido. A utilização do REDCap suprime a necessidade de digitar os dados, o que também permitiu a economia de tempo e recursos financeiros. Adicionalmente, a elaboração do DRISS no REDCap permite sua utilização em qualquer parte do país por outros pesquisadores, em tablets ou celulares, tanto online quanto offline.

No entanto, foi observada uma desvantagem no seu uso: o fato de não possuir tradução para a língua portuguesa, por exemplo, pois pode dificultar a compreensão dos respondentes, uma vez que algumas caixas de diálogo podem aparecer e, quando aparecem, estão em inglês. Desse modo, foi necessário incluir instruções em português para que as respostas fossem adequadas. Por exemplo, na primeira página do formulário, quando o respondente escolhia a opção 'Não aceito participar', aparecia uma caixa de diálogo com a opção End the survey now - o que gerou a necessidade de se instruir o participante em português.

A divulgação do link para o preenchimento do instrumento surpreendeu pela dificuldade em se alcançar o número de respostas que permitisse a validação psicométrica adequada; ou seja, deixar o DRISS online não garantiu que as pessoas o respondessem. Um dos motivos para a não adesão pode ter sido a divulgação insuficiente, pois, com a intensificação da divulgação de um vídeo caseiro, convidando as pessoas para participar, mais pessoas acessaram o link e responderam ao instrumento. 
Em relação ao grande número de abandonos no preenchimento do instrumento, pois somente um terço dos acessos gerou formulários respondidos integralmente, pode ter sido por vários motivos, por exemplo: as dificuldades com acesso e/ou estabilidade da internet; o fato do instrumento ser longo, o que pode desestimular seu preenchimento; a temática do DRISS ter desencorajado algumas pessoas, devido ao assunto trazer memórias que possam causar desconforto emocional; a falta de nitidez quanto ao aspecto tenha motivado o tratamento injusto, como grupo econômico, gênero, peso corporal, entre outros; a não identificação de pertencimento a um determinado grupo racial.

Com relação à suposta dificuldade do respondente em distinguir se foi a raça/cor da pele que motivou o tratamento injusto ou se foi a interseccionalidade de aspectos (grupo econômico, gênero, peso corporal, entre outros), tem sido objeto de vários estudos que, na verdade, consideram difícil isolar uma única variável interveniente na produção das desigualdades (Bastos et al., 2017; Hogan et al., 2017).

Quanto à não identificação de pertencimento a um determinado grupo racial, isso invisibiliza a percepção de discriminação devido à raça/cor, caso ela tenha ocorrido, e impede a possiblidade de quantificar essa problemática. Nesse contexto, Bastos et al. (2017) reuniram estudos que argumentam que a mistura das raças no Brasil e o mito da democracia racial (com sua relativa harmonia nas relações sociais) desencorajam os brasileiros a classificarem suas experiências de tratamento diferencial como discriminação (Bastos et al., 2017).

As dimensões que compõem o construto percepção sobre discriminação racial nos serviços de saúde são Sintoma Somático, Preparo, Consequências Emocionais, Expressão Emocional, Percepção Social e Reação. Essas dimensões emergiram das análises estatísticas e apresentaram-se ligeiramente diferentes do que foi considerado na etapa de fundamentação teórica. Segundo a revisão de literatura, seriam três as principais dimensões que comporiam o DRISS: experiência, reação e sentimento (subcapítulo "Fundamentação Teórica" desta tese). Porém, foi possível observar seis fatores, com nítida interligação entre os itens de um mesmo fator. No Fator 1, denominado Sintoma Somático, todos os itens continham sintomatologia somatizada, que se distinguiam nitidamente do Fator 6, denominado Consequências Emocionais, cujos itens se referiam também a sintomas, porém no nível psíquico. Na perspectiva adotada para a elaboração inicial da escala, ainda na fundamentação teórica para a 
construção do pool de itens, os itens dos Fatores 1 e 6 pertenciam todos à mesma dimensão, ou seja, 'sentimentos'.

No Fator 2, Preparo, todos os itens faziam menção às situações em que o respondente tomava alguma iniciativa no sentido de reduzir o risco de ser discriminado, configurando-se como um possível fator estressante por antecipação. Esse fator contém itens que foram extraídos da dissertação de mestrado da autora desta tese (Santa Rosa, 2013). O estresse antecipado pode resultar em danos à saúde física e mental, conforme explica o estudo norte-americano que encontrou associação entre o aumento da circunferência da cintura e o comportamento de vigilância. O mesmo estudo disserta sobre o risco da vigilância crônica e sua toxicidade para a saúde física e mental (Hicken, Lee, Hing, 2017).

O Fator 3, Expressão emocional, é composto por itens que indicam se há verbalização ou não da situação racialmente discriminatória eventualmente vivenciada, podendo se configurar como um aspecto relevante à medida em que o acúmulo de estresse pode gerar danos à saúde física e mental. Revisões sistemáticas da literatura vêm mostrando o risco do estresse crônico relacionado ao racismo sobre a saúde física e, especialmente, sobre a saúde mental (Paradies, 2006a; Goto, Couto, Bastos, 2013)

Fator 4, Percepção social, refere-se a momentos em que o respondente testemunhou situações de tratamento injusto devido à raça/cor. Trata-se de uma questão relevante, tendo em vista que testemunhar situações que ocorreram com terceiros pode significar compreensão mais nítida do que o que acontece consigo mesmo. Exemplificando, Venturi (2006), em um estudo realizado com mais de cinco mil pessoas de todo o Brasil, identificou que 90\% admitiram existir racismo, porém 19\% admitiram manifestar seu preconceito (Venturi, 2006).

O Fator 5, Reação, contém itens que revelam reações ou atitudes das pessoas frente a uma situação racialmente discriminatória. São itens que podem ser vistos também como estratégias de coping adotadas a fim de reduzir o estresse emocional. Para Paradies (2006), as estratégias de coping podem, inclusive, reduzir os efeitos nocivos do racismo na vida das pessoas (Paradies, 2006a).

Portanto, o DRISS ficou com 19 itens distribuídos em seis dimensões e apresentou boas propriedades psicométricas - segundo os parâmetros adotados. Vale lembrar que, apesar de todos os itens apresentarem cargas fatoriais dentro dos 
limites estabelecidos como aceitáveis, dois itens ( 1 e 24 ) ficaram com as comunalidade menores do que 0,4 - limite estabelecido para exclusão do item. No entanto, quando eles eram retirados, a escala se desestabilizava, comprometendo as cargas fatoriais e a comunalidade de outros itens, gerando uma escala que não atendia mais aos objetivos da pesquisa, pois se fazia necessário excluir vários outros itens. Esse julgamento por parte do pesquisador é aceitável e recomendado, a fim de gerar uma escala com significado teórico (Hair, Black, Babin, 2014)

Há que se destacar outro ponto: a despeito de a variância acumulada não ter sido utilizada como indicador de maior importância na AFE, observou-se que ela foi aumentando, conforme os itens problemáticos foram sendo retirados. No entanto, mesmo com a melhora da porcentagem total de variância explicada, o DRISS só explica $55 \%$ do fenômeno 'percepção sobre discriminação racial interpessoal nos serviços de saúde'. Todavia, isso não é um problema, pois, do ponto de vista psicométrico, nenhum fenômeno psicológico e/ou social será entendido por um constructo hipotético, de maneira que a variância total nunca será $100 \%$ (O'Grady, 1982; Damásio, 2012). Uma revisão de literatura avaliou os níveis de variância explicada de 568 estudos que utilizaram AFE e encontrou a média de variância total explicada de $56,6 \%$. Apesar de o autor não propor um ponto de corte para um bom valor de variância total explicada, ele sugere certa diretriz para um valor aceitável (Peterson, 2000; Damásio, 2012). Desse modo, o DRISS encontra-se muito perto desse valor médio aceitável.

Quanto às características sociodemográficas dos respondentes do DRISS, a maior parte foi do sexo feminino, com idade média de 35,9 anos de idade, residentes em áreas urbanas, pertencentes aos grupos econômicos $\mathrm{A}$ e $\mathrm{B}$ e mais da metade com curso superior completo. Quanto à raça/cor autodeclarada, a maioria se declarou de cor preta. Quase a metade possuía convênio médico. Portanto, trata-se de uma amostra de brasileiros bem distinta da média nacional, pois, segundo dados do IBGE (IBGE, 2015), em 2014, 51,6\% eram mulheres; a proporção de pessoas que viviam em áreas urbanas era de 85,1\%; a escolaridade média da população de 25 anos ou mais de idade era de 7,8 anos de estudo completos, o que não equivale nem ao ensino fundamental completo; $53,6 \%$ das pessoas se declaravam como de raça/cor da pele preta ou parda. Quanto à renda, segundo a $\operatorname{ABEP}$ (2016) (ABEP, 2016), a média de renda estimada dos grupos $A$ e $B$ era, respectivamente, $R \$ 20.888,00$ e $R \$ 4.852,00$ 
- porém, a média de renda nacional em 2014, segundo o IBGE, foi $\mathrm{R} \$$ 1.245,00 (IBGE, 2015). Ainda: 67\% do usuários do SUS são negros (Paixão et al., 2011).

De fato, tal participação de respondentes do DRISS predominantemente de indivíduos de alta escolaridade, grupos socioeconômicos mais favorecidos e autodeclarados pretos pode ser uma limitação deste estudo, principalmente ao se analisar a distribuição dos escores do DRISS segundo as características sociodemográficas, pois a amostra mostrou-se bastante homogênea. No entanto, é preciso ressaltar que não houve qualquer restrição à participação de outros grupos raciais, embora a participação de indivíduos brancos tenha sido mínima, mesmo com o esforço na divulgação. É possível que tenha havido uma certa solidariedade para responder ao DRISS por parte de acadêmicos, membros de movimentos sociais, entre outros, pois a divulgação foi mais intensa nesses grupos. Ainda, entre pessoas desses grupos pretos e pardos, a identificação racial é mais nítida, possibilitando assim um maior senso crítico em relação às experiências diárias de vida, inclusive as discriminatórias.

Foi investigado se o DRISS possuía validade discriminante para algumas das características sociodemográficas investigadas neste estudo (Furr, 2015). Os achados mostraram que não foi observada diferença estatisticamente significativa dos valores médios dos escores do DRISS - quando comparadas as características sociodemográficas; ou seja, o DRISS pareceu não possuir validade discriminante para nenhuma das variáveis investigadas.

Tendo em vista que se tratou de uma amostra predominantemente de negros com elevada renda e escolaridade, mas com presença de indivíduos de baixa renda e baixa escolaridade, os resultados parecem indicar que a percepção de discriminação racial nos serviços de saúde é similar para indivíduos de alta e baixa rendas, muito ou pouco escolarizados; ou seja, não dependeu de sua inserção social. Em outras palavras, apesar de a inserção social determinar diferentes indicadores entre negros e brancos em relação à educação e ao acesso à moradia, aos serviços de saúde e ao emprego (IPEA, 2014), a percepção sobre discriminação racial nos serviços de saúde é similar. Assim, entende-se que, talvez, a percepção de discriminação racial nos serviços de saúde brasileiros seja similar entre os grupos, ainda que as consequências dessa discriminação possam variar e ser mais deletérias entre os grupos mais vulneráveis. No entanto, é preciso avançar no entendimento 
dessa questão por meio da aplicação do DRISS em grupos com características sociodemográficas diferentes do grupo participante desta validação.

Ainda, futuros estudos poderão testar a validade discriminante do DRISS em função das diferentes cores de pele, pois a percepção de discriminação racial pode ser maior quanto mais escura for a cor da pele. Também, recomenda-se a testagem do escore do DRISS em função de outras características que possam indicar o estado de saúde da pessoa, como depressão, ansiedade, doenças crônicas, entre outros.

Embora o instrumento elaborado e validado para mensurar as percepções sobre discriminação racial em serviços de saúde seja válido e confiável, este estudo apresenta limitações. Uma delas é que não foi possível realizar a análise fatorial confirmatória, que é fortemente recomentada e possibilita acrescentar mais uma evidência de validade ao instrumento (DeVellis, 2012; Furr, 2015). Tampouco foi possível criar pontos de corte para o escore - o que permitiria classificar a amostra como tendo, por exemplo, baixa, média ou alta percepção de DRISS.

Uma outra limitação foi o predomínio de respondentes do sexo feminino, o que, de certa forma, era esperado devido à natureza cultural do cuidado da saúde e o fato que a presença em serviços de saúde ser majoritariamente feminina (Hoga, 2008; Santa Rosa et al., 2014). Apesar de não ter havido restrição à participação de nenhum grupo racial, predominou a participação de negros (pretos e pardos), o que limita o processo de validação às percepções desse grupo racial. Provavelmente, a maior quantidade de respondentes do grupo dos negros refira-se à maior demanda por justiça no sistema de saúde brasileiro, mesmo porque, são os negros que compõem a maioria dos usuários do Sistema Único de Saúde e também são os mais insatisfeitos com o atendimento (Paixão et al., 2011). Possivelmente, entre as pessoas que acessaram o link para o REDCap, havia muitas de outras raças/cores. No entanto, como elas não sofreram discriminação ou não perceberam que sofreram, elas podem ter abandonado ou respondido 'não' a essa pergunta.

No Brasil, não é ainda comum outros grupos raciais, além de pretos e pardos, relatarem racismo. Entretanto, estudo qualitativo desenvolvido com 30 médicos, residentes das regiões sul e sudeste do Brasil, mostrou que pessoas da cor amarela (asiáticos) são estereotipadas, mas esse estereótipo é positivado de forma a abrir mais oportunidades, sem necessariamente precisar se esforçar ou demonstrar competência (Santos, 2012). Em outros países, como Estados Unidos e Austrália, 
outros grupos étnico-raciais - como latinos, asiáticos, aborígenes - são, frequentemente, objeto de estudo devido à discriminação racial que sofrem (Paradies, 2006a; Kressin, Raymond, Manze, 2008; Bastos et al., 2010).

O fato de o DRISS ser autopreenchido pode se configurar também como um fator limitador, tendo em vista que dificulta o preenchimento por pessoas analfabetas e pouco escolarizadas, necessitando de novo processo de validação caso se tenha a intenção de aplicá-lo por meio de entrevista face-a-face.

Não foi possível verificar a validade de critério do DRISS em função de outros instrumentos, pois não há nenhum instrumento que meça o mesmo constructo, com características aproximadas para ser considerado padrão-ouro em termos de comparação.

Finalizando, a assistência enviesada e injusta, conforme a diferença de raça/cor da pele dos indivíduos, por parte dos profissionais de saúde, originou a demanda pela produção deste trabalho. Essa assistência enviesada e injusta, segundo a raça/cor, reflete o racismo estrutural (Feagin, Bennefield, 2014), profundamente enraizado nas instituições de saúde brasileiras (UN, 2014). O DRISS investigou as percepções de discriminação racial no nível interpessoal, na relação profissional de saúde-usuário, sendo capaz de produzir informações relevantes e estratégicas para auxiliar no planejamento de ações programáticas visando à redução das iniquidades raciais em saúde. 




\section{CONCLUSÕES}

Foi produzida a escala multidimensional Percepções sobre Discriminação Racial Interpessoal nos Serviços de Saúde, cuja abreviação é DRISS. Essa escala é composta de questões introdutórias, mais 19 itens com as categorias de resposta raramente, algumas vezes, muitas vezes, quase sempre e sempre. É composta por seis dimensões, a saber: Sintoma Somático, Preparo, Consequências Emocionais, Expressão Emocional, Percepção Social e Reação. Seu escore varia entre 20 e 100 pontos, sendo que 20 pontos significam a menor percepção possível de DRISS e 100 pontos a maior percepção possível de DRISS. O processo de validação da escala foi executado com a participação de homens e mulheres, maiores de 18 anos. Apesar de o nome da escala conter o termo "serviços de saúde", a coleta de dados não foi realizada dentro dos serviços de saúde, para se evitarem eventuais vieses ocasionados pela proximidade com os profissionais de saúde.

Criado para ser utilizada em estudos epidemiológicos com vistas a medir a percepção de usuários de serviços de saúde, públicos ou privados, sobre a discriminação racial interpessoal perpetrada por profissionais de saúde, o DRISS inova pelos seguintes aspectos: ser específico para os serviços de saúde; a população-alvo constar de usuários dos serviços de saúde; conter itens que versam sobre preparo (Fator 2) e também sobre observação em relação a terceiros (Fator 4); e, por fim, de um modo geral, avalia o racismo institucional por um ângulo diferente do institucional - que é o dos usuários dos serviços de saúde.

As validades de conteúdo e constructo foram verificadas e apresentaram bons indicadores.

Aparentemente, o DRISS não possui validade discriminante para as variáveis sociodemográficas investigadas, que foram sexo, idade, estado, local de residência, religião, escolaridade, raça/cor, trabalho remunerado, convênio médico, união estável e grupo econômico. Isso parece mostrar que a percepção de discriminação racial perpassa os grupos sociais independentemente do grupo socioeconômico ou da escolaridade. Recomendam-se estudos futuros para testar o escore do DRISS em função das diferentes cores de pele de outras características que possam indicar o estado de saúde - como, por exemplo, doenças crônicas, depressão e ansiedade. 

REFERENCIAS 



\section{REFERÊNCIAS}

ABEP. Critério Brasil 2015 e atualização da distribuição de classes para 2016. 2016. Alexandre NMC, Coluci MZO. Validade de conteúdo nos processos de construção e adaptação de instrumentos de medidas. Cien Saude Colet 2011;16:3061-8. doi:10.1590/S1413-81232011000800006.

Allport GW. The nature of prejudice. Cambridge: Perseus Books; 1979.

ANVISA. Conceito de serviços de saúde. Agência Nac VigilâNcia Sanitária Tecnol Da Organ Dos Serviços Saúde 2003.

http://www.anvisa.gov.br/servicosaude/organiza/index.htm (accessed January 16, 2018).

Araújo EM de, Costa M da CN, Hogan VK, Mota ELA, Araújo TM de, Oliveira NF de. Diferenciais de raça/cor da pele em anos potenciais de vida perdidos por causas externas. Rev Saude Publica 2009;43:405-12. doi:10.1590/S003489102009005000021.

Araújo EM de, Costa M da CN, Oliveira NF de, Santana F dos S, Barreto ML, Hogan $\mathrm{V}$, et al. Spatial distribution of mortality by homicide and social inequalities according to race/skin color in an intra-urban Brazilian space. Rev Bras Epidemiol 2010;13:549-60. doi:10.1590/S1415-790X2010000400001.

Arteaga JS. Biological Discourses on Human Races and Scientific Racism in Brazil (1832-1911). J Hist Biol 2017;50:267-314. doi:10.1007/s10739-016-9445-8.

Aurélio. Psicometria, significado. Dicionário Online Aurélio 2017. https://dicionariodoaurelio.com/psicometria.

Azevedo $\mathrm{C}$. Onda negra medo branco: o negro no imaginário das elites do século XIX. Rio de Janeiro: Paz e Terra; 1987.

Bastos JL, Celeste RK, Faerstein E, Barros AJD. Racial discrimination and health: A systematic review of scales with a focus on their psychometric properties. Soc Sci Med 2010;70:1091-9. doi:10.1016/j.socscimed.2009.12.020.

Bastos JL, Dumith SC, Santos RV, Barros AJD, Del Duca GF, Gonçalves H, et al. Does the way I see you affect the way I see myself? Associations between interviewers' and interviewees' "color/race" in southern Brazil. Cad Saude Publica 2009;25. doi:10.1590/S0102-311X2009001000003.

Bastos JL, Duquia RP, González-Chica DA, Mesa JM, Bonamigo RR. Field work I: selecting the instrument for data collection. An Bras Dermatol 2014;89:918-23. doi:10.1590/abd1806-4841.20143884.

Bastos JL, Faerstein E. Discriminação e saúde: perspectivas e métodos. Rio de Janeiro: Fiocruz; 2012.

Bastos JL, Faerstein E, Celeste RK, Barros AJD. Explicit discrimination and health : development and psychometric properties of an assessment instrument Discriminação explícita e saúde : desenvolvimento e propriedades psicométricas de um instrumento. Rev Saude Publica 2012;46:269-78.

Bastos JL, Harnois CE, Bernardo CO, Peres MA, Paradies YC. When Does

Differential Treatment Become Perceived Discrimination? An Intersectional Analysis 
in a Southern Brazilian Population. Sociol Race Ethn 2017;3:301-18. doi:10.1177/2332649216681167.

Batista LE. Masculinidade, raça/cor e saúde. Cien Saude Colet 2005;10:71-80. doi:10.1590/S1413-81232005000100013.

Batista LE, Barros S. Enfrentando o racismo nos serviços de saúde. Cad Saude Publica 2017;33. doi:10.1590/0102-311x00090516.

Batista LE, Escuder MML, Pereira JCR. A cor da morte: causas de óbito segundo características de raça no Estado de São Paulo, 1999 a 2001. Rev Saude Publica 2004;38:630-6. doi:10.1590/S0034-89102004000500003.

Batista LE, Monteiro RB, Medeiros RA. Iniquidades raciais e saúde : o ciclo da política de saúde da população negra. Saúde Em Debate 2013;37:681-90. doi:10.1590/S0103-11042013000400016.

Beard K V, Volcy K. Increasing minority representation in nursing. Am J Nurs 2013;113:11. doi:10.1097/01.NAJ.0000426668.44751.f8.

Bentler PM. Comparative Fit Indexes in Structural Models. Psychol Bull 1990;107:238-46.

Bento MAS. Branqueamento e branquitude no Brasil. Psicol. Soc. do Racisimo, Vozes; 2002, p. 32.

Berman G, Paradies Y. Racism, disadvantage and multiculturalism: towards effective anti-racist praxis. Ethn Racial Stud 2010;33:214-32.

doi:10.1080/01419870802302272.

Borelli E. Vulnerabilidades sociais e juvenil nos mananciais da zona sul da cidade de São Paulo. Rev Katálysis 2012;15:62-9. doi:10.1590/S1414-49802012000100006.

Brandolo E, Brady N, Libby D, Pencelle M. Racism as a psycological stressor. Annu Rev Public Heal 2011;32:381-98.

Brasil. Política Nacional de Saúde Integral da População Negra : uma política para o SUS. 3a ed. Brasília: Editora do Ministério da Saúde; 2017.

Brasil. Indicadores Sociais Mínimos - conceitos (raça/cor). Inst Bras Geogr e Estatística 2015.

http://www.ibge.gov.br/home/estatistica/populacao/condicaodevida/indicadoresminim os/conceitos.shtm (accessed June 3, 2015).

Brasil. Características étnico-raciais da população: um estudo das categorias de classificação de cor ou raça - 2008. Rio de Janeiro: Instituto Brasileito de Geografia e Estatística; 2011.

Braveman P, Egerter S, Williams DR. The Social Determinants of Health: Coming of Age. Annu Rev Public Health 2011;32:381-98. doi:10.1146/annurev-publhealth031210-101218.

Brito C, Portela MC, Vasconcellos MTL de. Avaliação da concordância de dados clínicos e demográficos entre Autorizações de Procedimento de Alta Complexidade Oncológica e prontuários de mulheres atendidas pelo Sistema Único de Saúde no Estado do Rio de Janeiro, Brasil. Cad Saude Publica 2005;21:1829-35. doi:10.1590/S0102-311X2005000600032.

Burgess DJ, Crowley-Matoka M, Phelan S, Dovidio JF, Kerns R, Roth C, et al. 
Patient race and physicians' decisions to prescribe opioids for chronic low back pain. Soc Sci Med 2008;67:1852-60. doi:10.1016/j.socscimed.2008.09.009.

Byrt T, Bishop J, Carlin JB. Bias, prevalence and kappa. J Clin Epidemiol 1993;46:423-9. doi:10.1016/0895-4356(93)90018-V10.1016/0895-4356(93)90018-V.

Carril L. O negro em São Paulo: da senzala à periferia. Quilombo, favela e Perif. a longa busca por Cid., São Paulo: Annablume; Fapesp; 2006.

Clark R. Brief report: Initial psychometric properties of the everyday discrimination scale in black adolescents*1. J Adolesc 2004;27:363-8. doi:10.1016/S01401971(03)00102-7.

Contrada R, Ashmore R, Gary ML, Coups E, Egeth J, Sewell a, et al. Measures of ethnicity-related stress: Psychometric properties, ethnic group differences, and associations with well-being. J Appl Soc Psychol 2001;31:1775-820.

doi:10.1111/j.1559-1816.2001.tb00205.x.

Costello AB, Osborne JW. Best Practices in Exploratory Factor Analysis: Four Recommendations for Getting the Most From Your Analysis. Pract Assessment, Res Eval 2005;10:1-9.

Couto PF, Goto JB, Bastos JL. Pressão arterial e discriminação interpessoal: revisão sistemática de estudos epidemiológicos. Arq Bras Cardiol 2012;99:956-63. doi:10.1590/S0066-782X2012005000090.

Cunningham M. More than Just the Kappa Coefficient: A Program to Fully Characterize Inter-Rater Reliability between Two Raters. SAS Glob. Forum 2009 Stat. Data Anal., 2009, p. 1-7.

d'Orsi E, Brüggemann OM, Diniz CSG, Aguiar JM de, Gusman CR, Torres JA, et al. Desigualdades sociais e satisfação das mulheres com o atendimento ao parto no Brasil: estudo nacional de base hospitalar. Cad Saude Publica 2014;30:S154-68. doi:10.1590/0102-311X00087813.

Damásio BF. Uso da análise fatorial exploratória em psicologia. Aval Psicol 2012;11:213-28.

Dehon E, Weiss N, Jones J, Faulconer W, Hinton E, Sterling S. A Systematic Review of the Impact of Physician Implicit Racial Bias on Clinical Decision Making. Acad Emerg Med 2017;24:895-904. doi:10.1111/acem.13214.

DeVellis RF. Scale development: theory and applications. 3a ed. SAGE Publications, Inc; 2012.

DeVellis RF. Classical Test Theory. Med Care 2006;44:S50-9. doi:10.1097/01.mlr.0000245426.10853.30.

Dicio. Dicionário Online de Português. Significado de discriminar. Dicionário Online Port 2018. https://www.dicio.com.br/discriminar/.

Dicio. Dicionário Online de Português. Significado de construto 2017. https://www.dicio.com.br/construto/.

Dickason R, Chauhan V, Mor A, Ibler E, Kuehnle S, Mahoney D, et al. Racial Differences in Opiate Administration for Pain Relief at an Academic Emergency Department. West J Emerg Med 2015;16:372-80.

doi:10.5811/westjem.2015.3.23893. 
Dovidio JF. Prejudice, stereotyping and discrimination: theorical and empirical overview. In: Dovidio JF, editor. Sage Handb. Prejud. stereotyping Discrim., London: Sage; 2010.

Duckitt J. Historical overview. In: Dovidio JF, editor. Handb. Prejud. Stereotyping Discrim., London: Sage; 2010, p. 29-44.

Feagin J, Bennefield Z. Systemic racism and U.S. health care. Soc Sci Med 2014;103:7-14. doi:10.1016/j.socscimed.2013.09.006.

Feagin JR. Racist America. Revised. New York: Routledge; 2010.

Fernandes F. Aspectos da questão racial. O negro no mundo dos brancos. 2a ed revi, São Paulo: Global; 2007.

Fielding NG, Lee RM, Blank G. Handbook of Online Research Methods. London: SAGE Publications; 2008.

Figueiredo Filho DB, Silva Júnior JA da. Visão além do alcance: uma introdução à análise fatorial. Opinião Pública 2010;16:160-85. doi:10.1590/S010462762010000100007.

Fisher CB. Discrimination Distress During Adolescence. J Youth Adolesc 2000;29:679-95. doi:10.1023/A:1026455906512.

Fitzpatrick AR. The meaning of content validity. Applied Psychological Measurement; 1983.

Fragoso S, Recuero R, Amaral A. Métodos de pesquisa para a Internet. $3^{\text {a }}$ reimpre. Porto Alegre: Sulina; 2015.

Freitas D. Palmares, a guerra dos escravos. Porto Alegre: 1984.

Fry P. A persistência da raça: ensaios antropológicos sobre o Brasil e a África austral. Rio de Janeiro: Civilização Brasileira; 2005.

Furr RM. Scale Construction and Psychometrics for social and personality psychology. Washington D. C.: Sage; 2015.

Gee GC, Ro A, Shariff-Marco S, Chae D. Racial Discrimination and Health Among Asian Americans: Evidence, Assessment, and Directions for Future Research. Epidemiol Rev 2009;31:130-51. doi:10.1093/epirev/mxp009.

Geledés. Guia de enfrentamento do racismo institucional. São Paulo: Trama Design; 2013.

Gonçalves PC. Escravos e imigrantes são o que importam: fornecimento e controle damão de obra para a economia agroexportadora Oitocentista. Almanack 2017:30761. doi:10.1590/2236-463320171710.

Goto JB, Couto PFM, Bastos JL. Revisão sistemática dos estudos epidemiológicos sobre discriminação interpessoal e saúde mental. Cad Saude Publica 2013;29:44559. doi:10.1590/S0102-311X2013000300004.

Guimarães ASA. Classes, raças e democracia. 2nd ed. São Paulo: 34; 2012.

Guimarães ASA. Como trabalhar com "raça" em sociologia. Educ e Pesqui 2003;29:93-107. doi:10.1590/S1517-97022003000100008.

Guimarães ASA. Combatendo o racismo: Brasil, África do Sul e Estados Unidos. Rev Bras Ciências Sociais 1999;14:103-15. doi:10.1590/S0102-69091999000100006. 
Hair J f., Black WC, Babin BJ. Multivariate Data Analysis. 7th ed. Harlow, USA: Pearson; 2014.

Hall W, Chapman M, Colby R, Coyne-Beasley T, Day S, Eng E, et al. A systematic review to understand what we know about implicit racial/ethnic bias and healthcare outcomes. 143rd APHA Annu. Meet. Expo., 2015.

Harrell CJP, Burford TI, Cage BN, Nelson TM, Shearon S, Thompson A, et al. MULTIPLE PATHWAYS LINKING RACISM TO HEALTH OUTCOMES. Du Bois Rev Soc Sci Res Race 2011;8:143-57. doi:10.1017/S1742058X11000178.

Harris PA, Taylor R, Thielke R, Payne J, Gonzalez N, Conde JG. Research electronic data capture (REDCap) - A metadata-driven methodology and workflow process for providing translational research informatics support. J Biomed Inform 2009;42:37781. doi:10.1016/j.jbi.2008.08.010.

Hicken MT, Lee H, Ailshire J, Burgard SA, Williams DR. "Every Shut Eye, Ain't Sleep": The Role of Racism-Related Vigilance in Racial/Ethnic Disparities in Sleep Difficulty. Race Soc Probl 2013;5:100-12. doi:10.1007/s12552-013-9095-9.

Hicken MT, Lee $\mathrm{H}$, Hing AK. The weight of racism: Vigilance and racial inequalities in weight-related measures. Soc Sci Med 2017:1-10.

doi:10.1016/j.socscimed.2017.03.058.

Hoga LAK. Cuidado da enfermidade em casa ou em instituição de saúde: o processo de decisão em uma comunidade de baixa renda. Rev Lat Am Enfermagem 2008;16:115-21. doi:10.1590/S0104-11692008000100018.

Hogan VK, de Araujo EM, Caldwell KL, Gonzalez-Nahm SN, Black KZ. "We black women have to kill a lion everyday": An intersectional analysis of racism and social determinants of health in Brazil. Soc Sci Med 2017.

doi:10.1016/j.socscimed.2017.07.008.

Hooper D, Coughlan J, Mullen MR. Structural Equation Modelling: Guidelines for Determining Model Fit Daire. Electron J Bus Res Methods 2008;6:53-60.

IBGE IB de G e E. Síntese de indicadores sociais, uma análise das condições de vida da população brasileira 2015. Rio de Janeiro: 2015.

IPEA I de PE e A. Retratos das desigualdades de gênero e raça 2014.

http://www.ipea.gov.br/retrato/indicadores.html (accessed January 1, 2017).

James K, Lovato C, Cropanzano R. Correlational and Known-Group Comparison Validation of a Workplace Prejudice/Discrimination Inventory. J Appl Soc Psychol 1994;24:1573-92. doi:10.1111/j.1559-1816.1994.tb01563.x.

Jones CP. Confronting Institutionalized Racism. Phylon (1960-) 2002;50:7. doi:10.2307/4149999.

Jones CP. Levels of racism: a theoretic framework and a gardener's tale. Am J Public Health 2000;90:1212-5. doi:10.2105/AJPH.90.8.1212.

Kalckmann S, Santos CG dos, Batista LE, Cruz VM da. Racismo institucional: um desafio para a eqüidade no SUS? Saúde e Soc 2007;16:146-55.

doi:10.1590/S0104-12902007000200014.

Klonoff E a., Landrine H. No Title. J Behav Med 2000;23:329-38.

doi:10.1023/A:1005580300128. 
Klonoff E a., Landrine H. Cross-Validation of the Schedule of Racist Events. J Black Psychol 1999;25:231-54. doi:10.1177/0095798499025002006.

Klonoff $\mathrm{E}$ a., Landrine $\mathrm{H}$, Ullman JB. Racial discrimination and psychiatric symptoms among Blacks. Cultur Divers Ethnic Minor Psychol 1999;5:329-39.

doi:10.1037/1099-9809.5.4.329.

Kreling MCGD, Pimenta CA de M, Garanhani ML. Racial discrimination in pain management. Rev Dor 2014;15. doi:10.5935/1806-0013.20140049.

Kressin NR, Raymond KL, Manze M. Perceptions of race/ethnicity-based discrimination: a review of measures and evaluation of their usefulness for the health care setting. J Health Care Poor Underserved 2008;19:697-730. doi:10.1353/hpu.0.0041.

Krieger N. A glossary for social epidemiology. J Epidemiol Community Heal 2001;55:693-700. doi:10.1136/jech.55.10.693.

Krieger N. Racial and gender discrimination: Risk factors for high blood pressure? Soc Sci Med 1990;30:1273-81. doi:10.1016/0277-9536(90)90307-E.

Krieger N, Smith K, Naishadham D, Hartman C, Barbeau EM. Experiences of discrimination: Validity and reliability of a self-report measure for population health research on racism and health 2005;61:1576-96.

doi:10.1016/j.socscimed.2005.03.006.

Kung H-C. Deaths: Final data for 2005. Natl Vital Stat Reports 2008;56:4-26.

Landrine H, Klonoff EA, Corral I, Fernandez S, Roesch S. Conceptualizing and Measuring Ethnic Discrimination in Health Research. J Behav Med 2006;29:79-94. doi:10.1007/s10865-005-9029-0.

Laros J. O uso da análise fatorial: algumas diretrizes para pesquisadores. In:

Pasquali L, editor. Análise fatorial para Pesqui., Petrópolis: Vozes; 2004.

Leal M do C, Gama SGN da, Pereira APE, Pacheco VE, Carmo CN do, Santos RV. A cor da dor: iniquidades raciais na atenção pré-natal e ao parto no Brasil. Cad Saude Publica 2017;33. doi:10.1590/0102-311x00078816.

Liang CTH, Li LC, Kim BSK. The Asian American Racism-Related Stress Inventory: Development, Factor Analysis, Reliability, and Validity. J Couns Psychol 2004;51:103-14. doi:10.1037/0022-0167.51.1.103.

Lobão JSB, Washington de Jesus Sant'anna da F-R, Ardemírio de Barros S.

Aplicação dos Índices KAPPA \& PABAK na validação da classificação automática de imagem de satélite em Feira de Santana-BA. An. XII Simpósio Bras. Sensoriamento Remoto, Goiânia, Bras., 2005, p. 1207-14.

Loo CM, Fairbank JA, Scurfield RM, Ruch LO, King DW, Adams LJ, et al. Measuring exposure to racism: Development and validation of a Race-Related Stressor Scale (RRSS) for Asian American Vietnam veterans. Psychol Assess 2001;13:503-20. doi:10.1037/1040-3590.13.4.503.

López LC. O conceito de racismo institucional: aplicações no campo da saúde. Interface - Comun Saúde, Educ 2012;16:121-34. doi:10.1590/S141432832012005000004.

Lorenzo-Seva U, Ferrando PJ. FACTOR: A computer program to fit the exploratory factor analysis model. Behav Res Methods 2006;38:88-91. 
doi:10.3758/BF03192753.

Major B, Dover TL. Attributions to discrimination: Antecedents and consequences. In: TD N, editor. Handb. Prejud. stereotyping, Discrim. 2nd ed., New York: Psychology Press; 2016, p. 213-34.

Malcarne VL, Chavira DA, Fernandez S, Liu P-J. The Scale of Ethnic Experience: Development and Psychometric Properties. J Pers Assess 2006;86:150-61. doi:10.1207/s15327752jpa8602_04.

Martins AL. Mortalidade materna de mulheres negras no Brasil. Cad Saude Publica 2006;22:2473-9. doi:10.1590/S0102-311X2006001100022.

Mattos H. "Remanescentes das comunidades dos quilombos": memória do cativeiro e políticas. Rev USP 2006;68:104-11.

Monk EP. The Consequences of "Race and Color" in Brazil. Soc Probl 2016;63:41330. doi:10.1093/socpro/spw014.

Morse ML, Fonseca SC, Barbosa MD, Calil MB, Eyer FPC. Mortalidade materna no Brasil: o que mostra a produção científica nos últimos 30 anos? Cad Saude Publica 2011;27:623-38. doi:10.1590/S0102-311X2011000400002.

Muniz JO. Inconsistências e consequências da variável raça para a mensuração de desigualdades. Civ - Rev Ciências Sociais 2016;16:62. doi:10.15448/19847289.2016.2.23097.

Muniz JO, Bastos JL. Volatilidade classificatória e a (in)consistência da desigualdade racial. Cad Saude Publica 2017;33:1-12. doi:10.1590/0102-311x00082816.

Nogueira O. Preconceito racial de marca e preconceito racial de origem: sugestão de um quadro de referência para a interpretação do material sobre relações raciais no Brasil. Tempo Soc 2007;19. doi:10.1590/S0103-20702007000100015.

Noronha APP, Pinto LP, Ottati F. Análise fatorial confirmatória da Escala de Aconselhamento Profissional. Arq Bras Psicol 2016;68:62-71.

O'Grady KE. Measures of explained variance: Cautions and limitations. Psychol Bull 1982;92:766-77. doi:10.1037/0033-2909.92.3.766.

ONU O das NU. ONU: era digital deve garantir prosperidade para todos. Notícias e Mídia - Rádio ONU 2017.

http://www.unmultimedia.org/radio/portuguese/2017/10/onu-era-digital-deve-garantirprosperidade-para-todos/\#.WILHTqinHIU.

Paixão M, Rossetto I, Montovanele F, Carvano LM. Relatório anual das desigualdades raciais no Brasil 2009-2010 - Constituição Cidadã, seguridade social e seus efeitos sobre as assimetrias de cor ou raça. Rio de Janeiro: 2011.

Paradies Y. Defining, conceptualizing and characterizing racism in health research. Crit Public Health 2006a;16:143-57. doi:10.1080/09581590600828881.

Paradies Y. A systematic review of empirical research on self-reported racism and health. Int J Epidemiol 2006b;35:888-901. doi:10.1093/ije/dyl056.

Paradies Y, Ben J, Denson N, Elias A, Priest N, Pieterse A, et al. Racism as a Determinant of Health: A Systematic Review and Meta-Analysis. PLoS One 2015;10:e0138511. doi:10.1371/journal.pone.0138511.

Paradies Y, Cunningham J. Development and validation of the Measure of 
Indigenous Racism Experiences (MIRE). Int J Equity Health 2008;7:9. doi:10.1186/1475-9276-7-9.

Paradies Y, Truong M, Priest N. A Systematic Review of the Extent and Measurement of Healthcare Provider Racism. J Gen Intern Med 2014;29:364-87. doi:10.1007/s11606-013-2583-1.

Pascoe EA, Smart Richman L. Perceived discrimination and health: A meta-analytic review. Psychol Bull 2009;135:531-54. doi:10.1037/a0016059.

Pasquali L. Psicometria. Rev Da Esc Enferm Da USP 2009;43:992-9. doi:10.1590/S0080-62342009000500002.

Pasquali L. Análise fatorial: um manual teórico-prático. Brasília: UNB; 1999.

Perreira KM, Telles EE. The color of health: Skin color, ethnoracial classification, and discrimination in the health of Latin Americans. Soc Sci Med 2014;116:241-50. doi:10.1016/j.socscimed.2014.05.054.

Peterson RA. A Meta-Analysis of Variance Accounted for and Factor Loadings in Exploratory Factor Analysis. Mark Lett 2000;11:261-75.

doi:10.1023/A:1008191211004.

Polit D, Beck C, Hungler B. Fundamentos de pesquisa em enfermagem: métodos, avaliação e utilizaçãoPOLIT, D.; BECK, C.; HUNGLER, B. Fundamentos de pesquisa em enfermagem: métodos, avaliação e utilização. 5th ed. Porto Alegre: Artmed, 2004. 5th ed. Porto Alegre: Artmed; 2004.

Priest N, Paradies Y, Trenerry B, Truong M, Karlsen S, Kelly Y. A systematic review of studies examining the relationship between reported racism and health and wellbeing for children and young people. Soc Sci Med 2013;95:115-27. doi:10.1016/j.socscimed.2012.11.031.

$\mathrm{R}$ Core Team. R: A language and environment for statistical computing. $\mathrm{R}$ Foundation for 2017.

Reichenheim ME, Moraes CL. Desenvolvimento de instrumentos de aferição epidemiológicos. In: Kac G, Sichieri R, Gigante DP, editors. Epidemiol. Nutr., Rio de Janeiro: ABRASCO/Editora Atheneu; 2007, p. 227-43.

Reis J. Rebelião escrava no Brasil: a história do levante dos Malês. São Paulo: Companhia das Letras; 2004.

Revelle W, Zinbarg RE. Coefficients Alpha, Beta, Omega, and the glb: Comments on Sijtsma. Psychometrika 2009;74:145-54. doi:10.1007/s11336-008-9102-z.

Rocha PR da, David HMSL. Determination or determinants? A debate based on the Theory on the Social Production of Health. Rev Da Esc Enferm Da USP 2015;49:129-35. doi:10.1590/S0080-623420150000100017.

Santa Rosa PLF. Mulheres negras, o cuidado com a saúde e as barreiras na busca por assistência: estudo etnográfico em uma comunidade de baixa renda. Escola de Enfermagem da Universidade de São Paulo (Dissertação), 2013.

Santa Rosa PLF, Hoga LAK, Santana MF, Silva PAL. Uso de plantas medicinais por mulheres negras: estudo etnográfico em uma comunidade de baixa renda. Rev Da Esc Enferm Da USP 2014;48:45-52. doi:10.1590/S0080-623420140000600007.

Santos GA dos. Racismo institucional: uma análise a partir da perspectiva dos 
estudos pós-coloniais e da Ética. Ensaios Filosóficos 2015;11:1-21.

Santos MOP. Médicos e pacientes tem sexo e cor? A perspectiva de médicos sobre a relação médico-paciente na prática ambulatorial. Instituto de Psicologia da Universidade de São Paulo, 2012.

Santos WS dos, Gouveia V V., Navas MS, Pimentel CE, Gusmão EÉ da S. Escala de racismo moderno: adaptação ao contexto brasileiro. Psicol Em Estud 2006;11:637-45. doi:10.1590/S1413-73722006000300020.

Sartes LMA, Souza-Formigoni MLO De. Avanços na Psicometria : Da Teoria Clássica dos Testes à Teoria de Resposta ao Item Advances in Psychometrics : From Classical Test Theory to Item Response Theory. Psicol Reflexão e Crítica 2013;26:241-50. doi:10.1590/S0102-79722013000200004.

Seyferth G. A estratégia do branqueamento. Ciência Hoje 1986;5:54-6.

Smedley B, Myers H, Harrell S. Minority-status stresses and the college adjustment of ethnic minority freshmen. J Higher Educ 1993;64:434-52. doi:10.2307/2960051.

Souza IM de, Araújo EM de, Nery FS. Mortalidade masculina segundo a raça/cor da pele em estados do nordeste e sudeste do Brasil, 2009-2011. Rev Da Assoc Bras Pesqui Negros 2015;7:154-67.

Tabachinick B, Fidell L. Using multivariate Statistics. 6a. Pearson; 2012.

Taguieff PA. O racismo. Lisboa: Instituto Piaget; 1997.

Telles E, Flores RD, Urrea-Giraldo F. Pigmentocracies: Educational inequality, skin color and census ethnoracial identification in eight Latin American countries. Res Soc Stratif Mobil 2015;40:39-58. doi:10.1016/j.rssm.2015.02.002.

Telles E, Steele L. Pigmentocracy in the Americas: how is educational attainment related to skin color? Lat Am Public Opin Proj Insights Ser 2012;73:1-8.

Tischauser LV. Jim Crow Laws. Denver: Greenwood; 2012.

Travassos C, Williams DR. The concept and measurement of race and their relationship to public health: a review focused on Brazil and the United States. Cad Saude Publica 2004;20:660-78. doi:10.1590/S0102-311X2004000300003.

Ture K, Hamilton C V. Black power: politics of libertation in America. New York: Vintaje; 1967.

UN. United Nations. Statement by the United Nations' Working Group of Experts on People of African Descent, on the conclusion of its official visit to Brazil, 3- 13 December 2013. United Nations 2014.

http://www.ohchr.org/EN/NewsEvents/Pages/DisplayNews.aspx?NewsID=14159\&La nglD=E\%23sthash.104dXOaj.dpuf (accessed December 22, 2018).

Venturi G. Entrevista: Gustavo Venturi comenta dados relevantes sobre a pesquisa "Discriminação racial e preconceito de cor no Brasil." Fundação Perceu Abramo Partido Dos Trab 2006. https://fpabramo.org.br/2006/05/09/entrevista-gustavoventuri-comenta-dados-relevantes-sobre-a-pesquisa-discriminacao-racial-epreconceito-de-cor-no-brasil/?storytopic=736 (accessed December 20, 2018).

Viellas EF, Domingues RMSM, Dias MAB, Gama SGN da, Theme Filha MM, Costa JV da, et al. Assistência pré-natal no Brasil. Cad Saude Publica 2014;30:S85-100. doi:10.1590/0102-311X00126013. 
Vines AI, McNeilly MD, Stevens J, Hertz-Picciotto I, Baird M, Baird DD. Development and reliability of a Telephone-Administered Perceived Racism Scale (TPRS): a tool for epidemiological use. Ethn Dis 2001;11:251-62.

Werneck J. Racismo institucional e saúde da população negra. Saúde e Soc 2016;25:535-49. doi:10.1590/S0104-129020162610.

Widhiarso W, Ravand $\mathrm{H}$. Estimating reliability coefficient for multidimensional measures: A pedagogical illustration. Rev Psychol 2014;21:111-21.

Williams DR, Mohammed SA. Discrimination and racial disparities in health: evidence and needed research. J Behav Med 2009;32:20-47. doi:10.1007/s10865-008-91850 .

Williams DR, Yan Yu, Jackson JS, Anderson NB. Racial Differences in Physical and Mental Health: Socio-economic Status, Stress and Discrimination. J Health Psychol 1997;2:335-51. doi:10.1177/135910539700200305.

Wilson FR, Pan W, Schumsky DA. Recalculation of the Critical Values for Lawshe's Content Validity Ratio. Meas Eval Couns Dev 2012;45:197-210.

doi:10.1177/0748175612440286.

Zinbarg RE, Revelle W, Yovel I. Estimating $\omega \mathrm{h}$ for Structures Containing Two Group Factors: Perils and Prospects. Appl Psychol Meas 2007;31:135-57.

doi:10.1177/0146621606291558.

Zinbarg RE, Revelle W, Yovel I, Li W. Cronbach's a, Revelle's $\beta$, and Mcdonald's $\omega \mathrm{H}$ : their relations with each other and two alternative conceptualizations of reliability. Psychometrika 2005;70:123-33. doi:10.1007/s11336-003-0974-7.

Zinbarg RE, Yovel I, Revelle W, McDonald RP. Estimating Generalizability to a Latent Variable Common to All of a Scale's Indicators: A Comparison of Estimators for $\omega$ h. Appl Psychol Meas 2006;30:121-44. doi:10.1177/0146621605278814. 
APÊNDICES 



\section{APÊNDICES}

\section{APÊNDICE I - INSTRUMENTO PARA COLETA DE DADOS (POPULAÇÃO-ALVO) Confidential \\ PERCEPCÕES SOBRE DISCRIMINACCÃO RACIAL INTERPESSOAL EM SERVIÇOS DE SAÚDE

Por gentileza, você deve responder todos os itens!

Ao teminar, clique no botão 'Submit'.

Caso você prefira terminar de preencher em outro momento, salve suas respostas e retorne depois, clicando no botão 'Save \& Return Later'

Obrigada!

\section{TERMO DE CONSENTIMENTO LIVRE E ESCLARECIDO}

Convidamos o (a) Sr. (a) para participar da pesquisa intitulada "Desenvolvimento e validação do instrumento de medida das percepções sobre discriminação racial interpessoal nos serviços de saúde brasileiros", da enfermeira Patricia Lima Ferreira Santa Rosa, do curso de Doutorado da Escola de Enfermagem da Universidade de São Paulo, sob a orientação das professoras doutoras Ana Luíza Vilela Borges e Edna Maria de Araújo.

O objetivo deste estudo é desenvolver e validar um instrumento para mensurar a percepção sobre discriminação racial interpessoal no contexto dos serviços de saúde brasileiros.

A sua participação na pesquisa consiste em responder perguntas online sobre suas percepções a respeito da discriminação racial interpessoal no contexto dos serviços de saúde brasileiros.

Esclarecemos que a sua participação até o final desse questionário online vai gerar um arquivo que será salvo pelas pesquisadoras e seu preenchimento durará aproximadamente 15 minutos.

Essa pesquisa não oferece risco, mas é possível que alguma lembrança de sua história de vida traga algum desconforto imediato. $\mathrm{O}$ estudo trará benefício à população uma vez que, ao reconhecermos situações de discriminação racial nos serviços de saúde, podemos elaborar estratégias para reduzir desigualdades étnico-raciais no atendimento em serviços de saúde.

Esclarecemos que a sua participação é voluntária, anônima e o (a) Sr. (a) tem total liberdade de recusar e interromper a participação a qualquer momento, sem qualquer prejuízo agora ou no futuro. Os resultados serão analisados em conjunto com os resultados de outras pessoas e seu nome não constará nos registros.

A participação no estudo não acarretará custos para você e não será disponibilizada nenhuma compensação financeira adicional. É garantida indenização diante de eventuais danos decorrentes desta pesquisa.

Em qualquer etapa do estudo, você terá acesso às pesquisadoras responsáveis pela investigação para esclarecimento de dúvidas:

Coordenadora da pesquisa: Patricia Lima Ferreira Santa Rosa, que pode ser encontrada no endereço: Av. Dr. Enéas de Carvalho Aguiar, 419 - 05403-000 - São Paulo - SP. Telefone: (11) 99963-0886 - Email: patricialfsantarosa@gmail.com

Orientadora: Professora Ana Luiza Vilela Borges, telefone: 3061-7652, email: alvilela@usp.br

Caso você tenha alguma consideração ou dúvida sobre a ética dessa pesquisa, entre em contato com o Comitê de Ética em Pesquisa (CEP) - Endereço - Av. Dr. Enéas de Carvalho Aguiar, 419 - Cerqueira Cesar - São Paulo/SP CEP . 05403-000 Telefone- (11) 30618858 e-mail - cepee@usp.br

Esta pesquisa atende todas as especificações da Resolução 466, de 12 de dezembro de 2012 que aprova as diretrizes e normas regulamentadoras de pesquisas envolvendo seres humanos. 


\section{Confidential}

Page 2 of 15

Não aceito participar deste estudo (Escolhendo esta opção, o programa direcionará você para o final do formulário. Agradecemos pela sua participação. Gentileza clicar em 'End the survey now' da caixa de diálogo que aparecerá).

Sim, aceito participar deste estudo (Você deverá clicar abaixo em "Next Page" e proceder assim até a penúltima página). 


\section{Confidential}

\section{INFORMAÇÕES SOCIODEMOGRÁFICAS}

Qual é o seu sexo?

Masculino

Feminino

Outro

Qual é a sua outra opção de pertencimento em termos de sexo?

Data de nascimento

(Dia-mês-ano (Exemplo: 30-03-1976); menores de 18 anos não poderão participar.)

Qual é a sua idade?

(Anos completos.)

Estado

(Estado onde mora atualmente)

Acre

Alagoas

Amapá

Amazonas

Bahia

Ceará

Distrito Federal

Espírito Santo

Goiás

Maranhão

Mato Grosso

Mato Grosso do Sul

Minas Gerais

Pará

Paraíba

Paraná

Pernambuco

Piauí

Rio de Janeiro

Rio Grande do Norte

Rio Grande do Sul

Rondônia

Roraima

Santa Catarina

São Paulo

Sergipe

Tocantins

A cidade onde você mora fica em área urbana ou rural?

Urbana

Rural 


\section{Confidential}

Qual é a sua religião?

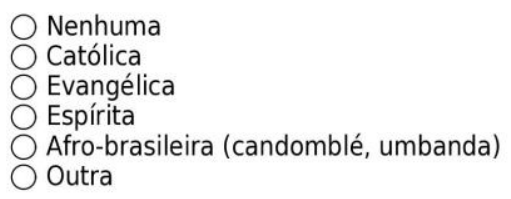

Qual é a sua escolaridade?

Analfabeto/ Fundamental 1 Incompleto

O Fundamental 1 Completo/ Fundamental 2 Incompleto

Fundamental 2 Completo/ Médio Incompleto

O Médio Completo/ Superior Incompleto

Superior Completo

Como você classifica a sua raça/cor?

$$
\begin{aligned}
& \bigcirc \text { Branca } \\
& \bigcirc \text { Parda } \\
& \bigcirc \text { Preta } \\
& \bigcirc \text { Amarela } \\
& \bigcirc \text { Indígena }
\end{aligned}
$$

Qual é a sua profissão?

Você trabalha?

(Trabalho remunerado, com ou sem registro em carteira)

Não

○im

Está procurando emprego atualmente?

○ão

$\bigcirc \mathrm{Sim}$

Você tem plano de saúde ou convênio?

○ Não

O Sim

Atualmente está casada/o ou em união estável com alguém?

Não

$\bigcirc \mathrm{Sim}$ 


\section{Confidential}

Page 5 of 15

\section{INFORMAÇÕES SOCIOECONÔMICAS}

Na residência em que você mora há quantos banheiros?

$\bigcirc 0$

$\bigcirc 1$

3

○ ou +

Na residência em que você mora, há quantas empregadas/os domésticas/os mensalistas, quer dizer, que trabalhe em sua casa de modo permanente por cinco ou mais dias por semana, incluindo babás, motoristas, cozinheiras etc.?

$\bigcirc 0$

1 1

(1)

4 ou +

Na residência em que você mora, há quantos automóveis/carros para uso pessoal ou da família (não considerar taxis, vans ou caminhonetes usadas para fretes, ou qualquer veículo usado para atividade profissional)?

$\bigcirc$

$\bigcirc 2$

○ 3

○ ou +

Na residência em que você mora, há quantos microcomputadores? (Considerar também notebooks.)

0

$\bigcirc 1$

$\bigcirc 2$

○ ou +

Na residência em que você mora, há quantas máquinas de lavar louças?

$\bigcirc 0$

$\bigcirc 1$

(1)

$\bigcirc 3$

○ 4 ou +

Na residência em que você mora, há quantas geladeiras?

0

$\bigcirc 1$

○2

3

○ 4 ou +

Na residência em que você mora, há quantos freezers?

Considerar aparelho independente ou 2. a porta externa da geladeira duplex.

$\bigcirc 0$

○ 1

$\bigcirc 2$

○ 3

○ ou + 


\section{Confidential}

Na residência em que você mora, há quantas máquinas de lavar roupa?
$\bigcirc 0$
1
○ 2
$\bigcirc 3$
$\bigcirc 4$ ou +

Na residência em que você mora, há quantos aparelhos de DVD?
$\bigcirc 0$
$\bigcirc 1$
2
33
○ ou +

Na residência em que você mora, há quantos aparelhos de microondas?
$\bigcirc 0$
1
02
$\bigcirc 3$
○ ou +

Na residência em que você mora, há quantas motocicletas?
$\bigcirc 0$
$\bigcirc 1$
2
更
○ ou +

Na residência em que você mora, há quantas máquinas de secar roupa?
$\bigcirc 0$
1
02
○ 3
○ ou +

Quem é a/o chefe da sua família?

$\mathrm{Ou}$

Meu companheiro ou minha companheira

Minha mãe

Meu pai

Outra pessoa

Quem?

Qual é a escolaridade do/a chefe da sua família?

Analfabeto/ Fundamental 1 Incompleto

Fundamental 1 Completo/ Fundamental 2 Incompleto

O Fundamental 2 Completo/ Médio Incompleto

O Médio Completo/ Superior Incompleto

$\bigcirc$ Superior Completo 


\section{QUESTÕES INTRODUTÓRIAS DO INSTRUMENTO: PERCEPÇÕES SOBRE DISCRIMINAÇÃO RACIAL INTERPESSOAL EM SERVIÇOS DE SAÚDE}

Alguma vez na sua vida, você foi tratada/o injustamente, em relação a outras pessoas presentes, devido à sua raça/cor da pele em alguma dessas instituições?

Se SIM, responda lembrando da ÚLTIMA VEZ em que isso aconteceu.

○ão (Escolhendo esta opção, o programa direcionará você para o final do formulário. Agradecemos pela sua participação. Gentileza clicar em 'End the survey now' da caixa de diálogo que aparecerá).

Posto de saúde

Hospital

Pronto-socorro

Ambulatório

Consultório odontológico

Maternidade

SAMU

Farmácia da unidade

$\bigcirc$ Laboratório

Central de regulação

Outro

Qual?

Qual foi o tratamento injusto que você recebeu devido à sua raça/cor da pele? Lembre-se que, segundo a sua percepção, a única diferença que havia entre você e as demais pessoas presentes era a sua raça/cor.

Algum funcionário te olhou com uma cara de desprezo

Foi deixada/o para trás em uma fila

$\bigcirc$ Recebeu medicamento menos potente

Recebeu medicamento de menor qualidade

Foi maltratada/o verbalmente

Foi submetida/o a um procedimento médico ou de enfermagem mais doloroso do que o que devia ser

0 profissional de saúde não te examinou direito

0 profissional pareceu não querer tocar em você

Foi maltratado fisicamente pelo/a profissional de saúde

Outro

Por favor, descreva resumidamente o que aconteceu:

Há quanto tempo isso aconteceu?

No último ano

Há mais de 1 ano, mas menos que 5 anos

Há mais de 5 anos 


\section{Confidential}

Qual foi o/a profissional que te tratou injustamente devido à sua raça/cor da pele?

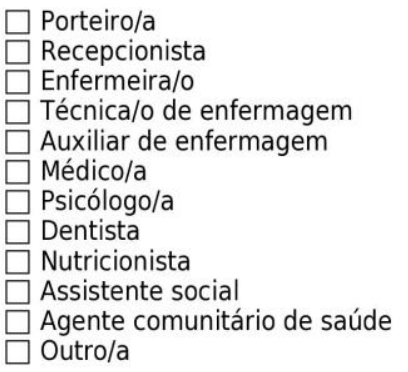

Quem?

Qual era o sexo da/o profissional que te tratou injunstamente?

$$
\begin{aligned}
& \text { Masculino } \\
& \text { Feminino } \\
& \text { Outro }
\end{aligned}
$$

Qual era o sexo de pertencimento da/o profissional?

Qual era a raça/cor da pele da/o profissional que te tratou injustamente?

$$
\begin{aligned}
& \bigcirc \text { Branca } \\
& \text { Preta } \\
& \bigcirc \text { Parda } \\
& \bigcirc \text { Amarela } \\
& \text { Indígena }
\end{aligned}
$$


PERCEPÇÕES SOBRE DISCRIMINAÇÃO RACIAL INTERPESSOAL EM SERVIÇOS DE SAÚDE, DEVIDO À RAÇA/COR DA/O USUÁRIA/O

Quando eu sou tratada/o injustamente devido à minha raça/cor da pele, em serviços de saúde, eu

1. Ignoro

$\bigcirc$ Raramente

$\bigcirc$ Algumas vezes

Muitas vezes

$\bigcirc$ Quase sempre

O Sempre

2. Encaro como um acontecimento cotidiano

Raramente

Algumas vezes

$\bigcirc$ Muitas vezes

Quase sempre

O Sempre

3. Converso com alguma pessoa sobre o que aconteceu (familiar ou amiga/o)

Raramente

Algumas vezes

$\bigcirc$ Muitas vezes

$\bigcirc$ Quase sempre

$\bigcirc$ Sempre

4. Procuro esquecer o que aconteceu

Raramente

Algumas vezes

$\bigcirc$ Muitas vezes

$\bigcirc$ Quase sempre

O Sempre

5. Faço uma oração (ou rezo) pela situação.

Raramente

Algumas vezes

Muitas vezes

$\bigcirc$ Quase sempre

$\bigcirc$ Sempre

6. Guardo isso para mim mesma/o

Raramente

Algumas vezes

O Muitas vezes

$\bigcirc$ Quase sempre

Sempre 


\section{Confidential}

7. Me sinto humilhada/o.

Raramente

Algumas vezes

$\bigcirc$ Muitas vezes

Quase sempre

$\bigcirc$ Sempre

8. Me sinto impotente.

$\bigcirc$ Raramente

Algumas vezes

Muitas vezes

$\bigcirc$ Quase sempre

$\bigcirc$ Sempre

9. Sinto raiva

Raramente

Algumas vezes

$\bigcirc$ Muitas vezes

$\bigcirc$ Quase sempre

Sempre

10. Sinto dores de cabeça

$\bigcirc$ Raramente

Algumas vezes

Muitas vezes

$\bigcirc$ Quase sempre

$\bigcirc$ Sempre

11. Sinto dores de estômago

Raramente

Algumas vezes

Muitas vezes

$\bigcirc$ Quase sempre

Sempre

12. Sinto tensão nos músculos

Raramente

Algumas vezes

$\bigcirc$ Muitas vezes

$\bigcirc$ Quase sempre

$\bigcirc$ Sempre

13. Sinto palpitação no coração

Raramente

Algumas vezes

$\bigcirc$ Muitas vezes

$\bigcirc$ Quase sempre

$\bigcirc$ Sempre 


\section{Confidential}

Page 12 of 15

14. Tenho receio de ter que esperar mais do que o normal para ser atendida/o

Raramente

Algumas vezes

$\bigcirc$ Muitas vezes

Quase sempre

Sempre

15. Reclamo em voz alta

Raramente

Algumas vezes

Muitas vezes

Q Quase sempre

Sempre

16. Denuncio para as autoridades (por exemplo: registro uma ocorrência na polícia ou abro um processo na justiça).

Raramente

Algumas vezes

Muitas vezes

Quase sempre

Sempre 
Confidential

Page 13 of 15

Para evitar ser tratada/o injustamente, em serviços de saúde, devido à minha raça/cor de pele, eu:

17. Tomo cuidados adicionais com a higiene

$\bigcirc$ Raramente

Algumas vezes

Muitas vezes

$\bigcirc$ Quase sempre

Sempre

18. Tomo cuidados adicionais com a depilação/barba

Raramente

Algumas vezes

Muitas vezes

$\bigcirc$ Quase sempre

Sempre

19. Tomo cuidados adicionais com as minhas roupas

Raramente

Algumas vezes

Muitas vezes

Quase sempre

$\bigcirc$ Sempre

20. Me preparo para não reclamar do atendimento

Raramente

O Algumas vezes

0 Muitas vezes

$\bigcirc$ Quase sempre

Sempre 


\section{Confidential}

Page 14 of 15

Responda as próximas perguntas pensando em situações que ocorreram com outras pessoas.

21. Eu presenciei uma/m familiar, parente ou amiga/o ser tratada/o injustamente devido à raça/cor da pele em serviços de saúde

Raramente

Algumas vezes

Muitas vezes

Quase sempre

Sempre

22. Eu presenciei outras pessoas desconhecidas serem tratadas injustamente devido à raça/cor da pele em serviços de saúde

Raramente

Algumas vezes

Muitas vezes

Quase sempre

Sempre 
Confidential

Page 15 of 15

Responda as próximas perguntas pensando em situações em que você observou privilégio.

23. Eu já me senti tratada/o com privilégios devido à minha raça/cor da pele em serviços de saúde

Raramente

Algumas vezes

Muitas vezes

Quase sempre

$\bigcirc$ Sempre

24. Eu já vi um/a desconhecido/a ser tratado/a com privilégios devido à raça/cor da pele DA PESSOA, em serviços de saúde

Raramente

Algumas vezes

Muitas vezes

$\bigcirc$ Quase sempre

○ Sempre

Caso tenha interesse e disponibilidade para responder este instrumento novamente em 15 dias, por favor, escreva seu e-mail abaixo:

Você gostaria de fazer algum comentário, crítica ou sugestão sobre este instrumento ou sobre algum item específico? 


\section{APÊNDICE II - TRECHO DO VÍDEO CONVIDANDO O PÚBLICO-ALVO PARA RESPONDER AO DRISS}

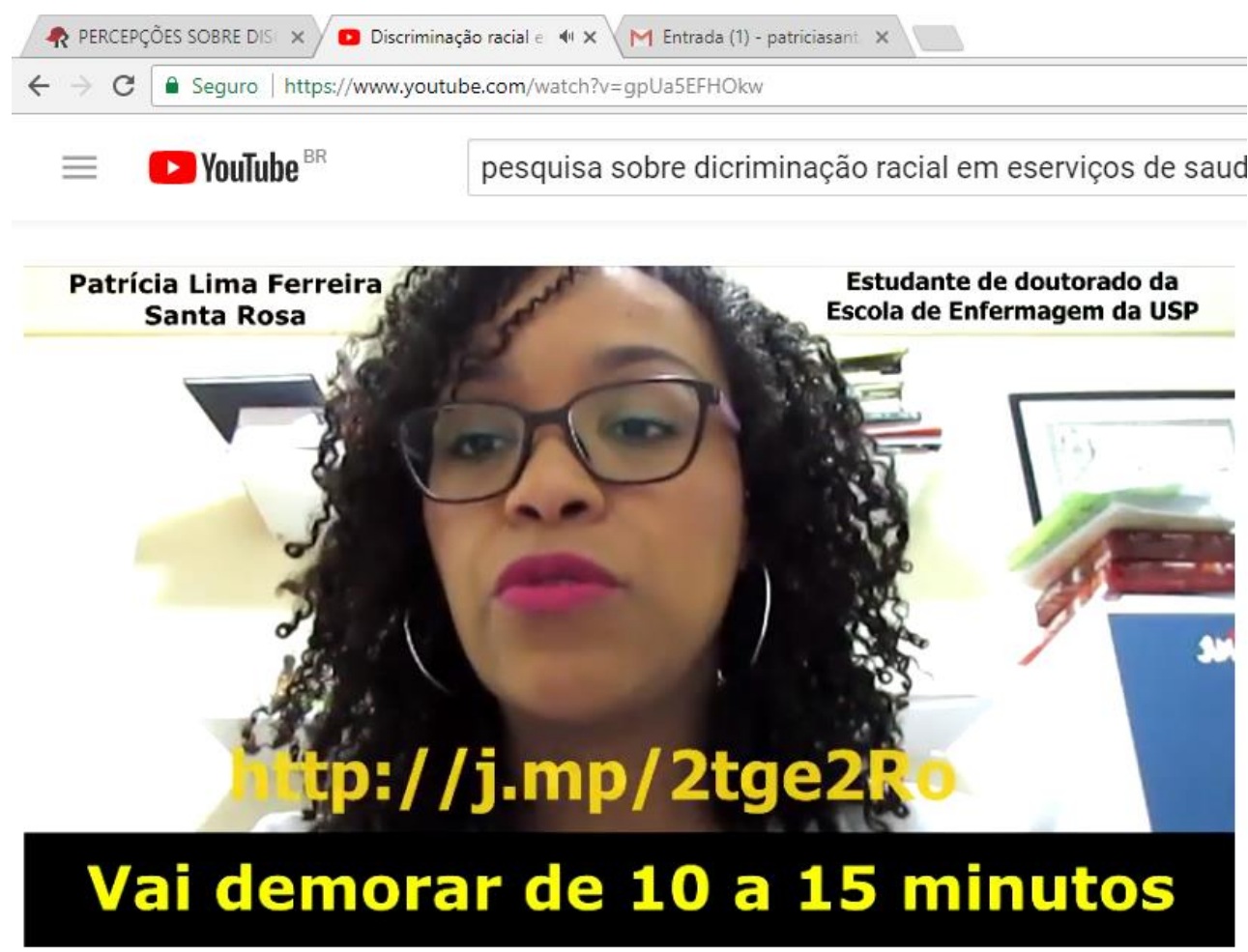

Discriminação racial em serviços de saúde
413 visualizações
ا 27 I $0 \Rightarrow$ COMPARTILHAR $\equiv+\ldots$
\# $\bigcirc$ Digite aqui para pesquisar

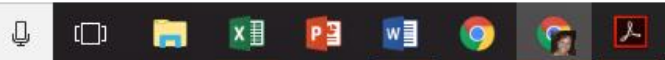

Fonte: https://www.youtube.com/watch?v=gpUa5EFHOkw 


\section{APÊNDICE III - QUESTÕES INTRODUTÓRIAS À APLICAÇÃO DO DRISS}

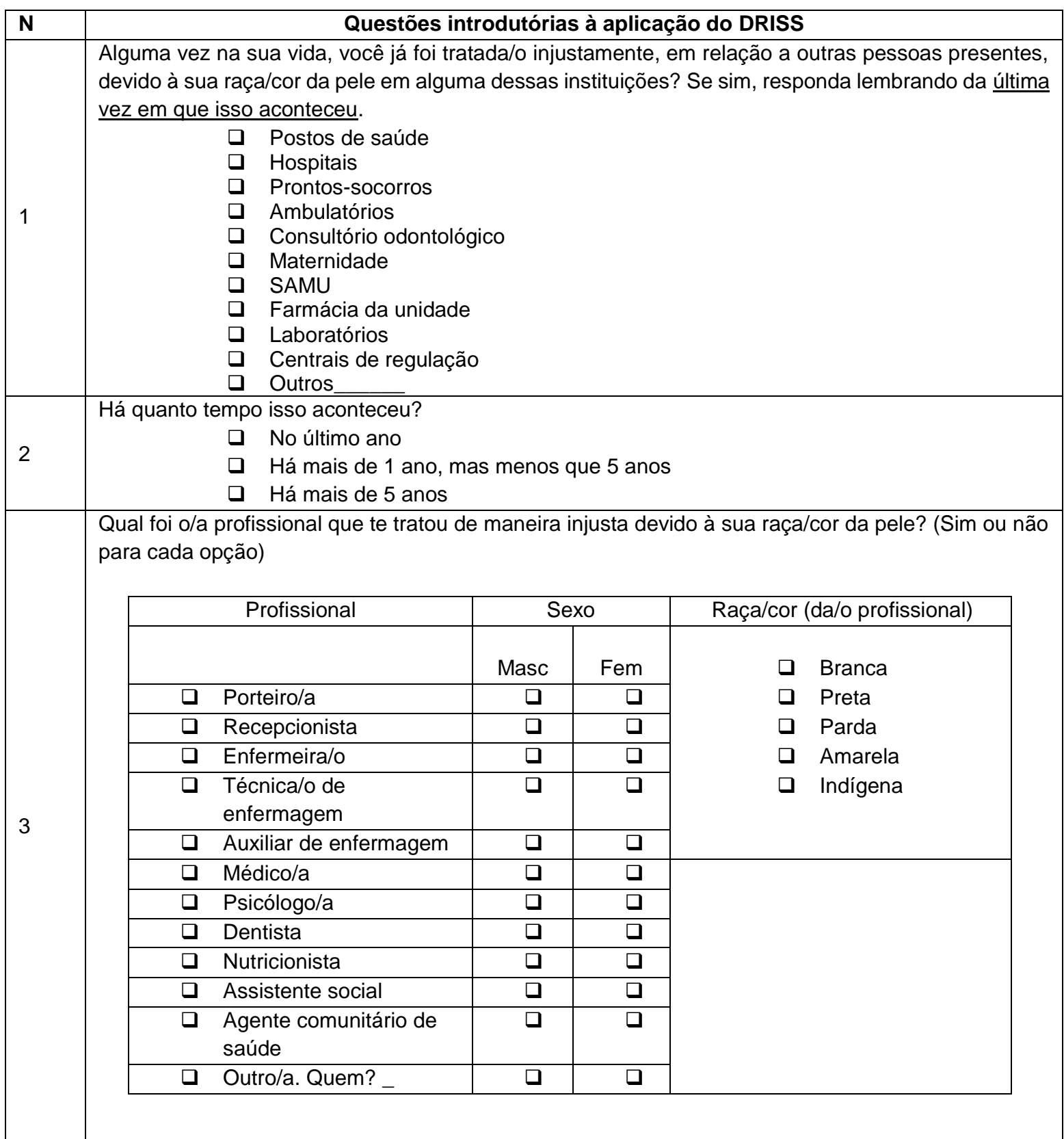




\section{APÊNDICE IV - QUESTIONÁRIO SÓCIO-ECONÔMICO-DEMOGRÁFICO}

\begin{tabular}{|c|c|}
\hline N.으 & Item sócio-econômico-demográfico \\
\hline 1. & Identificação do questionário: (numerado automaticamente pelo Software Redcap \\
\hline 2. & $\begin{array}{l}\text { Qual é o seu sexo? } \\
1 \text { Masculino } \\
2 \text { Feminino } \\
3 \text { Outro. Qual é a sua outra opção de pertencimento em termos de sexo? }\end{array}$ \\
\hline 3. & $\begin{array}{l}\text { Data de nascimento } \\
\text { (Dia-mês-ano (Exemplo: 30-03-1976); menores de } 18 \text { anos não poderão participar.) } \\
\text { Obs.: O Redcap, automaticamente, não permitia a participação de menores de } 18 \text { anos) }\end{array}$ \\
\hline 4. & $\begin{array}{l}\text { Qual é a sua idade? } \\
\text { (Anos completos.) }\end{array}$ \\
\hline 5. & $\begin{array}{l}\text { Estado (Estado onde mora atualmente) } \\
1 \text { Acre } \\
2 \text { Alagoas } \\
3 \text { Amapá } \\
4 \text { Amazonas } \\
5 \text { Bahia } \\
6 \text { Ceará } \\
7 \text { Distrito Federal } \\
8 \text { Espírito Santo } \\
9 \text { Goiás } \\
10 \text { Maranhão } \\
11 \text { Mato Grosso } \\
12 \text { Mato Grosso do Sul } \\
13 \text { Minas Gerais } \\
14 \text { Pará } \\
15 \text { Paraíba } \\
16 \text { Paraná } \\
17 \text { Pernambuco } \\
18 \text { Piauí } \\
19 \text { Rio de Janeiro } \\
20 \text { Rio Grande do Norte } \\
21 \text { Rio Grande do Sul } \\
22 \text { Rondônia } \\
23 \text { Roraima } \\
24 \text { Santa Catarina } \\
25 \text { São Paulo } \\
26 \text { Sergipe } \\
27 \text { Tocantins }\end{array}$ \\
\hline 6. & $\begin{array}{l}\text { A cidade onde você mora fica em área urbana ou rural? } \\
1 \text { Urbana } \\
2 \text { Rural }\end{array}$ \\
\hline 7. & $\begin{array}{l}\text { Qual é a sua religião? } \\
1 \text { Nenhuma } \\
2 \text { Católica } \\
3 \text { Evangélica } \\
4 \text { Espírita } \\
5 \text { Afro-brasileira (candomblé, umbanda) } \\
6 \text { Outra }\end{array}$ \\
\hline 8. & $\begin{array}{l}\text { Qual é a sua escolaridade? } \\
1 \text { Analfabeto/ Fundamental } 1 \text { Incompleto } \\
2 \text { Fundamental } 1 \text { Completo/ Fundamental } 2 \text { Incompleto } \\
3 \text { Fundamental } 2 \text { Completo/ Médio Incompleto } \\
4 \text { Médio Completo/ Superior Incompleto } \\
5 \text { Superior Completo }\end{array}$ \\
\hline
\end{tabular}




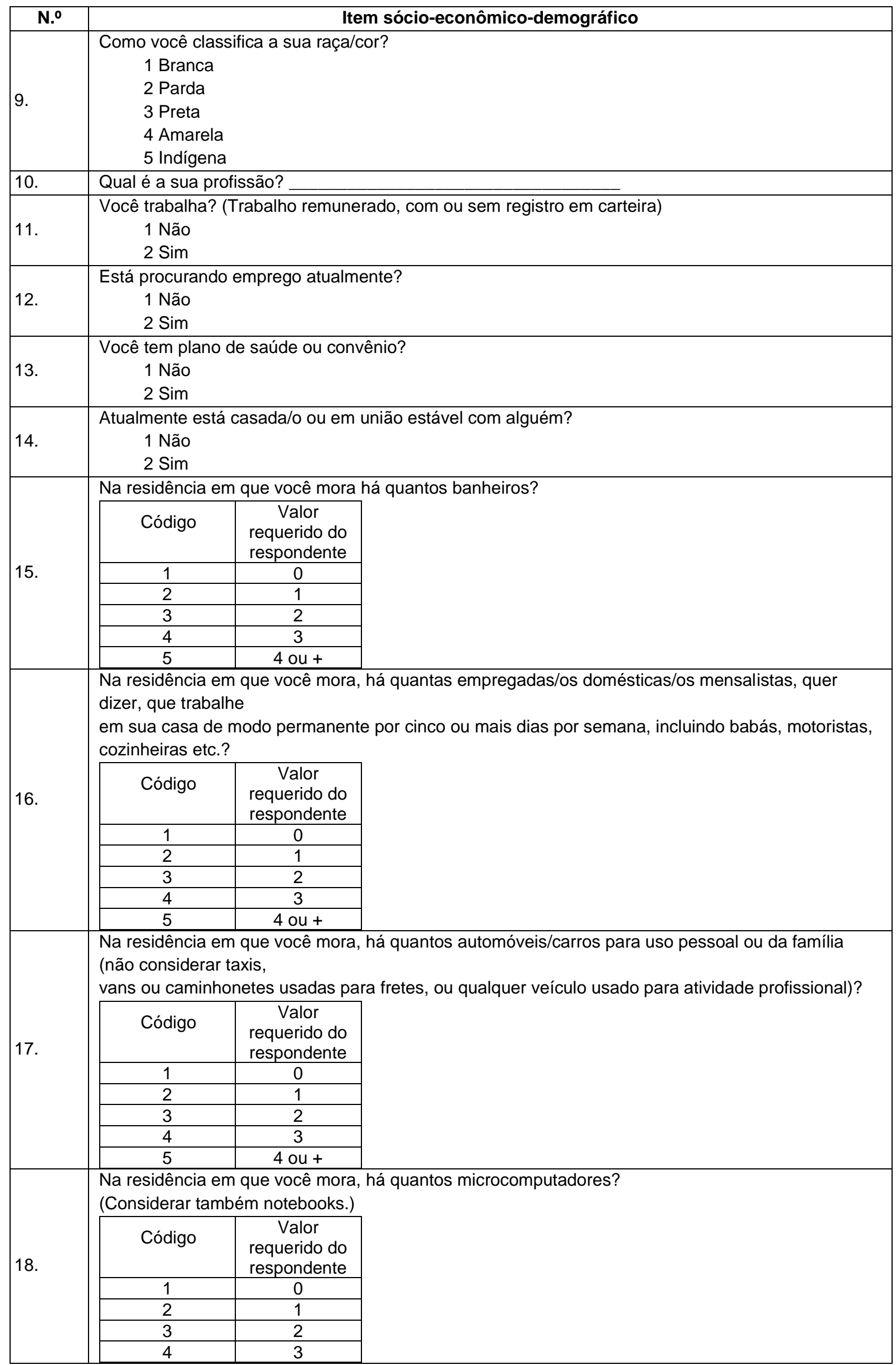




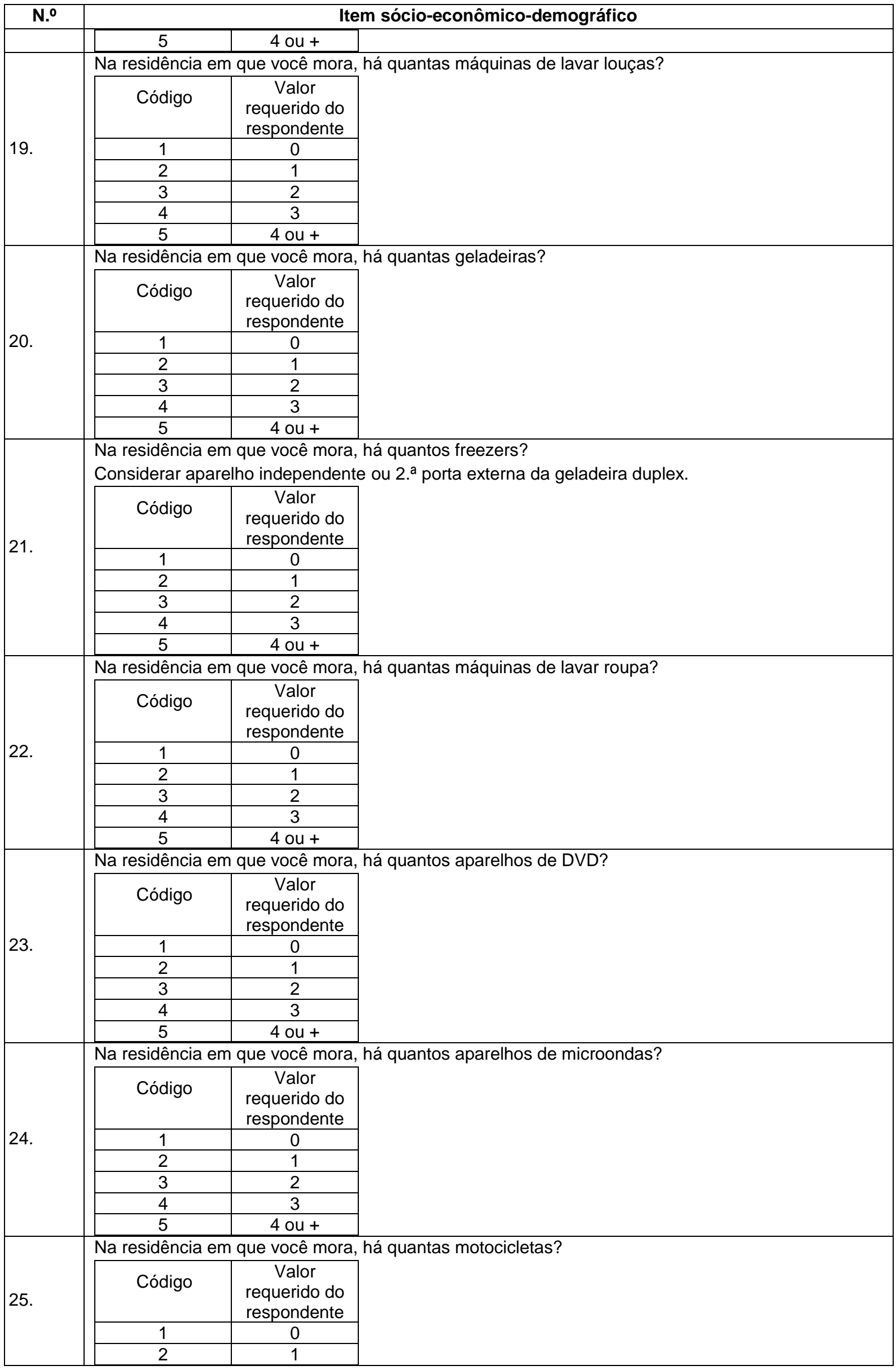




\begin{tabular}{|c|c|c|}
\hline N.․․ & & Item sócio-econômico-demográfico \\
\hline & 3 & 2 \\
\hline & 4 & 3 \\
\hline & 5 & $4 \mathrm{ou}+$ \\
\hline \multirow{7}{*}{26.} & \multicolumn{2}{|c|}{ Na residência em que você mora, há quantas máquinas de secar roupa? } \\
\hline & Código & $\begin{array}{c}\text { Valor } \\
\text { requerido do } \\
\text { respondente }\end{array}$ \\
\hline & 1 & 0 \\
\hline & 2 & 1 \\
\hline & 3 & 2 \\
\hline & 4 & 3 \\
\hline & 5 & $4 \mathrm{ou}+$ \\
\hline 27. & \multicolumn{2}{|c|}{$\begin{array}{l}\text { Quem é a/o chefe da sua família? } \\
1 \text { Eu } \\
2 \text { Meu companheiro ou minha companheira } \\
3 \text { Minha mãe } \\
4 \text { Meu pai } \\
5 \text { Outra pessoa } \\
\text { Quem? }\end{array}$} \\
\hline 28. & \multicolumn{2}{|c|}{$\begin{array}{l}\text { Qual é a escolaridade do/a chefe da sua família? } \\
1 \text { Analfabeto/ Fundamental } 1 \text { Incompleto } \\
2 \text { Fundamental } 1 \text { Completo/ Fundamental } 2 \text { Incompleto } \\
3 \text { Fundamental } 2 \text { Completo/ Médio Incompleto } \\
4 \text { Médio Completo/ Superior Incompleto } \\
5 \text { Superior Completo }\end{array}$} \\
\hline 29. & \multicolumn{2}{|c|}{$\begin{array}{l}\text { Você ou alguém do seu domicílio recebe algum tipo de benefício social? } \\
1 \text { Não } \\
2 \text { Seguro-desemprego } \\
3 \text { Bolsa-família } \\
4 \text { Bolsa-escola } \\
5 \text { Pensão } \\
6 \text { Aposentadoria } \\
7 \text { Outro } \\
\text { Qual outro benefício social? }\end{array}$} \\
\hline 30. & \multicolumn{2}{|c|}{$\begin{array}{l}\text { Na rua em que você mora, tem água encanada? } \\
1 \text { Não } \\
2 \text { Sim }\end{array}$} \\
\hline 31. & \multicolumn{2}{|c|}{$\begin{array}{l}\text { A rua em que você mora é pavimentada? } \\
\begin{array}{l}1 \text { Não } \\
2 \text { Sim }\end{array}\end{array}$} \\
\hline
\end{tabular}


ANEXO 



\section{ANEXO}

\section{ANEXO I -PARECER CONSUBTANCIADO DO CEP}

ESCOLA DE ENFERMAGEM DA
UNIVERSIDADE DE SÃO
ENFERMAGEM

\section{PARECER CONSUBSTANCIADO DO CEP}

\section{DADOS DO PROJETO DE PESQUISA}

Título da Pesquisa: DESENVOLVIMENTO E VALIDAÇÃO DO INSTRUMENTO DE MEDIDA DAS PERCEPÇÕES SOBRE DISCRIMINAÇÃO RACIAL INTERPESSOAL NOS SERVIÇOS DE SAÚDE BRASILEIROS

Pesquisador: Patricia Lima Ferreira Santa Rosa

Área Temática:

Versão: 2

CAAE: 55713316.1 .0000 .5392

Instituição Proponente: Escola de Enfermagem da Universidade de São Paulo - EEUSP

Patrocinador Principal: $\mathrm{CNPQ}$

\section{DADOS DO PARECER}

Número do Parecer: 1.622 .586

Apresentação do Projeto:

O projeto é bastante relevante no âmbito social , econômico e demográfico. O projeto pretende desenvolver e validar um instrumento para mensurar a percepção sobre discriminação racial interpessoal no contexto dos serviços de saúde brasileiros (PEDIRSS).

Objetivo da Pesquisa:

Objetivo Primário:

Desenvolver e validar um instrumento para mensurar a percepção sobre discriminação racial interpessoal no contexto dos serviços de saúde brasileiros.

Objetivos Secundários: 1) Verificar as evidências de validade de face, conteúdo e constructo.

2) Verificar evidências de confiabilidade;

3) Identificar fatores sócio-econômicos e demográficos associados.

Avaliação dos Riscos e Benefícios:

Riscos:

Essa pesquisa não oferece risco, segundo a pesquisadora, mas é possível que alguma lembrança

Endereço: Av. Dr Enéas de Carvalho Aguiar, 419

Bairro: Cerqueira Cesar

UF: SP Municipio: SAO PAULO

Telefone: (11)3061-8858

CEP: $\quad 05.403-000$

E-mail: cepee@usp.br 


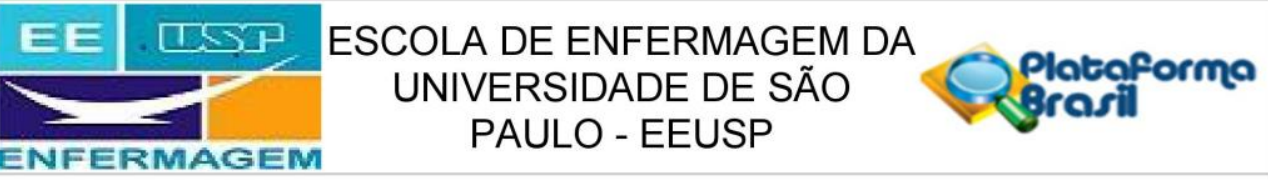

Continuação do Parecer: 1.622 .586

da história de vida traga algum desconforto imediato, ainda segundo a mesma.

Benefícios:

Para a pesquisadora, " O estudo trará benefício à população uma vez que, ao reconhecermos situações de discriminação racial nos serviços de saúde, podemos elaborar estratégias para reduzir desigualdades étnico -raciais no atendimento em serviços de saúde."

\section{Comentários e Considerações sobre a Pesquisa:}

Não há.

Considerações sobre os Termos de apresentação obrigatória:

Os termos exigidos para a análise do projeto foram devidamente apresentados.

Recomendações:

Não há.

Conclusões ou Pendências e Lista de Inadequações:

Foi inserido no TCLE a referência ao item "Indenização" relacionado ao respondente da pesquisa.

Considerações Finais a critério do CEP:

- Este CEP informa a necessidade de registro dos resultados parciais e finais na Plataforma Brasil;

- Esta aprovação não substitui a autorização da instituição coparticipante, antes do início da coleta de dados.

Este parecer foi elaborado baseado nos documentos abaixo relacionados:

\begin{tabular}{|c|c|c|c|c|}
\hline Tipo Documento & Arquivo & Postagem & Autor & Situação \\
\hline $\begin{array}{l}\text { Informações Básicas } \\
\text { do Projeto }\end{array}$ & $\begin{array}{l}\text { PB_INFORMAÇÕES_BÁSICAS_DO_P } \\
\text { ROJETO_709033.pdf }\end{array}$ & $\begin{array}{c}20 / 06 / 2016 \\
20: 24: 20 \\
\end{array}$ & & Aceito \\
\hline $\begin{array}{l}\text { Recurso Anexado } \\
\text { pelo Pesquisador }\end{array}$ & $\begin{array}{l}\begin{array}{l}\text { Formulario_avaliacao_especialistas_Pat } \\
\text { ricia_Santa_Rosa.pdf }\end{array} \\
\end{array}$ & $\begin{array}{c}20 / 06 / 2016 \\
20: 21: 03\end{array}$ & $\begin{array}{l}\text { Patricia Lima Ferreira } \\
\text { Santa Rosa }\end{array}$ & Aceito \\
\hline Outros & \begin{tabular}{|l|} 
Carta_convite_Projeto_Patricia_Lima_F \\
erreira_Santa_Rosa_20_jun_2016.docx
\end{tabular} & $\begin{array}{c}20 / 06 / 2016 \\
20: 13: 21\end{array}$ & $\begin{array}{l}\text { Patricia Lima Ferreira } \\
\text { Santa Rosa }\end{array}$ & Aceito \\
\hline $\begin{array}{l}\text { TCLE / Termos de } \\
\text { Assentimento / } \\
\text { Justificativa de } \\
\text { Ausência }\end{array}$ & $\begin{array}{l}\text { TCLE_Patricia_Lima_Ferreira_Santa_R } \\
\text { osa_20_junho_2016.docx }\end{array}$ & $\begin{array}{c}20 / 06 / 2016 \\
20: 12: 07\end{array}$ & $\begin{array}{l}\text { Patricia Lima Ferreira } \\
\text { Santa Rosa }\end{array}$ & Aceito \\
\hline $\begin{array}{l}\text { Projeto Detalhado / } \\
\text { Brochura }\end{array}$ & $\begin{array}{l}\text { Projeto_Patricia_Lima_Ferreira_Santa_ } \\
\text { Rosa_20_jun_2016.docx }\end{array}$ & $\begin{array}{c}20 / 06 / 2016 \\
20: 07: 21 \\
\end{array}$ & $\begin{array}{l}\text { Patricia Lima Ferreira } \\
\text { Santa Rosa }\end{array}$ & to \\
\hline
\end{tabular}

Endereço: Av. Dr Enéas de Carvalho Aguiar, 419

Bairro: Cerqueira Cesar

CEP: $\quad 05.403-000$

UF: SP

Município: SAO PAULO

Telefone: (11)3061-8858

E-mail: cepee@usp.br 


\begin{tabular}{|c|c|c|c|c|c|c|}
\hline$\equiv \equiv$ & \multicolumn{2}{|c|}{$\begin{array}{l}\text { ILSP } \\
=1 \\
\text { RMAGEM }\end{array}$} & \multicolumn{2}{|c|}{$\begin{array}{c}\text { ESCOLA DE ENFERMAGEM DA } \\
\text { UNIVERSIDADE DE SÃO } \\
\text { PAULO - EEUSP }\end{array}$} & $\begin{array}{l}\text { Ploteqfor } \\
\text { :rafil }\end{array}$ & no \\
\hline \multicolumn{7}{|c|}{ Continuaçāo do Parecer: 1.622 .586} \\
\hline Investigad & & $\begin{array}{l}\text { Proj } \\
\text { Ros } \\
\end{array}$ & $\begin{array}{l}\text { eto_Patricia_Lima_Ferreira_Santa_ } \\
\text { a } 20 \text { jun } 2016 \text {.docx }\end{array}$ & $\begin{array}{c}20 / 06 / 2016 \\
20: 07: 21 \\
\end{array}$ & \begin{tabular}{|l|} 
Patricia Lima Ferreira \\
Santa Rosa
\end{tabular} & Aceito \\
\hline Folha de $F$ & osto & Folh & aderosto.docx & $\begin{array}{c}02 / 05 / 2016 \\
21: 05: 55\end{array}$ & \begin{tabular}{|l|} 
Patricia Lima Ferreira \\
Santa Rosa
\end{tabular} & Aceito \\
\hline
\end{tabular}

Situação do Parecer:

Aprovado

Necessita Apreciação da CONEP:

Não

SAO PAULO, 05 de Julho de 2016

Assinado por:

Lisabelle Mariano Rossato

(Coordenador)

Endereço: Av. Dr Enéas de Carvalho Aguiar, 419

Bairro: Cerqueira Cesa

CEP: $\quad 05.403-000$

UF: SP

Município: SAO PAULO

Telefone: (11)3061-8858

E-mail: cepee@usp.br 